\title{
Self-reported physician prescribing behavior and factors related to antidepressant prescribing to children and adolescents with major depressive disorder
}

\author{
Andrea R. Pfalzgraf \\ West Virginia University
}

Follow this and additional works at: https://researchrepository.wvu.edu/etd

\author{
Recommended Citation \\ Pfalzgraf, Andrea R., "Self-reported physician prescribing behavior and factors related to antidepressant \\ prescribing to children and adolescents with major depressive disorder" (2009). Graduate Theses, \\ Dissertations, and Problem Reports. 4512. \\ https://researchrepository.wvu.edu/etd/4512
}

This Dissertation is protected by copyright and/or related rights. It has been brought to you by the The Research Repository @ WVU with permission from the rights-holder(s). You are free to use this Dissertation in any way that is permitted by the copyright and related rights legislation that applies to your use. For other uses you must obtain permission from the rights-holder(s) directly, unless additional rights are indicated by a Creative Commons license in the record and/ or on the work itself. This Dissertation has been accepted for inclusion in WVU Graduate Theses, Dissertations, and Problem Reports collection by an authorized administrator of The Research Repository @ WVU. For more information, please contact researchrepository@mail.wvu.edu. 
Self-Reported Physician Prescribing Behavior and Factors Related to Antidepressant Prescribing to Children and Adolescents with Major Depressive Disorder

Andrea R. Pfalzgraf, MPH

Dissertation submitted to the School of Pharmacy

at West Virginia University in partial fulfillment of the requirements for the degree of

Doctor in Philosophy

in Pharmaceutical Systems and Policy

Virginia (Ginger) Scott, PhD, MS, RPh Chair

Steve Hartsock, PhD, MSW

Jan Kavookjian, PhD, MBA

Gene Makela, PharmD, BCPP

Lesley-Ann Miller, PhD

Department of Pharmaceutical Systems and Policy

\author{
Morgantown, West Virginia \\ 2009
}

Keywords: Major depressive disorder; Antidepressants; Children; Adolescents Copyright 2009 Andrea R. Pfalzgraf 


\section{ABSTRACT \\ Self-Reported Physician Prescribing Behavior and Factors Related to Antidepressant Prescribing to Children and Adolescents with Major Depressive Disorder}

\section{Andrea R. Pfalzgraf, MPH}

Major depressive disorder is a serious public health problem and impacts approximately $2 \%$ of children and $4-8 \%$ of the adolescents in the United States (Birmaher et al., 1996). There are risks associated with untreated major depressive disorder and no sound epidemiological basis for treating children and adolescents with this disorder (Brent, 2005). The purpose of this study was to examine physician treatment preferences for children and adolescents with major depressive disorder and to examine the factors which impact these choices.

The study was conducted in two phases. Phase I involved identifying pediatricians who treat child and adolescents for major depressive disorder and who were willing to participate in the larger Phase II survey, regarding specific treatment practices. Survey methodology was utilized in both phases and a national random sample of pediatricians $(n=2,000)$ and child psychiatrists $(n=2,250)$ was employed.

Approximately $40.00 \%$ of the pediatricians who returned surveys indicated they treat children and/or adolescents. Of those 163 pediatricians who treat children and/or adolescents, only $67.48 \%(n=110)$ were willing to participate in the Phase II survey. Phase II of this study determined the majority of the child psychiatrists indicated they utilize a combination of antidepressants and counseling to treat children (52.19\%) and adolescents $(76.95 \%)$ with major depressive disorder. A preponderance of pediatricians also use a combination of antidepressants and counseling to treat children $(63.46 \%)$ and adolescents $(87.72 \%)$ with major depressive disorder. In the event physicians utilize an antidepressant medication for the first-line of treatment for children or adolescents, they indicated they most commonly prescribe medication was either Prozac ${ }^{\mathbb{R}}$ or Zoloft ${ }^{\mathbb{R}}$.

It was found that child psychiatrists and pediatricians monitor both children and adolescents significantly less $(p=0.000)$ than the U.S. FDA recommendations during the first and second months of antidepressant therapy. During month three, pediatricians still monitor children and adolescents significantly less $(p=0.000)$ than the U.S. FDA recommendations. However, the frequency with which child psychiatrists monitor children $(\mathrm{p}=0.098)$ and adolescents $(\mathrm{p}=0.101)$, who are on antidepressant treatment, during the third month of treatment, does not differ significantly from the U.S. FDA recommendations

It was found the type of physician, age of the physician, and geographic region in which the physician practiced was associated with prescribing antidepressant medication for a child with major depressive disorder. Exploratory factor analysis revealed four underlying factors; socio-economic status of patient, disease severity, medication cost, and drug profile. Based on this analysis, it was concluded that these four factors influence child psychiatrists' decision of whether or not to prescribe antidepressant medication to a child or adolescent who had been newly diagnosed with major depressive disorder. 
In the absence of empirical research to guide the selection of treatment of children and adolescents with major depressive disorder this study determined physicians prefer to treat children and/or adolescents with a combination of antidepressants and counseling. Physicians reported an adequate course of treatment to help prevent relapse of depressive symptoms. However, physicians need to increase the amount of monitoring to be in line with U.S. FDA monitoring recommendations. Limitations to the study are those inherent with any research utilizing survey methodology. The rationales behind physician preferences for treatment and monitoring choices for children and adolescents with major depressive disorder were not studied and are subject to future research. Further investigation is also warranted to better understand the associations between physician characteristics (specialty, age, and geographic location) and the treatment prescribed. 


\section{TABLE OF CONTENTS}

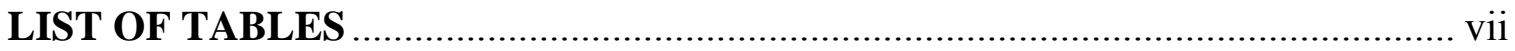

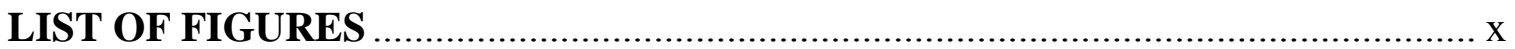

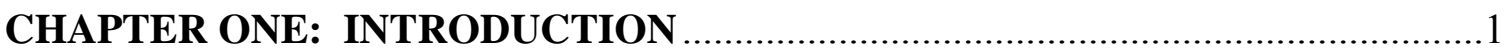

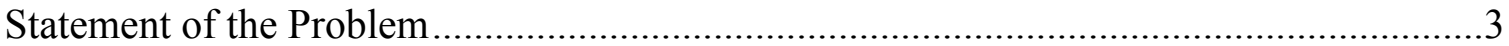

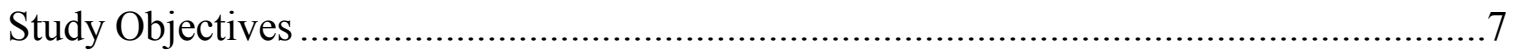

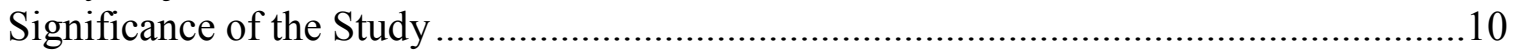

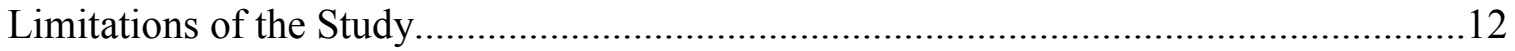

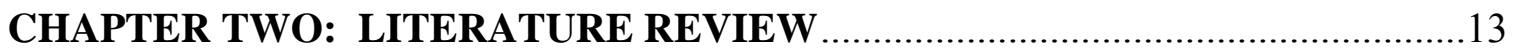

Diagnosis of Major Depressive Disorder................................................................... 14

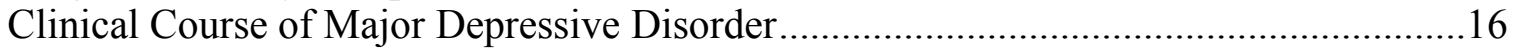

Risk Factors Associated with Major Depressive Disorder ..........................................18

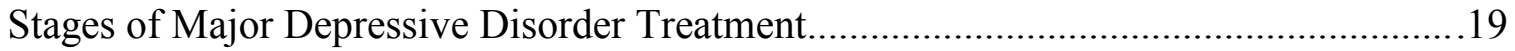

Treatment of Major Depressive Disorder in Children and Adolescents..........................20

Antidepressant Treatment of Major Depressive Disorder ..........................................21

Mechanism of Action...................................................... 21

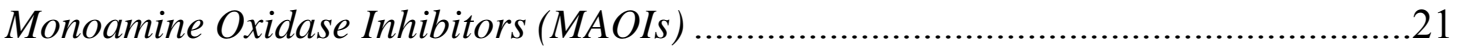

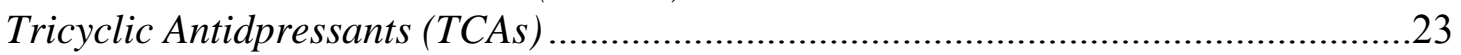

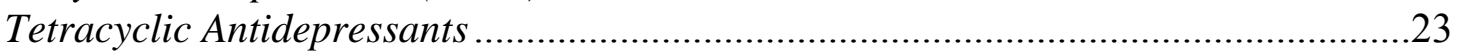

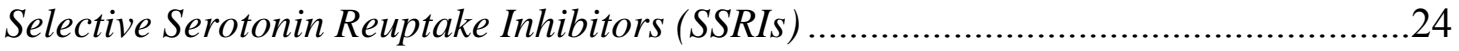

Serotonin-Norepinephrine Reuptake Inhibitors (SNRIs) .........................................24

Norepinephrine and Dopamine Reuptake Inhibitors (NDRIs) ...................................25

Other Antidepressants......................................................................................26

Outcome Measures Utilized in Randomized Clinical Trials .........................................26

Efficacy of Antidepressants in Children and Adolescents with

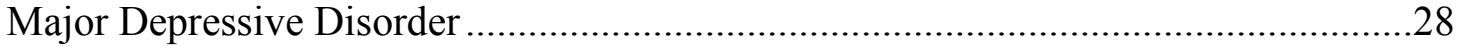

Psychotherapy Treatment for Major Depressive Disorder .............................................34

Combination Therapy for Major Depressive Disorder.............................. 37

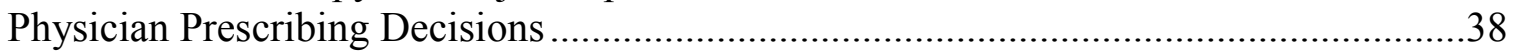

Prescribing Decisions for Adult Populations............................................................39

Prescribing Decisions for Children and Adolescents .............................................41

Psychotropic Prescribing to Children and Adolescents ............................................41

Antidepressant Prescribing to Children and Adolescents ..........................................48

Summary of Factors Influencing Physician Prescribing Decisions ...........................52

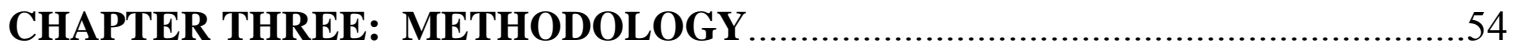

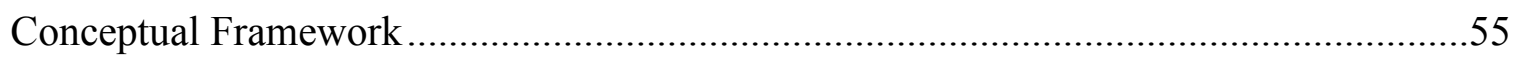

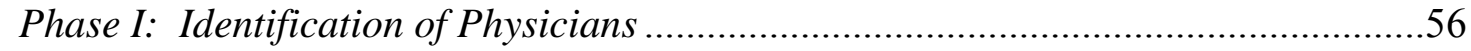

Phase II: Determination of Physician Prescribing Behavior ...................................57 
Phase II: Variables Influencing Physicians' Decisions to Prescribe Antidepressants ....................................................................59

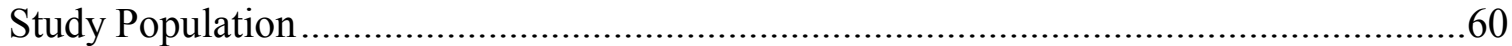

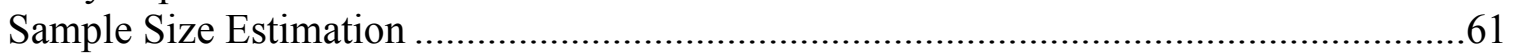

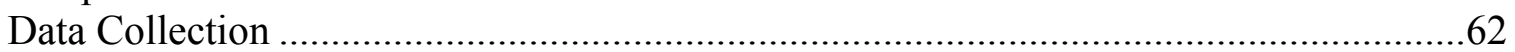

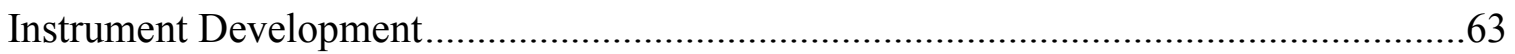

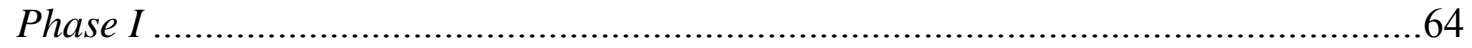

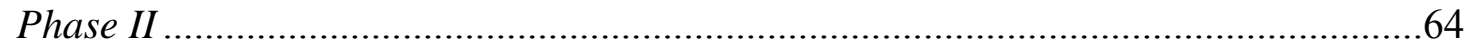

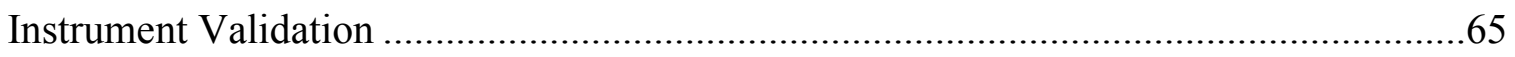

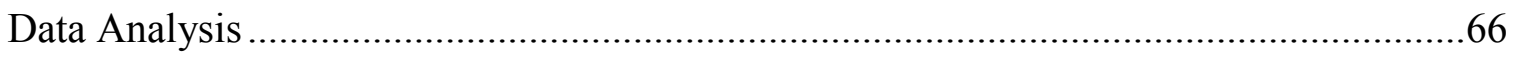

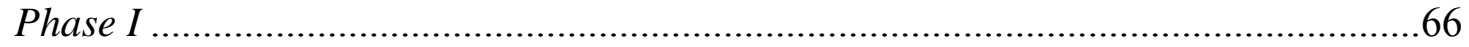

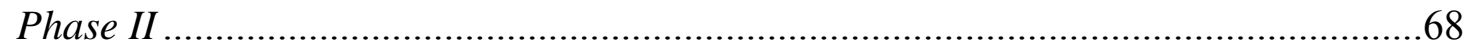

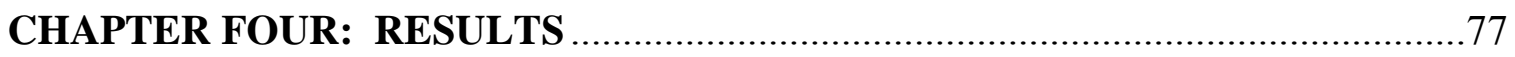

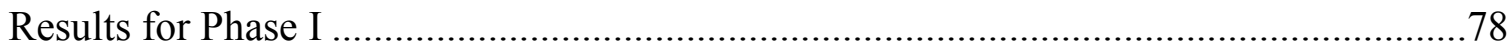

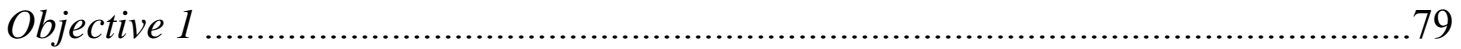

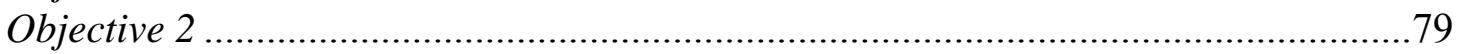

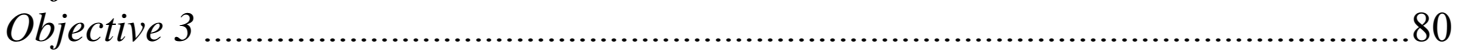

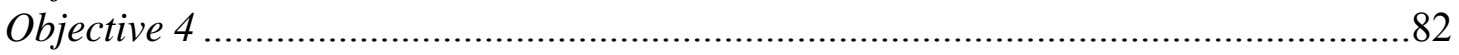

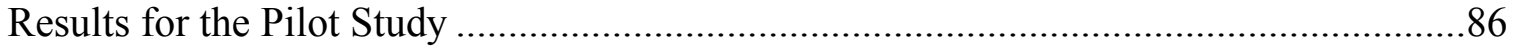

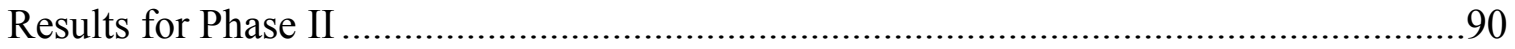

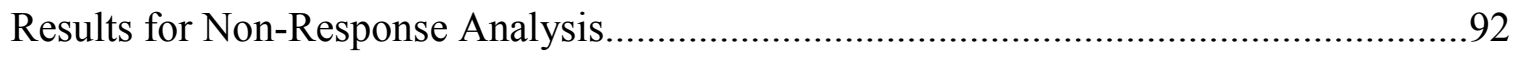

Phase II Results for Children with Major Depressive Disorder ...................................94

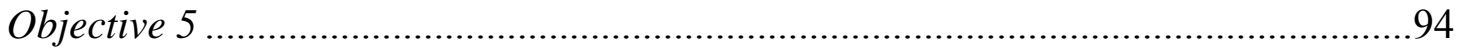

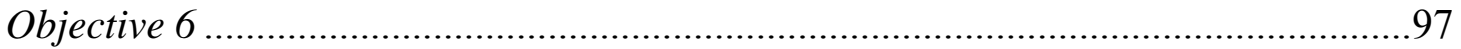

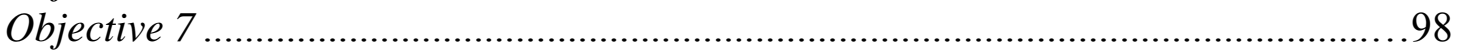

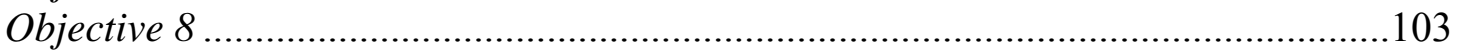

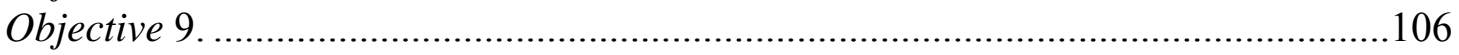

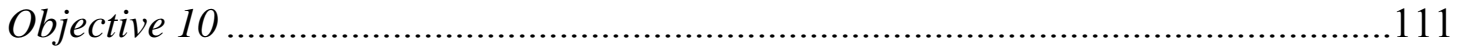

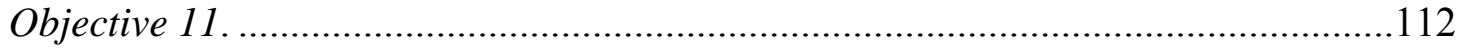

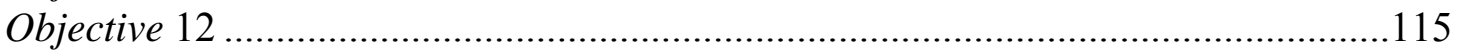

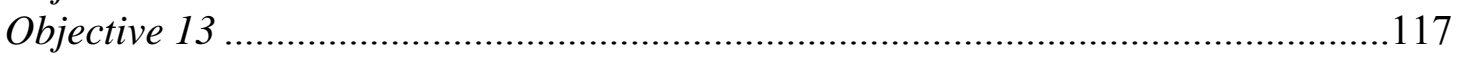

Phase II Results for Adolescents with Major Depressive Disorder ...............................119

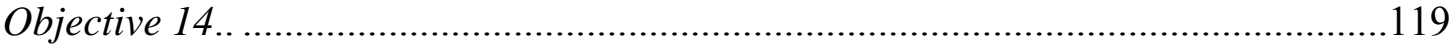

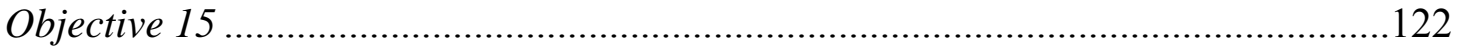

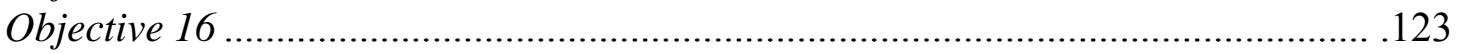

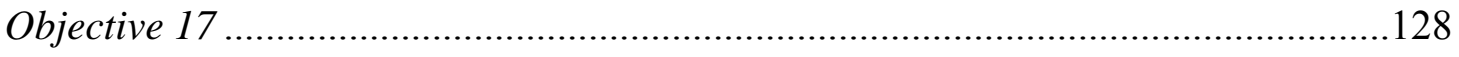

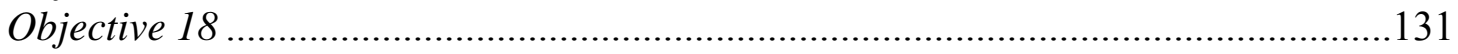

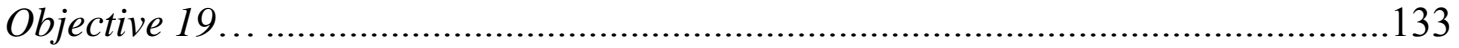

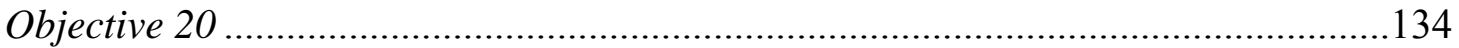

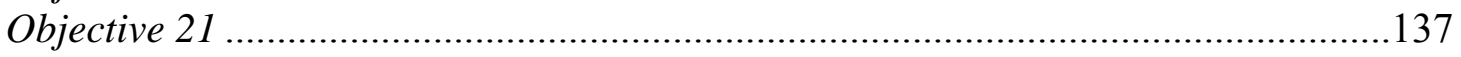

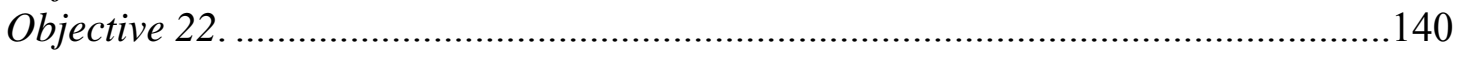

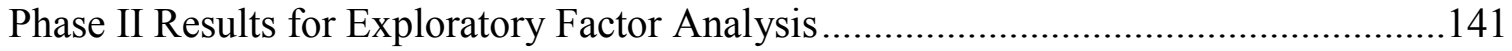

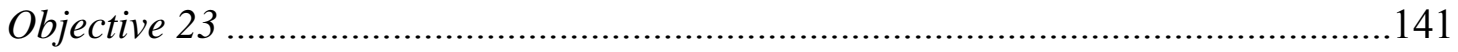

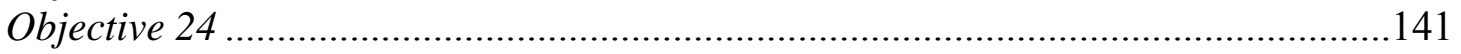




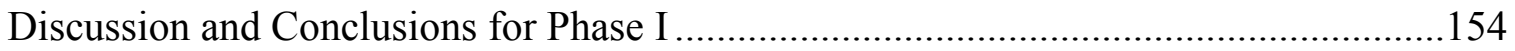

Discussion and Conclusions for Phase II................................................................. 156

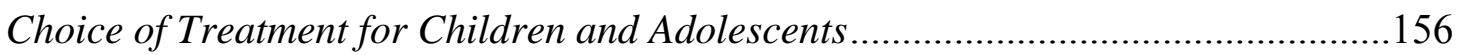

Association of Physician Type and Antidepressant Category ...................................160

Association of Physician Type and Specific Antidepressant..................................... 161

Association of Physician Characteristics and Type of Treatment Prescribed for

Children and Adolescents with Major Depressive Disorder .....................................161

Average Length of Treatment for Children and Adolescents.....................................162

Pharmacotherapy Monitoring for Children and Adolescents ..................................163

Variables Influencing Physicians' Decision to Prescribe Antidepressants .................165

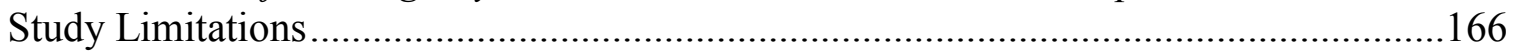

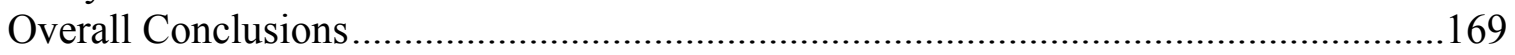

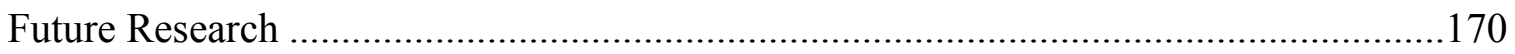

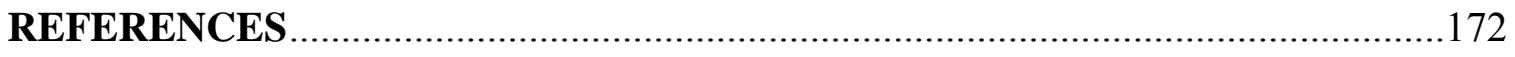

\section{LIST OF APPENDICES}

Appendix A: Phase I Survey................................................ 183

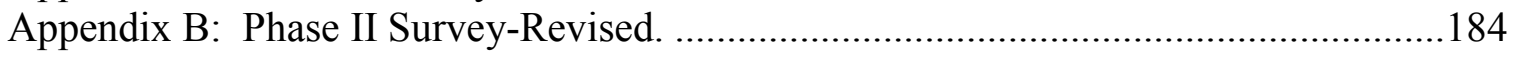

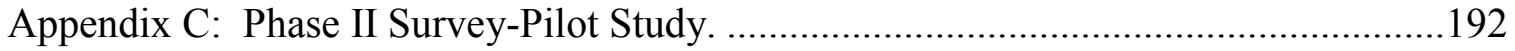

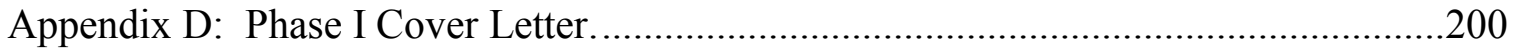

Appendix E: Phase II Cover Letter Child Psychiatrists................................................201

Appendix F: Phase II Cover Leter Pediatricians....................................................202 


\section{LIST OF TABLES}

Table 2.1: Nine Symptoms from DSM-IV-TR Utilized to Diagnose Major Depressive Disorder

Table 2.2: Terms and Definitions Describing the Clinical Course of Major Depressive Disorder

Table 2.3: Instruments Utilized to Measure Patient Outcomes in

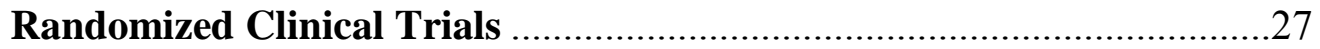

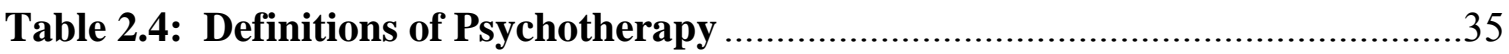

Table 3.1: 28 Variables Utilized in Exploratory Factor Analysis..........................59

Table 3.2: States Included in Each Geographical Region ....................................68

Table 4.1: Response Rate for Phase I ............................................................... 78

Table 4.2: Pediatricians Treating Children and/or Adolescents with Major Depressive Disorder

Table 4.3: Pediatricians Referring Children and/or Adolescents with Major Depressive Disorder

Table 4.4: Health Care Provider to whom Pediatricians Refer Children and Adolescents with Major Depressive Disorder

Table 4.5: States Included in Each Geographic Region

Table 4.6: Treatment of Children Across Geographic Regions

Table 4.7: Treatment of Adolescents Across Geographic Regions.

Table 4.8: Treating Pediatricians Willing to Participate in Phase II .......................85

Table 4.9: Response Rate for Pilot Study

Table 4.10: Demographics of Child Psychiatrists from Pilot Study .........................88

Table 4.11: Response Rate for Child Psychiatrists - Phase II .................................91

Table 4.12: Response Rate for Pediatricians- Phase II ........................................91

Table 4.13: Comparisons of Demographics of Early Responders and

Non-Responders

Table 4.14: Comparisons of Treatment Variables of Early Responders and Non-Responders

Table 4.15: Demographics of Physicians who Treat Children for Major Depressive

Disorder

Table 4.16: First-Line of Treatment for Children with Major Depressive Disorder

Table 4.17: Therapeutic Category of Antidepressant Used as First-Line of Treatment for Children

Table 4.18: Specific Antidepressant Used as First-Line Treatment for Children ....98

Table 4.19: Second-Line of Treatment for Children with Major Depressive Disorder

Table 4.20: Therapeutic Category of Antidepressant Used as Second-Line of Treatment for Children

Table 4.21: Specific Antidepressant Used as Second-Line Treatment for Children 
Table 4.22: Third-Line of Treatment for Children with

Major Depressive Disorder

Table 4.23: Pediatricians" "Other $3^{\text {rd }}$ Line of Treatment" for Children .................101

Table 4.24: Child Psychiatrists" "Other $3^{\text {rd }}$ Line of Treatment" for Children .......101

Table 4.25: Therapeutic Category of Antidepressant Used as Third-Line of Treatment for Children

Table 4.26: Specific Antidepressant Used as Third Line Treatment for Children

Table 4.27: Association Between Physician Type and Antidepressant

Category

Table 4.28: Association Between Physician Type and Prozac $^{\circledR}$ versus Non-Prozac $^{\circledR}$ Groups

Table 4.29: Logistic Regression Analysis of Physicians' Antidepressant Prescribing to Children with Major Depressive Disorder 110

Table 4.30: Frequencies of Average Length of Antidepressant Treatment for Children

Table 4.31: Length of Antidepressant Treatment Compared to AACAP Recommendations

Table 4.32: Mode of Antidepressant Monitoring for Children

Table 4.33: Healthcare Provider Conducting Antidepressant Monitoring for Children

Table 4.34: Types of Antidepressant Monitoring for Children

Table 4.35: Frequency of Antidepressant Monitoring: Month One

Table 4.36: Frequency of Antidepressant Monitoring: Month Second

Table 4.37: Frequency of Antidepressant Monitoring: Month Three

Table 4.38: Recoded Frequency of Antidepressant Monitoring: Month One........116

Table 4.39: Recoded Frequency of Antidepressant Monitoring: Month Two .......116

Table 4.40: Recoded Frequency of Antidepressant Monitoring: Month Three.....116

Table 4.41: Comparisons of Physician Monitoring to U.S. FDA

Recommendations.....

Table 4.42: Comparison of Pediatricians and Child Psychiatrists Monitoring of Children

Table 4.43: Demographics of Physicians who Treat Adolescents for Major Depressive Disorder

Table 4.44: First-Line of Treatment for Adolescents with Major Depressive Disorder

Table 4.45: Therapeutic Category of Antidepressant Used as First-Line Treatment for Adolescents

Table 4.46: Specific Antidepressant Used as First-Line Treatment for Adolescents

Table 4.47: Second-Line of Treatment for Adolescents with Major Depressive Disorder

Table 4.48: Therapeutic Category of Antidepressant Used as Second-Line Treatment for Adolescents...

Table 4.49: Specific Antidepressant Used as Second-Line Treatment for Adolescents 
Table 4.50: Third-Line of Treatment for Adolescents with Major Depressive Disorder

Table 4.51: Pediatricians" "Other $3^{\text {rd }}$ Line of Treatment" for Adolescents

Table 4.52: Child Psychiatrists" "Other $3^{\text {rd }}$ Line of Treatment" for Adolescents ..126

Table 4.53: Therapeutic Category of Antidepressant Used as Third-Line Treatment for Adolescents

Table 4.54: Specific Antidepressant Used as Third-Line Treatment for Adolescents

Table 4.55: Association of Physician Type and Antidepressant Category .............130

Table 4.56: Association of Physician Type and Specific Antidepressant................131

Table 4.57: Crosstabs of Treatment by Number of Adolescents Seen Per Week ...132

Table 4.58: Logistic Regression Analysis of Physicians' Antidepressant Prescribing to Adolescents with Major Depressive Disorder .

Table 4.59: Frequencies of Average Length of Antidepressant Treatment for Adolescents

Table 4.60: Length of Antidepressant Treatment Compared to AACAP Recommendations...

Table 4.61: Mode of Antidepressant Monitoring for Adolescents

Table 4.62: Healthcare Provider Conducting Antidepressant Monitoring for Adolescents

Table 4.63: Types of Antidepressant Monitoring for Adolescents

Table 4.64: Frequency of Antidepressant Monitoring: Month One

Table 4.65: Frequency of Antidepressant Monitoring: Month Second

Table 4.66: Frequency of Antidepressant Monitoring: Month Three

Table 4.67: Recoded Frequency of Antidepressant Monitoring: Month One.

Table 4.68: Recoded Frequency of Antidepressant Monitoring: Month Two .......138

Table 4.69: Recoded Frequency of Antidepressant Monitoring: Month Three.....139

Table 4.70: Comparisons of Physician Monitoring to U.S. FDA Recommendations

Table 4.71: Comparison of Pediatricians and Child Psychiatrists Monitoring of Adolescents

Table 4.72: Means and Standard Deviations of Variables/Factors Which Influence Antidepressant Prescribing Decisions for Child Psychiatrists and Pediatricians

Table 4.73: Initial Factor Pattern

Table 4.74: Results of Rotated Factor Pattern and Factor Structure Matrix........150

Table 4.75: Factor Loadings on the Reference Structure Matrix 


\section{LIST OF FIGURES}

Figure 3.1: Conceptual Framework for Phase I ..............................................56

Figure 3.2: Conceptual Framework for Phase II ..............................................58

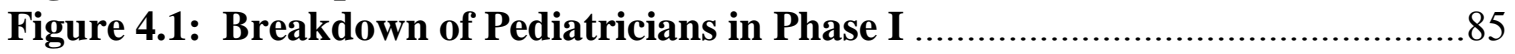




\section{CHAPTER ONE: INTRODUCTION}

Chapter one provides an introduction for this dissertation. The statement of the research

problem and the specific research objectives follow. The chapter concludes with a discussion of the significance and limitations of the study. 
Major depressive disorder in children and adolescents is a serious public health problem in the United States (U.S.). Studies indicate that between ten and 15 percent (\%) of all children and adolescents in the U.S. show at least some symptoms of depression (United States Department of Health and Human Services-SAMHSA, 2004). Major depressive disorder in children under the age of six years is rare, but does occur (American Academy of Child and Adolescent Psychiatry, 2007; National Alliance for the Mentally Ill, 2004). However, as age increases so does the prevalence of major depressive disorder. Approximately, two percent of all children between the ages of six and 12 years have been diagnosed with major depressive disorder, while between four and $8.3 \%$ of adolescents (13-18 years) in the U.S. are affected by major depressive disorder (Birmaher, Ryan, \& Williamson, 1996; National Alliance for the Mentally Ill, 2004). Before children reach puberty, the rates of depression among males and females indicate that they are equally impacted by the disorder (American Academy of Child and Adolescent Psychiatry, 2007; Costello, Mustillo, Erkanli, Keeler, \& Angold, 2003). Once an individual reaches adolescence, females are twice as likely as males to have major depressive disorder (American Academy of Child and Adolescent Psychiatry, 2007; Costello et al., 2003). It is estimated that $14-25 \%$ of children and adolescents will experience at least one episode of major depressive disorder before adulthood (Lewinsohn, Rohde, \& Seeley, 1998; Ryan, 2005).

Globally, depression is among the leading cause of disability (World Health Organization, 2007). Although the cost in children and adolescents is unknown, the economic cost of depression in adults is large (Haby, Tonge, Littlefield, Carter, \& Vos, 2004; Lynch \& Clarke, 2006; World Health Organization, 2007). Researchers calculated the economic burden of depression in the U.S. in 2000 to be $\$ 83.1$ billion (Greenberg et al., 2003). This amount included 
\$26.1 billion in direct medical costs and \$51.5 billion in associated workplace costs (Greenberg et al., 2003).

Major depressive disorder is diagnosed in both adults and youth by utilizing the criteria (See Table 2.1) set forth by the American Psychiatric Association's Diagnostic and Statistical Manual of Mental Disorders (DSM). A diagnosis of major depressive disorder is made if the patient has at least five of the nine symptoms specified in the DSM, for a period of at least two weeks (American Psychiatric Association, 2000).

There are risks associated with untreated major depressive disorder. Studies indicate that major depressive disorder in children and adolescents tends to be a chronic and recurring disorder, which may persist into adulthood (Costello et al., 2002; Emslie et al., 1997; Lewinsohn, Rohde, Klein, \& Seeley, 1999). Additionally, children and adolescents with major depressive disorder have a greater risk for drug abuse, difficulties in school, impaired functioning, and even suicide (Lewinsohn et al., 1999; Weissman et al., 1999). Given that there are serious consequences associated with major depressive disorder, treatment of children and adolescents with this disorder becomes crucial.

\section{Statement of the Problem}

Unfortunately, for physicians the optimal treatment for children and adolescents who have major depressive disorder is not a clear decision. There is no sound epidemiological basis for choosing antidepressant treatment in children and adolescents with major depressive disorder (Brent, 2005). Even the most recently updated Practice Parameters published by the American Academy of Child and Adolescent Psychiatry are intended to provide physicians with some guidelines for their treatment decisions (American Academy of Child and Adolescent Psychiatry, 
2007). These Practice Parameters are not meant to serve as or define the standard of care for children and adolescents with major depressive disorder (American Academy of Child and Adolescent Psychiatry, 2007). Only in the last several decades has major depressive disorder in children and adolescents been recognized as a problem in the scientific community (Costello et al., 2002). Thus, the scientific literature demonstrating efficacy of antidepressant treatment in children and adolescents with major depressive disorder is limited and physicians have a limited number of positive controlled trials upon which to base antidepressant treatment (Ryan, 2005). Currently, only one antidepressant, Prozac ${ }^{\circledR}$, is approved by the U.S. Food and Drug Administration (FDA) to treat major depressive disorder in children and adolescents, but much, off-label use of other antidepressants occurs (Brent, 2005). Furthermore, all antidepressant treatments, even those demonstrating efficacy, have been the subject of debate because of a U.S. FDA Public Health Advisory (U.S. FDA, 2004b).

On October 15, 2004 the U.S. FDA directed manufacturers of antidepressants to revise the labels of these medications (U.S. FDA, 2004b). It was recommended that a black-box warning indicating that the use of antidepressant medications increased the risk of suicidality (suicidal thinking and suicidal behavior) in children and adolescent patients (U.S. FDA, 2004b). In addition to the warning, the U.S. FDA has suggested certain monitoring should accompany antidepressant treatment (U.S. FDA, 2005). Ideally, a child or adolescent receiving antidepressant treatment should be seen by the physician one time per week for the first four weeks of treatment (U.S. FDA, 2005). During the second and third months of treatment, the patient should be seen biweekly and at week 12 , respectively (U.S. FDA, 2005). 
However, scientific evidence is not the only factor that impacts physicians' antidepressant prescribing decisions to children and adolescents with major depressive disorder. Other factors impacting physicians' prescribing decisions include, patient-related (e.g., patient's age), physician-related (e.g., physician's specialty), marketing-related (e.g., advertisements), and drugrelated (e.g., drug cost) factors (Benson, 1983; Cates, 2001; Eisenberg, 1979).

The majority of the scientific literature which examines prescribing patterns of medication to children and adolescents encompass all psychotropic medications (Elfron, 2003; Goodwin, Gould, Blanco, \& Olfson, 2001; Haapasalo-Pesu, Erkolahti, Saarijarvi, \& Aalberg, 2004; Harpaz-Rotem \& Rosenheck, 2006; Hugtenburg, Heerdink, \& Tso, 2005; Hong \& Shepherd, 1996; Jensen et al., 1999; Kaplan \& Busner, 1997; Lekhwani, Nair, Nikhinson, \& Ambrosini, 2004; Najjar et al., 2004; Olfson, Gameroff, Marcus, \& Waslick, 2003; Rushton \& Whitmire, 2001; Safer, 1997; Zito et al., 2000; Zito et al., 2003), all mental illness diagnoses (Elfron, 2003; Goodwin et al., 2001; Haapasalo-Pesu et al., 2004; Harpaz-Rotem \& Rosenheck, 2006; Hugtenburg et al., 2005; Hong \& Shepherd, 1996; Jensen et al., 1999; Kaplan \& Busner, 1997; Lekhwani et al., 2004; Najjar et al., 2004; Rushton \& Whitmire, 2001; Safer, 1997; Zito et al., 2000; Zito et al., 2003), and examine prescribing trends over time (Goodwin et al., 2001; Haapasalo-Pesu et al., 2004; Hong \& Shepherd, 1996; Lekhwani et al., 2004; Najjar et al., 2004; Olfson et al., 2003; Rushton \& Whitmire, 2001; Safer, 1997; Zito et al., 2000; Zito et al., 2003). These studies have limited generalizability because of geographic limitations (Elfron, 2003; Haapasalo-Pesu et al., 2004; Hugtenburg et al., 2005; Kaplan \& Busner, 1997; Lekhwani et al., 2004; Najjar et al., 2004; Rushton \& Whitmire, 2001; Safer, 1997). For example, the Rushton \& Whitmire (2001) study was limited to the state of North Carolina. Several other studies are not 
generalizable to the U. S. because they examine prescribing trends in European countries or Australia (Elfron, 2003; Haapasalo-Pesu et al., 2004; Hugtenburg et al., 2005; Kaplan \& Busner, 1997).

Fewer studies focus only on antidepressant prescribing to children and adolescents (Bramble, 1995; Fegert, Kolch, Zito, Glaeske, \& Janhsen, 2006; Kurian et al., 2007; Murray, deVries, \& Wong, 2004; Murray, Thompson, Santosh, \& Wong, 2005; Nemeroff et al., 2007; Rushton, Clark, \& Freed, 2000; Vitiello, Zuvekas, \& Norquist, 2006; Zito et al., 2002). These studies do limit their analysis to only antidepressant medications but no studies were located that limited the patient diagnosis to major depressive disorder. The majority of the scientific literature, which examines the prescribing of antidepressants to children and adolescents, has utilized large databases. The exception being three studies, Bhatia et al., 2008, Bramble, 1995, and Rushton, Clark, \& Freed, 2000, which used surveys to obtain prescribing information directly from physicians who prescribe antidepressants to children and adolescents. Thus, most of these studies capture information about antidepressant utilization, and not data regarding the decisionmaking process. A few studies examined antidepressant use in relation to the demographic characteristics of patients (Fegert et al., 2006; Rushton et al., 2000; Vitiello et al., 2006; Zito et al., 2002). No studies were located which examined predictors of antidepressant prescribing in the U.S. after the 2004 FDA warning, however a few studies did examine the impact of the 2004 warnings on the number of prescriptions for antidepressants to children and adolescents (Bhatia et al., 2008; Kurian et al., 2007; Nemeroff et al., 2007).

In the absence of empirical research to guide the selection of antidepressant treatment additional research needs to be conducted to examine: 1) what physicians consider to be the 
most appropriate antidepressant treatment, 2) physicians' recommended course of treatment, and 3) the factors which impact physicians' decisions to treat major depressive disorder in children and adolescents with antidepressants. Thus, the purpose of this study is designed to examine physician antidepressant choices for children and adolescents with major depressive disorder and to examine the factors which impact these choices.

\section{Study Objectives}

The study will be conducted in two phases. Phase I will consist of a national survey to determine the proportion of pediatricians who treat children and adolescents with major depressive disorder, in the U.S. These physicians will also be asked to participate in phase II of this study. The specific objectives of phase I are as follows:

\section{Phase I Objectives:}

Objective 1: To determine the proportion of pediatricians who treat children and adolescents with major depressive disorder.

Objective 2: To determine the proportion of pediatricians who refer children and adolescents with major depressive disorder.

Objective 3: To determine the health care provider to whom pediatricians refer a child or adolescent with major depressive disorder.

Objective 4: To determine geographic differences in pediatricians' willingness to treat versus referral of children and/or adolescents with major depressive disorder.

Null Hypothesis 4.0: There is no difference in the geographic locations of pediatricians who treat versus refer children and/or adolescents for major depressive disorder.

Phase II of this study will survey the pediatricians identified in phase I plus a random sample of child psychiatrists. This phase is designed to ascertain information about physicians' treatment and prescribing patterns of antidepressants to both newly diagnosed children (five 
through 12 years of age) and adolescents (13 through 18 years of age) with major depressive disorder. The specific objectives address each age category separately.

\section{Phase II Objectives:}

Objectives 5 through 13 focus on the treatment and prescribing patterns of children (five through 12 years of age) with major depressive disorder.

Objective 5: To determine the demographic characteristics of physicians who treat newly diagnosed children with major depressive disorder.

Objective 6: To determine physicians' first line of treatment for newly diagnosed children with major depressive disorder by: a) type of treatment, b) drug category, and c) specific antidepressant prescribed.

Objective 7: To determine physicians' second and third lines of treatment for newly diagnosed children with major depressive disorder by: a) drug category, and b) specific antidepressant prescribed.

Objective 8: To determine the difference in first, second, and third lines of antidepressant treatment prescribed by physicians to newly diagnosed children with major depressive disorder by a) the pharmacotherapy category and b) specific antidepressant prescribed.

Null Hypothesis 8.a: There is no difference in the pharmacotherapy category prescribed by physicians for first, second, and third lines of antidepressant treatment for newly diagnosed children with major depressive disorder.

Null Hypothesis 8.b: There is no difference in the specific antidepressant prescribed by physicians for first, second, and third lines of treatment for newly diagnosed children with major depressive disorder.

Objective 9: To predict which physician characteristics effect the treatment prescribed for children with major depressive disorder.

Objective 10: To determine the average length of antidepressant treatment for newly diagnosed children with major depressive disorder.

Objective 11: To determine the types of pharmacotherapy monitoring in newly diagnosed children with major depressive disorder.

Objective 12: To determine differences in antidepressant monitoring for newly diagnosed children with major depressive disorder and the U.S. FDA recommendations for monitoring children treated with antidepressants. 
Null Hypothesis 12.0: There is no difference in pharmacotherapy monitoring for newly diagnosed children with major depressive disorder and the U.S. FDA recommendations for monitoring children treated with antidepressants.

Objective 13: To determine whether there are differences, by physician type, in the average number of times per month physicians monitor children with major depressive disorder.

Null Hypothesis 13.0: There is no difference, by physician type, in the average number of times per month physicians monitor children with major depressive disorder.

Next, Objectives 14 through 22 address these same issues but in the adolescents (13 through 18 years of age) population.

Objective 14: To determine the demographic characteristics of physicians who treat newly diagnosed adolescents with major depressive disorder.

Objective 15: To determine physicians' first line of treatment for newly diagnosed adolescents with major depressive disorder by: a) type of treatment, b) drug category, and c) specific antidepressant prescribed.

Objective 16: To determine physicians' second and third lines of treatment for newly diagnosed adolescents with major depressive disorder by: a) drug category, and b) specific antidepressant prescribed.

Objective 17: To determine the difference in first, second, and third lines of antidepressant treatment prescribed by physicians to newly diagnosed adolescents with major depressive disorder by a) the pharmacotherapy category and b) specific antidepressant prescribed.

Null Hypothesis 17.a: There is no difference in the pharmacotherapy category prescribed by physicians for first, second, and third lines of antidepressant treatment for newly diagnosed adolescents with major depressive disorder.

Null Hypothesis 17.b: There is no difference in the specific antidepressant prescribed by physicians for first, second, and third lines of treatment for newly diagnosed adolescents with major depressive disorder.

Objective 18: To predict which physician characteristics effect the treatment prescribed for adolescents with major depressive disorder.

Objective 19: To determine the average length of antidepressant treatment for newly diagnosed adolescents with major depressive disorder. 
Objective 20: To determine the types of pharmacotherapy monitoring in newly diagnosed adolescents with major depressive disorder.

Objective 21: To determine differences in antidepressant monitoring for newly diagnosed adolescents with major depressive disorder and the U.S. FDA recommendations for monitoring adolescents treated with antidepressants.

Null Hypothesis 21.0: There is no difference in pharmacotherapy monitoring for newly diagnosed adolescents with major depressive disorder and the U.S. FDA recommendations for monitoring children treated with antidepressants.

Objective 22: To determine whether there are differences, by physician type, in the average number of times per month physicians monitor adolescents with major depressive disorder.

Null Hypothesis 22.0: There is no difference, by physician type, in the average number of times per month physicians monitor adolescents with major depressive disorder.

Phase II of this study also utilizes survey methodology to determine factors which influence child psychiatrists' decisions to prescribe antidepressant therapy to children and adolescents who have been diagnosed with major depressive disorder. The relative importance of the factors, which influence these physicians' decisions regarding antidepressant treatment, will also, be determined. The specific objectives for this portion of the study are listed below.

Objective 23: To determine the relative importance which physicians place on each factor prior to prescribing antidepressants to newly diagnosed children and adolescents with major depressive disorder.

Objective 24: To determine the factors associated with physicians' antidepressant prescribing behavior for children and adolescents newly diagnosed with major depressive disorder.

\section{Significance of the Study}

The current study will be a valuable addition to the literature because it will be the first study, in the U.S. to determine, on a national scale, which factors physicians consider when making decisions to treat children and adolescents with major depressive disorder. This will also be the first U.S. study to determine physicians' first, second, and third-lines of antidepressant treatment 
by category and specific drug; the length of treatment; and monitoring practices in the treatment of newly diagnosed children and adolescents with major depressive disorder.

Additionally, little is known about the variables which influence child psychiatrists' decision to prescribe antidepressant medication to children and adolescents with major depressive disorder. Thus, by examining the variables which influence child psychiatrists' antidepressant prescribing decisions, the results may be utilized as the basis for future studies to research prescribing decisions in greater detail.

The results of the current study will also be beneficial to health care organization and pharmaceutical manufactures in the creation of marketing and educational strategies aimed at physicians who utilize antidepressants to treat children and adolescents with major depressive disorder. By taking into consideration what physicians deem important in the prescribing decision, newly created marketing, promotional, and educational materials may incorporate this information and create advertising and educational messages which better appeal to physicians.

Another benefit of this study is the identification of the most appropriate treatment for children and adolescents with major depressive disorder. Child psychiatrists are the experts in treating children and adolescents for major depressive disorder. According to the American Academy of Child and Adolescent Psychiatry, child psychiatrists undergo two years of specialized training beyond that of an adult psychiatrist (American Academy of Child and Adolescent Psychiatry, 2001). Although other physicians may treat children and adolescents with major depressive disorder child psychiatrists should be the experts based on their training. Thus, the information gleaned from this study will not only provide guidance to other physician 
specialties, but also to parents about the best treatment options for children and adolescents with major depressive disorder.

\section{Limitations of the Study}

Limitations to the current study are similar to other studies that employ survey methodology. These limitations include errors such as sampling error, measurement error, and non-response error. Sampling error will be minimized by conducting a national survey and utilizing the most comprehensive mailing lists of physicians available. Non-response error should be minimized by repeated mailings and the identification of pediatricians who treat children and adolescents in Phase I of the study. Chapter two will discuss the literature reviewed for the basis of this study. 


\section{CHAPTER TWO: LITERATURE REVIEW}

Chapter two discusses the treatment of major depressive disorder in children and adolescents. The chapter begins with the topic of diagnosis, clinical course of major depressive disorder, and the risk factors associated with untreated major depressive disorder. Next, the stages of major depressive disorder treatment are described. This is followed by a discussion of the different classes of antidepressant treatment, their mechanism of action, and their efficacy for the treatment of major depressive disorder in children and adolescents. Efficacy of psychotherapy and the combination of antidepressant treatment and psychotherapy are then reviewed. An examination of the factors which influence physicians' prescribing decisions, with specific attention given to the scientific literature regarding antidepressant prescribing to children and adolescents follows. The chapter concludes with a summary of these factors and additional factors which have been found to influence other prescribing decisions. 


\section{Diagnosis of Major Depressive Disorder}

The Diagnostic and Statistical Manual of Mental Disorders (DSM) is a standard classification of mental disorders and is written and published by the American Psychiatric Association. The American Psychiatric Association is an organization that represents United States (U.S.) psychiatrists (American Psychiatric Association, 2006a). The last revisions to the DSM were made when the DSM-IV-TR edition was published in July 2000 (American Psychiatric Association, 2006c). The DSM is utilized by mental health professionals to help diagnose mental disorders. It contains a list of psychiatric disorders, diagnostic criteria, text describing the disorder and its epidemiology, and a diagnostic code that corresponds to each of these disorders (American Psychiatric Association, 2006c). Institutions, agencies, and researchers may use these codes for data collection and billing purposes (American Psychiatric Association, 2006c). These diagnostic codes have been derived from the International Statistical Classification of Diseases and Related Health Problems (ICD) (American Psychiatric Association, 2006c). No information about treatment is included in the DSM (American Psychiatric Association, 2006c).

According to the DSM-IV-TR a patient can be diagnosed with major depressive disorder if

five or more of the nine specified symptoms have been present during the same two-week period and represent a change from previous functioning (American Psychiatric Association, 2000). These nine symptoms are described in Table 2.1 . 
Table 2.1: Nine Symptoms from DSM-IV-TR Utilized to Diagnose Major Depressive Disorder $^{\mathrm{a}}$

1. Depressed mood most of the day, nearly every day, as indicated by either subjective report (e.g., feels sad or empty) or observation made by others (e.g., appears tearful). Note: In children and adolescents, can be irritable mood.

2. Markedly diminished interest or pleasure in all, or almost all, activities most of the day, nearly every day (as indicated by either subjective account or observation made by others)

3. Significant weight loss when not dieting or weight gain (e.g. a change of more than $5 \%$ of body weight in a month) or decrease or increase in appetite nearly every day. Note: In children, failure to make expected weight gains

4. Insomnia or hypersomnia nearly every day

5. Psychomotor agitation or retardation nearly every day (observable by others, no merely subjective feelings of restlessness or being slowed down)

6. Fatigue or loss of energy nearly every day

7. Feelings of worthlessness or excessive or inappropriate guilt (which may be delusional) nearly every day (not merely self-reproach or guilt about being sick)

8. Diminished ability to think or concentrate, or indecisiveness, nearly every day (either by subjective account or as observed by others)

9. Recurrent thoughts of death (not just fear of dying), recurrent suicidal ideation without a specific plan, or a suicide attempt or a specific plan or committing suicide.

${ }^{\text {a }}$ Adapted from DSM-IV-TR(American Psychiatric Association, 2000)

It should be noted the DSM-IV-TR requires that either depressed mood or loss of interest or pleasure in activities be a present symptom for the patient to be diagnosed with major depressive disorder (American Psychiatric Association, 2000). Additionally, the DSM-IV-TR requires that certain symptoms may not be utilized to make a diagnosis of major depressive disorder. These 
symptoms are as follows: any symptom that is due to a general medical condition, moodincongruent delusions, or hallucinations (American Psychiatric Association, 2000). The DSM indicates that for children and adolescents the irritable mood symptom may replace the depressed mood symptom, which is usually present in adults who are diagnosed with major depressive disorder (American Psychiatric Association, 2000). Also, children may fail to make expected weight gains when they have major depressive disorder (American Psychiatric Association, 2000).

\section{Clinical Course of Major Depressive Disorder}

A major depressive episode is defined by utilizing the diagnostic criteria set forth by the American Psychiatric Association and are listed in Table 2.1 (American Psychiatric Association, 2000). It is estimated that between $14-25 \%$ of children and adolescents experience at least one episode of major depressive disorder before adulthood (Lewinsohn, Rhode, \& Seeley, 1998; Ryan, 2005). The median duration of a major depressive episode for youth is between seven to nine months (American Academy of Child and Adolescent Psychiatry, 1998; Kovacs, Obrosky, Gatsonis, \& Richards, 1997). Several terms have been frequently utilized by clinicians and researchers to describe the clinical course of an episode of major depressive disorder. Unfortunately, these terms have not always been utilized in a standardized manner. Frank et al. (1991) proposed standard definitions for these terms so that research results regarding the clinical course of major depressive disorder in children and adolescents might be compared. The American Academy of Child and Adolescent Psychiatry has adapted these terms and utilized them in their 1998 practice parameters (American Academy of Child and Adolescent Psychiatry, 1998). The terms and definitions can be found in Table 2.2. 
Table 2.2: Terms and Definitions Describing the Clinical Course of Major Depressive Disorder $^{\mathrm{a}}$

\begin{tabular}{|l|l|}
\hline Term: & Definition: \\
\hline 1. Response & $\begin{array}{l}\text { Significant improvement of depressive } \\
\text { symptoms during the initial or acute } \\
\text { treatment phase. In general, response } \\
\text { coincides with the onset of remission. }\end{array}$ \\
\hline 2. Remission & $\begin{array}{l}\text { A period of at least two weeks and less } \\
\text { than two months with no more than one } \\
\text { clinically significant symptom. }\end{array}$ \\
\hline 3. Partial remission & $\begin{array}{l}\text { A period of at least two weeks and less } \\
\text { than two months with more than one } \\
\text { clinically significant symptom but fewer } \\
\text { symptoms than the full syndrome. }\end{array}$ \\
\hline 4. Recovery & $\begin{array}{l}\text { An asymptomatic period of more than two } \\
\text { months. }\end{array}$ \\
\hline 5. Relapse & $\begin{array}{l}\text { An episode of depression during the period } \\
\text { of remission. }\end{array}$ \\
\hline 6. Recurrence & $\begin{array}{l}\text { The emergence of symptoms of major } \\
\text { depressive disorder during the period of } \\
\text { recovery (a new episode). }\end{array}$ \\
\hline
\end{tabular}

a Adapted from Frank et al., 1991

Emslie et al. (1997) assessed remission, recovery, and recurrence of major depressive disorder in hospitalized children and adolescents, utilizing the definitions established by Frank et al. (1991).

The average time to remission was 59.5 days with a range of 14 to 246 days (Emslie et al, 1997).

Recovery was achieved in $98 \%$ of the patients within one year and recurrence occurred in $61 \%$

of the children and adolescents (Emslie et al, 1997). Of those with a recurrence of major depressive disorder, $47.2 \%$ had the recurrence within the first year, while another $22.2 \%$ (a total of $69.4 \%$ ) had the recurrence of major depressive disorder by the end of year two (Emslie et al., 1997).

Other studies have indicated that depression is chronic and most children and adolescents who have experienced an episode of major depressive disorder will have a recurrence of the disorder 
within five years (Kovacs et al., 1984; Ryan, 2005). Additionally, depressed youth have recurrences of depression into adulthood at rates of 30\%-50\% (Angst, Gamma, Sellaro, Lavori, \& Zhang, 1990; Costello et al., 2002; Lewinsohn, Rhode, Klein, \& Seeley, 1999). Since major depressive disorder can be chronic and recur, treatment of this disorder in children and adolescents becomes important. Treatment is also important as there are various risk factors associated with major depressive disorder in children and adolescents. The next section discusses some of the risk factors associated with major depression in children and adolescents.

\section{Risk Factors Associated with Major Depressive Disorder}

Major depressive disorder in children and adolescents is associated with a high degree of morbidity and mortality. Children and adolescents with major depressive disorder, compared to normal controls are at greater risk for drug and alcohol abuse, tend to experience significantly greater difficulty in school and work, and have greater impairment in overall functioning (Lewinsohn et al., 1999; Weissman et al., 1999). Left untreated, major depressive disorder is likely to recur in children and adolescents (Lewinsohn et al., 1999). Research indicates that untreated depression, which began during childhood or adolescence, tends to persist into adulthood (Lewinsohn et al., 1999; Weissman et al., 1999).

Left untreated major depressive disorder can a have serious impact on the lives of children and adolescents. Major depressive disorder is associated with a higher risk of substance abuse, impaired functioning, and even suicide. Although not all depressed youth commit suicide, it has been estimated that between $40-80 \%$ of youth with depression have experienced thoughts of suicide (American Psychiatric Association \& American Academy of Child and Adolescent Psychiatry, 2004). As age increases so does the risk of suicide, from 1.3/100,000 for youth aged 
10-14 years to 8.2/100,000 for adolescents aged 15-19 years (National Institute of Mental Health, 2004). Furthermore, research indicates that over $50 \%$ of those children and adolescents diagnosed with depression will attempt suicide, and at least $7 \%$ will take their lives as a result of depression (Ringold, 2005).

Untreated major depressive disorder tends to recur in youth and continue into adulthood. Furthermore, there are serious risks related to untreated major depressive disorder. Therefore, it is imperative that this disorder be treated in children and adolescents.

\section{Stages of Major Depressive Disorder Treatment}

Treatment is commonly referred to in the literature as being divided into three stages or phases (Agency for Health Care Policy and Research, 1993). The Agency for Healthcare Research and Quality (AHRQ), formerly the Agency for Healthcare Policy and Research (AHCPR) defined the three phases for the treatment of major depressive disorder (Karasu, Gelenberg, Merriam, \& Wang, 2000; Agency for Health Care Policy and Research, 1993). The aim of each phase is the "attainment of a stable, fully asymptomatic state and full restoration of psychosocial function" (Agency for Health Care Policy and Research, 1993). The first or initial phase of treatment is the acute treatment phase. This phase uses formal procedures to reduce or remove the symptoms and signs of depression and helps to restore the patient's psychosocial function (Agency for Health Care Policy and Research, 1993). The patient is considered a responder and remission is induced when the patient improves with the use of treatment. The next phase is the continuation phase of treatment. The purpose of the continuation phase of treatment is to prevent a relapse and maintain remission (Agency for Health Care Policy and Research, 1993). Based on the AHRQ definition, the continuation phase continues until the 
patient has maintained remission for six months (Agency for Health Care Policy and Research, 1993). Some physicians may discontinue treatment at the end of the continuation phase; however treatment may be continued into the maintenance phase of treatment (Agency for Health Care Policy and Research, 1993). The purpose of maintenance treatment is to prevent a recurrence or a new episode of major depressive disorder in the patient (Agency for Health Care Policy and Research, 1993).

\section{Treatment of Major Depressive Disorder in Children and Adolescents}

Antidepressant medication and psychotherapy have each been found to be beneficial in the treatment of major depressive disorder. The research on the efficacy of major depressive disorder treatments for children and adolescents has only been conducted in the more recent years and literature in this area is limited when compared to the literature in the treatment of major depressive disorder in the adult population. Additionally, some of the treatments that have proved helpful in the adult population are not efficacious when treating children and adolescents with major depressive disorder. Therefore, the adult research results should not be generalized to the child and adolescent population and additional research needs to be conducted in this area.

The following two sections of this dissertation will be devoted to antidepressant treatments for children and adolescents with major depressive disorder. First, each class of antidepressant medication will be reviewed. Second, the randomized clinical trials of antidepressant medication for major depressive disorder in children and adolescents will be examined. 


\section{Antidepressant Treatment of Major Depressive Disorder}

\section{Mechanism of Action}

Although the mechanism of antidepressants is not completely understood, the general action of these medications is believed to be the following: Neurotransmitters, including norepinephrine, serotonin, and dopamine, are released from one neuron or the presynaptic neuron into the synapse, or space between two neurons (Lieberman, 2003; Trujillo \& Chinn, 1996). Once in the synapse neurotransmitters can be deactivated by being reabsorbed by the presynaptic neuron or by being broken down by an enzyme called monoamine oxidase (Trujillo \& Chinn, 1996). It is thought that depression results from a decrease in the concentration of neurotransmitters within the synapse. Therefore, antidepressants act to increase concentrations of neurotransmitters within the synapse by either blocking the reuptake or re-absorption of neurotransmitters from the synapse or by preventing the enzymatic action of monoamine oxidase with the synapse.

Each class of antidepressants, their mechanism of action, and their side effects will be discussed in the following section. Randomized controlled trials related to each class of antidepressant will be discussed later in this chapter.

\section{Monoamine Oxidase Inhibitors (MAOIs)}

Monoamine Oxidase Inhibitors (MAOIs) are a class of antidepressant medication and include

the drugs Marplan ${ }^{\circledR}$ (isocarboxazid), $\operatorname{Nardil}^{\circledR}$ (phenelzine sulfate), and Parnate ${ }^{\circledR}$ (tranlcypromine sulfate). These medications were among the first antidepressants to be synthesized and their utilization began in the early 1950’s (Lieberman, 2003; Plestscher, 1991; Trujillo \& Chinn, 1996). 
The MAOIs operate by inhibiting the action of the enzyme, monoamine oxidase which breaks down neurotransmitters, including norepinephrine, serotonin, and dopamine, within the synaptic cleft (Lieberman, 2003; Plestscher, 1991; Trujillo \& Chinn, 1996). Because the MAOIs block the action of monoamine oxidase these neurotransmitters are not destroyed and they build up in the synapse. It is thought that the decreased levels of neurotransmitters are associated with depression. Therefore, MAOIs increase neurotransmitter concentrations, and this higher concentration is believed to relieve depressive symptoms.

Although, MAOIs can be effective in treating depression these medications have the potential for serious side effects and numerous drug and food interactions. Side effects range from dizziness, blurred vision, and weight gain to hypertensive crisis (National Institutes of Health, 2005). Patients taking MAOIs must avoid foods and drugs that have a high tyramine content including cheeses, poultry, alcoholic beverages, coffee, tea, and chocolate (National Institutes of Health, 2005). This trend seems to be related to the potentially serious side effects and dangerous interactions with any food or drug which contains tyramine (McCrabe, 1986). Tyramine aids in regulating blood pressure (Mayo Clinic, 2004). MAOIs prevent the normal destruction of tyramine, which results in a high level of this amino acid to build up in the human body (Mayo Clinic, 2004). Higher than normal levels of tyramine may cause a severe increase in blood pressure and the results can be fatal (Mayo Clinic, 2004).

It has been noted in the literature that MAOIs have not been widely utilized in the child and adolescent population (Emslie, Walkup, Pliszka, \& Ernst, 1999). In fact due to the potential for side effects and interactions some psychiatrists never prescribe MAOIs (Fiedorowicz \& Swartz, 2004). 


\section{$\underline{\text { Tricyclic Antidepressants (TCAs) }}$}

Concurrent to the development and utilization of the MAOIs was the synthesis and use of the class of antidepressants known as TCAs (Lieberman, 2003; Pletscher, 1991). The first TCA to be synthesized was Tofranil ${ }^{\circledR}$ (imipramine HCl) (Lieberman, 2003; Pletscher, 1991; Trujillo \& Chinn, 1996). By the 1960 's other TCAs, including Norpramin ${ }^{\circledR}$ (desipramine $\left.\mathrm{HCl}\right)$ and Elavil ${ }^{\circledR}$ (amitriptyline $\mathrm{HCl}$ ), were developed (Lieberman, 2003). These newer TCAs were relatively safer and better tolerated by patients than the older Tofranil ${ }^{\circledR}$ (Lieberman, 2003; Pletscher, 1991).

The TCAs act by blocking the reuptake of neurotransmitters into neurons (Pletscher, 1991). The disadvantage of this class of antidepressants is that they are associated with undesirable side effects including dry mouth, dizziness, and weight gain (Hazell, O'Connell, \& Heathcote, 1995). Additionally, the TCAs may cause more serious adverse effects including cardiovascular events and the potential for overdose (Hazell et al., 1995).

\section{$\underline{\text { Tetracyclic Antidepressants }}$}

In 1980, the U.S. Food and Drug Administration (FDA) approved Ludiomil ${ }^{\circledR}$ (maprotiline $\mathrm{HCl}$ ) for use in the treatment of depression (United States Food and Drug Administration, 2007). The other tetracyclic antidepressant Remeron ${ }^{\circledR}$ (mirtazpine) was not approved by the U.S. FDA until 1996 (MedicineNet.com, 1999; United States Food and Drug Administration, 2007). Tetracyclic antidepressants increase the amount of the neurotransmitters, norepinephrine and serotonin (MedicineNet.com, 1999). Like the MAOIs and TCAs, the tetracyclic antidepressants have relatively more side effects than some of the other antidepressants developed in the last two decades. The more prominent side effects of the tetracyclic antidepressants include sedation and risk of overdose (HealthyPlace, 2006). 


\section{$\underline{\text { Selective Serotonin Reuptake Inhibitors (SSRIs) }}$}

The next major class of antidepressants to be developed was the SSRIs (Pletscher, 1991). In 1987, Prozac ${ }^{\circledR}$ (fluoxetine $\mathrm{HCl}$ ), was the first SSRI to be approved and launched in the U.S.(United States Food and Drug Administration, 2007). It should be noted that Prozac ${ }^{\circledR}$ is the only antidepressant that has been approved for use in the child and adolescent population, and the U.S. FDA granted this approval in 2003 (United States Food and Drug Administration, 2007). The 1990's and early 2000's brought the development and launch of other SSRIs including Celexa ${ }^{\circledR}$ (citalopram HBr), Lexapro ${ }^{\circledR}$ (escitalopram oxalate), Paxil ${ }^{\circledR}$ (paroxetine $\mathrm{HCl}$ ), Luvox ${ }^{\circledR}$ (fluvoxamine maleate), and Zoloft ${ }^{\circledR}$ (sertraline $\mathrm{HCl}$ ) (United Stated Food and Drug Administration, 2007). As their name suggests, the SSRIs act by selectively inhibiting the reuptake of the neurotransmitter serotonin (Pletscher, 1991). This results in an increase in serotonin levels which helps to treat depressive symptoms (Pletscher, 1991).

This class of antidepressants has the advantage of an improved safety and tolerability profile, relative to the MAOIs or TCAs (Emslie et al., 1999; Lieberman, 2003; Pletscher, 1991). Additionally, the SSRIs have the advantage of being safer to the patient if taken in excess, such as in an attempt at a drug overdose (Emslie et al., 1999). Common side effects of the SSRIs include agitation, sleep difficulties, and gastrointestinal upset (Emslie et al., 1999).

\section{$\underline{\text { Serotonin-Norepinephrine Reuptake Inhibitors (SNRIs) }}$}

The SNRIs were developed during the same time period as the SSRIs. By 1993, the U.S. FDA approved, the first SNRI, Effexor ${ }^{\circledR}$ (venlafaxine $\mathrm{HCl}$ ) for the treatment of depression (United States Food and Drug Administration, 2007). Cymbalta ${ }^{\circledR}$ (duloxetine $\mathrm{HCl}$ ) was 
approved in 2004, in the U.S., for use in the treatment of depression (United States Food and Drug Administration, 2007).

The SNRIs have an action similar to that of the TCAs, as these antidepressants block the reuptake of both norepinephrine and serotonin. However, SNRIs have an improved side effect profile compared to TCAs including less risk of cardiovascular events and less potential for overdose (United States Food and Drug Administration, 2007).

\section{Norepinephrine and Dopamine Reuptake Inhibitors (NDRIs)}

Wellbutrin ${ }^{\circledR}$ (buproprion $\mathrm{HCl}$ ) is an NDRI and is unique as its mechanism of action mainly affects the neurotransmitter dopamine (GlaxoSmithKline, 2006). However, this NDRI inhibits the reuptake of serotonin, norepinephrine, and dopamine (GlaxoSmithKline, 2006). Wellbutrin ${ }^{\circledR}$ was initially approved by the U.S. FDA for use in the treatment of depression in 1985 (United States Food and Drug Administration, 2007). Since that time two other dosage forms of Wellbutrin ${ }^{\circledR}$ have gained approval for the treatment of depression. In 1996 Wellbutrin $\mathrm{SR}^{\circledR}$ was approved and in 2003 Wellbutrin XL ${ }^{\circledR}$ gained approval (United States Food and Drug Administration, 2007). The SR or sustained-release and XL or extended-release versions of Wellbutrin ${ }^{\circledR}$ both release bupropion at a slower rate.

This antidepressant seems to be well-tolerated and is relatively safe, even in overdose situations (Carson, Butcher, \& Mineka, 2002). Common side effects with this antidepressant are agitation, insomnia, dizziness, headache, rapid heartbeat, and weight loss (GlaxoSmithKline, 2006). 


\section{Other Antidepressants}

Two chemically related antidepressants Desyrel ${ }^{\circledR}$ (trazodone $\mathrm{HCl}$ ) and Serzone ${ }^{\circledR}$ (nefazodone $\mathrm{HCl}$ ), which are unrelated to other classes of antidepressants, were approved by the U.S. FDA to treat depression, in 1982 and 1994 respectively (United States Food and Drug Administration, 2007). Desyrel ${ }^{\circledR}$ is believed to inhibit the reuptake of serotonin, while Serzone ${ }^{\circledR}$ inhibits the reuptake of serotonin and norepinephrine (MedicineNet.com, 1997; MedicineNet.com, 2003).

Desyrel $^{\circledR}$ can be helpful in treating patients that are depressed but also have symptoms of anxiety, as it has a sedative effect (MedicineNet.com, 2003). Serzone ${ }^{\circledR}$ has been associated with side effects such as low blood pressure, sleepiness, dry mouth, nausea, dizziness, vision problems, and confusion (United States Food and Drug Administration, 2005c). More critically, Serzone ${ }^{\circledR}$ has been associated with liver failure. Serzone ${ }^{\circledR}$ has been removed from many markets including the European, Australian, New Zealand, and Canadian markets (United States Food and Drug Administration, 2005c; WebMD, 2004). As of June 14, 2004, Bristol-Myers Squibb stopped selling Serzone ${ }^{\circledR}$, however generic versions of the antidepressant are still available (United States Food and Drug Administration, 2005c; WebMD, 2004). The U.S. FDA now requires that nefazodone's label carry a black box warning of life-threatening liver damage (United States Food and Drug Administration, 2007; WebMD, 2004).

\section{Outcome Measures Utilized in Randomized Clinical Trails}

The randomized clinical trials (RCTs) for antidepressants and psychotherapy have utilized several different outcome measures to quantify patients' response to treatment. Table 2.3 provides an overview of the measures utilized in the antidepressant and psychotherapeutic RCTs, which will be described in the following section. 
Table 2.3: Instruments Utilized to Measure Patient Outcomes in Randomized Clinical Trials

\begin{tabular}{|c|c|c|c|c|}
\hline Scale & Reference & $\begin{array}{c}\text { Number of Items } \\
\text { on the Scale }\end{array}$ & $\begin{array}{l}\text { Age for which } \\
\text { Scale is } \\
\text { Appropriate }\end{array}$ & Purpose of Scale \\
\hline $\begin{array}{l}\text { Beck Depression } \\
\text { Inventory (BDI) }\end{array}$ & $\begin{array}{l}\text { (Beck \& Steer, } \\
1987)\end{array}$ & 21 & $\begin{array}{l}\text { Adolescents and } \\
\text { Adults (13-80 yrs.) }\end{array}$ & $\begin{array}{l}\text { Self-inventory } \\
\text { scale designed to } \\
\text { measure } \\
\text { depressive } \\
\text { symptoms } \\
\end{array}$ \\
\hline $\begin{array}{l}\text { Child Behavior } \\
\text { Checklist (CBCL) }\end{array}$ & $\begin{array}{l}\text { (Achenbach \& } \\
\text { Rescorla, 2001) }\end{array}$ & $\begin{array}{l}118 \text { plus } 2 \text { open- } \\
\text { ended questions }\end{array}$ & $\begin{array}{l}\text { Children (6-18 } \\
\text { yrs.) }\end{array}$ & $\begin{array}{l}\text { Parent-report scale } \\
\text { designed to } \\
\text { measure the child's } \\
\text { behavior and social } \\
\text { competency }\end{array}$ \\
\hline $\begin{array}{l}\text { Children's } \\
\text { Depression } \\
\text { Inventory (CDI) }\end{array}$ & (Kovacs, 1992) & 27 & $\begin{array}{l}\text { Children and } \\
\text { Adolescents (7-17 } \\
\text { yrs.) }\end{array}$ & $\begin{array}{l}\text { Self-reported } \\
\text { inventory to assess } \\
\text { depression }\end{array}$ \\
\hline $\begin{array}{l}\text { Children's } \\
\text { Depression Rating } \\
\text { Scale (CDRS-R) }\end{array}$ & $\begin{array}{l}\text { (Poznanski \& } \\
\text { Mokros, 1996) }\end{array}$ & 17 & $\begin{array}{l}\text { Children (6-12 } \\
\text { yrs.) and } \\
\text { Adolescents }\end{array}$ & $\begin{array}{l}\text { Semi-structured } \\
\text { interview to } \\
\text { diagnose } \\
\text { depression or } \\
\text { monitor treatment } \\
\text { response }\end{array}$ \\
\hline $\begin{array}{l}\text { Children's Global } \\
\text { Assessment Scale } \\
\text { (CGAS) }\end{array}$ & $\begin{array}{l}\text { (American } \\
\text { Psychiatric } \\
\text { Association, 2000) }\end{array}$ & $\begin{array}{l}\text { Numeric Scale } \\
1-100\end{array}$ & $\begin{array}{l}\text { Children and } \\
\text { Adolescents }(<18 \\
\text { yrs. })\end{array}$ & $\begin{array}{l}\text { Utilized by } \\
\text { clinicians to rate } \\
\text { the general } \\
\text { functioning of a } \\
\text { child }\end{array}$ \\
\hline $\begin{array}{l}\text { Clinical Global } \\
\text { Impressions (CGI) }\end{array}$ & (Guy, 1979) & 3 & $\begin{array}{l}\text { Appropriate for all } \\
\text { Ages }\end{array}$ & $\begin{array}{l}\text { Utilized by } \\
\text { clinicians to assess } \\
\text { a patient's } \\
\text { response to } \\
\text { treatment }\end{array}$ \\
\hline $\begin{array}{l}\text { Hamilton } \\
\text { Depression Rating } \\
\text { Scale (HAM-D) }\end{array}$ & (Hamilton, 1960) & 21 & Adults (> 18 yrs.) & $\begin{array}{l}\text { Semi-structured } \\
\text { interview to } \\
\text { designed to rate } \\
\text { the severity of } \\
\text { depressive } \\
\text { symptoms }\end{array}$ \\
\hline $\begin{array}{l}\text { Raskin Depression } \\
\text { Scale }\end{array}$ & (Rush, 2000) & 3 & Adults (> 18yrs.) & $\begin{array}{l}\text { Utilized by } \\
\text { clinicians to assess } \\
\text { the severity of } \\
\text { depression }\end{array}$ \\
\hline $\begin{array}{l}\text { Social Adjustment } \\
\text { Scale Self Report } \\
\text { (SAS-SR) }\end{array}$ & $\begin{array}{l}\text { (Weissman \& } \\
\text { Bothwell, 1976) }\end{array}$ & 54 & 17 yrs. and older & $\begin{array}{l}\text { Self-report } \\
\text { inventory designed } \\
\text { to assess } \\
\text { individuals ability } \\
\text { to adapt and be } \\
\text { satisfied with their } \\
\text { social situation }\end{array}$ \\
\hline
\end{tabular}




\section{Efficacy of Antidepressants in Children and Adolescents with Major Depressive Disorder}

Few studies regarding the efficacy of MAOIs in treating any psychiatric disorder in the child and adolescent population can be found in the literature (Emslie et al., 1999). Ryan et al. (1988) conducted a published chart review of 23 adolescent patients who had been diagnosed with depression and treated with MAOIs. While this study demonstrated some improvement in depressive symptoms among patients, the authors concluded that the potential risks associated with these antidepressants outweighed the therapeutic benefit (Ryan et al., 1988).

Despite the fact that TCAs have demonstrated efficacy in adults, this has not proved to be the case in the child and adolescent population (Hazell et al., 1995; Geller, Reising, Leonard, Riddle, \& Walsh, 1999). Unlike the MAOI class of antidepressant, where there have been few scientific studies conducted in the child and adolescent population, many RCTs have been conducted for TCAs. Unfortunately, the results of these trials have not proved TCAs to be efficacious in the treatment of major depressive disorder in children and adolescents. Included in the literature is a meta-analysis conducted by (Hazell et al., 1995). This study includes 12 RCTs of TCAs, such as amitriptyline, desipramine, impramine, and nortriptyline (Hazell et al., 1995). The conclusion of this study was that TCAs are no more effective than placebo in treating child and adolescent depression (Hazell et al., 1995). Geller et al. (1999) conducted a systematic review of tricyclic antidepressant use in children and adolescents. This review also concluded that the TCAs did not demonstrate efficacy in the treatment of child and adolescent depression (Geller et al., 1999).

Although the literature contains no published RCTs of the tetracyclic antidepressants, there are results of two unpublished, multi-center, double-blind, placebo controlled trials of Remeron ${ }^{\circledR}$ in outpatient children and adolescents with major depressive disorder (Dubitsky, 2004). The two 
trials (hereafter, referred to as Trial \#1 and Trial \#2) had identical protocols (Medicines and Healthcare Products Regulatory Agency, 2004). Trial \#1 randomized 126 children and adolescents, while Trial \#2 randomized 133 children and adolescents seven to17 years of age to a dose of 15 milligram (mg) to $45 \mathrm{mg}$ of Remeron ${ }^{\circledR}$ or placebo for eight weeks (Dubitsky, 2004; Medicines and Healthcare Products Regulatory Agency, 2004). Patients randomized to the Remeron ${ }^{\circledR}$ arm began treatment with a $15 \mathrm{mg}$ dose of the antidepressant (Dubitsky, 2004). The investigators had the option of increasing the dose in $15 \mathrm{mg}$ increments to a maximum of $45 \mathrm{mg}$ (Dubitsky, 2004). The primary efficacy measure was the change in the score on the Children's Depression Rating Scale-Revised from baseline to the eight-week study endpoint (Medicines and Healthcare Products Regulatory Agency, 2004; Emslie, Ryan, \& Wagner, 2005). There was no statistically significant difference between treatment groups in either of these trials (Emslie et al, 2005; Medicines and Healthcare Products Regulatory Agency, 2004).

The SSRIs have been shown to have greater efficacy than other antidepressants in the treatment of child and adolescent depression, and have subsequently been studied more in this population than other classes of antidepressants (Emslie et al., 2005). However, efficacy has not been consistently demonstrated across RCTs in which children and adolescents diagnosed with major depressive disorder have been treated with SSRIs (Emslie et al., 2005).

Simeon, Denicola, Ferguson, \& Copping (1990) conducted a placebo-controlled double-blind trial of fluoxetine. The study population consisted of 40 outpatients and inpatients between the ages of 13 and 18 years who had been diagnosed with major depressive disorder (Simeon et al., 1990) The 40 adolescents were randomized to a seven-week treatment period (Simeon et al., 1990). The fluoxetine treatment was $20 \mathrm{mg}$ per day, increased to $40 \mathrm{mg}$ daily after four to seven 
days, and then increased to $60 \mathrm{mg}$ during the second week of treatment (Simeon et al., 1990). Outcome measures for this study included the following: Hamilton Rating Scale for Depression, Clinical Global Impression, and Raskin Depression Scale (Simeon et al., 1990). The researchers found that fluoxetine was not a statistically superior treatment to placebo based on any of these outcome measures (Simeon et al., 1990).

Emslie et al. (1997) conducted an eight-week double-blind randomized, placebo-controlled trial to evaluate the efficacy, safety, and tolerability of fluoxetine (20 mg per day) compared to placebo in a child and adolescent population. The study population consisted of outpatients between the ages of seven and 17 years who met the DSM-III-R criteria for major depressive disorder (Emslie et al., 1997). After a one week, single-blind placebo run-in period, 96 children were randomized to either an eight-week treatment of fluoxetine or placebo (Emslie et al., 1997). Primary outcome measures were the Clinical Global Impressions and the Children's Depression Rating Scale-Revised (Emslie et al., 1997). At the completion of the treatment period, the fluoxetine arm was found to be statistically significant to the placebo arm, on both of the primary outcome measures ( $\mathrm{p}=.02$ Clinical Global Impressions; $\mathrm{p}<.001$ Children's Depression Rating Scale-Revised) (Emslie et al., 1997). In the fluoxetine arm, 27 of the 48 patients compared to 16 of the 48 patients in the placebo arm responded to treatment $\left(\chi^{2}=5.097, \mathrm{df}=1, \mathrm{p}=.02\right)($ Emslie et al., 1997).

Keller et al. (2001) conducted an eight-week trial, which randomized 275 patients 12 to 18 years of age who had been diagnosed with major depressive disorder, to three treatment arms. The three treatments included paroxetine ( $20 \mathrm{mg}-40 \mathrm{mg}$ per day), imipramine (gradual titration to $200 \mathrm{mg}-300 \mathrm{mg}$ per day), and placebo (Keller et al., 2001). The primary outcome measure 
was the Hamilton Rating Scale for Depression and the authors defined a response to treatment as a Hamilton Rating Scale for Depression score of less than or equal to eight, or a greater than or equal to 50\% reduction in baseline Hamilton Rating Scale for Depression score at end of treatment (Keller et al., 2001). The percentage of patients who achieved a Hamilton Rating Scale for Depression score of less than or equal to eight were as follows: paroxetine $63.3 \%$, imipramine 50.0\%, and placebo $46.0 \%$ (Keller et al., 2001). There were significantly more "responders" in the paroxetine treatment groups than in the placebo group $(p=0.02)($ Keller et al., 2001). The percentage of patients who achieved a Hamilton Rating Scale for Depression of less than or equal to eight or a greater than or equal to $50 \%$ reduction in baseline Hamilton Rating Scale for Depression score were as follows: paroxetine $66.7 \%$, imipramine $58.5 \%$, and placebo 55.2\% (Keller et al., 2001). On this second measure of response neither the paroxetine group nor the imipramine group was statistically significant when compared to the placebo group (Keller et al., 2001).

Emslie et al. (2002) conducted a second RCT in children and adolescents, eight to 18 years of age, who had been diagnosed with major depressive disorder. This trial included a three-week screening period, then a single-blind, placebo run-in period (Emslie et al., 2002). Those patients $(n=219)$ who did not respond to placebo were randomized to either treatment with Prozac ${ }^{\circledR}$ or placebo (Emslie et al., 2002). The primary outcome measure was a treatment response as measured by the Children's Depression Rating Scale-Revised. A treatment response was defined as a greater than or equal to $30 \%$ decrease in Children's Depression Rating Scale-Revised score from week zero to study endpoint (Emslie et al., 2002). A treatment remission was defined as an endpoint Children's Depression Rating Scale-Revised score of less than 28 (Emslie et al., 2002). 
The mean change in Children's Depression Rating Scale-Revised score was statistically significant $(\mathrm{p}<0.001)$ for fluoxetine as compared to placebo (Emslie et al., 2002). The response rate for patients treated with fluoxetine (65.1\%) compared to those treated with placebo (53.5\%) was not statistically significant (Emslie et al., 2002). The remission rate for patients treated with fluoxetine $(41.3 \%)$ compared to those treated with placebo (19.8\%) was statistically significant $(\mathrm{p}<0.01)$ (Emslie et al., 2002).

Mandoki, Tapia, Tapia, Sumner, \& Parker (1997) conducted a six-week, double-blind, placebo-controlled trial with 40 patients between the ages of eight and 17 years who had major depressive disorder (Mandoki et al., 1997). Among patients receiving Effexor ${ }^{\circledR}$ the dose varied from $37.5 \mathrm{mg}$ per day for children and $75 \mathrm{mg}$ per day for adolescents (Mandoki et al., 1997). Response was measured by the Hamilton Depression Rating Scale, and the Children's Depression Rating Scale, Children's Depression Inventory, and the Children's Behavioral Checklist (Mandoki et al., 1997). All rating scales indicated an improvement in depressive symptoms, but there were no statistically significant differences found between treatment groups (Mandoki et al., 1997). Therefore, this study did not demonstrate efficacy of Effexor ${ }^{\circledR}$ in children and adolescents with major depressive disorder (Mandoki et al., 1997). The authors stated that the insignificant findings could be a result of the fact that all of the patients received cognitive-behavioral therapy along with the antidepressant or placebo, which might have obscured any treatment effect (Mandoki et al., 1997). Also, the insignificant result may have been a result of the small doses of Effexor ${ }^{\circledR}$ (Mandoki et al., 1997). However, later trials of this antidepressant have not shown efficacy in the treatment of children and adolescents with major depressive disorder. 
Two unpublished eight-week, double-blind, placebo-controlled trials evaluated the efficacy of Effexor ER ${ }^{\circledR}$ in children and adolescents with major depressive disorder (Medicines and Healthcare Products Regulatory Agency, 2004). Patients began on a dose of $37.5 \mathrm{mg}$ per day and then were titrated up to a maximum of $225 \mathrm{mg}$ per day (Medicines and Healthcare Products Regulatory Agency, 2004). Primary efficacy measurement for both trials was the change in Children's Depression Rating Scale-Revised score (Medicines and Healthcare Products Regulatory Agency, 2004). There was no statistically significant difference between treatment groups, therefore Effexor $\mathrm{ER}^{\circledR}$ did not demonstrate efficacy in the treatment of children and adolescents with major depressive disorder (Medicines and Healthcare Products Regulatory Agency, 2004).

Emslie, Findling, Yeung, Kunz, \& Li (2007) conducted an eight-week, double-blind, placebocontrolled trial evaluated the efficacy of Effexor ER ${ }^{\circledR}$. Patients seven to seventeen years of age were randomized to a flexible dose of Effexor $\mathrm{ER}^{\circledR}$ or placebo (Emslie et al., 2007). The primary outcome was change from baseline on the Children's Depression Rating Scale (Emslie et al., 2007). There was no statistical significant improvement between the treatment and placebo groups (Emslie et al., 2007). A post-hoc analysis showed greater improvement for adolescents $(\mathrm{p}=0.022)$ based on the Children's Depression Rating Scale, but no significant improvement for children (Emslie et al., 2007). Therefore, this analysis indicates efficacy for Effexor $\mathrm{ER}^{\circledR}$ in the adolescent population (Emslie et al., 2007).

The NDRIs' efficacy have not been tested for children and adolescents with major depressive disorder. Although these antidepressants have been studied for the treatment of children and 
adolescents with other disorders, no RCTs of Wellbutrin ${ }^{\circledR}$, Wellbutrin SR ${ }^{\circledR}$, or Wellbutrin $\mathrm{XL}^{\circledR}$ exist in the literature involving children and adolescents with major depressive disorder.

Only one unpublished trial was located for the "Other Antidepressants", including Desyrel ${ }^{\circledR}$ and Serzone ${ }^{\circledR}$. Rynn, Riddle, Yeung, \& Kunz, (2007) conducted a trial to determine the efficacy

of Serzone ${ }^{\circledR}$ in the treatment of major depressive disorder in children and adolescents before liver damage warnings were made public (Rynn et al., 2007). However, this study did not demonstrate the antidepressant's efficacy in this population (Rynn et al., 2007). The lack of RCTs for this group of antidepressants may be a result of the liver damage that has been associated with their use and Bristol Myers Squibb pulled Serzone ${ }^{\circledR}$ from the U.S. market, however the generic version nefazodone HCL is still available (U.S. FDA, 2008).

\section{Psychotherapy Treatment for Major Depressive Disorder}

According to the 1998 American Academy of Child and Adolescent Psychiatry Practice Parameters, psychotherapy is an appropriate treatment for depressive disorders in both children and adolescents (American Academy of Child and Adolescent Psychiatry, 1998). There are many different types of psychotherapy and some of these are utilized to treat children and adolescents with major depressive disorder. These types are defined in Table 2.4. 
Table 2.4: Definitions of Psychotherapy

Cognitive Behavioral Therapy (CBT) teaches the patient to identify and counteract cognitive distortions. CBT is based on the premise that people with depression have cognitive distortions of themselves, the world, and the future; that these cognitive distortions contribute to their depression (American Academy of Child and Adolescent Psychiatry, 1998).

Interpersonal Therapy (IPT) focuses on the clarification and resolution of problem areas such as prolonged grief, interpersonal roles, role disputes, role transitions, and personal difficulties (Agency for Health Care Policy and Research, 1993; American Academy of Child and Adolescent Psychiatry, 1998).

Supportive Counseling establishes and maintains rapport with the patient and provides support to the patient and helps the patient identify and express feelings. The health care provider can achieve these goals through the use of reflective listening, empathy, and discussions of personal problems (Brent, 1997).

Play Therapy utilizes the therapeutic powers of play to help patients prevent or resolve psychosocial difficulties and achieve optimal growth and development (O’Connor, 2000).

Family Therapy is a treatment approach that makes the assumption that the within-family behavior of a particular family member is largely influenced by the behaviors and communication patterns of other family members (Carson, 2002).

Unfortunately, efficacy of psychotherapy for the treatment of major depressive disorder in children and adolescents is difficult to assess due to the limited number of RCTs in the scientific literature. Of those RCTs conducted the sample sizes have been small (Ryan, 2005). Small samples sizes and high placebo rates make the results of these existing studies difficult to interpret (Ryan, 2005). Studies found in the literature are described in the next section.

Although there are no empirically validated psychotherapy treatments for children with major depressive disorder (Bridge, Salary, Birmaher, Asare, \& Brent, 2005) there is some support for two different psychotherapeutic approaches in the treatment of major depressive disorder in adolescents (Dopheide, 2006; Bridge et al., 2005; Ryan, 2005; Compton et al., 2004). These two approaches are cognitive behavioral therapy (CBT) and interpersonal therapy (IPT). Brent et al. (1997) conducted a trial in which 107 adolescents who had been diagnosed with major 
depressive disorder were randomized to receive 12 to 16 sessions of CBT, family therapy, or supportive therapy. Those patients treated with CBT showed a more rapid treatment response (p $=0.03)$ and a higher remission rate than family therapy $(\mathrm{p}=0.03)$ or supportive therapy $(\mathrm{p}=$ 0.04) than patients in other treatment arms (Brent et al., 1997). Remission was defined as absence of major depressive disorder as defined by the DSM-III-R and three consecutive scores of nine or less on the Beck Depression Inventory (Brent et al., 1997).

Mufson, Weissman, Moreau, \& Garfinkel (1999) conducted a randomized controlled clinical trial in which 48 adolescents aged 12 to 18 years were randomized to 12 -weeks of IPT or clinical monitoring. The clinical monitoring consisted of therapists reviewing patients' depressive symptoms, school attendance, supportive listening, and assessing the patients' suicidality (Mufson et al., 1999). The adolescents who received interpersonal therapy had a higher rate of recovery than the control group $(\mathrm{p}=0.04)$. The recovery criterion was a score of six or less on the Hamilton Rating Scale for Depression at the end of the 12-weeks of treatment (Mufson et al., 1999).

In 2004 Mufson et al. conducted another RCT in which 63 adolescents aged 12 to 18 years who had been diagnosed with major depressive disorder were randomized to 16 weeks of IPT or treatment as usual (Mufson et al., 2004). At the end of the 16 weeks, the adolescents who had received IPT had significantly fewer depressive symptoms as measured by the Hamilton Depression Rating Scale $(p=0.04)$, significantly better functioning on the Children's Global Assessment Scale $(p=0.04)$, significantly better overall social functioning on the Social Adjustment Scale-Self-Report $(p=0.01)$, significantly greater clinical improvement $(p=0.03)$ 
and greater decrease in clinical severity $(p=0.03)$ as measured by the Clinical Global Impressions Scale (Mufson et al., 2004).

\section{Combination Therapy for Major Depressive Disorder}

Another strategy is the combination of pharmacotherapy and psychotherapy. However, effectiveness for this treatment combination has been established only for adolescents who have been diagnosed with major depressive disorder (March \& The Treatment for Adolescents with Depression Study (TADS) Team, 2004). A description of the only RCT, sponsored by the National Institute of Mental Health, which supports this type of therapy, follows.

The TADS team conducted an RCT which randomized 439 adolescents 12 to 17 years of age, who were diagnosed with major depressive disorder (March \& TADS Team, 2004). The adolescents received one of four treatments for 12 -weeks. These treatments included fluoxetine (10 mg per day for week one, then increased to $20-40 \mathrm{mg}$ per day), CBT, a combination of fluoxetine and CBT, or placebo (March \& TADS Team, 2004). The primary outcome measures consisted of the Children's Depression Rating Scale-Revised and the Clinical Global Impressions improvement score (March \& TADS Team, 2004). This study found that the combination treatment of fluoxetine and $\mathrm{CBT}$ was superior and statistically significant to placebo as measured by the Children's Depression Rating Scale-Revised $(\mathrm{p}=0.001)$ (March \& TADS Team, 2004). Additionally, treatment with fluoxetine and CBT was superior to either fluoxetine $(\mathrm{p}=0.02)$ or CBT $(\mathrm{p}=0.01)$ alone, as measured by the Children's Depression Rating ScaleRevised (March \& TADS Team, 2004). 


\section{Physician Prescribing Decisions}

As the reviewed studies in the above sections indicate, some types of antidepressant therapy and psychotherapy have been shown to have efficacy in the treatment of major depressive disorder in children and/or adolescents. However, opinions vary as to which of these treatments should be offered as a first-line of treatment or whether they should be offered as a combination treatment (American Academy of Child and Adolescent Psychiatry, 1998). Ideally the choice of antidepressant medication should rely on Evidence-Based Medicine (EBM) (Depont et al., 2003). Evidence- Based Medicine has been defined as the "use of current best evidence in making decisions about the care of individual patients" (Sackett, Rosenberg, Gray, Haynes, \& Richardson, 1996).

Fluoxetine is the only antidepressant approved by the U.S. FDA for the treatment of major depressive disorder in children and adolescents (United States Food and Drug Administration, 2007). However, $40 \%$ of patients will not respond to this antidepressant and off-label use of other antidepressants for the treatment of major depressive disorder in children and adolescents is common (Brent, 2005; March \& TADS Team, 2004). Therefore, EBM is not the only factor to influence physicians' decision to prescribe antidepressants to children and adolescents. According to the American Academy of Child and Adolescent Psychiatry, the choice of initial therapy depends in part on "clinical", "psychosocial factors", and the "therapist's expertise" (American Academy of Child and Adolescent Psychiatry, 1998). Since the choice of antidepressant treatment for children and adolescents is not based solely on empirical research, it is important to explore other factors that influence physicians' decision-making. 


\section{Prescribing Decisions for Adult Populations}

Characteristics of physicians' decisions is that they tend to be made quickly, require an enormous amount of information, and differ in style depending on the physician and the clinical problem (Eisenberg, 1979). Researchers have proposed models that depict factors which influence physicians' prescribing decisions. However, the majority of these studies focused on prescribing any type of medication to adults rather than focusing on antidepressant prescribing decisions to children and adolescents. One study did focus on antidepressant prescribing to adults and will be discussed first. Sleath \& Shih (2003) demonstrated that Eisenberg's model of sociological influences on physicians' prescribing could be applied to antidepressant prescribing to depressed adults. In 1979 Eisenberg's theory of decision-making by clinicians stated that in addition to the scientific criteria (EBM and clinical information) upon which physicians' decisions are based, there are four types of sociological factors which influence physicians' decision-making (Eisenberg, 1979). These sociological factors are as follows: characteristics of the patient, characteristics of the physician, the physician's interaction with his profession and the health care system, and the physician's relationship with the patient (Eisenberg, 1979). Sleath \& Shih (2003) determined that patients' age, patients' depression severity (any type of depression was examined, not only major depressive disorder), patients' insurance, geographic location, and physicians' specialty influenced physicians' prescribing of antidepressants to adults.

Benson (1983) modeled the relative influence of patient characteristics, physician characteristics, and treatment setting characteristics on antipsychotic drug prescribing by North Carolina psychiatrists. Patients' level of functional impairment, patients' diagnosis, physicians' 
board certification, psychiatrists' professional activism, psychiatrists' comfort with their knowledge of psychopharmacology, and the treatment setting were factors Benson (1983) determined to influence the antipsychotic prescribing decision.

Cates (2001) suggested that when considering an antidepressant for the treatment of major depressive disorder, drug-related factors should be considered. These factors include efficacy, adverse effects, drug interactions, dosing, and cost (Cates, 2001). Other researchers have suggested that marketing and promotional efforts influence physicians' prescribing decisions (Caplow \& Raymond, 1954; Chew et al., 2000; Freeman, Barnes, Summers, \& Szeinbach, 1993). Chew et al. (2000) demonstrated that the availability of drug samples influenced physicians' decisions to prescribe antidepressants.

Freeman et al. (1993) determined that side effects, efficacy, and patient characteristics were most influential to physicians' prescribing decisions for the treatment of panic disorder. Additionally, Freeman et al. (1993) demonstrated that product attributes and promotional influences were also influential, but to a lesser extent.

A more recent study by Nutescu et al. (2005) demonstrated the importance of some drugrelated factors to physicians' prescribing decisions. Nutescu et al. (2005) suggested that the decision to prescribe one drug instead of another within a specific therapeutic class (lowmolecular-weight-heparins) is influenced by a variety of factors. Nutescu et al. (2005) determined that drug efficacy, drug formulary status, restrictions on prescribing, physicians' personal experience, safety, cost, prescribing guidelines, and U.S. FDA approval were important factors in the physicians' decision-making process. Nutescu et al. (2005) determined that marketing and promotional factors such as face-to-face detailing by pharmaceutical 
representatives, samples of drugs, free drugs to indigent patients, and advertising efforts were somewhat influential to physicians' decision-making process. However, these factors were much less influential than other drug-related factors which physicians considered when making a decision to prescribe one drug instead of another within the same therapeutic class (Nutescu et al., 2005).

\section{Prescribing Decisions for Children and Adolescents}

Chen \& Chang (2002) determined that specific patient factors are related to increased utilization of prescription medications. It was determined that race, insurance status, and family income levels had significant impact on child and adolescent prescription drug utilization (Chen \& Chang, 2002). Children who were white, had private insurance, and were from high-income families were more likely to use prescription medications (Chen \& Chang, 2002). This study focused on all prescription medications whereas, other studies have focused specifically on the prescribing patterns associated with psychotropic medications in children and adolescents. The sections that follow will review the scientific literature pertaining to factors associated with physicians prescribing medication to children and adolescents. The first section will consist of a review of the scientific literature pertaining to factors associated with physicians prescribing of psychotropic medication to children and adolescents. The second section will consist of a review of the literature pertaining to factors associated specifically with physicians prescribing of antidepressants to children and adolescents.

\section{Psychotropic Prescribing to Children and Adolescents}

Hong \& Shepherd (1996) examined prescription drug benefit data for children and adolescents during the 1992-1993 time-period. The researchers found that children and 
adolescents were more likely to take psychotropic medication if their parents took them (Hong \& Shepherd, 1996). Males were more likely to take psychotropic medications at younger ages, while females were more likely to take psychotropic medications at older ages (Hong \& Shepherd, 1996). For the antidepressant drug class, children and adolescents from single parent homes were less likely than children from two parent homes to utilize antidepressants (Hong \& Shepherd, 1996). Additionally, parental use of antidepressants was associated with child and adolescent utilization of antidepressants (Hong \& Shepherd, 1996).

Kaplan \& Busner (1997) compared the psychotropic medication prescribing practices of inpatient child psychiatrists at a state hospital, a private hospital, and a county-university hospital in New York during 1991. The percentage of patients at the state, private and county-university hospital who received psychotropic medications were 79\%, 76\%, and 68\%, respectively (Kaplan \& Busner, 1997). Of those patients who received medication, more children and adolescents at the private hospital (80\%) compared with those patients at the state $(26 \%)$, or county-university (26\%) hospital received antidepressants $(\mathrm{p}<0.001)$ (Kaplan \& Busner, 1997). Additionally, significantly more county-university patients $(74 \%)$ received antipsychotic medications than those patients in the private (35\%) hospital (Kaplan \& Busner, 1997).

Safer (1997) examined the records of outpatient children and adolescents (their outpatient information was supplemented with inpatient records, if available) who were seen by child psychiatrists at four community mental health care centers in Maryland. Safer (1997) found that from 1988 to 1994 there was an increase in psychotropic medication treatment for children and adolescents. There was also an increase in SSRI utilization (Safer, 1997). Additionally, it was 
found that most children and adolescents who were prescribed psychotropic medications discontinued this treatment within three months (Safer, 1997).

Jensen et al. (1999) conducted a study which utilized prescribing data from the 1995 National Ambulatory Medical Care Survey (NAMCS) and the 1995 National Disease and Therapeutic Index (NDTI) to determine national trends for prescribing psychotropic medications to children 18 years and younger. Jensen et al. (1999) determined that stimulants are the most commonly prescribed psychotropic medication for this population (Jensen et al., 1999). Stimulant prescriptions were followed in frequency by SSRIs, anticonvulsant mood stabilizers, TCAs, central adrenergic agonists, antipsychotics, benzodiazepines, and lithium (Jensen et al., 1999).

Zito et al. (2000) utilized two Medicaid databases and one health maintenance organization (HMO) database to determine the prevalence and utilization trends of psychotropic medication use in children aged two through four. Zito et al. (2000) determined that psychotropic medication utilization trends increased for children aged two through four during the years 1991 to1995 (Zito et al., 2000). All three databases indicated that stimulants were the most widely utilized psychotropic medication for children aged two through four (Zito et al., 2000). Stimulant use frequency was followed by antidepressants, clonidine, and neuroleptics in both of the Medicaid populations (Zito et al., 2000). The HMO database indicated that clonidine was the second most frequently utilized psychotropic medication followed by antidepressants and neuroleptics (Zito et al., 2000). It should be noted that the TCA class of antidepressants represented the majority of the antidepressant use in this population during the years 1991-1995 (Zito et al., 2000). 
Goodwin, Gould, Blanco, \& Olfson (2001) utilized the National Ambulatory Medical Care Survey from 1992 - 1996 to determine prescribing patterns, patient characteristics, and clinical management of physicians who prescribed psychotropic medications to children and adolescents. It was found that a majority $(84.8 \%)$ of psychotropic medications were prescribed by pediatricians and general practitioners (Goodwin et al., 2001). It was also determined that stimulants $(53.9 \%)$ were the most often prescribed psychotropic medication prescribed (Goodwin et al., 2001). Antidepressants (30\%) were the second most commonly prescribed psychotropic medication (Goodwin et al., 2001). This study demonstrated that there are significant differences by gender, age, payment source, and race among those children and adolescents receiving prescriptions for psychotropic medications (Goodwin et al., 2001).

Rushton \& Whitmire (2001) conducted a study utilizing the North Carolina Medicaid database to describe prescription trends for SSRIs and stimulants in children. Stimulants and SSRI utilization increased during the 1992 to 1998 timeframe (Rushton \& Whitmire, 2001). For the year 1998, SSRI utilization was also higher for white males $(2.8 \%)$ than it was for black females (0.6\%) (Rushton \& Whitmire, 2001).

Elfron et al. (2003) conducted a survey of pediatricians and child and adolescent psychiatrists in Australia to determine the prescribing patterns for psychotropic medications. Stimulants and clonidine were the most frequently prescribed medications (Elfron et al., 2003). Child psychiatrists were more likely than pediatricians to indicate prescribing SSRIs (93\% versus 75\%) (Elfron et al., 2003).

Olfson, Gameroff, Marcus, \& Waslick (2003) utilized the Medical Expenditure Panel Survey (MEPS) from 1996 through 1999 to describe treatment patterns of children and adolescents 
(aged six to 18 years) with depression. More than half (56.9\%) of the children and adolescents were prescribed an antidepressant medication and most of these patients were treated with an SSRI (Olfson et al., 2003). Children and adolescents who were treated with an antidepressant were more likely (as compared to those patients not treated with an antidepressant) to have parents who graduated from high school, have health insurance, and live in large communities (Olfson et al., 2003).

Zito et al. (2003) utilized information from two Medicaid (a Midwestern state Medicaid database (MWM) and a mid-Atlantic state Medicaid database (MAM)) and one health maintenance organization (HMO) databases over a ten year period $(1987$ - 1996) to examine the changes in the prevalence and utilization trends of psychotropic medication use in children and adolescents less than 20 years of age. During the ten year period, there was a three-fold increase in total psychotropic medication prevalence in the MWM and HMO population, and a two-fold increase in total psychotropic medication prevalence in the MAM (Zito et al., 2003). By 1996, stimulants followed by antidepressants were the most commonly prescribed psychotropic medications for children and adolescents in all three populations (Zito et al., 2003). Additionally in 1996 , ten to 14 year old children and adolescents were utilizing more psychotropic medications in both Medicaid populations, while 15 to 19 year olds were utilizing more medications in the HMO population (Zito et al., 2003). In 1996, antidepressant utilization was highest in the 15 to 19 year old group for the HMO population, and highest in the ten to 14 year old group in both Medicaid populations (Zito et al., 2003). In 1996, the antidepressant utilization rate for males was two times that of the female rate (Zito et al., 2003). Over the ten year period, males increased their utilization of antidepressants more than females in the MAM population, 
and males and females had similar antidepressant utilization rates in the MWM population (Zito et al., 2003). In the HMO population, during the same ten-year period, more males than females utilized antidepressants in the zero to four, five to nine, and ten to 14 year olds (Zito et al., 2003). However, in the 15 to 19 year old group more females than males utilized antidepressants during this ten year period (Zito et al., 2003). There were race disparities among whites and African American patients in the MAM population, as shown by a greater utilization of antidepressant among white patients (Zito et al., 2003).

Haapasalo-Pesu, Erkolahti, Saarijarvi, \& Aalberg (2004) assessed adolescent psychiatrists' prescribing practices in hospital settings in Finland. The researchers sent a questionnaire to adolescent psychiatrists in 1991 and again in 1999 (Haapaslo-Pesu et al., 2004). It was determined by these surveys that 30\% of inpatients in 1991 and $68 \%$ in 1999 received a psychotropic medication (Haapaslo-Pesu et al., 2004). The researchers conclude that this increase may be related to availability of newer antidepressants (Haapaslo-Pesu et al., 2004).

Lekhwani, Nair, Nikhinson, \& Ambrosini (2004) conducted a chart review of inner city children, age nine or younger, receiving public assistance, and who were admitted as inpatients during the 1998 to 2001 time period. The study objective was to determine prescribing patterns of psychotropic medications to these patients (Lekhwani et al., 2004). It was determined that $51.8 \%$ of the children were taking a psychotropic medication when they were admitted to the hospital, and $78.7 \%$ of the patients were taking a psychotropic medication at the time of discharge (Lekhwani et al., 2004). Additionally, stimulants were the most widely utilized psychotropic medication (Lekhwani et al., 2004). 
Najjar et al. (2004) examined inpatient prescribing patterns of psychotropic medications for children and adolescents utilizing hospital pharmacy dispensing data from 1991 through 1998. Researchers found that there was a $73.0 \%$ increase in use of psychotropic medications during the 1991 to 1998 time frame (Najjar et al., 2004). Additionally, there was a significant increase in the use of antidepressants from $35.6 \%$ to $77.3 \%$ during the same time frame (Najjar et al., 2004).

Hugtenburg, Heerdink, \& Tso (2005) conducted a survey of child psychiatrists in the Netherlands to gain more information about the prescribing patterns of psychoactive medications. This survey gathered information regarding the preferred medication treatment for various disorders (Hugtenburg et al., 2005). For depressive disorders (including major depressive disorders, dsythymia, and bipolar disorder), child psychiatrists reported a preference for paroxetine (Hugtenburg et al., 2005).

Harpaz-Rotem \& Rosenheck (2006), in the year 2000, compared prescribing practices of psychiatrists and primary care physicians (PCP) for children and adolescents with any mental illness. Utilizing MarketScan ${ }^{\circledR}$, a national claims database from private insurance plans, HarpazRotem and Rosenheck determined that PCPs were more likely to see younger children and psychiatrists were more likely to see adolescents (Harpaz-Rotem \& Rosenheck, 2006). However, no differences were found in psychotropic prescribing practices including the proportion of patients receiving psychotropic medication, types of psychotropic medications prescribed, or the dosages of psychotropic medications prescribed (Harpaz-Rotem \& Rosenheck, 2006). 


\section{Antidepressant Prescribing to Children and Adolescents}

Other studies have focused specifically on the prescribing of antidepressant medications to children and adolescent patients. Bramble (1995) conducted a mail survey of child psychiatrists in Britain to gain information about prescribing patterns of antidepressants. Of those psychiatrists who responded $85 \%$ had prescribed antidepressants to their patients (Bramble, 1995). The most frequently prescribed antidepressants were amitriptyline and imipramine, and SSRIs were prescribed only "very rarely" at the time of this survey (Bramble, 1995).

Rushton, Clark, \& Freed (2000) conducted a survey of North Carolina pediatricians and primary care physicians to determine the prescribing patterns of SSRIs in the child and adolescent population. This study determined that $72 \%$ of the surveyed physicians had prescribed an SSRI to a child or adolescent patient (Rushton et al., 2000). Physicians indicated that depression was the most frequent reason for prescribing an SSRI to these patients (Rushton et al., 2000). Furthermore, primary care physicians were more likely to prescribe SSRIs to adolescents than young children, with only $6 \%$ of the physicians surveyed indicating that they had prescribed an SSRI to a child less than six years of age (Rushton et al., 2000). Additionally, primary care physicians were also more likely than pediatricians to prescribe SSRIs to an adolescent (41\% versus 26\%) (Rushton et al., 2000). Primary care physicians were more likely than pediatricians (91\% versus 58\%) to prescribe SSRIs to all youth (including both children and adolescent patients) (Rushton et al., 2000). Primary care physicians also indicated a greater belief in the effectiveness ( $40 \%$ versus $32 \%)$ and safety ( $63 \%$ versus $48 \%)$ of the SSRI medication, and indicated they were more comfortable with the management of depression in the child and adolescent population (22\% versus $11 \%$ ) as compared to pediatricians (Rushton et al., 
2000). This study also indicated that physicians were more likely to prescribe an SSRI to children and adolescents if they were primary care physicians, could not refer patients to another health care provider, felt comfortable managing depressed patients, and believed in the safety and efficacy of SSRIs (Rushton et al., 2000).

Bhatia et al. (2008) conducted a survey of prescribing clinicians (child psychiatrists, general psychiatrists, pediatricians, family practice physicians, nurse practitioners, and physician assistants) within the state of Nebraska, to evaluate the impact of the U.S. FDA black box warning on physician prescribing. Almost all (96.8\%) of the clinicians were aware of the black box warning (Bhatia et al., 2008). Of the responding clinicians $76.9 \%$ prescribed antidepressants to children and/or adolescents before the 2004 warning. Of the clinicians, who prescribed before the warning, $15.5 \%$ reported a decrease in prescribing antidepressants to children after the warning, while $36.6 \%$ reported a decrease in prescribing to adolescents (Bhatia et al., 2008). Some clinicians reported making modifications to their monitoring, with $31.9 \%$ of the clinicians reporting increasing contacts with the patients (Bhatia et al., 2008). Slightly more than a third (36.0\%) of the clinicians reported increasing referrals to mental health professionals (Bhatia et al., 2008).

Zito et al. (2002) examined changes in antidepressant utilization and factors associated with antidepressant utilization in the child and adolescent population by examining two Medicaid and one HMO database. Between the years 1988 and 1994 antidepressant use increased among this population (Zito et al., 2002). Additionally, the study indicated a modest significant difference in utilization associated with male gender (58.0\% versus 49.5\%; p<.001) (Zito et al., 2002). 
Murray, deVries, \& Wong (2004) examined prescribing patterns of antidepressants to children and adolescents in the United Kingdom during the 1992 to 2001 time frame. Murray et al. (2004) utilized the United Kingdom Practice Research Database to determine that $55.7 \%$ of all antidepressant prescriptions were for TCAs, $41.3 \%$ for SSRIs, and $2.9 \%$ for other antidepressants. Overall, antidepressant prevalence increased 1.7 times from 1992 to 2001 (Murray et al., 2004). During the same time frame, prevalence of TCAs decreased from 3.6 to 2.5 per 1000, and SSRI prevalence increased from 0.5 to 4.6 per 1000 (Murray et al., 2004). Murray, Thompson, Santosh, \& Wong (2005) compared the prevalence and incidences of children and adolescents who were prescribed antidepressant treatment in the United Kingdom during the 2000 to 2004 time frame. The researchers utilized information from Mediplus database, which contains records from primary care visits (Murray et al., 2005). Antidepressant prevalence increased from 5.4 to 6.6 patients per 1000 people during the 2000 to 2002 time frame (Murray et al., 2005). Additionally, prevalence decreased from 6.6 to 5.7 patients per 1000 people during the 2002 to 2004 time frame (Murray et al., 2005).

Fegert, Kolch, Zito, Glaeske, \& Janhsen (2006) examined prescription patterns of antidepressants (including St. John's Wort, an herb with antidepressant properties) for patients less than 20 years of age in Germany. The researchers utilized prescription data from a HMO for the years 2000 to 2003 (Fegert et al., 2006). It was determined that prevalence of antidepressants increased from 3.43 per 1000 in 2000, to 3.74 per 1000 in 2003 (Fegert et al., 2006). Fegert et al. (2006) defined prevalence as the dispensing of one or more prescriptions for an antidepressant per calendar year per 1000 continuously enrolled children and adolescents. St. John's Wort and TCAs accounted for approximately $80 \%$ of the antidepressant use (Fegert et al., 2006). Females 
were two times as likely as males to use an antidepressant, and females aged 15 to 19 years of age accounted for most of the antidepressant use in Germany during the 2000 to 2003 time frame (Fegert et al., 2006).

Vitiello, Zuvekas, \& Norquist (2006) analyzed the Medical Expenditure Panel Survey database for the 1997 to 2002 time frame to determine the utilization of antidepressants among children and adolescents (patients less than 19 years of age). During this time period, the percentage of children and adolescents receiving an antidepressant increased significantly from $1.3 \%$ to $1.8 \%(\mathrm{p}<0.01)$ (Vitiello et al., 2006). Utilization was highest in the 13 to 18 year olds and lowest among children less than six year of age (Vitiello et al., 2006). In 1996, utilization was highest among male children and adolescents when compared to females (Vitiello et al., 2006). However, by 2002 utilization of antidepressants was similar between males and females (Vitiello et al., 2006). In 2002, there was significantly more utilization among whites than blacks or Hispanics (Vitiello et al., 2006). Between 1997 and 2002, utilization of antidepressants increased among blacks and Hispanics (Vitiello et al., 2006). There were significant increases in utilization for children and adolescents from poor families and among those children and adolescents who had public insurance (Vitiello et al., 2006). Additionally, there was a significant increase in the utilization of SSRIs and other "newer antidepressants" but no increase for TCAs during the 1997 to 2002 time-frame (Vitiello et al., 2006).

Kurian et al. (2007) utilized Tennessee's Medicaid database to evaluate the impact of the 2004 warnings on prescriptions of antidepressants to pediatric patients. Data from 2002 to 2005 was analyzed and it was found there was a 33\% decrease in antidepressant users after the 
warnings (Kurian et al., 2007). Non-fluoxetine SSRIs and SNRIs showed the greatest decrease (54\%) in use, while new users of fluoxetine, actually increased 60\% (Kurian et al., 2007).

Nemeroff et al. (2007) utilized retail pharmacy database, Verispan, to investigate prescribing trends in the United States. This study found that the number of children and adolescents prescribed an antidepressant after the 2004 warnings decreased significantly $(\mathrm{p}=0.02)$ (Nemeroff et al, 2007). The other impacts of the warnings seem to be a shift away from "generalist" care to "specialist" care for patients seeking antidepressants (Nemeroff et al., 2007). Also, the study showed a slight shift or increase in prescriptions of Wellbutrin ${ }^{\circledR}$ to children and adolescents (Nemeroff et al., 2007).

\section{$\underline{\text { Summary of Factors Influencing Physician Prescribing Decisions }}$}

Based on the studies above, factors related to antidepressant prescribing in children and adolescents include patients' gender (Fegert et al., 2006; Vitiello et al., 2006) patients' race (Goodwin et al., 2001; Olfson et al., 2003; Vitiello et al., 2006), type of insurance (Goodwin et al., 2001; Olfson et al., 2003), patients' age (Fegert et al., 2006; Goodwin et al., 2001; Vitiello et al., 2006; Zito et al., 2002), geographic location (Olfson et al., 2003) and physicians' specialty (Rushton et al., 2000). Additional factors were found to influence physicians' decisions regarding antidepressant prescriptions to children and adolescents. These factors were family income (Olfson et al., 2003), parents education level (Olfson et al., 2003), parental use of antidepressant medication (Hong \& Shepherd, 1996), single parent household (Hong \& Shepherd, 1996), physicians' comfort level in managing depression (Rushton et al., 2000), and physicians' belief in the safety and efficacy of antidepressants for youth (Rushton et al., 2000). 
The reviewed randomized clinical trials illustrate that there is no sound epidemiological basis for choosing antidepressant treatment in children and adolescents with major depressive disorder (Brent, 2005). Even those antidepressants demonstrating efficacy in the treatment of major depressive disorder in children and adolescents have been subject to the 2004 U.S. FDA black box warning. However, scientific evidence is not the only factor to impact physicians' prescribing decisions. The last part of this chapter reviewed research regarding factors which impact physicians' prescribing decisions. The purpose of the current study is to examine physician antidepressant choices for children and adolescents with major depressive disorder and to examine the factors which impact these choices. The methods to accomplish these goals will be the focus of the next chapter. 


\section{CHAPTER THREE: METHODOLOGY}

The purpose of this study was to examine physician antidepressant choices for children and adolescents with major depressive disorder and to examine the factors which impact these choices. The study consisted of two phases. Thus, this chapter outlines the conceptual framework for each phase of the study, the study population, sample size, and data collection. This will be followed by a description of the development and validation of each survey instrument. The chapter concludes with a description of the data analysis for each objective. 


\section{Conceptual Framework}

The optimal treatment for children and adolescents who have major depressive disorder is not a clear decision for physicians. There is no empirical basis for choosing antidepressant treatment in children and adolescents with major depressive disorder (Brent, 2005). In the absence of empirical research to guide the selection of antidepressant treatment, additional research needs to be conducted to examine what physicians consider to be the most appropriate antidepressant treatment and recommended course of treatment. These goals were accomplished in Phase I and Phase II of this study.

It has been suggested that ideally the choice of antidepressant treatment could be based on evidence-based medicine (Depont et al., 2003). However, this would exclude other factors which may influence physicians' antidepressant prescribing decisions to newly diagnosed children and adolescents with major depressive disorder. The current literature has highlighted some patient and physician-related factors that influence physicians' prescribing decisions, including decisions to prescribe antidepressants (Benson, 1983; Sleath \& Shih, 2003). Additionally, research suggests that drug-related factors, including marketing-related factors, also influence prescribing decisions of physicians, but may be less influential, at least in some situations, than patient and physician-related factors (Freeman et al., 1993; Nutescu et al., 2005).

Furthermore, prescribing decisions have been conceptualized as a two-stage process (Benson, 1983; Sleath \& Shih, 2003). First, the physician makes a decision about whether or not to prescribe an antidepressant (Benson, 1983; Sleath \& Shih, 2003). Second, the decision of which specific antidepressant to prescribe must be made (Benson, 1983; Sleath \& Shih, 2003). 
Phase II of the current study examined variables/factors associated with the first stage, "whether or not to prescribe an antidepressant" to children and adolescents with major depressive disorder. This study is a more comprehensive examination of variables associated with the decisions to prescribe an antidepressant, than any found in the scientific literature to date and allowed for the relative influence of these factors to be determined. The conceptual framework for each study phase is depicted below.

\section{Phase I: Identification of Physicians}

Phase I of this study consisted of a short survey to a sample of pediatricians to determine which physicians treat children and adolescents with newly diagnosed major depressive disorder. Figure 3.1a shows a visual representation of the conceptual framework for Phase I.

Figure 3.1: Conceptual Framework for Phase I

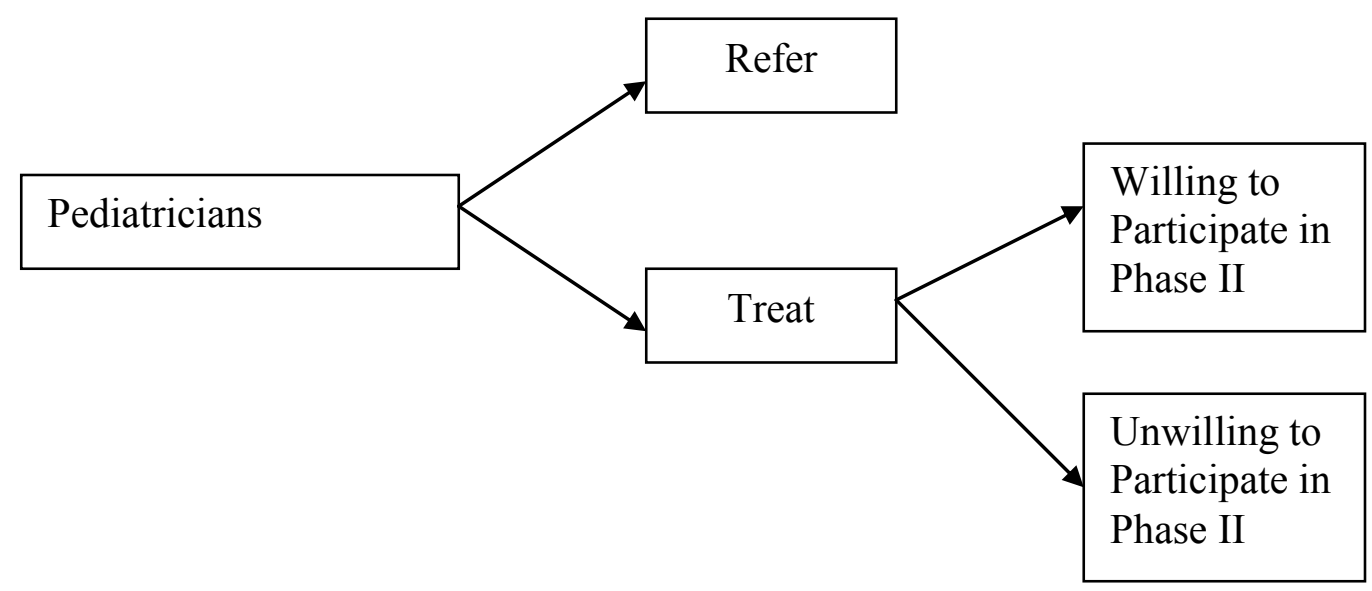




\section{Phase II: Determination of Physician Prescribing Behavior}

Phase II of the study surveyed pediatricians and child psychiatrists. This portion of the study determined treatment behavior and specific antidepressant prescribing behavior for children and adolescents with newly diagnosed major depressive disorder. A visual representation of the conceptual framework for Phase II can be seen in Figure 3.1b. 
Figure 3.2: Conceptual Framework of Phase II

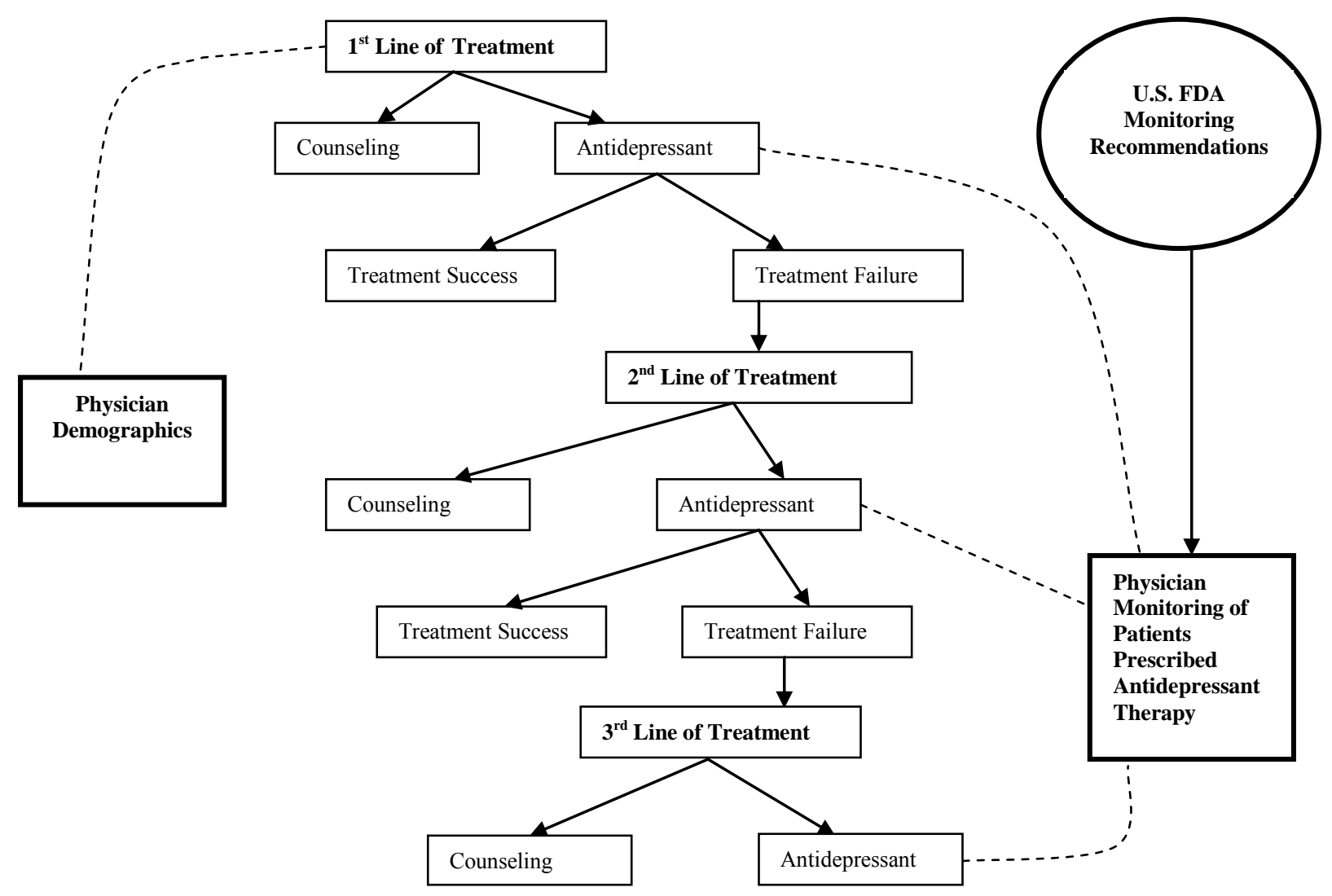




\section{Phase II: Variables Influencing Physicians' Decisions to Prescribe Antidepressants}

Additionally, Phase II of this study determined the variables, and the importance of the variables which influence pediatricians' and child psychiatrists' antidepressant prescribing behavior. A listing of the 28 variables examined in this portion of the study and subjected to exploratory factor analysis are listed in Table 3.1.

Table 3.1: 28 Variables Utilized in Exploratory Factor Analysis

\section{Variables}

Advertisements to physicians via journals

Availability of patient education materials

Clinical experience with prescribing antidepressants

Co-existing conditions of patients (eg. OCD)

Comfort in managing MDD in youth

Direct-to-consumer advertising

Drug efficacy

Drug safety

Face-to-face detailing by medical sciences liaison and/or pharmaceutical representatives

Familiarity with an antidepressant being prescribed

FDA approval

Formulary inclusion

Frequency in dosing

Generic form of drug available

Manufacturer provides free drugs to indigent patients

Medication cost

Monitoring requirements

Parents' education level

Parental use of antidepressants

Patient's ability to perform daily activities

Patient's age

Patient's family income

Patient's gender

Patient's insurance

Potential adverse events

Sample drugs available

Severity of MDD symptoms

Suicidal Thinking 


\section{Study Population}

In any study the reference, target, or study population "is the group we wish to study" and the random sample "is selected from the study population" (Rosner, 2000). The random sample is a "sample in which each group member has the same probability of being selected" (Rosner, 2000). The population in the current study consisted of all pediatricians and child psychiatrists in the United States (U.S.). Child psychiatrists, undoubtedly treat children and adolescents with major depressive disorder, as they are trained to do so (American Academy of Child and Adolescent Psychiatrists, 2006). Since there is currently a shortage of child psychiatrists in the U.S., it has been documented in the literature that some children and adolescents with major depressive disorder receive treatment from other types of physicians such as pediatricians (American Academy of Child and Adolescent Psychiatry, 2006). However, all pediatricians are not willing to treat children and adolescents with major depressive disorder (American Academy of Child and Adolescent Psychiatry, 2006). To obtain adequate responses for Phase II, it was important to first identify which physicians treat these patients.

The SK\&A Informational Services, Inc. maintains databases of over two million medical records, including records of 615,000 physicians. Another database is the American Medical Association's Member list. This database served as the sampling frame for the current study. This database was chosen because it is a more exhaustive list of physicians (compared to others that were identified) in the U.S. The specialty count includes 59,237 pediatricians and 7,496 child and adolescent psychiatrists for a total of 66,733 physicians.

The sample for Phase I consisted of a random sample of pediatricians in the U. S. selected from the total population of these specialty areas. The information collected from Phase I of this survey provides an estimate of the number of pediatricians who are currently treating major depressive disorder in newly diagnosed children and/or adolescents in the U.S. The sample for Phase II 
consisted of those pediatricians who indicated they treat children and/or adolescents with major depressive disorder, and who were willing to participate in a follow-up survey designed to gain information about prescribing habits to newly diagnosed children and adolescents with major depressive disorder. The sample for Phase II also included a random sample of child psychiatrists from the SK\&A database.

\section{Sample Size Estimation}

The sample size was calculated using the following formula:

$\mathrm{n}=\frac{\mathrm{Z}^{2} *(\mathrm{p} * 1-\mathrm{p})}{\mathrm{C}^{2}}$

$\mathrm{n}=$ the sample size

$\mathrm{Z}=$ the $\mathrm{Z}$ value for the confidence interval, or the number of standard errors away from the mean $\mathrm{p}=$ the true proportion of the population

$\mathrm{C}=$ the confidence interval

Several samples were utilized for this study. First, it was necessary to calculate the sample size for Phase I of the study. This sample size was estimated utilizing a 95\% confidence level and a confidence interval equal to $5 \%$, so that $\mathrm{C}=0.05$ and $\mathrm{Z}=1.96$. This means that the researcher is $95 \%$ confident that an estimate of the true proportion of the variable of interest will be no more than $\pm 5 \%$ (Salant \& Dillman, 1994). No prior knowledge of the true proportion of the population is known. Since this was the case, a conservative estimate was assumed and $p=0.5$ (Salant $\&$ Dillman, 1994). Substituting these values $(Z=1.96, \mathrm{p}=0.5$, and $\mathrm{C}=0.05)$ in the formula above, a sample size of 384 was calculated.

Research suggests that response rates for physicians are low compared to the response rates of the general public and this may impair the generalizability of the results of the survey (Kellerman \& Herold, 2001). A study which reviewed the medical literature during a one year time frame indicated that the physician response rate was 54\% (Martin, 1974). Another study, which examined survey methodology of physician surveys from 1967 through 1999 found response rates to range 
from $38 \%$ to $84 \%$ (Kellerman \& Herold, 2001). The current study assumed a much more conservative response rate of $20 \%$. Therefore, $2,000((1,920=384 * 5)$ plus an additional 80 for incorrect addresses) randomly selected pediatricians were sent a survey, for a total of 2,000 surveyed in Phase I of this study.

The sample for Phase II consisted of those pediatricians who indicated they treat children and/or adolescents with major depressive disorder, and who indicated they were willing to participate in Phase II of this study. In addition, a random sample of 2,500 $(384 * 5=1,920$ plus an additional 580 for incorrect addresses and non-responses) child psychiatrists were surveyed.

When conducting factor analysis it is usually suggested that a sample size of between 10 and 20 subjects for each variable being measured be utilized (Thompson, 2004). An absolute minimum of five subjects per measured variable has also been suggested (Gorsuch, 1983). The current study had 28 variables. Therefore, a minimum sample size of $28 * 5=140$ was needed for conducting the factor analysis in this study.

\section{Data Collection}

This study utilized primary data for both phases. Primary data may be collected by telephone, face-to-face, internet, or mail surveys. Mail surveys have some advantages over some other data collection methods. These advantages include the facts that mail surveys typically require less time, money, and research staff than other primary data collection methods (Salant \& Dillman, 1994). The major reason mail surveys were utilized for this study was to reach physicians nationally. Research indicates that phone surveys yield only slightly higher, but not statistically significant, response rates as compared to response rates of mail surveys of physicians (Kellerman \& Herold, 2001). Furthermore, personal interviews of physicians yield significantly higher response rates than mail surveys of physicians (Kellerman \& Herold, 2001). However, to conduct personal interviews on a national basis, for this study, was not feasible. Therefore, mail surveys were utilized. 
Research suggests a survey mailing procedure that consists of four separate mailings (Salant \& Dillman, 1994). This begins with an initial letter sent to all sample participants. The purpose of this letter is to alert the participants who have been selected for the survey and to make them aware that they will be receiving a questionnaire (Salant \& Dillman, 1994). The next mailing, which should take place approximately a week after the initial letter, consists of a cover letter providing the details of the survey, the questionnaire, and a return postage-paid envelope (Salant \& Dillman, 1994). Approximately four to eight days after the questionnaire is sent, a postcard thanking those who have responded and asking for a response from those participants who have not responded should be mailed (Salant \& Dillman, 1994). The fourth mailing occurs approximately three weeks after the questionnaire was sent (Salant \& Dillman, 1994). This mailing entails mailing to those people who have not returned the first questionnaire and consists of a new cover letter which again asks for their participation and includes a replacement questionnaire and return postage-paid envelope (Salant \& Dillman, 1994). According to Salant \& Dillman (1994) this procedure should yield a 50-60\% response rate from the general public. Due to limited resources, the current study varied Salant \& Dillman's (1994) recommendations slightly. Data for each phase was collected via two survey mailings. The first mailing for each phase consisted of a cover letter, survey, and return postagepaid envelope to each physician. The second mailing consisted of a cover letter, survey, and return postage-paid envelop to each physician who did not respond to the first mailing.

Approval for the research protocol, cover letters, survey for Phase I, and survey for Phase II, was obtained from the Institutional Review Board of West Virginia University.

\section{Instrument Development}

Surveys for this study were developed by obtaining information from reviews of the scientific literature and from informal discussions with psychiatrists who treat children and adolescents. Instrument development for each phase of the study will be discussed in detail. 


\section{Phase I}

The survey for Phase I (See Appendix A) was designed to determine which physicians treat newly diagnosed children and adolescents with major depressive disorder. Additionally, the information gathered from this survey combined with demographic information discerned from the physician database allowed the researcher to detect whether there are geographical differences in pediatricians' willingness to treat children or adolescents with major depressive disorder. The survey also asked physicians if they would be willing to participate in a more in-depth questionnaire in the next phase of this study.

\section{Phase II}

The survey utilized in Phase II consisted of eight sections. The questions were designed to obtain information about prescribing habits to newly diagnosed children and adolescents with major depressive disorder. A copy of the survey can be found in Appendix B and each section will be discussed in detail. The first section of the survey gathered information regarding whether or not physicians treated and/or referred children and adolescents for the treatment of major depressive disorder, as it was possible that physicians treated only one of these groups of patients. The second section of the survey gathered information about physicians' preferred first-line of treatment for newly diagnosed children and adolescents with major depressive disorder. This section also determined a physicians' antidepressant prescribing habits regarding these patients, including dosage, titration, and length of treatment. Section three of the survey obtained information regarding the physicians' preferred second-line of treatment (in the event of a treatment failure with the firstline of treatment). The fourth section asked physicians to indicate their preferred third-line of treatment assuming the second-line of treatment is a failure. The fifth section gathered some basic information about physicians' counseling and psychotherapy practices. Section six collected information regarding pharmacotherapy monitoring of children and adolescents receiving 
antidepressants. Section seven consisted of a listing of variables which may influence the physicians' decision to prescribe an antidepressant medication to a child or adolescent who has been newly diagnosed with major depressive disorder. The physicians were asked to indicate how much influence each factor has when making the decision to prescribe an antidepressant medication to children and adolescents. A four point, Likert scale (where $1=$ not influential and $4=$ extremely influential) was utilized to determine the degree of influence each variable has on the physicians' decision to prescribe antidepressant medication. The last section of the instrument collected physician demographic information, including age, gender, specialty, practice location, practice volume, and training.

\section{Instrument Validation}

In general, the validity of a measurement has to do with the correctness or accuracy of the measurement. More specifically, the validity of an instrument or measurement reflects the extent to which scores on the instrument are reflective of the true differences of the measured characteristic among individuals (Churchill, 1991). One type of validity is content validity. Content validity is the ability of the measurement or instrument to capture all of the content, or all domains of the characteristic the researchers wants to measure (Churchill, 1991). Face validity refers to what an instrument appears to measure (Churchill, 1991).

Content and face validity were assessed for both surveys utilized in this study. During the development of the surveys, the input of experts in psychiatry and faculty members with expertise in health outcomes research at West Virginia University was sought. The psychiatry experts and researchers assessed the readability, clarity of the questions, and the relevance of the questions in this survey.

Non-response bias was assessed by comparing the responses of early responders to those of late responders. This method of assessing non-response bias involves viewing non-response bias as a 
continuum, with early respondents at one end and late responders at the other. It is also assumed that late responders are more like non-responders and may be used as proxy for non-respondents. Therefore, a comparison of the responses from the early responders to the late responders (i.e., Nonresponders) can be made as a method for assessing non-response bias (Armstrong \& Overton, 1977).

A pilot study was conducted for Phase II of the study. The pilot study consisted of a random sample equal to $10 \%$ (or 250 subjects) of the sample size for Phase II. This study allowed the researchers to determine the clarity of the survey questions. Based on the feedback from the pilot study, final adjustments to the content of the survey instrument were made, prior to the first mailing. A copy of the survey utilized in the pilot study can be found in Appendix C.

\section{Data Analysis}

Objectives for each of the two phases are stated and followed by the data analysis to be utilized in this study. All statistical analyses were conducted utilizing either Statistical Package for the Social Sciences, $\operatorname{SPSS}^{\circledR}$ Version 16.0 or Statistical Analysis Software, $\operatorname{SAS}^{\circledR}$ Version 9.1.

\section{Phase I:}

The overall goal of Phase I was to identify pediatricians who treat children and/or adolescents with major depressive disorder. There were four specific objectives for this phase.

Objective 1: To determine the proportion of pediatricians who treat children and adolescents with major depressive disorder.

The Phase I survey asked pediatricians to indicate all age groups they treat for major depressive disorder. The choices were "children (5-12 years old)", "adolescents (13-18 years old)", or "do not treat". Descriptive statistics were calculated for the responses. More specifically the frequencies and proportions of pediatricians who treat children and/or adolescents with major depressive disorder were calculated based on physicians' responses.

Objective 2: To determine the proportion of pediatricians who refer children and adolescents with major depressive disorder. 
The Phase I survey asked pediatricians to indicate all age groups they refer for the treatment of major depressive disorder. The choices were "refer children (5-12 years old)", "refer adolescents (13-18 years old)", or "do not refer". Descriptive statistics were calculated for the responses. More specifically the frequencies and proportions of pediatricians who refer children and/or adolescents with major depressive disorder were calculated based on physicians' responses.

Objective 3: To determine the health care provider to whom pediatricians refer a child or adolescent with major depressive disorder.

Pediatricians were asked to indicate in an open ended format what type of health care provider they would refer children and then adolescents, in the event they refer these patients. The frequencies of the type of health care provider, to which pediatricians refer children and/or adolescents, were calculated.

Objective 4: To determine geographic differences in pediatricians' willingness to treat versus referral of children and/or adolescents with major depressive disorder.

Null Hypothesis 4.0: There is no difference in the geographic locations of pediatricians who treat versus refer children and/or adolescents for major depressive disorder.

Some physicians indicated they treated and referred, so that treating and referring patients was not a mutually exclusive decision. Frequencies and proportions of pediatricians who treat children and/or adolescents with major depressive disorder were calculated directly from the phase I survey questions, as indicated above. The geographic location (state) was ascertained from the mailing address for each pediatrician. The geographic regions were specified according to the U.S. Census Bureau's definitions. The U.S. Census Bureau divides the United States into five geographic regions as follows: Northeast, South, Midwest, West, and Pacific. The states included in each of the geographic regions are listed below in Table 3.2. 
Table 3.2: States Included in Each Geographic Region

\begin{tabular}{|l|l|l|l|l|}
\hline Northeast & South & Midwest & West & Pacific \\
\hline Connecticut & Alabama & Illinois & Arizona & Alaska \\
Maine & Arkansas & Indiana & California & Hawaii \\
Massachusetts & Delaware & Iowa & Colorado & \\
New Hampshire & District of Columbia & Kansas & Idaho & \\
New Jersey & Florida & Michigan & Montana & \\
Pennsylvania & Georgia & Minnesota & Nevada & \\
Rhode Island & Kentucky & Missouri & New Mexico & \\
Vermont & Louisiana & Nebraska & Oregon & \\
& Maryland & North Dakota & Utah & \\
& Mississippi & Ohio & Washington & \\
& North Carolina & South Dakota & Wyoming & \\
& Oklahoma & Wisconsin & & \\
& South Carolina & & & \\
& Tennessee & & & \\
& Texas & & & \\
& Virginia & & & \\
& West Virginia & & & \\
\end{tabular}

Since both variables (treat, categorized as "yes" or "no" and geographic region, categorized as "northeast", "south", "midwest", "west", and "pacific") are categorical in nature the results of the $\chi^{2}$ statistic tested whether the proportion of pediatricians who treat children and adolescents by geographic location are equal.

\section{Phase II:}

The overall goal of Phase II was to determine what physicians consider to be the most appropriate treatment for children and/or adolescents with major depressive disorder, their recommended course of treatment (i.e., length of treatment, pharmacotherapy monitoring), and the factors which impact their decisions to treat major depressive disorder in children and adolescents with an antidepressant. There were 20 specific objectives for this phase.

\section{Objectives and Analysis for Children}

Objectives 5 through 13 focused on the treatment, prescribing patterns, and factors which impact the treatment of children (five through 12 years of age) with major depressive disorder.

Objective 5: To determine the demographic characteristics of physicians who treat newly diagnosed children with major depressive disorder. 
This objective was determined from the pediatricians' and child psychiatrists' responses to the survey questions in section eight of the Phase II survey. Descriptive statistics or frequency distributions were estimated for these categorical variables (physicians' gender, age, year of graduation, practice site, geographic location, population of practice area, specialty, board certifications, patient volume, and length of time treating children and adolescents).

Objective 6: To determine physicians' first line of treatment for newly diagnosed children with major depressive disorder by: a) type of treatment, b) drug category, and c) specific antidepressant prescribed.

Descriptive statistics were calculated for the pediatricians' and child psychiatrists' responses to the questions in section two of the Phase II survey. Frequency distributions were estimated for the categorical variables type of treatment, drug category, and specific antidepressant prescribed.

Objective 7: To determine physicians' second and third lines of treatment for newly diagnosed children with major depressive disorder by: a) drug category, and b) specific antidepressant prescribed.

These categorical variables are the responses to the survey questions in section three and section four, of the Phase II survey. For both pediatricians and child psychiatrists, analysis consisted of descriptive statistics, of the drug category and specific antidepressant variables.

Objective 8: To determine the difference in first, second, and third lines of antidepressant treatment prescribed by physicians (pediatricians versus child psychiatrists) to newly diagnosed children with major depressive disorder by a) the pharmacotherapy category and b) specific antidepressant prescribed.

Null Hypothesis 8.a: There is no difference in the pharmacotherapy category prescribed by physicians (pediatricians versus child psychiatrists) for first, second, and third lines of antidepressant treatment for newly diagnosed children with major depressive disorder.

Sections two, three, and four of the Phase II survey gathered information from the physicians regarding their first, second, and third lines of antidepressant treatment. The physicians were asked to give their specific antidepressant choices. The variable, class of antidepressant, was created by the researcher based on the specific answers from the physicians. Since both variables (pharmacotherapy category and physician type) are categorical the $\chi^{2}$ statistic was utilized. The $\chi^{2}$ 
statistic tested whether the proportion of Monoamine Oxidase Inhibitors (MAOIs), Tricyclic Antidepressants (TCAs), Tetracyclic Antidepressants, Selective Serotonin Reuptake Inhibitors (SSRIs), Serotonin-Norepinephrine Reuptake Inhibitors (SNRIs), Norepinephrine and Dopamine Reuptake Inhibitors (NDRIs), and Other Antidepressants for the first, second, and third lines of treatment were equal for pediatricians versus child psychiatrists.

Null Hypothesis 8.b: There is no difference in the specific antidepressant prescribed by physicians (pediatricians versus child psychiatrists) for first, second, and third lines of treatment for newly diagnosed children with major depressive disorder.

Both variables are categorical (specific type of antidepressant and physician type) and the $\chi^{2}$ statistic was utilized to test for an association between specific antidepressant $\left(\right.$ Celexa $^{\circledR}$, Cymbalta $^{\circledR}$, Effexor $^{\circledR}$, etc.) and first, second, and third lines of treatment prescribed by pediatricians versus child psychiatrists.

Objective 9: To predict which physician characteristics affect the treatment prescribed for children with major depressive disorder.

The $\chi^{2}$ statistic is useful when the researcher wants to find the association between two categorical variables. However, when there are more than one predictor variable regression is usually a more useful statistical tool (Rosner, 2000; Vittinghoff, Glidden, Shiboski, \& McCulloch, 2005). Logistic regression is commonly utilized to investigate the association between binary outcomes and multiple predictors (Rosner, 2000; Vittinghoff et al., 2005). This objective was met by using logistic regression. Logistic regression was utilized to investigate the association between categorical outcome variables (type of treatment, type of antidepressant treatment) and physician characteristics (e.g. age, gender, year of graduation, specialty, board certifications, practice site, geographic location, patient volume, and length of time treating children and adolescents).

Objective 10: To determine the average length of antidepressant treatment for newly diagnosed children with major depressive disorder. 
Section two of the Phase II survey asked the physicians "how long they continue to prescribe the antidepressant(s)" to the child, if the antidepressant is a successful treatment. The frequencies, as these are categorical variables, related to how long physicians continue prescribing an antidepressant assuming it is a successful treatment were calculated.

These categorical variables were transformed into continuous variables so that comparisons could be made to the newly published American Academy of Child and Adolescent Psychiatry’s recommended six months minimum length of treatment with antidepressant medication (AACAP, 2007).

Objective 11: To determine the types of pharmacotherapy monitoring in newly diagnosed children with major depressive disorder.

Section six of the Phase II survey asked the physicians to indicate their primary mode of pharmacotherapy monitoring, who conducts the monitoring, and the specific types of monitoring conducted. Based on these responses the frequencies of the categorical variables (mode of monitoring, who conducts the monitoring, type of monitoring, and frequency of monitoring) were calculated.

Objective 12: To determine differences in antidepressant monitoring for newly diagnosed children with major depressive disorder and the U.S. FDA recommendations for monitoring children treated with antidepressants.

Null Hypothesis 12.0: There is no difference in pharmacotherapy monitoring for newly diagnosed children with major depressive disorder and the U.S. FDA recommendations for monitoring children treated with antidepressants.

Section six of the Phase II survey contained questions designed to determine how often physicians monitor for the first, second, and third month of treatment. These categorical variables were transformed into continuous variables so comparisons could be made to the U.S. FDA recommendations. The average number of times the physicians monitor per month for month one, two, and three of treatment were then compared to the U.S. FDA recommendations for months one, 
two, and three of treatment. A t-test was utilized to test for any significant differences between how often physicians report they monitor and the U.S. FDA recommendations.

Objective 13: To determine whether there are differences, by physician type, in the average number of times per month physicians monitor children with major depressive disorder.

Null Hypothesis 13.0: There is no difference, by physician type, in the average number of times per month physicians monitor children with major depressive disorder.

The information gathered in section six of the Phase II survey was utilized to determine whether there are differences in the average number of times per month physicians monitor children treated with antidepressants by physician type. A comparison of the average number of times per month child psychiatrists and pediatricians monitor was tested utilizing the t-test.

\section{Objectives and Analysis for Adolescents}

Next, Objectives 14 through 22 focused on the treatment, prescribing patterns, and factors which impact the treatment of adolescents (13 through 18 years of age) with major depressive disorder.

Objective 14: To determine the demographic characteristics of physicians who treat newly diagnosed adolescents with major depressive disorder.

This objective was determined from the pediatricians' and child psychiatrists' responses to the survey questions in section eight of the Phase II survey. Descriptive statistics or frequency distributions were estimated for these categorical variables (physicians' gender, age, year of graduation, practice site, geographic location, population of practice area, specialty, board certifications, patient volume, and length of time treating children and adolescents).

Objective 15: To determine physicians' first line of treatment for newly diagnosed adolescents with major depressive disorder by: a) type of treatment, b) drug category, and c) specific antidepressant prescribed.

Descriptive statistics were calculated for the pediatricians' and child psychiatrists' responses to the questions in section two of the Phase II survey. Frequency distributions were estimated for the categorical variables type of treatment, drug category, and specific antidepressant prescribed. 
Objective 16: To determine physicians' second and third lines of treatment for newly diagnosed adolescents with major depressive disorder by: a) drug category, and b)specific antidepressant prescribed.

These categorical variables are the responses to the survey questions in section three and section four, of the Phase II survey. For both pediatricians and child psychiatrists, analysis consisted of descriptive statistics of the drug category and specific antidepressant variables.

Objective 17: To determine the difference in first, second, and third lines of antidepressant treatment prescribed by physicians (pediatricians versus child psychiatrists) to newly diagnosed adolescents with major depressive disorder by a) the pharmacotherapy category and b) specific antidepressant prescribed.

Null Hypothesis 17.a: There is no difference in the pharmacotherapy category prescribed by physicians (pediatricians versus child psychiatrists) for first, second, and third lines of antidepressant treatment for newly diagnosed adolescents with major depressive disorder.

Sections two, three, and four of the Phase II survey gathered information from the physicians regarding their first, second, and third lines of antidepressant treatment. The physicians were asked to give their specific antidepressant choices. The variable, class of antidepressant, was created by the researcher based on the specific answers from the physicians. Since both variables (pharmacotherapy category and physician type prescribed) are categorical the $\chi^{2}$ statistic was utilized. The $\chi^{2}$ statistic tested whether the proportion of Monoamine Oxidase Inhibitors (MAOIs), Tricyclic Antidepressants (TCAs), Tetracyclic Antidepressants, Selective Serotonin Reuptake Inhibitors (SSRIs), Serotonin-Norepinephrine Reuptake Inhibitors (SNRIs), Norepinephrine and Dopamine Reuptake Inhibitors (NDRIs), and Other Antidepressants for the first, second, and third lines of treatment are equal for pediatricians versus child psychiatrists.

Null Hypothesis 17.b: There is no difference in the specific antidepressant prescribed by physicians (pediatricians versus child psychiatrists) for first, second, and third lines of treatment for newly diagnosed adolescents with major depressive disorder.

Both variables are categorical (specific type of antidepressant and physician type) and the $\chi^{2}$ statistic was utilized to test for an association between specific antidepressant $\left(\mathrm{Celexa}^{\circledR}, \mathrm{Cymbalta}^{\circledR}\right.$, 
Effexor $^{\circledR}$, etc.) and first, second, and third lines of treatment prescribed by pediatricians versus child psychiatrists.

Objective 18: To predict which physician characteristics affect the treatment prescribed for adolescents with major depressive disorder.

The $\chi^{2}$ statistic is useful when the researcher want to find the association between two categorical variables. However, when there are multiple predictors regression is a more useful statistical tool (Rosner, 2000; Vittinghoff et al., 2005). Specifically, logistic regression is commonly utilized to investigate the association between binary outcomes and multiple predictors (Rosner, 2000; Vittinghoff et al., 2005). This objective was met by using logistic regression. Logistic regression was utilized to investigate the association between categorical outcome variables (type of treatment, type of antidepressant treatment) and physician characteristics (e.g. age, gender, year of graduation, specialty, board certifications, practice site, geographic location, patient volume, and length of time treating children and adolescents).

Objective 19: To determine the average length of antidepressant treatment for newly diagnosed adolescents with major depressive disorder.

Section two of the Phase II survey asked the physicians "how long they continue to prescribe the antidepressant(s)" to the child, if the antidepressant is a successful treatment. The frequencies, as these are categorical variables, related to how long physicians continue prescribing an antidepressant, assuming it is a successful treatment, were calculated. These categorical variables were transformed into continuous variables so that comparisons may be made to the newly published American Academy of Child and Adolescents Psychiatry's recommended six month minimum length of treatment with antidepressant medication (AACAP, 2007).

Objective 20: To determine the types of pharmacotherapy monitoring in newly diagnosed adolescents with major depressive disorder.

Section six of the Phase II survey asked the physicians to indicate their primary mode of pharmacotherapy monitoring, who conducts the monitoring, and the specific types of monitoring 
conducted. Based on these responses the frequencies of the categorical variables (mode of monitoring, who conducts the monitoring, type of monitoring, and frequency of monitoring) were calculated.

Objective 21: To determine differences in antidepressant monitoring for newly diagnosed adolescents with major depressive disorder and the U.S. FDA recommendations for monitoring adolescents treated with antidepressants.

Null Hypothesis 21.0: There is no difference in pharmacotherapy monitoring for newly diagnosed adolescents with major depressive disorder and the U.S. FDA recommendations for monitoring children treated with antidepressants.

Section six of the Phase II survey contained questions designed to determine how often the physicians monitor for the first, second, and third month of treatment. These categorical variables were transformed into continuous variables so comparisons could be made to the U.S. FDA recommendations. The average number of times the physicians monitor per month for month one, two, and three of treatment were compared to the U.S. FDA recommendations for months one, two, and three of treatment. A t-test was utilized to test for any significant differences between how often physicians report they monitor and the U.S. FDA recommendations.

Objective 22: To determine whether there are differences, by physician type, in the average number of times per month physicians monitor adolescents with major depressive disorder.

Null Hypothesis 22.0: There is no difference, by physician type, in the average number of times per month physicians monitor adolescents with major depressive disorder.

The information gathered in section six of the Phase II survey was also utilized to determine whether there are differences in the average number of times per month physicians monitor children treated with antidepressants by physician type. A comparison of the average number of times per month child psychiatrists and pediatricians monitor was tested utilizing the t-test.

\section{Objectives for Factor Analysis}

Objective 23: To determine the relative importance which physicians place on each factor prior to prescribing antidepressants to newly diagnosed children and adolescents with major depressive disorder. 
Objective 24: To determine the factors associated with physicians' antidepressant prescribing behavior for children and adolescents newly diagnosed with major depressive disorder.

Objectives 23 and 24 utilized the information collected in section seven of the Phase II survey. This portion of the survey asked physicians to rate the extent to which 28 variables influences their decision of whether or not to prescribe an antidepressant medication to a child or adolescent. The physicians rated the influence of the 28 variables on a scale from $1-4$, where $1=$ not influential, $2=$ somewhat influential, 3 = influential, and 4= extremely influential. Descriptive statistics including measures of central tendency (mean) and dispersion (standard deviation) were calculated for the physicians' ratings of each of the variables. An exploratory factor analysis was utilized to identify the hypothetical constructs that influence these 28 variables. The results of the analyses for both phases of this study will be the focus of Chapter Four. 


\section{CHAPTER FOUR: RESULTS}

This chapter contains the results for this study. The results of the Phase I survey of pediatricians

is presented first. As part of Phase II, a pilot study was conducted to evaluate the survey instrument. These results are presented next in this chapter, followed by the results of the final survey to pediatricians and child psychiatrists. 


\section{Results for Phase I}

A national random sample of 2,000 pediatricians was obtained from SK\&A Informational Services, Inc's, American Medical Association member list. A cover letter, phase I survey, and return postage-paid envelope was sent to 2,000 pediatricians. A second mailing was conducted approximately five weeks later to those pediatricians who did not respond to the first mailing. According to Salant \& Dillman (1994) mailings of questionnaires should occur more closely together than the five weeks allowed in this study. In this case, however, the second mailing would have coincided with the Christmas holiday season. The decision was made to delay the second mailing of the survey until after the holiday season in order to potentially increase the response rate of the pediatricians.

Of the 2,000 pediatricians surveyed, a total of 424 responded and a total of 200 surveys were retuned as bad addresses. Of the 424 pediatricians who responded 11 indicated they had retired or were not in practice and another five surveys were not completed. Therefore, a total of 408 useable surveys were received. This resulted in a usable response rate of $22.9 \%$ for phase I of the study.

Table 4.1: Response Rate for Phase I

\begin{tabular}{lrr}
\hline & N & Percentage (\%) \\
\hline Original sample size & 2,000 & \\
Undeliverable surveys & 200 & \\
Effective Sample Size & $\mathbf{1 , 8 0 0}$ & $\mathbf{1 0 0 . 0}$ \\
Number of Surveys Returned & 424 & 23.6 \\
Unusable Surveys & 16 & \\
Usable Surveys & 408 & $\mathbf{2 2 . 9}$ \\
Usable Response Rate & & \\
\hline
\end{tabular}

The first three objectives intended to determine the proportion of pediatricians in the United States who children and adolescents with major depressive disorder. In the case a pediatrician did not treat major depressive disorder in this population the researcher sought to determine which type of health care provider children and/or adolescents would likely be referred. The purpose for determining this information was two-fold. This information is not in the current scientific literature 
and the researcher could identify pediatricians who would be willing to participate in Phase II of this study. Each objective will be noted followed by the findings from the study.

Objective 1: To determine the proportion of pediatricians who treat children and adolescents with major depressive disorder.

The frequency and proportion of pediatricians who treat children and/or adolescents with major depressive disorder was calculated. The majority of pediatricians $(60.0 \%)$ indicated they do not treat either children or adolescents with major depressive disorder. Additionally, $28.2 \%$ of the pediatricians surveyed indicated they treat both children and adolescents for major depressive disorder. No pediatricians indicated they treat children only, while $11.8 \%$ indicated they treat adolescents only. The results for Objective 1 are listed in Table 4.2.

Table 4.2: Pediatricians Treating Children and/or Adolescents with Major Depressive Disorder

\begin{tabular}{|l|c|c|}
\hline & $\begin{array}{c}\text { Frequency } \\
(\mathbf{N})\end{array}$ & $\begin{array}{c}\text { Percentage } \\
(\mathbf{\%})\end{array}$ \\
\hline Treat Children Only & 0 & 0.0 \\
\hline Treat Adolescents Only & 48 & 11.8 \\
\hline Treat Both Children and Adolescents & 115 & 28.2 \\
\hline Do Not Treat & 245 & 60.0 \\
\hline
\end{tabular}

Objective 2: To determine the proportion of pediatricians who refer children and adolescents with major depressive disorder.

A minority of pediatricians $(6.7 \%)$ indicated they do not refer either children or adolescents to another type of health care provider for the treatment of major depressive disorder. Approximately the same percentage of pediatricians indicated they refer children only (4.2\%) or adolescents only $(4.5 \%)$ to another type of health care provider for the treatment of major depressive disorder. The majority of the pediatricians $(84.6 \%)$ indicated they referred both children and adolescents for the treatment of major depressive disorder. These results are listed in Table 4.3. 
Table 4.3: Pediatricians Referring Children and/or Adolescents with Major Depressive Disorder

\begin{tabular}{|l|c|c|}
\hline & $\begin{array}{c}\text { Frequency } \\
(\mathbf{N})\end{array}$ & $\begin{array}{c}\text { Percentage } \\
(\mathbf{\%})\end{array}$ \\
\hline Refer Children Only & 17 & 4.2 \\
\hline Refer Adolescents Only & 18 & 4.5 \\
\hline Refer Both Children and Adolescents & 341 & 84.6 \\
\hline Do Not Refer & 27 & 6.7 \\
\hline
\end{tabular}

Objective 3: To determine the health care provider to whom pediatricians refer a child or adolescent with major depressive disorder.

The results for pediatricians seeing children with major depressive disorder will be discussed first followed by the results for adolescents. Pediatricians listed up to three different health care providers to which they would refer children for treatment. This resulted in 358 total responses. Pediatricians cited they most often refer children to some type of psychiatrist (67.6\%), with $29.3 \%$ of the responses indicating a child and adolescent psychiatrist and 38.3\% indicating a psychiatrist. The second most popular health care provider to refer children was a psychologist. A small percentage of responses indicated they refer specifically to a child psychologist (1.4\%), while some responses (13.7\%) indicated referral to a psychologist. A small percentage 5.9\% of responses indicated referral to a counselor, therapist, or Master's in Social Work (MSW). These results are listed in Table 4.4. 
Table 4.4: Health Care Provider to whom Pediatricians Refer Children and Adolescents with Major Depressive Disorder

\begin{tabular}{|l|c|c|c|c|}
\hline Health Care Provider & $\begin{array}{c}\text { Total } \\
\text { Frequency- } \\
\text { children } \\
\text { (N) }\end{array}$ & $\begin{array}{c}\text { Percentage- } \\
\text { children } \\
(\%)\end{array}$ & $\begin{array}{c}\text { Total } \\
\text { Frequency- } \\
\text { adolescents } \\
\text { (N) }\end{array}$ & $\begin{array}{c}\text { Percentage- } \\
\text { adolescents } \\
(\%)\end{array}$ \\
\hline Psychiatrist & 137 & 38.3 & 154 & 42.3 \\
\hline $\begin{array}{l}\text { Child \& Adolescent } \\
\text { Psychiatrist }\end{array}$ & 105 & 29.3 & 91 & 25.0 \\
\hline Psychologist & 49 & 13.7 & 51 & 14.0 \\
\hline $\begin{array}{l}\text { Counselor, Therapist, } \\
\text { or MSW }\end{array}$ & 21 & 5.9 & 25 & 6.9 \\
\hline $\begin{array}{l}\text { Crisis Center, Mental } \\
\text { Health Clinic, Hospital }\end{array}$ & 20 & 5.5 & 23 & 6.3 \\
\hline Other Physician & 10 & 2.8 & 6 & 1.6 \\
\hline $\begin{array}{l}\text { Unspecified Mental } \\
\text { Health Care Provider }\end{array}$ & 6 & 1.7 & 5 & 1.4 \\
\hline $\begin{array}{l}\text { Any Available Mental } \\
\text { Health Care Provider }\end{array}$ & 5 & 1.4 & 5 & 1.4 \\
\hline Child Psychologist & 5 & 1.4 & 4 & 1.1 \\
\hline Total & 358 & 100.0 & 364 & 100.0 \\
\hline
\end{tabular}

The responses for adolescents mirrored that of children. Pediatricians listed up to three different health care providers to which they would refer adolescents for treatment. This resulted in 364 total responses. Pediatricians cited they most often refer adolescents to some type of psychiatrist (67.3\%), with $25.0 \%$ of the responses indicating a child and adolescent psychiatrist and $42.3 \%$ indicating a psychiatrist. The second most popular health care provider to refer adolescents was a psychologist. A small percentage of responses indicated they refer specifically to a child psychologist (1.1\%), while some responses (14.0\%) indicated referral to a psychologist. A small percentage $6.9 \%$ of responses indicated referral to a counselor, therapist, or Master's in Social Work (MSW). These results are listed in Table 4.4. 
The next study objective sought to determine whether there were geographic differences in pediatricians' willingness to treat versus refer children and/or adolescents with major depressive disorder. This objective and null hypothesis read as follows:

Objective 4: To determine geographic differences in pediatricians' willingness to treat versus referral of children and/or adolescents with major depressive disorder.

Null Hypothesis 4.0: There is no difference in the geographic locations of pediatricians who treat versus refer children and/or adolescents for major depressive disorder.

Based on the responses, the results showed, that treating and referring patients was not a mutually exclusive choice for pediatricians. Some physicians indicated they treated and referred. Some pediatricians even indicated they would try one line of treatment and if that treatment did not produce a response they would refer. Since treating and referring were not mutually exclusive events it was decided to analyze the data by geographic region according to whether or not pediatricians treated children. Next, the data was analyzed by geographic region according to whether or not pediatricians treated adolescents. Since none of the pediatricians indicated they "treated children only", pediatricians were said to treat children if they indicated they "treat both children and adolescents". Likewise, pediatricians where said not to treat children if they indicated they "treated adolescents only" or "did not treat". Similarly, pediatricians were classified as treating adolescents if they indicated they "treated adolescents only" or "treated both children and adolescents". Pediatricians were said not to treat adolescents if they indicated they "did not treat". Geographic regions were specified according to the U.S. Census Bureau's definitions. The U.S. Census Bureau divides the United States into five geographic regions as follows: Northeast, South, Midwest, West, and Pacific. The states included in each geographic region are listed in Table 4.5. 
Table 4.5: States Included in Each Geographic Region

\begin{tabular}{|l|l|l|l|l|}
\hline Northeast & South & Midwest & West & Pacific \\
\hline Connecticut & Alabama & Illinois & Arizona & Alaska \\
Maine & Arkansas & Indiana & California & Hawaii \\
Massachusetts & Delaware & Iowa & Colorado & \\
New Hampshire & District of Columbia & Kansas & Idaho & \\
New Jersey & Florida & Michigan & Montana & \\
Pennsylvania & Georgia & Minnesota & Nevada & \\
Rhode Island & Kentucky & Missouri & New Mexico & \\
Vermont & Louisiana & Nebraska & Oregon & \\
& Maryland & North Dakota & Utah & \\
& Mississippi & Ohio & Washington & \\
& North Carolina & South Dakota & Wyoming & \\
& Oklahoma & Wisconsin & & \\
& South Carolina & & & \\
& Tennessee & & & \\
& Texas & & & \\
& Virginia & & & \\
& West Virginia & & & \\
\end{tabular}

There were only four pediatricians classified as practicing in the Pacific geographic location. Instead of dropping these physicians from the analysis it was decided to collapse or combine the Pacific and West categories. This was conducted for the analysis of children and adolescents (below). The results, for pediatricians treating children, are shown in Table 4.6 below and reflect the combining of the Pacific and West categories.

Table 4.6: Treatment of Children Across Geographic Regions

\begin{tabular}{|l|l|l|l|c|c|}
\hline $\begin{array}{l}\text { Treatment } \\
\text { of Children }\end{array}$ & Northeast & South & Midwest & $\begin{array}{l}\text { Pacific and } \\
\text { West }\end{array}$ & Total \\
\hline Yes & 21 & 35 & 37 & 22 & 115 \\
\hline No & 86 & 85 & 68 & 54 & 293 \\
\hline Total & 107 & 120 & 105 & 76 & 408 \\
\hline Proportion & 0.1963 & 0.2917 & 0.3524 & 0.2895 & -- \\
\hline
\end{tabular}

The $\chi^{2}$ statistic was utilized to determine whether or not there were differences in whether or not pediatricians treated children across the four geographic regions. The $\chi^{2}$ statistic was equal to 6.532 , $\mathrm{df}=3$, and $\mathrm{p}=0.088$. This means that the proportion of pediatricians who treat children does not significantly vary according to geographic region and we fail to reject the Null Hypothesis 4.0. Since the $\mathrm{p}$-value is close to 0.05 , this result warranted a closer look because it is marginally significant. Examining the results and the proportions of physicians who treat in each region 
revealed the following trend. Pediatricians in the Midwest are somewhat more likely to treat children, while pediatricians in the Northeast are somewhat less likely to treat children for major depressive disorder. Again this is not a significant difference, but a trend.

Next, the $\chi^{2}$ statistic was utilized to determine whether or not there were differences in whether or not pediatricians treated adolescents across the four geographic regions. The results are shown in Table 4.7 below.

Table 4.7: Treatment of Adolescents Across Geographic Regions

\begin{tabular}{|l|c|c|c|c|c|}
\hline $\begin{array}{l}\text { Treatment } \\
\text { of } \\
\text { Adolescents }\end{array}$ & Northeast & South & Midwest & $\begin{array}{l}\text { Pacific and } \\
\text { West }\end{array}$ & Total \\
\hline Yes & 37 & 44 & 47 & 35 & 163 \\
\hline No & 70 & 76 & 58 & 41 & 245 \\
\hline Total & 107 & 120 & 105 & 76 & 408 \\
\hline
\end{tabular}

The $\chi^{2}$ statistic was equal to $4.019, \mathrm{df}=3$, and $\mathrm{p}=0.259$. This result means the proportion of pediatricians who treat adolescents does not significantly vary by geographic region and again we fail to reject the Null Hypothesis 4.0.

One purpose of Phase I of this study was to identify study participants for Phase II of this study. This was important since all pediatricians do not treat children and/or adolescents for major depressive disorder and Phase II of the study was designed to determine the treatment and prescribing practices of pediatricians and child psychiatrists. If a pediatrician indicated they treated either children or adolescents, they were asked if they would be willing to participate in the Phase II survey. The results indicate that 110 pediatricians were both eligible and willing to participate in Phase II. These results are listed below in Table 4.8 and depicted in Figure 4.1. These 110 pediatricians were included in Phase II of this study. 
Table 4.8: Treating Pediatricians Willing to Participate in Phase II

\begin{tabular}{|l|c|c|}
\hline & $\begin{array}{c}\text { Frequency } \\
(\mathbf{N})\end{array}$ & $\begin{array}{c}\text { Percentage } \\
(\boldsymbol{\%})\end{array}$ \\
\hline Yes & 106 & 26.4 \\
\hline Yes, depending on length of survey & 4 & 1.0 \\
\hline No & 46 & 11.5 \\
\hline Not Applicable & 245 & 61.1 \\
\hline
\end{tabular}

Figure 4.1: Breakdown of Pediatricians in Phase I

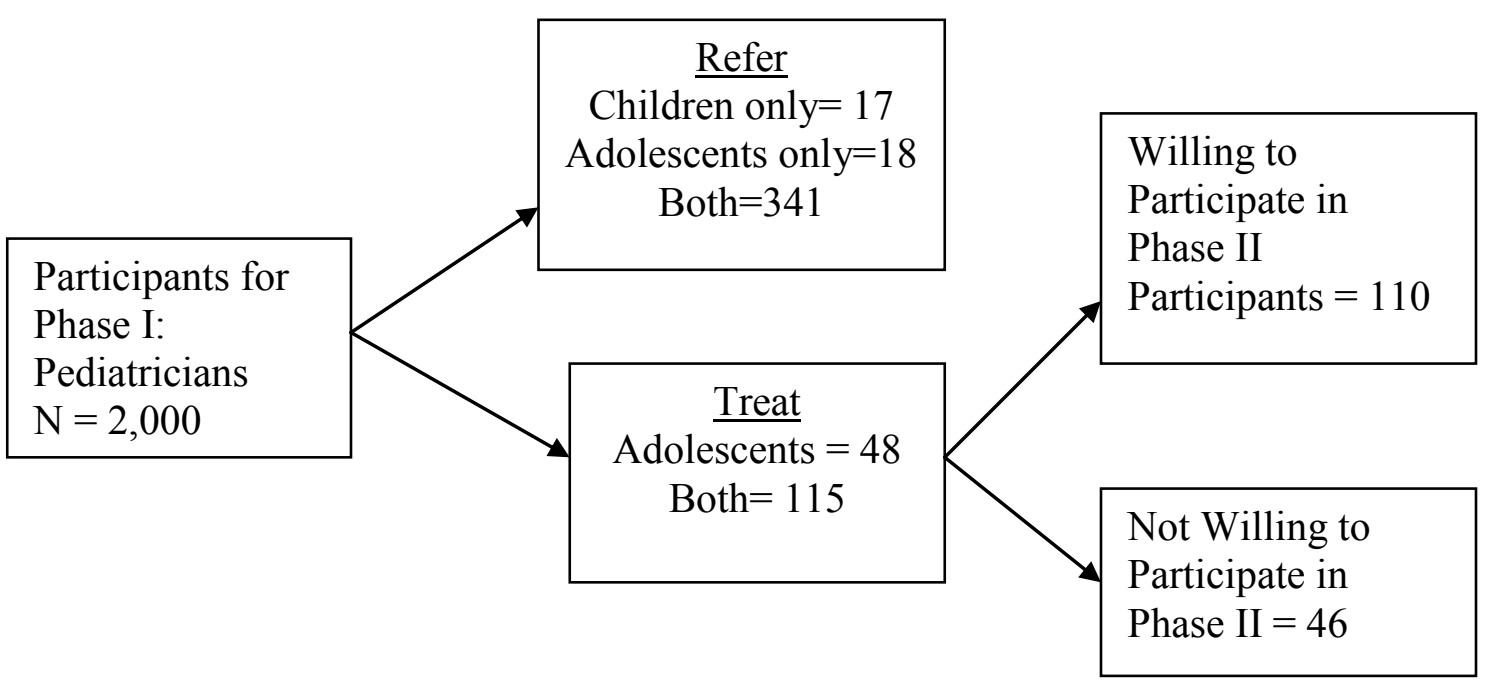




\section{Results for the Pilot Study}

A national random sample of 2,500 child psychiatrists was obtained from SK\&A Informational Services, Inc's, American Medical Association member list. A cover letter, Phase II survey, and return postage-paid envelope were sent to $10 \%$ or 250 of these 2,500 pediatricians. Due to resource constraints only one mailing was performed for the pilot study. Of the 250 child psychiatrists surveyed 22 returned a usable survey and six surveys were returned due to bad addresses. This information is listed below in Table 4.9.

Table 4. 9: Response Rate for Pilot Study

$\underline{\text { N }} \quad$ Percentage $(\%)$

Original sample size 250

Undeliverable surveys

Effective Sample Size

6

Number of Surveys Returned

244

Unusable Surveys

22

0

Usable Responses

22

Usable Response Rate

$9.02 \%$

The demographics for the 22 child psychiatrists, who returned surveys for the pilot study are listed in Table 4.10. The majority of the physicians were males $(68.18 \%)$ and between 41 and 60 years of age $(54.55 \%)$. The year of graduation from medical school varied: $36.36 \%$ indicated they graduated in 1996- 2003, 22.73\% indicated they graduated in $1976-1985,18.18 \%$ indicated they graduated in 1966 - 1975, another $18.18 \%$ indicated they graduated in $1986-1995$, and only $4.55 \%$ graduated in 1965 or earlier. The majority (63.63\%) of the physicians indicated their primary practice site was private-based, as opposed to hospital-based. The geographic region of the physicians' primary practice site varied. No physicians practice in the Pacific region, while the number practicing in the other regions ranged from $9.09 \%$ to $31.82 \%$. The population of the primary practice area varied as $47.62 \%$ practice in areas with 250,000 - 999,999 people, $33.33 \%$ have primary practice sites in areas with $50,000-249,999$ people, $19.05 \%$ practice in areas with a 
population of 1 million or more people, and none of the physicians practice in areas with 50,000 people or less. The majority ( $81.82 \%)$ of the physicians indicated specialties of both adult and child psychiatry. The preponderance of the physicians are board certified as either both adult psychiatrists and child psychiatrists $(47.62 \%)$ or as adult psychiatrists (38.09\%). The majority of physicians (78.95\%) indicated they treat 10 or less children per week. Additionally, the bulk (55.00\%) of the physicians indicated they treat 10 or less adolescents per week. The majority $(54.55 \%)$ of the physicians indicated they treated children and/or adolescents for greater than 10 years. 
Table 4.10: Demographics of Child Psychiatrists from Pilot Study

\begin{tabular}{|c|c|}
\hline Variable & $\mathrm{N}(\%)$ \\
\hline $\begin{array}{l}\text { Type of Physician: } \\
\text { Child Psychiatrists }\end{array}$ & $22(100.00 \%)$ \\
\hline $\begin{array}{l}\text { Gender: } \\
\text { Male } \\
\text { Female }\end{array}$ & $\begin{array}{c}15(68.18 \%) \\
7(31.82 \%)\end{array}$ \\
\hline $\begin{array}{l}\text { Age: } \\
40 \text { years or younger } \\
41 \text { years }-60 \text { years } \\
61 \text { years or older }\end{array}$ & $\begin{array}{c}6(27.27 \%) \\
12(54.55 \%) \\
4(18.18 \%)\end{array}$ \\
\hline $\begin{array}{l}\text { Year Graduated from Medical School: } \\
1965 \text { or Before } \\
1966-1975 \\
1976-1985 \\
1986-1995 \\
1996-2003\end{array}$ & $\begin{array}{l}1(4.55 \%) \\
4(18.18 \%) \\
5(22.73 \%) \\
4(18.18 \%) \\
8(36.36 \%)\end{array}$ \\
\hline $\begin{array}{l}\text { Primary Practice Site: } \\
\text { Private Based Practice } \\
\text { Hospital Based Practice } \\
\text { Other (ex.hospital and private) }\end{array}$ & $\begin{array}{l}14(63.63 \%) \\
3(13.64 \%) \\
5(22.73 \%)\end{array}$ \\
\hline $\begin{array}{l}\text { Geographic Location of Practice: } \\
\text { Northeast } \\
\text { South } \\
\text { Midwest } \\
\text { West } \\
\text { Pacific }\end{array}$ & $\begin{array}{l}2(9.09 \%) \\
7(31.82 \%) \\
6(27.27 \%) \\
7(31.82 \%) \\
0(0.00 \%)\end{array}$ \\
\hline $\begin{array}{l}\text { Population of Practice Area: } \\
\text { Less than } 50,000 \\
50,000-249,999 \\
250,000-999,999 \\
1 \text { million or more }\end{array}$ & $\begin{array}{c}0(0.00 \%) \\
7(33.33 \%) \\
10(47.62 \%) \\
4(19.05 \%)\end{array}$ \\
\hline $\begin{array}{l}\text { Physician Specialty: } \\
\text { Adult Psychiatrist } \\
\text { Child Psychiatrist } \\
\text { Adult and Child Psychiatrist }\end{array}$ & $\begin{array}{c}1(4.54 \%) \\
3(13.64 \%) \\
18(81.82 \%)\end{array}$ \\
\hline $\begin{array}{l}\text { Board Certification: } \\
\text { Adult Psychiatrist } \\
\text { Adult and Child Psychiatrist } \\
\text { Not Board Certified }\end{array}$ & $\begin{array}{c}8(38.09 \%) \\
10(47.62 \%) \\
3(14.29 \%)\end{array}$ \\
\hline $\begin{array}{l}\text { Child Patient Volume Per Week: } \\
10 \text { or less } \\
11-40\end{array}$ & $\begin{array}{c}15(78.95 \%) \\
4(21.05 \%)\end{array}$ \\
\hline $\begin{array}{l}\text { Adolescent Patient Volume Per Week: } \\
10 \text { or less } \\
11-40\end{array}$ & $\begin{array}{c}11(55.00 \%) \\
9(45.00 \%)\end{array}$ \\
\hline $\begin{array}{l}\text { Number of Years Treating Children and/or } \\
\text { Adolescents: } \\
\text { Greater than } 1 \text { year to } 5 \text { years } \\
\text { Greater than } 5 \text { years to } 10 \text { years } \\
\text { Greater than } 10 \text { years }\end{array}$ & $\begin{array}{c}2(9.09 \%) \\
8(36.36 \%) \\
12(54.55 \%)\end{array}$ \\
\hline
\end{tabular}

The purpose of the pilot study was to assess the survey instrument within the population prior to mailing to the study population. All of the child psychiatrists who returned surveys for the pilot 
study indicated they treat both children and adolescents for major depressive disorder. The majority $(59.09 \%)$ of the child psychiatrists indicated they treat children with counseling/psychotherapy as a first-line of treatment. Additionally, the majority (68.18\%) of the child psychiatrists indicated they treat adolescents with both antidepressants and counseling as a first-line of treatment. Physicians were then asked to indicate, which antidepressant they would prescribe as their first-line of treatment, in the event they utilized both antidepressants and counseling as the first-line of treatment. The results of the pilot study showed that many of the physicians, who indicated they treat children and adolescents with counseling only, as a first-line of treatment, also indicated an antidepressant for this line of treatment. More specifically, 12 of the physicians who indicated they treat children with counseling only as the first-line of treatment also indicated they utilize an antidepressant. Another six of the physicians who indicated they treat adolescents with counseling only as the first-line of treatment also indicated they utilize an antidepressant. Therefore, $54.55 \%$ of the physicians answered the first-line of treatment for children incorrectly. Another, $27.27 \%$ of the physicians answered the first-line of treatment for adolescents incorrectly. Based on these findings, it was concluded the questions regarding treatment for children and adolescents were not clear and were misunderstood and lacked clarity. Thus the questions regarding first, second, and third-line of treatment were revised before the final survey was mailed to the larger sample of child psychiatrists.

The following changes were made to the survey instrument. First, the questions regarding treatment were re-worded and headings denoting first, second, and third-lines of treatment were added to the survey. Second, the directions, associated with these treatment questions were altered by telling physicians if they indicated use of antidepressants for their first-line of treatment, then they should answer the question regarding antidepressant treatment. More specifically, the directions read as follows: "If your first-line of treatment (in Question \#4) included antidepressants 
(either alone or in combination with counseling/psychotherapy), for EITHER children or adolescents please answer Questions \#5 - \#8, otherwise skip to Section 3, Question \#9”.

Based on the results from the final survey, the changes in the questions on the survey seemed to help clarify the issue in the pilot study, somewhat. Only nine pediatricians $(15.00 \%)$ indicated they utilized counseling only as a first-line of treatment for children and/or adolescents and listed an antidepressant also on the first-line of treatment. Only sixty-four child psychiatrists $(20.25 \%)$ indicated their preferred first line of treatment was counseling only for children and/or adolescents and listed an antidepressant also on the first-line of treatment. The majority of the physicians went on to list this same antidepressant as their answer for the second line of treatment. Since this was the case, it was assumed, that counseling only was truly their first-line of treatment and the antidepressant listed was actually part of their choice for the second-line of treatment.

\section{Results for Phase II}

Two groups of physicians were surveyed for Phase II of this study. The pediatricians $(n=110)$ who indicated in phase I they treated children and/or adolescents diagnosed with major depressive disorder, and whom agreed to participate in phase II were included. Additionally, a random sample of child psychiatrists $(n=2,250)$ were surveyed in phase II. Pediatricians and child psychiatrists were mailed a cover letter, eight-page survey, and return postage paid-envelope. Those who did not respond to the first mailing were mailed a second copy of the cover letter, survey, and postage-paid envelope approximately two and a half weeks later. Response rates are based on those surveys received two months after the initial mailing, for both groups of physicians. Details of the number of respondents are discussed next. 


\section{Child Psychiatrists:}

Of the 2,250 mailed surveys, 316 surveys were returned, and 268 were undeliverable, due to bad addresses. Of the 316 returned surveys, 14 surveys were unusable as these physicians indicated they were either retired or no longer in practice. Another three surveys were unusable because the physicians failed to complete the survey. The usable number of surveys from the child psychiatrists equaled 299.

Table 4.11: Response Rate for Child Psychiatrists - Phase II

\begin{tabular}{lrc}
\hline & Percentage (\%) & \\
\hline Original sample size & 2,250 & \\
Undeliverable surveys & 268 & $\mathbf{1 0 0 . 0 \%}$ \\
Effective Sample Size & $\mathbf{1 , 9 8 2}$ & $15.9 \%$ \\
Number of Surveys Returned & 316 & \\
Unusable Surveys & 17 & $\mathbf{1 5 . 1 \%}$ \\
Usable Responses & 299 & \\
Usable Response Rate & & \\
\hline
\end{tabular}

\section{Pediatricians:}

One hundred ten pediatricians indicated they treated children and/or adolescents and were willing to participate in the phase II survey. Of these 110 pediatricians surveyed, 60 returned surveys were returned. Of the 60 returned surveys three were not useable, so these mailings resulted in 57 useable surveys from pediatricians.

Table 4.12: Response Rate for Pediatricians - Phase II

N

Original sample size

Undeliverable surveys

Effective Sample Size

Number of Surveys Returned

Unusable Surveys

Usable Responses

Usable Response Rate
110

0

110

60

3

57

Percentage (\%) 


\section{Results for Non-Response Analysis}

Bias refers to any differences between an estimate from a survey and the actual value in the population. Non-response is a type of bias and refers to the difference between respondents and non-respondents of a survey. More specifically, non-response bias refers to the idea that people who do not respond to surveys may answer questions differently than those people who do respond to surveys. One method to assess non-response bias involves comparing "early responders" to "late responders". This method assumes late responders are similar to non-responders and thus late responders serve as a proxy for non-responders. Utilizing this method revealed no statistical differences among the demographic characteristics of early responders and non-responders, in this study. Table 4.13 shows the statistical results of the comparisons of the demographic variables. 
Table 4.13: Comparison of Demographics of Early Responders and Non-Responders

\begin{tabular}{|c|c|c|c|c|}
\hline Variable & $\begin{array}{l}\text { Early } \\
\text { Responders } \\
\text { (N) }\end{array}$ & $\begin{array}{l}\text { Non- } \\
\text { Responders } \\
\text { (N) }\end{array}$ & $\begin{array}{c}\text { Test } \\
\text { Statistic }\end{array}$ & $\begin{array}{c}\text { Significance } \\
\text { (p) }\end{array}$ \\
\hline $\begin{array}{l}\text { Gender: } \\
\text { Male } \\
\text { Female }\end{array}$ & $\begin{array}{l}80 \\
42\end{array}$ & $\begin{array}{l}66 \\
51\end{array}$ & $\chi^{2}=2.110$ & 0.146 \\
\hline $\begin{array}{l}\text { Primary Practice Site: } \\
\text { Hospital-Based } \\
\text { Private Practice } \\
\end{array}$ & $\begin{array}{l}20 \\
76 \\
\end{array}$ & $\begin{array}{l}25 \\
65 \\
\end{array}$ & $\chi^{2}=1.221$ & 0.269 \\
\hline $\begin{array}{l}\text { Population of Practice Area: } \\
\text { Less than 50,000 } \\
50,000-249,999 \\
250,000-999,999 \\
1 \text { million or more } \\
\end{array}$ & $\begin{array}{l}18 \\
42 \\
24 \\
34\end{array}$ & $\begin{array}{l}18 \\
32 \\
35 \\
33\end{array}$ & $\chi^{2}=3.417$ & 0.332 \\
\hline $\begin{array}{l}\text { Geographic Location of Practice: } \\
\text { Northeast } \\
\text { South } \\
\text { Midwest } \\
\text { West } \\
\text { Pacific }\end{array}$ & $\begin{array}{c}37 \\
29 \\
31 \\
19 \\
1\end{array}$ & $\begin{array}{c}24 \\
44 \\
23 \\
23 \\
1\end{array}$ & $\chi^{2}=7.402$ & 0.116 \\
\hline $\begin{array}{l}\text { Physician Specialty: } \\
\text { Child \& Adolescent Psychiatry } \\
\text { Pediatrics } \\
\text { Adult/Child \& Adolescent Psychiatry }\end{array}$ & $\begin{array}{l}10 \\
17 \\
87\end{array}$ & $\begin{array}{l}15 \\
18 \\
82\end{array}$ & $\chi^{2}=1.172$ & 0.557 \\
\hline $\begin{array}{l}\text { Board Certification: } \\
\text { Adult Psychiatry } \\
\text { Child \& Adolescent Psychiatry } \\
\text { Pediatrics } \\
\text { Not Board Certified } \\
\text { Adult/Child \& Adolescent Psychiatry }\end{array}$ & $\begin{array}{c}17 \\
0 \\
20 \\
10 \\
65\end{array}$ & $\begin{array}{c}22 \\
1 \\
20 \\
5 \\
66\end{array}$ & $\chi^{2}=3.298$ & 0.509 \\
\hline $\begin{array}{l}\text { Number of Years Treating Children } \\
\text { and/ or Adolescents: } \\
1-5 \text { years } \\
5-10 \text { years } \\
\text { Greater than } 10 \text { years }\end{array}$ & $\begin{array}{c}7 \\
17 \\
96 \\
\end{array}$ & $\begin{array}{c}8 \\
21 \\
87 \\
\end{array}$ & $\chi^{2}=0.863$ & 0.650 \\
\hline
\end{tabular}

Comparisons were also made to see if early responders and non-responders differed in the way they answered treatment questions for children and adolescents. These comparisons are listed in Table 4.14. No statistical differences were found between early responders and non-responders on the age groups they treat, first-line of treatment for children, first-line of treatment for adolescents, antidepressant treatment for children, antidepressant treatment for adolescents, and patient volume. 
Table 4.14: Comparisons of Treatment Variables of Early Responders and Non-Responders

\begin{tabular}{|c|c|c|c|c|}
\hline Variable & $\begin{array}{l}\text { Early } \\
\text { Responders } \\
\text { (N) }\end{array}$ & $\begin{array}{l}\text { Non- } \\
\text { Responders } \\
\text { (N) }\end{array}$ & $\begin{array}{c}\text { Test } \\
\text { Statistic }\end{array}$ & $\begin{array}{c}\text { Significance } \\
\text { (p) }\end{array}$ \\
\hline $\begin{array}{l}\text { Age Group Physician Treats: } \\
\text { Adolescents } \\
\text { Both Children and Adolescents }\end{array}$ & $\begin{array}{c}3 \\
113 \\
\end{array}$ & $\begin{array}{c}8 \\
112 \\
\end{array}$ & $\chi^{2}=2.210$ & 0.137 \\
\hline $\begin{array}{l}\text { First-line of Treatment (Children): } \\
\text { Antidepressants or Antidepressants and } \\
\text { Counseling } \\
\text { Counseling Only }\end{array}$ & $\begin{array}{c}3 \\
105\end{array}$ & $\begin{array}{c}2 \\
110\end{array}$ & $\begin{array}{c}\text { Fisher's } \\
\text { Exact } \\
\text { Test }\end{array}$ & 0.679 \\
\hline $\begin{array}{l}\text { First-line of Treatment (Adolescents): } \\
\text { Antidepressants or Antidepressants and } \\
\text { Counseling } \\
\text { Counseling Only }\end{array}$ & $\begin{array}{c}1 \\
107 \\
\end{array}$ & $\begin{array}{c}1 \\
111 \\
\end{array}$ & $\begin{array}{l}\text { Fisher's } \\
\text { Exact } \\
\text { Test } \\
\end{array}$ & 1.000 \\
\hline $\begin{array}{l}\text { First-line of Antidepressant Treatment } \\
\text { for Children: } \\
\text { Non-Prozac }^{\circledR} \\
\text { Prozac }^{\circledR}\end{array}$ & $\begin{array}{l}32 \\
35 \\
\end{array}$ & $\begin{array}{l}36 \\
39 \\
\end{array}$ & $\chi^{2}=0.001$ & 0.977 \\
\hline $\begin{array}{l}\text { First-line of Antidepressant Treatment } \\
\text { for Adolescents: } \\
\text { Non-Prozac }^{\circledR} \\
\text { Prozac }^{\circledR}\end{array}$ & $\begin{array}{l}47 \\
46\end{array}$ & $\begin{array}{l}53 \\
49\end{array}$ & $\chi^{2}=0.039$ & 0.843 \\
\hline $\begin{array}{l}\text { Child Patient Volume Per Week: } \\
40 \text { patients or less } \\
\text { Greater than } 40 \text { patients }\end{array}$ & $\begin{array}{c}112 \\
6 \\
\end{array}$ & $\begin{array}{c}111 \\
5 \\
\end{array}$ & $\chi^{2}=0.078$ & 0.780 \\
\hline $\begin{array}{l}\text { Adolescent Patient Volume Per Week: } \\
40 \text { patients or less } \\
\text { Greater than } 40 \text { patients }\end{array}$ & $\begin{array}{c}109 \\
9\end{array}$ & $\begin{array}{c}111 \\
5\end{array}$ & $\chi^{2}=1.144$ & 0.285 \\
\hline
\end{tabular}

Based on the non-response analysis, it was found that there was no significant statistical difference between early responders and non-responders.

\section{Phase II: Results for Children with Major Depressive Disorder- Objectives 5-13}

Objectives 5 through 13 focus on the treatment and prescribing patterns of children (five through 12 years of age) with major depressive disorder. Each objective will be stated followed by the results pertaining to the objective.

Objective 5: To determine the demographic characteristics of physicians who treat newly diagnosed children with major depressive disorder.

The demographics of physicians who treat children with major depressive disorder are listed in Table 4.15 below. Of those physicians from phase II who indicated they treat children with major depressive disorder, 42 (12.50\%) were pediatricians and $294(87.50 \%)$ were child psychiatrists. The 
majority of physicians who treat children with major depressive disorder are males (61.75\%), and are between 41 and 60 years of age $(66.57 \%)$. The year of graduation from medical school varied: $33.66 \%$ indicated they graduated in $1986-1995,27.83 \%$ indicated they graduated in $1976-1985$, $20.06 \%$ indicated they graduated in $1966-1975,11.97 \%$ indicated they graduated in $1996-2003$, and only $6.47 \%$ graduated in 1965 or earlier. The majority $(56.93 \%)$ of the physicians indicated their primary practice site was private-based, as opposed to hospital-based. The geographic region of the physicians' primary practice site varied as only $0.63 \%$ practice in the Pacific. The number practicing in the other four regions ranged between $19.75 \%$ and $29.15 \%$. The population of the primary practice area varied as $34.26 \%$ have primary practice sites in areas with $50,000-249,999$ people, $25.93 \%$ practice in areas with a population of 1 million or more people, $24.38 \%$ practice in areas with $250,000-999,999$ people, and $15.43 \%$ practice in areas with 50,000 people or less. The majority $(73.57 \%)$ of the physicians indicated specialties of both adult and child psychiatry, and the majority $(57.14 \%)$ are board certified as both adult psychiatrists and child psychiatrists. The practice volume also varied somewhat, however the majority of physicians indicated they treat both, 10 or less children (70.68\%) and 10 or less adolescents $(56.17 \%)$ per week. The majority $(74.77 \%)$ of the physicians reported treating children for greater than 10 years. 
Table 4.15: Demographics of Physicians Who Treat Children for Major Depressive Disorder

\begin{tabular}{|c|c|}
\hline Variable & $\mathrm{N}(\%)$ \\
\hline $\begin{array}{l}\text { Type of Physician: } \\
\text { Pediatricians } \\
\text { Child Psychiatrists }\end{array}$ & $\begin{array}{c}42(12.50 \%) \\
294(87.50 \%)\end{array}$ \\
\hline $\begin{array}{l}\text { Gender: } \\
\text { Male } \\
\text { Female }\end{array}$ & $\begin{array}{l}205(61.75 \%) \\
127(38.25 \%)\end{array}$ \\
\hline $\begin{array}{l}\text { Age: } \\
40 \text { years or younger } \\
41 \text { years }-60 \text { years } \\
61 \text { years or older }\end{array}$ & $\begin{array}{c}43(12.95 \%) \\
221(66.57 \%) \\
68(20.48 \%)\end{array}$ \\
\hline $\begin{array}{l}\text { Year Graduated from Medical School: } \\
1965 \text { or Before } \\
1966-1975 \\
1976-1985 \\
1986-1995 \\
1996-2003\end{array}$ & $\begin{array}{c}20(6.47 \%) \\
62(20.06 \%) \\
86(27.83 \%) \\
104(33.66 \%) \\
37(11.97 \%) \\
\end{array}$ \\
\hline $\begin{array}{l}\text { Primary Practice Site: } \\
\text { Private Based Practice } \\
\text { Hospital Based Practice } \\
\text { Other (ex. hospital and private) }\end{array}$ & $\begin{array}{c}189(56.93 \%) \\
66(19.88 \%) \\
77(23.19 \%)\end{array}$ \\
\hline $\begin{array}{l}\text { Geographic Location of Practice: } \\
\text { Northeast } \\
\text { South } \\
\text { Midwest } \\
\text { West } \\
\text { Pacific }\end{array}$ & $\begin{array}{c}73(22.88 \%) \\
93(29.15 \%) \\
88(27.59 \%) \\
63(19.75 \%) \\
2(0.63 \%)\end{array}$ \\
\hline $\begin{array}{l}\text { Population of Practice Area: } \\
\text { Less than } 50,000 \\
50,000-249,999 \\
250,000-999,999 \\
1 \text { million or more }\end{array}$ & $\begin{array}{c}50(15.43 \%) \\
111(34.26 \%) \\
79(24.38 \%) \\
84(25.93 \%)\end{array}$ \\
\hline $\begin{array}{l}\text { Physician Specialty: } \\
\text { Child Psychiatrist } \\
\text { Pediatrics } \\
\text { Adult and Child Psychiatrist } \\
\text { Other (ex. adult and child psychiatry and general practice) }\end{array}$ & $\begin{array}{c}36(10.81 \%) \\
37(11.11 \%) \\
245(73.57 \%) \\
15(4.50 \%)\end{array}$ \\
\hline $\begin{array}{l}\text { Board Certification: } \\
\text { Adult Psychiatrist } \\
\text { Child Psychiatrist } \\
\text { General Practitioner } \\
\text { Pediatrician } \\
\text { Adult and Child Psychiatrist } \\
\text { Other (ex. adult and child psychiatry and pediatrics) } \\
\text { Not Board Certified }\end{array}$ & $\begin{array}{c}58(17.63 \%) \\
1(0.30 \%) \\
1(0.30 \%) \\
41(12.46 \%) \\
188(57.14 \%) \\
18(5.47 \%) \\
22(6.69 \%)\end{array}$ \\
\hline $\begin{array}{l}\text { Child Patient Volume Per Week: } \\
10 \text { or less } \\
11-40 \\
41-80 \\
81 \text { or greater }\end{array}$ & $\begin{array}{c}229(70.68 \%) \\
79(24.38 \%) \\
13(4.01 \%) \\
3(0.93 \%)\end{array}$ \\
\hline $\begin{array}{l}\text { Adolescent Patient Volume Per Week: } \\
10 \text { or less } \\
11-40 \\
41-80 \\
81 \text { or greater } \\
\end{array}$ & $\begin{array}{c}182(56.17 \%) \\
121(37.35 \%) \\
16(4.94 \%) \\
5(1.54 \%) \\
\end{array}$ \\
\hline $\begin{array}{l}\text { Number of Years Treating Children and/or Adolescents: } \\
\text { Greater than } 1 \text { year to } 5 \text { years } \\
\text { Greater than } 5 \text { years to } 10 \text { years } \\
\text { Greater than } 10 \text { years }\end{array}$ & $\begin{array}{c}24(7.29 \%) \\
59(17.93 \%) \\
246(74.77 \%)\end{array}$ \\
\hline
\end{tabular}


Objective 6: To determine physicians' first-line of treatment for newly diagnosed children with major depressive disorder by: a) type of treatment, b) drug category, and c) specific antidepressant prescribed.

A majority of physicians, both pediatricians $(63.46 \%)$ and child psychiatrists $(52.19 \%)$ indicated their preferred first-line of treatment for children with major depressive disorder is a combination treatment of antidepressants and counseling. Counseling only was the next most frequently preferred choice as a first-line of treatment for both pediatricians $(28.85 \%)$ and child psychiatrists (40.07\%). Few pediatricians $(7.69 \%)$ and child psychiatrists $(1.01 \%)$ indicated they use antidepressants only as a first-line of treatment for children. The results for the first-line of treatment for children with major depressive disorder are listed in Table 4.16.

Table 4.16 : First-Line of Treatment for Children with Major Depressive Disorder

\begin{tabular}{|l|c|c|c|}
\hline \multicolumn{1}{|c|}{ Type of Treatment } & $\begin{array}{c}\text { All Physicians } \\
\mathbf{N}(\boldsymbol{\%})\end{array}$ & $\begin{array}{c}\text { Pediatricians } \\
\mathbf{N}(\boldsymbol{\%})\end{array}$ & $\begin{array}{c}\text { Child } \\
\text { Psychiatrists } \\
\mathbf{N}(\boldsymbol{\%})\end{array}$ \\
\hline Antidepressants Only & $7(2.00 \%)$ & $4(7.69 \%)$ & $3(1.01 \%)$ \\
\hline Counseling/Psychotherapy Only & $134(38.40 \%)$ & $15(28.85 \%)$ & $119(40.07 \%)$ \\
\hline Both Antidepressants and Counseling & $188(53.87 \%)$ & $33(63.46 \%)$ & $155(52.19 \%)$ \\
\hline Other Treatment & $20(5.73 \%)$ & $0(0.00 \%)$ & $20(6.73 \%)$ \\
\hline
\end{tabular}

In the event a physician utilized antidepressants as a first-line of treatment, all of the pediatricians $(100.00 \%)$ indicated their first-line of treatment would include an Selective Serotonin Reuptake Inhibitors (SSRI) type antidepressant. The majority of the child psychiatrists $(96.00 \%)$ also indicated they utilize an SSRI type antidepressant. The results for the first-line of treatment by drug class are listed in Table 4.17. 
Table 4.17: Therapeutic Category of Antidepressants Used as First-Line of Treatment for Children

\begin{tabular}{|l|c|c|c|}
\hline \multicolumn{1}{|c|}{ Drug Class } & $\begin{array}{c}\text { All Physicians } \\
\text { N (\%) }\end{array}$ & $\begin{array}{c}\text { Pediatricians } \\
\mathbf{N}(\boldsymbol{\%})\end{array}$ & $\begin{array}{c}\text { Child } \\
\text { Psychiatrists } \\
\text { N (\%) }\end{array}$ \\
\hline Tricyclic Antidepressants (TCAs) & $2(0.95 \%)$ & $0(0.00 \%)$ & $2(1.14 \%)$ \\
\hline Tetracyclic Antidepressants & $1(0.47 \%)$ & $0(0.00 \%)$ & $1(0.57 \%)$ \\
\hline $\begin{array}{l}\text { Selective Serotonin Reuptake } \\
\text { Inhibitors (SSRIs) }\end{array}$ & $204(96.68 \%)$ & $36(100.00 \%)$ & $168(96.00 \%)$ \\
\hline $\begin{array}{l}\text { Norepinephrine and Dopamine } \\
\text { Reuptake Inhibitors (NDRIs) }\end{array}$ & $4(1.90 \%)$ & $0(0.00) \%$ & $4(2.29 \%)$ \\
\hline
\end{tabular}

The specific type of antidepressant varied somewhat for both pediatricians and child psychiatrists. Still greater than half of the pediatricians $(56.76 \%)$ and child psychiatrists $(51.98 \%)$ indicated they utilized Prozac $^{\circledR}$ as their first-line of antidepressant treatment for children with major depressive disorder. For first-line treatment, both pediatricians $(24.33 \%)$ and child psychiatrists $(27.12 \%)$ indicated Zoloft ${ }^{\circledR}$ to be the second most commonly utilized antidepressant. Results for the first-line of antidepressant treatment for children are listed in Table 4.18.

Table 4.18: Specific Antidepressant Used as First-Line Treatment for Children

\begin{tabular}{|c|c|c|c|}
\hline Antidepressant & $\begin{array}{c}\text { All Physicians } \\
\text { N }(\%)\end{array}$ & $\begin{array}{c}\text { Pediatricians } \\
\text { N }(\%)\end{array}$ & $\begin{array}{c}\text { Child } \\
\text { Psychiatrists } \\
\text { N (\%) }\end{array}$ \\
\hline Prozac $^{(R)}$ & $113(52.80 \%)$ & $21(56.76 \%)$ & $92(51.98 \%)$ \\
\hline Zoloft $^{(R)}$ & $57(26.64 \%)$ & $9(24.33 \%)$ & $48(27.12 \%)$ \\
\hline Celexa $^{(B)}$ & $21(9.81 \%)$ & $5(13.51 \%)$ & $16(9.04 \%)$ \\
\hline Lexapro $^{(R)}$ & $11(5.14 \%)$ & $0(0.00 \%)$ & $11(6.21 \%)$ \\
\hline Wellbutrin $^{(B)}$ & $4(1.87 \%)$ & $0(0.00 \%)$ & $4(2.26 \%)$ \\
\hline Tofranil $^{(\mathbb{R})}$ & $2(0.93 \%)$ & $0(0.00 \%)$ & $2(1.13 \%)$ \\
\hline Paxil $\left.^{(}\right)$ & $1(0.47 \%)$ & $1(2.70 \%)$ & $0(0.00 \%)$ \\
\hline Remeron $^{(B)}$ & $1(0.47 \%)$ & $0(0.00 \%)$ & $1(0.57 \%)$ \\
\hline Listed multiple antidepressants & $4(1.87 \%)$ & $1(2.70 \%)$ & $3(1.69 \%)$ \\
\hline
\end{tabular}

Objective 7: To determine physicians' second and third-lines of treatment for newly diagnosed children with major depressive disorder by: a) drug category, and b) specific antidepressant prescribed.

In the event the first-line of treatment was not successful, pediatricians indicated they would switch to a different antidepressant (48.00\%), while another $26.00 \%$ indicated they would add antidepressant treatment. The majority $(53.85 \%)$ of child psychiatrists, reported switching to a 
different antidepressant, in the event the first-line of treatment was not successful. Many child psychiatrists (39.86\%) indicated they would add antidepressant treatment to the first-line of treatment. The results for the second-line of treatment for children are listed in Table 4.19.

Table 4.19: Second-Line of Treatment for Children with Major Depressive Disorder

\begin{tabular}{|l|c|c|c|}
\hline \multicolumn{1}{|c|}{ Type of Treatment } & $\begin{array}{c}\text { All } \\
\text { Physicians } \\
\text { N (\%) }\end{array}$ & $\begin{array}{c}\text { Pediatricians } \\
\text { N (\%) }\end{array}$ & $\begin{array}{c}\text { Child } \\
\text { Psychiatrists } \\
\text { N (\%) }\end{array}$ \\
\hline Augment with Antidepressants & $127(37.80 \%)$ & $13(26.00 \%)$ & $114(39.86 \%)$ \\
\hline Switch to a Different Antidepressant & $178(52.98 \%)$ & $24(48.00 \%)$ & $154(53.85 \%)$ \\
\hline $\begin{array}{l}\text { Augment with } \\
\text { Counseling\Psychotherapy }\end{array}$ & $11(3.27 \%)$ & $4(8.00 \%)$ & $7(2.45 \%)$ \\
\hline $\begin{array}{l}\text { Switch or Augment with } \\
\text { Antidepressant }\end{array}$ & $4(1.19 \%)$ & $1(2.00 \%)$ & $3(1.04 \%)$ \\
\hline Other Treatment & $16(4.76 \%)$ & $8(16.00 \%)$ & $8(2.80 \%)$ \\
\hline
\end{tabular}

As was the case for the first-line of treatment, the majority of pediatricians $(97.22 \%)$ and child psychiatrists $(85.43 \%)$ indicated they utilize SSRIs as the second-line of treatment for children with major depressive disorder. The majority of pediatricians (Prozac ${ }^{\circledR} 36.85 \%$, Zoloft ${ }^{\circledR} 28.95 \%$ ) and child psychiatrists $\left(\operatorname{Prozac}^{\circledR} 30.08 \%\right.$, Zoloft $^{\circledR} 27.82 \%$ ) reported either Prozac ${ }^{\circledR}$ or Zoloft ${ }^{\circledR}$ as their principal choices of antidepressants for second-line of treatment. The antidepressant class and specific antidepressant reported as second-line of treatment are listed in Table 4.20 and Table 4.21.

Table 4.20: Therapeutic Category of Antidepressant Used as Second-Line of Treatment for Children

\begin{tabular}{|l|c|c|c|}
\hline \multicolumn{1}{|c|}{ Drug Class } & $\begin{array}{c}\text { All } \\
\text { Physicians } \\
\mathbf{N}(\%)\end{array}$ & $\begin{array}{c}\text { Pediatricians } \\
\mathbf{N}(\boldsymbol{\%})\end{array}$ & $\begin{array}{c}\text { Child } \\
\text { Psychiatrists } \\
\text { N (\%) }\end{array}$ \\
\hline Tricyclic Antidepressant (TCAs) & $6(2.07 \%)$ & $1(2.78 \%)$ & $5(1.97 \%)$ \\
\hline Tetracyclic Antidepressants & $2(0.69 \%)$ & $0(0.00 \%)$ & $2(0.79 \%)$ \\
\hline $\begin{array}{l}\text { Selective Serotonin Reuptake Inhibitors } \\
\text { (SSRIs) }\end{array}$ & $252(86.90 \%)$ & $35(97.22 \%)$ & $217(85.43 \%)$ \\
\hline $\begin{array}{l}\text { Selective-Norepinephrine Reuptake } \\
\text { Inhibtors (SNRIs) }\end{array}$ & $8(2.76 \%)$ & $0(0.00 \%)$ & $8(3.15 \%)$ \\
\hline $\begin{array}{l}\text { Norepinephrine and Dopamine Reuptake } \\
\text { Inhibitors (NDRIs) }\end{array}$ & $21(7.24 \%)$ & $0(0.00 \%)$ & $21(8.27 \%)$ \\
\hline Other Antidepressants & $1(0.34 \%)$ & $0(0.00 \%)$ & $1(0.39 \%)$ \\
\hline
\end{tabular}


Table 4.21: Specific Antidepressant Used as Second-Line Treatment for Children

\begin{tabular}{|c|c|c|c|}
\hline Antidepressant & $\begin{array}{c}\text { All } \\
\text { Physicians } \\
\text { N }(\%)\end{array}$ & $\begin{array}{c}\text { Pediatricians } \\
\text { N (\%) }\end{array}$ & $\begin{array}{c}\text { Child } \\
\text { Psychiatrists } \\
\text { N }(\%)\end{array}$ \\
\hline $\operatorname{Prozac}^{(\mathbb{R}}$ & $94(30.92 \%)$ & $14(36.85 \%)$ & $80(30.08 \%)$ \\
\hline Zoloft $^{(R)}$ & $85(27.96 \%)$ & $11(28.95 \%)$ & $74(27.82 \%)$ \\
\hline Celexa $^{(B)}$ & $29(9.54 \%)$ & $3(7.89 \%)$ & $26(9.77 \%)$ \\
\hline Lexapro $^{(R)}$ & $21(6.91 \%)$ & $3(7.89 \%)$ & $18(6.77 \%)$ \\
\hline Wellbutrin ${ }^{(R)}$ & $21(6.91 \%)$ & $0(0.00 \%)$ & $21(7.90 \%)$ \\
\hline Cymbalta $^{(B)}$ & $4(1.31 \%)$ & $0(0.00 \%)$ & $4(1.50 \%)$ \\
\hline Effexor $^{(R)}$ & $4(1.31 \%)$ & $0(0.00 \%)$ & $4(1.50 \%)$ \\
\hline Tofranil $^{(\mathbb{R})}$ & $3(0.99 \%)$ & $0(0.00 \%)$ & $3(1.13 \%)$ \\
\hline Remeron & $2(0.66 \%)$ & $0(0.00 \%)$ & $2(0.75 \%)$ \\
\hline Pamelor ${ }^{(R)}$ & $2(0.66 \%)$ & $0(0.00 \%)$ & $2(0.75 \%)$ \\
\hline Desyrel $^{(R)}$ & $1(0.33 \%)$ & $0(0.00 \%)$ & $1(0.38 \%)$ \\
\hline Elavil $^{(R)}$ & $1(0.33 \%)$ & $1(2.63 \%)$ & $0(0.00 \%)$ \\
\hline Paxil $^{(\mathbb{R})}$ & $1(0.33 \%)$ & $1(2.63 \%)$ & $0(0.00 \%)$ \\
\hline $\begin{array}{l}\text { Listed multiple } \\
\text { antidepressants }\end{array}$ & $36(11.84 \%)$ & $5(13.16 \%)$ & $31(11.65 \%)$ \\
\hline
\end{tabular}

In the event the second-line of treatment was not successful the majority (51.28\%) of pediatricians indicated they would try some "other" type of treatment for children with major depressive disorder. In comparison, the majority of child psychiatrists (66.43\%) reported they would persist with antidepressant treatment by switching these children to another antidepressant treatment. Table 4.22 shows the results for the third-line of treatment for children.

Table 4.22: Third-Line of Treatment for Children with Major Depressive Disorder

\begin{tabular}{|l|c|c|c|}
\hline \multicolumn{1}{|c|}{ Type of Treatment } & $\begin{array}{c}\text { All } \\
\text { Physicians } \\
\text { N (\%) }\end{array}$ & $\begin{array}{c}\text { Pediatricians } \\
\text { N (\%) }\end{array}$ & $\begin{array}{c}\text { Child } \\
\text { Psychiatrists } \\
\text { N (\%) }\end{array}$ \\
\hline Augment with Antidepressants & $21(6.58 \%)$ & $1(2.56 \%)$ & $20(7.15 \%)$ \\
\hline Switch to a Different Antidepressant & $191(59.88 \%)$ & $5(12.82 \%)$ & $186(66.43 \%)$ \\
\hline Augment with Counseling Psychotherapy & $24(7.52 \%)$ & $11(28.21 \%)$ & $13(4.64 \%)$ \\
\hline Switch or Augment with Antidepressant & $4(1.25 \%)$ & $2(5.13 \%)$ & $2(0.71 \%)$ \\
\hline Switch or Other Treatment & $3(0.94 \%)$ & $0(0.00 \%)$ & $3(1.07 \%)$ \\
\hline Other Treatment & $76(23.83 \%)$ & $20(51.28 \%)$ & $56(20.00 \%)$ \\
\hline
\end{tabular}

The majority of the pediatricians $(95.00 \%)$, who indicated they would try some "other" type of treatment for children, indicated they would refer these patients to psychiatry. The majority of the child psychiatrists (71.44\%) indicated they would try some other type of medication. The four 
medications reported to be utilized most often were antipsychotics, mood stabilizers, anticonvulsants, or lithium. These "other treatment" choices are listed in Tables 4.23 and 4.24.

Table 4.23: Pediatricians" "Other $3^{\text {rd }}$ Line of Treatment" for Children

\begin{tabular}{|l|c|}
\hline \multicolumn{1}{|c|}{ Type of Treatment } & Pediatricians N (\%) \\
\hline Refer to Psychiatry & $19(95.00 \%)$ \\
\hline Antipsychotic & $1(5.00 \%)$ \\
\hline
\end{tabular}

Table 4.24: Child Psychiatrists' "Other $3^{\text {rd }}$ Line Treatment" for Children

\begin{tabular}{|l|c|}
\hline \multicolumn{1}{|c|}{ Type of Treatment } & Child Psychiatrists N (\%) \\
\hline Antipsychotic & $10(17.86 \%)$ \\
\hline Mood Stabilizer & $10(17.86 \%)$ \\
\hline Anticonvulsants & $5(8.93 \%)$ \\
\hline Lithium & $5(8.93 \%)$ \\
\hline Combination of Antidepressants & $3(5.35 \%)$ \\
\hline Antipsychotic or Anticonvulsant & $2(3.56 \%)$ \\
\hline Thyroid & $1(1.79 \%)$ \\
\hline Lithium or Thyroid & $1(1.79 \%)$ \\
\hline Mood Stabilizer or Antipsychotic & $1(1.79 \%)$ \\
\hline Lithium or Antipsychotic & $1(1.79 \%)$ \\
\hline Thyroid or Antipsychotic & $1(1.79 \%)$ \\
\hline $\begin{array}{l}\text { Other: Re-evaluate environment, } \\
\text { hospitalization, other counseling, etc }\end{array}$ & $16(28.56 \%)$ \\
\hline
\end{tabular}

The third-line of treatment for children with major depressive disorder still included the use of an SSRI antidepressant for the majority (52.94\%) of the child psychiatrists. One-third, of the child psychiatrists (33.16\%) indicated they would utilize Norepinephrine and Dopamine Reuptake Inhibitors (NDRIs) as their third-line of treatment in comparison a majority $(55.56 \%)$ of pediatricians indicated they would utilize an NDRI type antidepressant as their third-line of treatment. In contrast, pediatricians $(44.44 \%)$ indicated they utilize SSRIs in their third-line of treatment. Findings for the therapeutic category associated with the third-line of treatment of children with major depressive disorder are listed in Table 4.25. 
Table 4.25: Therapeutic Category of Antidepressant Used as Third-Line of Treatment for Children

\begin{tabular}{|l|c|c|c|}
\hline \multicolumn{1}{|c|}{ Drug Class } & $\begin{array}{c}\text { All } \\
\text { Physicians } \\
\text { N (\%) }\end{array}$ & $\begin{array}{c}\text { Pediatricians } \\
\text { N (\%) }\end{array}$ & $\begin{array}{c}\text { Child } \\
\text { Psychiatrists } \\
\text { N (\%) }\end{array}$ \\
\hline Tricyclic Antidepressants (TCAs) & $1(0.51 \%)$ & $0(0.00 \%)$ & $1(0.53 \%)$ \\
\hline Tetracyclic Antidepressants & $2(1.02 \%)$ & $0(0.00 \%)$ & $2(1.07 \%)$ \\
\hline $\begin{array}{l}\text { Selective Serotonin Reuptake Inhibitors } \\
\text { (SSRIs) }\end{array}$ & $\begin{array}{c}103 \\
(52.55 \%)\end{array}$ & $4(44.44 \%)$ & $99(52.94 \%)$ \\
\hline $\begin{array}{l}\text { Selective-Norepinephrine Reuptake } \\
\text { Inhibitors (SNRIs) }\end{array}$ & $22(11.23 \%)$ & $0(0.00 \%)$ & $22(11.77 \%)$ \\
\hline $\begin{array}{l}\text { Norepinephrine and Dopamine Reuptake } \\
\text { Inhibitors (NDRIs) }\end{array}$ & $67(34.18 \%)$ & $5(55.56 \%)$ & $62(33.16 \%)$ \\
\hline Other Antidepressants & $1(0.51 \%)$ & $0(0.00 \%)$ & $1(0.53 \%)$ \\
\hline
\end{tabular}

Results for the specific antidepressant associated with the third-line of treatment for children are listed in Table 4.26. The majority of pediatricians indicated the use of either Wellbutrin ${ }^{\circledR}(55.56 \%)$ or Zoloft ${ }^{\circledR}(33.33 \%)$ as their third-line of treatment for children with major depressive disorder. Child psychiatrists' choice of antidepressant for use as their third-line of treatment for children was more varied than pediatricians'. Child psychiatrists indicated Wellbutrin ${ }^{\circledR}$ as their most frequently (30.24\%) utilized antidepressant for the third-line of treatment. As indicated above SSRIs were the most frequently utilized class of antidepressants, however the specific type of SSRI medication varied from Zoloft ${ }^{\circledR} 16.10 \%$, Prozac $^{\circledR} 11.22 \%$, Celexa $^{\circledR} 8.29 \%$, Lexapro ${ }^{\circledR} 5.36 \%$, and Paxil ${ }^{\circledR} 1.95 \%$. 
Table 4.26: Specific Antidepressant Used as Third-Line Treatment for Children

\begin{tabular}{|c|c|c|c|}
\hline Antidepressant & $\begin{array}{c}\text { All Physicians } \\
\text { N (\%) }\end{array}$ & $\begin{array}{c}\text { Pediatricians } \\
\text { N }(\%)\end{array}$ & $\begin{array}{c}\text { Child } \\
\text { Psychiatrists } \\
\text { N }(\%)\end{array}$ \\
\hline $\operatorname{Prozac}^{(\mathbb{}}$ & $24(11.22 \%)$ & $1(11.11 \%)$ & $23(11.22 \%)$ \\
\hline Zoloft $^{(R)}$ & $36(16.82 \%)$ & $3(33.33 \%)$ & $33(16.10 \%)$ \\
\hline Celexa $^{(R)}$ & $17(7.94 \%)$ & $0(0.00 \%)$ & $17(8.29 \%)$ \\
\hline Lexapro $^{(R)}$ & $11(5.14 \%)$ & $0(0.00 \%)$ & $11(5.36 \%)$ \\
\hline Wellbutrin $^{(R)}$ & $67(31.31 \%)$ & $5(55.56 \%)$ & $62(30.24 \%)$ \\
\hline Cymbalta $^{(B)}$ & $5(2.33 \%)$ & $0(0.00 \%)$ & $5(2.44 \%)$ \\
\hline Effexor $^{(R)}$ & $15(7.01 \%)$ & $0(0.00 \%)$ & $15(7.32 \%)$ \\
\hline Tofranil $^{(\mathbb{R}}$ & $1(0.47 \%)$ & $0(0.00 \%)$ & $1(0.49 \%)$ \\
\hline Remeron $^{(B)}$ & $2(0.93 \%)$ & $0(0.00 \%)$ & $2(0.98 \%)$ \\
\hline Desyrel $^{(\mathbb{R}}$ & $1(0.47 \%)$ & $0(0.00 \%)$ & $1(0.49 \%)$ \\
\hline Paxil $^{(\mathbb{R}}$ & $4(1.87 \%)$ & $0(0.00 \%)$ & $4(1.95 \%)$ \\
\hline Listed multiple antidepressants & $31(14.49 \%)$ & $0(0.00 \%)$ & $31(15.12 \%)$ \\
\hline
\end{tabular}

Objective 8: To determine the difference in first, second, and third-lines of antidepressant treatment prescribed by physicians to newly diagnosed children with major depressive disorder by a) the pharmacotherapy category and b) specific antidepressant prescribed.

Null Hypothesis 8.a: There is no difference in the pharmacotherapy category prescribed by physicians (pediatricians versus child psychiatrists) for first, second, and third lines of antidepressant treatment for newly diagnosed children with major depressive disorder.

Null Hypothesis 8.b: There is no difference in the specific antidepressant prescribed by physicians (pediatricians versus child psychiatrists) for first, second, and third lines of treatment for newly diagnosed children with major depressive disorder.

In order to determine whether there is an association between the first, second, and third lines of antidepressant treatment and physician type several steps were needed in the statistical analysis. Chi Square $\left(\chi^{2}\right)$ tests were utilized to examined the association between two variables: physician type (pediatrician versus child psychiatrist) and pharmacotherapy category or antidepressant (TCAs, Tetracyclics, SSRIs, SNRIs, NDRIs, and Other Antidepressants). Separate $\chi^{2}$ tests examined the association between the first-line of pharmacotherapy class and physician type, second-line of pharmacotherapy class and physician type, and third-line of pharmacotherapy class and physician type. Each of these three $\chi^{2}$ tests indicated no significance between the variables. Furthermore, over $20 \%$ of the cell counts for each of the tests were less than five. When this is the case the $\chi^{2}$ test is 
probably not a valid statistical test. To manage small cell sizes cells can be collapsed or combined. For this study, groups of antidepressant categories were collapsed or combined. Since the majority of the scientific research has focused on utilizing SSRIs in treating children antidepressant categories, were combined into SSRIs and Non-SSRIs. Therefore, the next set of analyses determined whether there was a relationship between physician type (pediatrician versus child psychiatrist) and SSRIs versus Non-SSRIs, for first, second, and third-lines of treatment. Even after collapsing the antidepressant drugs into these two groups, $\chi^{2}$ tests still resulted in small expected values. In this case, the Fisher's exact test may be used to examine the associations between physician type and antidepressant categories. The Fisher's exact test may be utilized when a researcher wants to make a comparison between two binomial variables and is especially useful for small sample sizes because the assumption of normal approximation to the binomial distribution is relaxed.

The association between physician type and antidepressant category prescribed for children is not statistically significant at the $p \leq 0.05$ level. These results are listed in Table 4.27. Therefore, we fail to reject the Null Hypothesis 8.a: There is no difference in the pharmacotherapy category prescribed by physicians (pediatricians versus child psychiatrists) for first, second, and third lines of antidepressant treatment for newly diagnosed children with major depressive disorder.

Table 4.27: Association Between Physician Type and Antidepressant Category

\begin{tabular}{|l|c|}
\hline Association & Two-sided Probability \\
\hline $\begin{array}{c}\text { Children's First-line of Antidepressant: } \\
\text { Physician Type * Antidepressant Type }\end{array}$ & 0.6058 \\
\hline $\begin{array}{c}\text { Children's Second-line of Antidepressant: } \\
\text { Physician Type * Antidepressant Type }\end{array}$ & 0.0616 \\
\hline $\begin{array}{c}\text { Children's Third-line of Antidepressant: } \\
\text { Physician Type * Antidepressant Type }\end{array}$ & 0.7382 \\
\hline
\end{tabular}


For Objective 8, several steps were used to determined the association between the first, second, and third lines of specific antidepressant treatment and physician type. First, three $\chi^{2}$ tests, one for each line of treatment (first, second, and third-line) were conducted to examine the association between two variables: physician type (pediatrician versus child psychiatrist) and specific antidepressant prescribed. Results showed the specific type of antidepressant medication used by the physicians varied across all three lines of treatment (first-line of treatment there were 11 different antidepressants, for the second-line of treatment there were 29 different antidepressants, and for the third-line there were 34 different antidepressants). Thus, it was necessary to collapse the antidepressant categories into two groups. Since Prozac ${ }^{\circledR}$ is the only FDA approved antidepressant, the researcher collapsed the specific antidepressants into, either a Prozac ${ }^{\circledR}$ or non- Prozac ${ }^{\circledR}$ group. After the antidepressants were recoded into these groups, $\chi^{2}$ tests were utilized to determine the association between physician type (pediatrician versus child psychiatrist) and specific antidepressant (Prozac ${ }^{\circledR}$ versus non- Prozac $^{\circledR}$ ) for each line of treatment (first, second, and third). Results of these analyses are below in Table 4.28 .

Table 4.28: Association Between Physician Type and Prozac ${ }^{\circledR}$ versus Non-Prozac $^{\circledR}$ Groups

\begin{tabular}{|c|c|c|c|c|}
\hline & $\begin{array}{l}\text { Pediatrician } \\
\text { (N) }\end{array}$ & $\begin{array}{l}\text { Child } \\
\text { Psychiatrist } \\
\text { (N) }\end{array}$ & Test Statistic & p-value \\
\hline $\begin{array}{l}1^{\text {st }} \text {-Line of Antidepressant } \\
\text { Treatment: } \\
\text { Non-Prozac }^{\circledR} \\
\text { Prozac }{ }^{\circledR}\end{array}$ & $\begin{array}{l}16 \\
21\end{array}$ & $\begin{array}{l}84 \\
92\end{array}$ & $\chi^{2}=0.2468$ & 0.6193 \\
\hline $\begin{array}{l}\text { 2nd-Line of Antidepressant } \\
\text { Treatment: } \\
\text { Non-Prozac }^{\circledR} \\
\text { Prozac }^{\circledR}\end{array}$ & $\begin{array}{l}24 \\
14\end{array}$ & $\begin{array}{c}186 \\
80\end{array}$ & $\chi^{2}=0.7128$ & 0.3985 \\
\hline $\begin{array}{l}3^{\text {rd }} \text {-Line of Antidepressant } \\
\text { Treatment: } \\
\text { Non-Prozac }^{\circledR} \\
\text { Prozac }{ }^{\circledR}\end{array}$ & $\begin{array}{l}8 \\
1\end{array}$ & $\begin{array}{c}182 \\
23\end{array}$ & $\begin{array}{c}\text { Fisher's } \\
\text { Exact Test }\end{array}$ & 1.0000 \\
\hline
\end{tabular}


Based on the $\chi^{2}$ tests and the Fisher's exact test it was concluded there is no statistically significant association between physician type and the specific antidepressant (Prozac ${ }^{\circledR}$ versus NonProzac $^{\circledR}$ ) prescribed to children. On the basis of these tests the Null Hypothesis 8.b: There is no difference in the specific antidepressant prescribed by physicians (pediatricians versus child psychiatrists) for first, second, and third lines of treatment for newly diagnosed children with major depressive disorder, is not rejected.

Objective 9: To predict which physician characteristics affect the treatment prescribed for children with major depressive disorder.

Regression is a useful statistical tool to assess the possible association between an outcome variable and one or more predictor variables. In this study, the association between the outcome variable type of treatment prescribed for children and physician characteristics will be assessed. For this analysis, the first line of treatment is the outcome or dependent variable. This line of treatment may be categorized as treatment type (antidepressant treatment versus counseling). The outcome variable is categorical in nature and necessitates a form of regression called logistic regression. Logistic regression provides a method to model the dependency of a binary outcome variable on one or more predictor or independent variables and was utilized to examine the association between firstline of treatment for major depressive disorder in children and physician characteristics. In this study, the predictor or independent variables are physician characteristics such as: specialty of physician, gender, age, physicians' primary practice site, geographic location of practice, population of community of physicians' primary practice site, board certification, patient volume per week, and the length of time the physician has treated the child and adolescent population. The logistic regression equation predicts the probability an individual will be in one of the two levels of the binary outcome. The logistic regression equation is as follows:

$$
\operatorname{logit}(p)=\alpha+\beta_{1} x_{1}+\ldots \ldots \ldots .+\beta_{k} x_{k}
$$


If $x_{1}, \ldots \ldots ., x_{k}$ are the independent variables of interest and $y$ is a binomial outcome variable with a probability of success $=p_{i}($ Rosner, 2000).

Variable selection involves coming up with the best subset of independent variables for the regression model. There are several variable selection methods which may be utilized including forward, backward, and stepwise (Cody \& Smith, 1997). Forward selection enters the most significant, independent variable followed by the next most significant independent variable until a specific criterion has been met. This criterion is usually based on statistical significance in the model (Cody \& Smith, 1997). Backward selection involves starting with all of the independent variables in the model and then removing the least significant variable, then the next least significant variable, and so on until the computer program finds the best subset of independent variables. Stepwise selection begins like forward selection, however in stepwise selection variables may leave the model as well as enter. After an independent variable is added to the regression model, the model is tested for significance. If the addition of the variable still results in a significant model the variable is retained, if not it is removed from the regression model. Stepwise selection provides an effective method to screen a relatively large number of independent variables. This method is especially useful if the outcome being studied is somewhat new and associations between the outcome and independent variables are not understood (Hosmer \& Lemeshow, 2000). The objective in this study is to examine the relationship between physician treatment choices and physician characteristics for a relatively large number of independent variables. Additionally, the relationships between the outcome and independent variables have not been studied in the context of the treatment of childhood or adolescent depression. Therefore, stepwise logistic regression will provide a means to screen the various physician characteristics (independent variables) and examine whether or not these associations exit. 
When utilizing stepwise logistic regression, the researcher selects the entry criterion or level of statistical significance for which independent variables enter the model. Research has shown that the choice of $p=0.05$ is too stringent and often excludes important variables from the model (Hosmer \& Lemeshow, 2000). Hosmer \& Lemeshow (2000) recommend choosing a p-value in range of $0.15-0.20$. A conservative approach was taken and the entry criterion was set at 0.15 .

Stepwise methods were utilized to estimate the probability a physician would prescribe an antidepressant versus prescribing counseling for children with major depressive disorder. The explanatory variables utilized in this model were physician characteristics (physicians' specialty, gender, age, primary practice site, geographic location of physician, population of community of physicians' primary practice site, physicians' board certification, patient volume per week, and the length of time the physician has treated the child and adolescent population). Based on our prespecified criterion $(\mathrm{p}=0.15)$ four variables, type of physician, age of physician, geographic location of primary practice site, and number of adolescents seen per week, were retained in the model.

Although, the four variables contribute significantly in statistical terms to the model there are other considerations. Clinical considerations, biological considerations, and common sense are also needed when deciding which variables to retain in a model (Hosmer \& Lemeshow, 2000). It seems unlikely that the number of adolescents a physician sees per week is associated with the type of treatment the physician prescribes for a child. Therefore, this variable will be excluded from the final model. It can be concluded from the logistic regression model that specialty of the physician, age of physician, and southern, midwest, and pacific/west geographic locations of the primary practice site are significantly associated with physicians prescribing antidepressants to children with major depressive disorder. Variables were retained in the final model if the p-value was less than or equal to 0.05 and the final regression model is as follows: 
$\operatorname{logit}(\mathrm{p})=0.3991+(-0.9124 *$ Specialty of Physician $)+(0.6197 *$ Age of Physician $)+(0.9649 *$ Southern Geographic Region $)+(0.9911 *$ Midwest Geographic Region $)+(0.8840 *$ Pacific/West Geographic Region $)$

Odds ratios were used to examine the magnitude of these associations and are listed in Table 4.29. After controlling for all other variables in the model, the odds in favor of a child psychiatrist prescribing an antidepressant is only 0.402 times greater than pediatricians. The odds ratio of 1.85 indicates that the odds in favor of a physician prescribing an antidepressant medication is 1.85 times greater for physicians who are more than 60 years of age, as compared to those who are less than 60 years of age. Finally, the odds in favor of physicians prescribing antidepressant medication for physicians whose practice location is in the South, Midwest, or Pacific/West are 2.625, 2.694, and 2.421, respectively, times greater as compared to physicians located in the Northeast.

Next, the goodness of fit of the model was assessed. Assessing the goodness-of-fit of the model, involves deciding whether the predicted values are an accurate representation of the observed values (Hosmer \& Lemeshow, 2000). In other words, the goodness-of-fit is a measure of how well the model describes the dependent variable. The Hosmer-Lemeshow test is a goodness-of-fit test which allows for any number of independent variables (Bewick, Cheek, \& Ball, 2005). For this model, the Hosmer-Lemeshow test is non-significant $(\mathrm{p}=0.8634)$. This indicates that the overall fit of the model is good. 
Table 4.29: Logistic Regression Analysis of Physicians' Antidepressant Prescribing to Children with Major Depressive Disorder

\begin{tabular}{|l|c|c|c|c|c|c|c|}
\hline \multicolumn{1}{|c|}{ Variable } & $\begin{array}{c}\text { Estimate } \\
\boldsymbol{\beta}\end{array}$ & SE $\boldsymbol{\beta}$ & $\begin{array}{c}\text { Wald's } \\
\boldsymbol{\chi}^{\mathbf{2}}\end{array}$ & $\boldsymbol{d f}$ & $\mathbf{p}$-value & $\begin{array}{c}\text { Point } \\
\text { Estimate }\end{array}$ & $\mathbf{9 5 \%}$ CI \\
\hline Intercept & 0.3991 & 0.4537 & 0.7738 & 1 & 0.3790 & NA & NA \\
\hline Child Psychiatrist & -0.9124 & 0.4069 & 5.0280 & 1 & $0.0249^{*}$ & 0.402 & $0.181-0.891$ \\
\hline $\begin{array}{l}\text { Age of Physician } \\
\text { Greater than 60 years }\end{array}$ & 0.6197 & 0.3230 & 3.6805 & 1 & $0.0551^{*}$ & 1.858 & $0.987-3.500$ \\
\hline $\begin{array}{l}\text { Southern Geographic } \\
\text { Region }\end{array}$ & 0.9649 & 0.3353 & 8.2788 & 1 & $0.0040^{*}$ & 2.625 & $1.360-5.064$ \\
\hline $\begin{array}{l}\text { Midwest Geographic } \\
\text { Region }\end{array}$ & 0.9911 & 0.3496 & 8.0375 & 1 & $0.0046^{*}$ & 2.694 & $1.358-5.346$ \\
\hline $\begin{array}{l}\text { Pacific/West } \\
\text { Geographic Region }\end{array}$ & 0.8840 & 0.3697 & 5.7182 & 1 & $0.0168^{*}$ & 2.421 & $1.173-4.996$ \\
\hline
\end{tabular}

$\mathrm{SE}=$ Standard Error, $\mathrm{df}=$ degrees of freedom, $\mathrm{CI}=$ Confidence Interval, *Significance at $\mathrm{p} \leq 0.05$

Multicollinearity occurs when there are strong linear dependencies among the independent variables (Allison, 1999). Basically, the independent variables should not be highly correlated with each other, as it is difficult to obtain good estimates of their association with the dependent variable. Multicollinearity can be assessed by utilizing the diagnostics tolerance and variance inflation factor. The tolerance can be computed by regressing each of the independent variables on all of the other independent variables, calculating the $\mathrm{R}^{2}$ (the proportion of the variance of $y$ that can be explained by $x$ ) and subtracting from one (Rosner, 2000). The variance inflation factor (VIF) is the reciprocal of the tolerance and tells how inflated the variance of the coefficient is compared to what it would be if the variable were not correlated with other variables in the model (Allison, 1999). Tolerance ranges between zero and one and VIF is one or greater, while tolerances below 0.40 may be an indication of multicollinearity (Allison, 1999). Others have suggested that VIF values of less than 4.00 should be considered acceptable (Allison, 1999). In conclusion, there is no strict rule for assessing multicollinearity. In this model the tolerances ranged from 0.61166 to 0.98574 and VIF values ranged from 1.01447 to 1.63488 , and therefore multicollinearity is not an issue in this model. 
Objective 10: To determine the average length of antidepressant treatment for newly diagnosed children with major depressive disorder.

Physicians were asked to indicate how long on average would they continue to prescribe an antidepressant to a child, if the treatment was successful in terms of decreasing depressive symptoms. The majority of the physicians, both pediatricians $(51.35 \%)$ and child psychiatrists $(65.17 \%)$ indicated they would prescribe the antidepressant medication to the child for ten months or longer. These frequencies are listed in Table 4.30 .

Table 4.30: Frequencies of Average Length of Antidepressant Treatment for Children

\begin{tabular}{|l|c|c|c|}
\hline $\begin{array}{l}\text { Length of } \\
\text { Antidepressant } \\
\text { Treatment }\end{array}$ & $\begin{array}{c}\text { All Physicians } \\
\mathbf{N}(\%)\end{array}$ & $\begin{array}{c}\text { Pediatricians } \\
\mathbf{N}(\boldsymbol{\%})\end{array}$ & $\begin{array}{c}\text { Child Psychiatrists } \\
\mathbf{N}(\boldsymbol{\%})\end{array}$ \\
\hline $\mathbf{1 - 3}$ months & $3(1.40)$ & $1(2.70)$ & $2(1.12)$ \\
\hline $\mathbf{4 - 6}$ months & $34(15.81)$ & $10(27.03)$ & $24(13.48)$ \\
\hline $\mathbf{7 - 9}$ months & $43(20.00)$ & $7(18.92)$ & $36(20.23)$ \\
\hline $\mathbf{1 0 - 1 2}$ months & $84(30.07)$ & $8(21.62)$ & $76(42.70)$ \\
\hline $\begin{array}{l}\text { Greater than 12 } \\
\text { months }\end{array}$ & $51(23.72)$ & $11(29.73)$ & $40(22.47)$ \\
\hline
\end{tabular}

The American Academy of Child and Adolescent Psychiatry has recently recommended children be treated for a minimum of six months (American Academy of Child and Adolescent Psychiatry, 2007). The categorical variable, length of treatment, was then transformed into a continuous variable so comparisons could be made to the six month minimum. The categorical variable was recoded by taking the average number of months the physician treats the children with an antidepressant. The variable was re-coded as follows: 1-3 months was transformed into 2 months, 4-6 months was transformed into 5 months, 7-9 months was transformed into 8 months, 10-12 months was transformed into 11 months, and greater than 12 months was transformed into 12 months. The average length of time pediatricians and child psychiatrists prescribed antidepressant treatment for children was then compared to the six month minimum length of time. It was found that both pediatricians and child psychiatrists treated children significantly longer than the six month minimum. These results are listed in Table 4.31. 
Table 4.31: Length of Antidepressant Treatment Compared to AACAP Recommendations

\begin{tabular}{|l|l|c|c|c|}
\hline $\begin{array}{l}\text { Physician } \\
\text { Type }\end{array}$ & $\begin{array}{l}\text { Length of } \\
\text { Antidepressant } \\
\text { Treatment } \\
\text { Mean }+ \text { SD) }\end{array}$ & $\begin{array}{l}\text { Minimum Length } \\
\text { of AACAP } \\
\text { Recommendations } \\
\text { (months) }\end{array}$ & Test Statistic & Significance p \\
\hline Pediatrician & $8.865+3.102$ & 6 & $\mathrm{t}=5.618$ & $0.000^{*}$ \\
\hline $\begin{array}{l}\text { Child } \\
\text { Psychiatrist }\end{array}$ & $9.708 \pm 2.485$ & 6 & $\mathrm{t}=19.909$ & $0.000^{*}$ \\
\hline
\end{tabular}

*Significant at $\mathrm{p} \leq 0.05, \mathrm{SD}=$ Standard Deviation

Objective 11: To determine the types of pharmacotherapy monitoring in newly diagnosed children with major depressive disorder.

Physicians were asked to indicate how they monitor antidepressants prescribed to children with major depressive disorder. More specifically physicians were asked the mode of monitoring (e.g., how is the monitoring done), who conducts the monitoring, the type of monitoring they conduct, and the frequency with which they monitor children. Physicians' responses to the mode of monitoring, who conducts the monitoring, and the type of monitoring conducted are listed in Table 4.32, Table 4.33, and Table 4.34, respectively. The majority of pediatricians $(89.58 \%)$ and child psychiatrists (96.04\%) indicated they conduct monitoring by an individual office visit with the child. Both pediatricians (95.83\%) and child psychiatrists (96.04\%) reported, almost exclusively, they would conduct the monitoring themselves. The majority of pediatricians and child psychiatrists monitor for adverse events, suicidality, and clinical symptoms. Some pediatricians (29.79\%) and child psychiatrists $(72.95 \%)$ also require the patient to get some type of labwork. Some pediatricians (4.26\%) and child psychiatrists (24.91\%) indicated they conduct some other type of monitoring for children. Other types of monitoring physicians listed included monitoring ongoing psychotherapy progress, monitoring school, social, family, or interpersonal functioning, and monitoring depressive symptoms through the use of scales (ex. Beck’s Depression Inventory). 
Table 4.32: Mode of Antidepressant Monitoring for Children

\begin{tabular}{|l|c|c|c|}
\hline $\begin{array}{l}\text { Mode of } \\
\text { Monitoring }\end{array}$ & $\begin{array}{c}\text { All Physicians } \\
\text { N (\%) }\end{array}$ & $\begin{array}{c}\text { Pediatricians } \\
\mathbf{N}(\boldsymbol{\%})\end{array}$ & $\begin{array}{c}\text { Child Psychiatrists } \\
\mathbf{N}(\boldsymbol{\%})\end{array}$ \\
\hline $\begin{array}{l}\text { Individual Office } \\
\text { Visit }\end{array}$ & $310(95.09)$ & $43(89.58)$ & $267(96.04)$ \\
\hline Telephone & $7(2.15)$ & $3(6.25)$ & $4(1.44)$ \\
\hline Other & $9(2.76)$ & $2(4.17)$ & $7(2.52)$ \\
\hline
\end{tabular}

Table 4.33: Healthcare Provider Conducting Antidepressant Monitoring for Children

\begin{tabular}{|l|c|c|c|}
\hline Healthcare Provider & $\begin{array}{c}\text { All Physicians } \\
\text { N (\%) }\end{array}$ & $\begin{array}{c}\text { Pediatricians } \\
\mathbf{N}(\boldsymbol{\%})\end{array}$ & $\begin{array}{c}\text { Child Psychiatrists } \\
\text { N (\%) }\end{array}$ \\
\hline Physician & $313(95.09)$ & $46(95.83)$ & $267(96.04)$ \\
\hline Nurse/Nurse Practitioner & $4(1.23)$ & $0(0.00)$ & $4(1.44)$ \\
\hline Counselor/Psychotherapist & $4(1.23)$ & $2(4.17)$ & $2(0.72)$ \\
\hline Other & $5(1.53)$ & $0(0.00)$ & $5(1.80)$ \\
\hline
\end{tabular}

Table 4.34: Type of Antidepressant Monitoring for Children

\begin{tabular}{|l|c|c|c|}
\hline $\begin{array}{l}\text { Type of } \\
\text { Monitoring }\end{array}$ & $\begin{array}{c}\text { All Physicians } \\
(\mathbf{N = 3 2 8})\end{array}$ & $\begin{array}{c}\text { Pediatricians } \\
(\mathbf{N = 4 7 )}\end{array}$ & $\begin{array}{c}\text { Child Psychiatrists } \\
(\mathbf{N = 2 8 1})\end{array}$ \\
\hline Adverse Events & $326(99.39)$ & $47(100.00)$ & $279(98.93)$ \\
\hline Suicidality & $323(98.48)$ & $45(95.74)$ & $278(98.93)$ \\
\hline Conduct Labwork & $219(66.77)$ & $14(29.79)$ & $205(72.95)$ \\
\hline Clinical Symptoms & $324(98.78)$ & $47(100.00)$ & $277(98.58)$ \\
\hline Other & $72(21.95)$ & $2(4.26)$ & $70(24.91)$ \\
\hline
\end{tabular}

Physicians were asked to indicate how frequently they monitor children treated with antidepressants during the first three months of treatment. During the first month of treatment the majority of pediatricians $(54.35 \%)$ indicated they monitor children every two weeks, with another $39.13 \%$ of pediatricians monitoring once a week. The majority of child psychiatrists reported monitoring children either once a week $(41.43 \%)$ or every two weeks $(30.71 \%)$ during the first month of antidepressant treatment. Results for the frequency of antidepressant monitoring during the first month of treatment are shown in Table 4.35 . 
Table 4.35: Frequency of Antidepressant Monitoring: Month One

\begin{tabular}{|l|c|c|c|}
\hline & $\begin{array}{c}\text { All Physicians } \\
(\mathbf{N})\end{array}$ & $\begin{array}{c}\text { Pediatricians } \\
(\mathbf{N})\end{array}$ & $\begin{array}{c}\text { Child Psychiatrists } \\
(\mathbf{N})\end{array}$ \\
\hline Frequency of Monitoring: & & & $3(1.07 \%)$ \\
\hline Two Times per Week & $3(0.92 \%)$ & $0(0.00 \%)$ & $116(41.43 \%)$ \\
\hline Once a Week & $134(41.11 \%)$ & $18(39.13 \%)$ & $86(30.71 \%)$ \\
\hline Every Two Weeks & $111(34.05 \%)$ & $25(54.35 \%)$ & $12(4.29 \%)$ \\
\hline Every Three Weeks & $12(3.68 \%)$ & $0(0.00 \%)$ & $34(12.14 \%)$ \\
\hline Once a Month & $36(11.04 \%)$ & $2(4.35 \%)$ & $0(0.00 \%)$ \\
\hline Greater than Once a Month & $0(0.00 \%)$ & $0(0.00 \%)$ & $29(10.36 \%)$ \\
\hline Other & $30(9.20 \%)$ & $1(2.17 \%)$ & \\
\hline
\end{tabular}

Physicians were asked to indicate how frequently they monitor children treated with antidepressants during the second month of treatment. During this time period the majority of pediatricians $(65.23 \%)$ reported monitoring children once a month compared to $42.65 \%$ of the child psychiatrists. Another $21.74 \%$ of the pediatricians indicated they monitor children every two weeks, while $34.06 \%$ of the child psychiatrists monitor children every two weeks. Table 4.36 shows the results for the frequency of monitoring during the second month of treatment.

Table 4.36: Frequency of Antidepressant Monitoring: Month Two

\begin{tabular}{|l|c|c|c|}
\hline & $\begin{array}{c}\text { All Physicians } \\
(\mathbf{N})\end{array}$ & $\begin{array}{c}\text { Pediatricians } \\
(\mathbf{N})\end{array}$ & $\begin{array}{c}\text { Child Psychiatrists } \\
(\mathbf{N})\end{array}$ \\
\hline Frequency of Monitoring: & & & $2(0.72 \%)$ \\
\hline Two Times per Week & $3(0.92 \%)$ & $1(2.17 \%)$ & $14(5.02 \%)$ \\
\hline Once a Week & $14(4.31 \%)$ & $0(0.00 \%)$ & $95(34.05 \%)$ \\
\hline Every Two Weeks & $105(32.31 \%)$ & $10(21.74 \%)$ & $26(9.32 \%)$ \\
\hline Every Three Weeks & $27(8.31 \%)$ & $1(2.17 \%)$ & $119(42.65 \%)$ \\
\hline Once a Month & $149(45.84 \%)$ & $30(65.23 \%)$ & $10(3.58 \%)$ \\
\hline Greater than Once a Month & $13(4.00 \%)$ & $3(6.52 \%)$ & $13(4.66 \%)$ \\
\hline Other & $14(4.31 \%)$ & $1(2.17 \%)$ & \\
\hline
\end{tabular}

During month three, the majority of pediatricians (52.18\%) reported monitoring children on antidepressants at some time interval greater than one month, while another $39.13 \%$ indicated they monitor children once a month. The majority of child psychiatrists $(62.72 \%)$ monitor children taking an antidepressant once a month with another $20.43 \%$ indicating they monitor children at some 
interval greater than once a month. Results for the frequency of monitoring children during the third month of antidepressant treatment are listed in Table 4.37 .

Table 4.37: Frequency of Antidepressant Monitoring: Month Three

\begin{tabular}{|l|c|c|c|}
\hline & $\begin{array}{c}\text { All Physicians } \\
(\mathbf{N})\end{array}$ & $\begin{array}{c}\text { Pediatricians } \\
(\mathbf{N})\end{array}$ & $\begin{array}{c}\text { Child Psychiatrists } \\
(\mathbf{N})\end{array}$ \\
\hline Frequency of Monitoring: & & & $2(0.72 \%)$ \\
\hline Two Times per Week & $2(0.62 \%)$ & $0(0.00 \%)$ & $7(2.51 \%)$ \\
\hline Once a Week & $7(2.15 \%)$ & $0(0.00 \%)$ & $11(3.94 \%)$ \\
\hline Every Two Weeks & $12(3.69 \%)$ & $1(2.17 \%)$ & $13(4.66 \%)$ \\
\hline Every Three Weeks & $15(4.62 \%)$ & $2(4.35 \%)$ & $175(62.72 \%)$ \\
\hline Once a Month & $193(59.38 \%)$ & $18(39.13 \%)$ & $57(20.43 \%)$ \\
\hline Greater than Once a Month & $81(24.92 \%)$ & $24(52.18 \%)$ & $14(5.02 \%)$ \\
\hline Other & $15(4.62 \%)$ & $1(2.17 \%)$ & \\
\hline
\end{tabular}

Objective 12: To determine differences in antidepressant monitoring for newly diagnosed children with major depressive disorder and the United States Food and Drug Administration (U.S. FDA) recommendations for monitoring children treated with antidepressants.

Null Hypothesis 12.0: There is no difference in pharmacotherapy monitoring for newly diagnosed children with major depressive disorder and the U.S. FDA recommendations for monitoring children treated with antidepressants.

The frequencies associated with physician monitoring of children treated with antidepressant medication was provided in Objective \#11. This information was gained from the Phase II survey as physicians were asked to indicate how often they monitored children on antidepressant therapy during the first, second, and third-months of treatment. Physicians could answer this question as follows: "two times per week", "once a week", "every two weeks', "every three weeks", “once a month", greater than once a month", or "other". These variables are categorical in nature. So that comparisons could be made to the U.S. FDA recommendations, these categorical variables needed to be transformed into continuous variables. Therefore, to compute an average number of times per month, the physicians' answers were transformed into a number corresponding to the number of times per month physicians monitored children. This was done as follows: "two times per week" was transformed into eight times per month, "once a week" was transformed into four times a month, "every two weeks" was transformed into two times per month, "every three weeks" was 
transformed into 1.4 times per month, “once a month" was transformed into 1 time per month, and "greater than once a month" was transformed into .5 times per month. In this case the "other" category was eliminated from the analysis. Frequencies of the transformed variables are provided below in Tables 4.38, 4.39, and 4.40.

Table 4.38: Recoded Frequency of Antidepressant Monitoring: Month One

\begin{tabular}{|c|c|c|c|}
\hline $\begin{array}{l}\text { Frequency of Monitoring } \\
\text { (Number of Times per } \\
\text { Month) : }\end{array}$ & $\begin{array}{c}\text { All Physicians } \\
(\mathbf{N})\end{array}$ & $\begin{array}{c}\text { Pediatricians } \\
(\mathbf{N})\end{array}$ & $\begin{array}{c}\text { Child Psychiatrists } \\
(\mathbf{N})\end{array}$ \\
\hline $\mathbf{0 . 5}$ & 0 & 0 & 0 \\
\hline $\mathbf{1}$ & 36 & 2 & 34 \\
\hline $\mathbf{1 . 4}$ & 12 & 0 & 12 \\
\hline $\mathbf{2}$ & 111 & 25 & 86 \\
\hline $\mathbf{4}$ & 134 & 18 & 116 \\
\hline $\mathbf{8}$ & 3 & 0 & 3 \\
\hline
\end{tabular}

Table 4.39: Recoded Frequency of Antidepressant Monitoring: Month Two

\begin{tabular}{|c|c|c|c|}
\hline $\begin{array}{l}\text { Frequency of Monitoring } \\
\text { (Number of Times per } \\
\text { Month): }\end{array}$ & $\begin{array}{c}\text { All Physicians } \\
(\mathbf{N})\end{array}$ & $\begin{array}{c}\text { Pediatricians } \\
(\mathbf{N})\end{array}$ & $\begin{array}{c}\text { Child Psychiatrists } \\
(\mathbf{N})\end{array}$ \\
\hline $\mathbf{0 . 5}$ & 13 & 3 & 10 \\
\hline $\mathbf{1}$ & 149 & 30 & 119 \\
\hline $\mathbf{1 . 4}$ & 27 & 1 & 26 \\
\hline $\mathbf{2}$ & 105 & 10 & 95 \\
\hline $\mathbf{4}$ & 14 & 0 & 14 \\
\hline $\mathbf{8}$ & 3 & 1 & 2 \\
\hline
\end{tabular}

Table 4.40: Recoded Frequency of Antidepressant Monitoring: Month Three

\begin{tabular}{|c|c|c|c|}
\hline $\begin{array}{l}\text { Frequency of Monitoring } \\
\text { (Number of Times per } \\
\text { Month): }\end{array}$ & $\begin{array}{c}\text { All Physicians } \\
(\mathbf{N})\end{array}$ & $\begin{array}{c}\text { Pediatricians } \\
(\mathbf{N})\end{array}$ & $\begin{array}{c}\text { Child Psychiatrists } \\
(\mathbf{N})\end{array}$ \\
\hline $\mathbf{0 . 5}$ & 81 & 24 & 57 \\
\hline $\mathbf{1}$ & 193 & 18 & 175 \\
\hline $\mathbf{1 . 4}$ & 15 & 2 & 13 \\
\hline $\mathbf{2}$ & 12 & 1 & 11 \\
\hline $\mathbf{4}$ & 7 & 0 & 2 \\
\hline $\mathbf{8}$ & 2 & 0 & 7 \\
\hline
\end{tabular}

The U.S. FDA made recommendations that a child receiving antidepressant treatment should be seen by a physician once per week for the first four weeks of treatment (U.S. FD, 2005). During the second month of treatment the patient should be seen biweekly and at week 12 during the third month (U.S. FDA, 2005). Comparisons were made between the U.S.FDA recommendations and the 
number of times per month the physicians reported monitoring children, during the first three months of antidepressant treatment. Pediatricians $(\mathrm{t}=-7.967, \mathrm{p}=0.000)$ and child psychiatrists $(\mathrm{t}=-$ 14.004, $\mathrm{p}=0.000$ ) monitor significantly less than the U.S. FDA recommended four times, during the first month of treatment. During the second month of treatment again, both pediatricians $(\mathrm{t}=-3.905$, $\mathrm{p}=0.000)$ and child psychiatrists $(\mathrm{t}=-7.156, \mathrm{p}=0.000)$ monitor significantly less than the U.S. FDA recommended two times per month. The findings show that pediatricians $(\mathrm{t}=-4.507, \mathrm{p}=0.000)$ still monitor significantly less than the U.S. FDA recommendations, during the third month of treatment. However, child psychiatrists' $(\mathrm{t}=1.660, \mathrm{p}=0.098)$ monitoring does not differ significantly from the U.S. FDA recommendations of one time during month three. These comparisons are listed in Table 4.41 .

Table 4.41: Comparisons of Physician Monitoring to U. S. FDA Recommendations

\begin{tabular}{|l|c|c|c|}
\hline & Mean \pm SD & Test Statistic & Significance (p) \\
\hline Month One: & & & \\
All Physicians & $2.820 \pm 1.282$ & $\mathrm{t}=-15.827$ & $0.000^{*}$ \\
Pediatricians & $2.756 \pm 1.048$ & $\mathrm{t}=-7.967$ & $0.000^{*}$ \\
Child Psychiatrists & $2.832 \pm 1.322$ & $\mathrm{t}=-14.004$ & $0.000^{*}$ \\
\hline Month Two: & & & \\
All Physicians & $1.554 \pm 0.967$ & $\mathrm{t}=-8.130$ & $0.000^{*}$ \\
Pediatricians & $1.272 \pm 1.111$ & $\mathrm{t}=-3.905$ & $0.000^{*}$ \\
Child Psychiatrists & $1.588 \pm 0.939$ & $\mathrm{t}=-7.156$ & $0.000^{*}$ \\
\hline Month Three: & & & \\
All Physicians & $1.040 \pm 0.795$ & $\mathrm{t}=0.893$ & 0.372 \\
Pediatricians & $0.773 \pm 0.337$ & $\mathrm{t}=-4.507$ & $0.000^{*}$ \\
Child Psychiatrists & $1.086 \pm 0.840$ & $\mathrm{t}=1.660$ & 0.098 \\
\hline
\end{tabular}

*Significant at $\mathrm{p} \leq 0.05, \mathrm{SD}=$ Standard Deviation, U.S. FDA= United States Food and Drug Administration

Objective 13: To determine whether there are differences, by physician type, in the average number of times per month physicians monitor children with major depressive disorder.

Null Hypothesis 13.0: There is no difference, by physician type, in the average number of times per month physicians monitor children with major depressive disorder.

The hypothesis that there is no difference by physician type (pediatricians versus child psychiatrists) in the average number of times per month physicians monitor children was tested. The survey for Phase II asked physicians to indicate how often they monitored children on antidepressant 
therapy during the first, second, and third-months of treatment. Physicians could answer this question as follows: "two times per week", “once a week”, “every two weeks', “every three weeks”, “once a month", greater than once a month", or "other". To compute an average number of times per month that physicians monitor children on antidepressant therapy, the categorical variables above, were converted to the number of times per month physicians monitored children. This was accomplished by transforming the variables as follows: "two times per week" was transformed into eight times per month, "once a week" was transformed into four times a month, "every two weeks" was transformed into two times per month, "every three weeks" was transformed into 1.4 times per month, "once a month" was transformed into 1 time per month, and "greater than once a month" was transformed into .5 times per month. After recoding, the average number of times per month that physicians monitor children, were computed for each group of physicians. The results are provided above in Tables 4.38. 4.39, and 4.40.

Next, comparisons for months one, two, and three, of the average number of times per month pediatricians monitor children could be made with the average number of times child psychiatrists monitor children. The Levene's test for equality of variances was first conducted on each of the comparisons. If the Levene's test for equality was significant then equal variances could not be assumed. If the Levene's test for equality was not significant then equal variances were assumed. Next, the appropriate two sample t-test, either for the assumption of equal variances or unequal variances was conducted. The results are listed below in Table 4.42. 
Table 4.42: Comparison of Pediatricians and Child Psychiatrists Monitoring of Children

\begin{tabular}{|l|c|c|c|}
\hline & Mean \pm SD & Test Statistic & p-value \\
\hline Month One: & $2.76 \pm 1.05$ & $t=-0.431$ & 0.668 \\
Pediatricians & $2.83 \pm 1.32$ & & \\
Child Psychiatrists & & & \\
\hline Month Two: & $1.35 \pm 1.11$ & $t=-1.508$ & 0.133 \\
Pediatricians & $1.59 \pm 0.94$ & & \\
\hline Monild Psychiatrists & $0.77 \pm 0.34$ & $t=-2.457$ & $0.015^{*}$ \\
Pediatricians & $1.09 \pm 0.84$ & & \\
Child Psychiatrists & & &
\end{tabular}

* Significant at $\mathrm{p} \leq 0.05$

The average number of times physicians (pediatricians versus child psychiatrists) monitored children did not significantly differ during the first $(p=0.668)$ and second months $(p=0.133)$ of antidepressant treatment. However, during the third month of treatment there was a significant difference in the average number of times, pediatricians versus child psychiatrists, monitored children on antidepressant therapy. Child psychiatrists monitored significantly $(p=0.015)$ more than pediatricians during the third month of treatment. Therefore, Null Hypothesis 13.0: There is no difference, by physician type, in the average number of times per month physicians monitor children with major depressive disorder, will fail to be rejected for months one and two, and will be rejected for month three of treatment.

\section{Phase II: Results for Adolescents with Major Depressive Disorder- Objectives 14-22}

Objectives 14 through 22 are identical to Objectives 1 through 13 for children with major depressive disorder except the population studied were adolescents (13 through 18 years of age) with major depressive disorder.

Objective 14: To determine the demographic characteristics of physicians who treat newly diagnosed adolescents with major depressive disorder.

Of those physicians from phase II who indicated they treat adolescents with major depressive disorder 57 (16.06\%) were pediatricians and $298(83.94 \%)$ were child psychiatrists. The majority of physicians who treat adolescents with major depressive disorder are males (61.25\%). Additionally, 
the majority $(66.10 \%)$ of the respondents who treat adolescents indicated they are between 41 and 60 years of age. The year of graduation from medical school varied: $33.03 \%$ indicated they graduated in $1986-1995,27.83 \%$ indicated they graduated in $1976-1985,20.18 \%$ indicated they graduated in $1966-1975,11.93 \%$ indicated they graduated in $1996-2003$, and only $7.03 \%$ graduated in 1965 or earlier. Approximately sixty percent, $(57.55 \%)$ of the physicians indicated their primary practice site was private-based, as opposed to hospital-based. The geographic region of the physicians' primary practice site varied: $29.29 \%$ practice in the South, 26.63\% practice in the Midwest, 23.08\% practice in the Northeast, $20.41 \%$ practice in the West, and only $0.59 \%$ practice in the Pacific. The population of the primary practice area varied as $34.40 \%$ have primary practice sites in areas with $50,000-249,999$ people, $25.36 \%$ practice in areas with a population of 1 million or more people, $24.78 \%$ practice in areas with 250,000 - 999,999 people, and $15.45 \%$ practice in areas with 50,000 people or less. The majority $(70.74 \%)$ of the physicians indicated specialties of both adult and child psychiatry, and the majority (54.89\%) are board certified as both adult psychiatrists and child psychiatrists. The practice volume also varied somewhat, however the majority of physicians indicated they treat both, 10 or less children (72.01\%) and 10 or less adolescents $(56.85 \%)$ per week. Approximately three-fourths, $(75.57 \%)$ of physicians, indicated they have treated adolescents for greater than 10 years. The demographics of physicians who treat adolescents with major depressive disorder are shown below in Table 4.43 . 
Table 4.43: Demographics of Physicians Who Treat Adolescents for Major Depressive Disorder

\begin{tabular}{|c|c|}
\hline Variable & $\mathbf{N}(\%)$ \\
\hline $\begin{array}{l}\text { Type of Physician: } \\
\text { Pediatricians } \\
\text { Child Psychiatrists }\end{array}$ & $\begin{array}{c}57(16.06 \%) \\
298(83.94 \%)\end{array}$ \\
\hline $\begin{array}{l}\text { Gender: } \\
\text { Male } \\
\text { Female } \\
\end{array}$ & $\begin{array}{l}215(61.25 \%) \\
136(38.75 \%)\end{array}$ \\
\hline $\begin{array}{l}\text { Age: } \\
40 \text { years or younger } \\
41 \text { years }-60 \text { years } \\
61 \text { years or older } \\
\end{array}$ & $\begin{array}{c}45(12.82 \%) \\
232(66.10 \%) \\
74(21.08 \%)\end{array}$ \\
\hline $\begin{array}{l}\text { Year Graduated from Medical School: } \\
1965 \text { or Before } \\
1966-1975 \\
1976-1985 \\
1986-1995 \\
1996-2003 \\
\end{array}$ & $\begin{array}{c}23(7.03 \%) \\
66(20.18 \%) \\
91(27.83 \%) \\
108(33.03 \%) \\
39(11.93 \%) \\
\end{array}$ \\
\hline $\begin{array}{l}\text { Primary Practice Site: } \\
\text { Private Based Practice } \\
\text { Hospital Based Practice } \\
\text { Other (ex. hospital and private) } \\
\end{array}$ & $\begin{array}{c}202(57.55 \%) \\
67(19.09 \%) \\
82(23.36 \%) \\
\end{array}$ \\
\hline $\begin{array}{l}\text { Geographic Location of Practice: } \\
\text { Northeast } \\
\text { South } \\
\text { Midwest } \\
\text { West } \\
\text { Pacific } \\
\end{array}$ & $\begin{array}{l}78(23.08 \%) \\
99(29.29 \%) \\
90(26.63 \%) \\
69(20.41 \%) \\
2(0.59 \%) \\
\end{array}$ \\
\hline $\begin{array}{l}\text { Population of Practice Area: } \\
\text { Less than } 50,000 \\
50,000-249,999 \\
250,000-999,999 \\
1 \text { million or more } \\
\end{array}$ & $\begin{array}{c}53(15.45 \%) \\
118(34.40 \%) \\
85(24.78 \%) \\
87(25.35 \%) \\
\end{array}$ \\
\hline $\begin{array}{l}\text { Physician Specialty: } \\
\text { Child Psychiatrist } \\
\text { Pediatrics } \\
\text { Adult and Child Psychiatrist } \\
\text { Other (ex. adult and child psychiatry and general practice) }\end{array}$ & $\begin{array}{c}36(10.23 \%) \\
52(14.77 \%) \\
249(70.74 \%) \\
15(4.26 \%)\end{array}$ \\
\hline $\begin{array}{l}\text { Board Certification: } \\
\text { Adult Psychiatrist } \\
\text { Child Psychiatrist } \\
\text { General Practitioner } \\
\text { Pediatrician } \\
\text { Adult and Child Psychiatrist } \\
\text { Other (ex. adult and child psychiatry and pediatrics) } \\
\text { Not Board Certified }\end{array}$ & $\begin{array}{c}59(16.95 \%) \\
1(0.29 \%) \\
1(0.29 \%) \\
56(16.09 \%) \\
191(54.89 \%) \\
18(5.17 \%) \\
22(6.32 \%)\end{array}$ \\
\hline $\begin{array}{l}\text { Child Patient Volume Per Week: } \\
10 \text { or less } \\
11-40 \\
41-80 \\
81 \text { or greater } \\
\end{array}$ & $\begin{array}{c}247(72.01 \%) \\
79(23.03 \%) \\
14(4.08 \%) \\
3(0.87 \%) \\
\end{array}$ \\
\hline $\begin{array}{l}\text { Adolescent Patient Volume Per Week: } \\
10 \text { or less } \\
11-40 \\
41-80 \\
81 \text { greater }\end{array}$ & $\begin{array}{c}195(56.85 \%) \\
126(36.73 \%) \\
16(4.66 \%) \\
6(1.75 \%) \\
\end{array}$ \\
\hline $\begin{array}{l}\text { Number of Years Treating Children and/or Adolescents: } \\
\text { Greater than } 1 \text { to } 5 \text { years } \\
\text { Greater than } 5 \text { to } 10 \text { years } \\
\text { Greater than } 10 \text { years }\end{array}$ & $\begin{array}{c}25(7.18 \%) \\
60(17.24 \%) \\
263(75.57 \%)\end{array}$ \\
\hline
\end{tabular}


Objective 15: To determine physicians' first line of treatment for newly diagnosed adolescents with major depressive disorder by: a) type of treatment, b) drug category, and c) specific antidepressant prescribed.

A majority of physicians, both pediatricians (87.72\%) and child psychiatrists $(76.95 \%)$ indicated their preferred first-line of treatment for adolescents with major depressive disorder is a combination treatment of antidepressants and counseling. Counseling only was the next most frequently preferred choice as a first-line of treatment of both pediatricians $(8.77 \%)$ and child psychiatrists $(15.93 \%)$. Few pediatricians $(3.51 \%)$ and child psychiatrists $(0.68 \%)$ indicated they use antidepressants only as a first-line of treatment for adolescents. These results are shown in Table 4.44.

Table 4.44: First-Line of Treatment for Adolescents with Major Depressive Disorder

\begin{tabular}{|c|c|c|c|}
\hline Type of Treatment & $\begin{array}{c}\text { All } \\
\text { Physicians } \\
\text { N }(\%)\end{array}$ & $\begin{array}{c}\text { Pediatricians } \\
\text { N (\%) }\end{array}$ & $\begin{array}{c}\text { Child } \\
\text { Psychiatrists } \\
\text { N }(\%)\end{array}$ \\
\hline Antidepressants Only & $4(1.14 \%)$ & $2(3.51 \%)$ & $2(0.68 \%)$ \\
\hline Counseling/Psychotherapy Only & $52(14.77 \%)$ & $5(8.77 \%)$ & $47(15.93 \%)$ \\
\hline Both Antidepressants and Counseling & $\begin{array}{c}277 \\
(78.69 \%)\end{array}$ & $50(87.72 \%)$ & $\begin{array}{c}227 \\
(76.95 \%)\end{array}$ \\
\hline Other Treatment & $19(5.40 \%)$ & $0(0.00 \%)$ & $19(6.44 \%)$ \\
\hline
\end{tabular}

In the event the physicians utilized antidepressants as a first-line of treatment, all pediatricians $(100.00 \%)$ indicated their first-line of treatment would include an SSRI type antidepressant. Over ninety percent $(94.67 \%)$ of the child psychiatrists also indicated they would utilize an SSRI type antidepressant. The results per antidepressant class, associated with the first-line treatment, for adolescents are displayed in Table 4.45 .

The specific type of antidepressant varied somewhat for both pediatricians and child psychiatrists. Similar to the findings in the child population, the majority of pediatricians and child psychiatrists indicated they would utilize either Prozac ${ }^{\circledR}$ or Zoloft ${ }^{\circledR}$ in their first-line of treatment for adolescents with major depressive disorder. For first-line treatment, $44.23 \%$ of pediatricians indicated they would utilize Prozac ${ }^{\circledR}$ and 50.21\% indicated they would utilize Zoloft ${ }^{\circledR}$. For first-line treatment 
$38.46 \%$ of the child psychiatrists indicated they would utilize Prozac ${ }^{\circledR}$ and $19.84 \%$ indicated they would utilize Zoloft ${ }^{\circledR}$ as part of their first-line of treatment for adolescents with major depressive disorder. The specific antidepressants utilized by physicians as a first-line of treatment for adolescents can be found in Table 4.46 .

Table 4.45: Therapeutic Category of Antidepressant Used as First-Line of Treatment for Adolescents

\begin{tabular}{|l|c|c|c|}
\hline \multicolumn{1}{|c|}{ Drug Class } & $\begin{array}{c}\text { All } \\
\text { Physicians } \\
\text { N (\%) }\end{array}$ & $\begin{array}{c}\text { Pediatricians } \\
\mathbf{N}(\%)\end{array}$ & $\begin{array}{c}\text { Child } \\
\text { Psychiatrists } \\
\text { N (\%) }\end{array}$ \\
\hline Tricyclic Antidepressants (TCAs) & $1(0.34 \%)$ & $0(0.00 \%)$ & $1(0.41 \%)$ \\
\hline Tetracyclic Antidepressants & $1(0.34 \%)$ & $0(0.00 \%)$ & $1(0.41 \%)$ \\
\hline $\begin{array}{l}\text { Selective Serotonin Reuptake Inhibitors } \\
\text { (SSRIs) }\end{array}$ & $281(95.58 \%)$ & $50(100.00 \%)$ & $231(94.67 \%)$ \\
\hline $\begin{array}{l}\text { Selective-norepinephrine Reuptake } \\
\text { Inhibitors (SNRIs) }\end{array}$ & $1(0.34 \%)$ & $0(0.00 \%)$ & $1(0.41 \%)$ \\
\hline $\begin{array}{l}\text { Norepinephrine and Dopamine } \\
\text { Reuptake Inhibitors (NDRIs) }\end{array}$ & $10(3.40 \%)$ & $0(0.00 \%)$ & $10(4.10 \%)$ \\
\hline
\end{tabular}

Table 4.46: Specific Antidepressant Used as First-Line of Treatment for Adolescents

\begin{tabular}{|c|c|c|c|}
\hline Antidepressant & $\begin{array}{c}\text { All } \\
\text { Physicians } \\
\text { N }(\%)\end{array}$ & $\begin{array}{c}\text { Pediatricians } \\
\text { N }(\%)\end{array}$ & $\begin{array}{c}\text { Child } \\
\text { Psychiatrists } \\
\text { N }(\%)\end{array}$ \\
\hline $\operatorname{Prozac}^{(\mathbb{R}}$ & $147(49.16 \%)$ & $23(44.23 \%)$ & $124(50.21 \%)$ \\
\hline Zoloft $^{(R)}$ & $69(23.08 \%)$ & $20(38.46 \%)$ & $49(19.84 \%)$ \\
\hline Celexa $^{\circledR}$ & $31(10.37 \%)$ & $5(9.61 \%)$ & $26(10.53 \%)$ \\
\hline Lexapro $^{(R)}$ & $33(11.04 \%)$ & $2(3.85 \%)$ & $31(12.55 \%)$ \\
\hline Wellbutrin $^{(B)}$ & $10(3.35 \%)$ & $0(0.00 \%)$ & $10(4.05 \%)$ \\
\hline Tofranil $^{(\mathbb{R})}$ & $1(0.33 \%)$ & $0(0.00 \%)$ & $1(0.40 \%)$ \\
\hline Cymbalta $^{(B)}$ & $1(0.33 \%)$ & $0(0.00 \%)$ & $1(0.40 \%)$ \\
\hline Remeron $^{\left({ }^{B}\right.}$ & $1(0.33 \%)$ & $0(0.00 \%)$ & $1(0.40 \%)$ \\
\hline $\begin{array}{l}\text { Listed multiple } \\
\text { antidepressants }\end{array}$ & $6(2.01 \%)$ & $2(3.85 \%)$ & $4(1.62 \%)$ \\
\hline
\end{tabular}

Objective 16: To determine physicians' second and third lines of treatment for newly diagnosed adolescents with major depressive disorder by: a) drug category, and b) specific antidepressant prescribed.

In the event the first-line of treatment is not successful, the majority of pediatricians, $68.43 \%$, indicated they would switch an adolescent patient to a different antidepressant. Also, approximately seventy percent (72.73\%) of child psychiatrists reported switching an adolescent patient to a 
different antidepressant. The results for physicians' second-line of treatment for adolescents are shown in Table 4.47.

Table 4.47: Second-Line of Treatment for Adolescents with Major Depressive Disorder

\begin{tabular}{|l|c|c|c|}
\hline \multicolumn{1}{|c|}{ Type of Treatment } & $\begin{array}{c}\text { All } \\
\text { Physicians } \\
\mathbf{N}(\mathbf{\%})\end{array}$ & $\begin{array}{c}\text { Pediatricians } \\
\mathbf{N}(\mathbf{\%})\end{array}$ & $\begin{array}{c}\text { Child } \\
\text { Psychiatrists } \\
\mathbf{N}(\mathbf{\%})\end{array}$ \\
\hline Augment with Antidepressants & $63(17.80 \%)$ & $5(8.77 \%)$ & $58(19.53 \%)$ \\
\hline Switch to a Different Antidepressant & $\begin{array}{c}255 \\
(72.03 \%)\end{array}$ & $39(68.43 \%)$ & $\begin{array}{c}216 \\
(72.73 \%)\end{array}$ \\
\hline Augment with Counseling\Psychotherapy & $15(4.24 \%)$ & $7(12.28 \%)$ & $8(2.69 \%)$ \\
\hline Switch or Augment with Antidepressant & $4(1.13 \%)$ & $1(1.75 \%)$ & $3(1.01 \%)$ \\
\hline Other Treatment & $17(4.80 \%)$ & $5(8.77 \%)$ & $12(4.04 \%)$ \\
\hline
\end{tabular}

As was the case for the first-line of treatment, the majority of pediatricians $(86.37 \%)$ and child psychiatrists $(74.00 \%)$ indicated they utilize SSRIs a part of the second-line of treatment for adolescents with major depressive disorder. The SSRIs most often utilized as part of the second-line of treatment by pediatricians are Prozac ${ }^{\circledR}(30.43 \%)$, Zoloft ${ }^{\circledR}(19.57 \%)$, and Celexa ${ }^{\circledR}(15.22 \%)$.

Whereas, the SSRIs most often utilized as part of the second-line of treatment by child psychiatrists $\operatorname{are~Prozac}^{\circledR}(18.73 \%)$, Zoloft $^{\circledR}(23.97 \%)$, and Celexa ${ }^{\circledR}(8.99 \%)$. The antidepressant drug categories and specific antidepressants utilized by physicians as part of their second-line of treatment for adolescents with major depressive disorder are listed in Tables 4.48 and 4.49.

Table 4.48: Therapeutic Category of Antidepressant used as Second-Line of Treatment for Adolescents

\begin{tabular}{|c|c|c|c|}
\hline Drug Class & $\begin{array}{c}\text { All } \\
\text { Physicians } \\
\text { N }(\%)\end{array}$ & $\begin{array}{c}\text { Pediatricians } \\
\text { N }(\%)\end{array}$ & $\begin{array}{c}\text { Child } \\
\text { Psychiatrists } \\
\text { N }(\%)\end{array}$ \\
\hline $\begin{array}{l}\text { Tricyclic Antidepressants } \\
\text { (TCAs) }\end{array}$ & $2(0.68 \%)$ & $0(0.00 \%)$ & $2(0.80 \%)$ \\
\hline Tetracyclic Antidepressants & $1(0.34 \%)$ & $0(0.00 \%)$ & $1(0.40 \%)$ \\
\hline $\begin{array}{l}\text { Selective Serotonin Reuptake } \\
\text { Inhibitors (SSRIs) }\end{array}$ & $223(75.85 \%)$ & $38(86.37 \%)$ & $185(74.00 \%)$ \\
\hline $\begin{array}{l}\text { Selective-norepinephrine } \\
\text { Reuptake Inhibitors (SNRIs) }\end{array}$ & $27(9.18 \%)$ & $1(2.27 \%)$ & $26(10.40 \%)$ \\
\hline $\begin{array}{l}\text { Norepinephrine and } \\
\text { Dopamine Reuptake } \\
\text { Inhibitors (NDRIs) }\end{array}$ & $41(13.95 \%)$ & $5(11.36 \%)$ & $36(14.40 \%)$ \\
\hline
\end{tabular}


Table 4.49: Specific Antidepressant Used as Second-Line of Treatment for Adolescents

\begin{tabular}{|c|c|c|c|}
\hline Antidepressant & $\begin{array}{c}\text { All } \\
\text { Physicians } \\
\text { N }(\%)\end{array}$ & $\begin{array}{c}\text { Pediatricians } \\
\text { N }(\%)\end{array}$ & $\begin{array}{c}\text { Child } \\
\text { Psychiatrists } \\
\text { N }(\%)\end{array}$ \\
\hline $\operatorname{Prozac}^{(\mathbb{R}}$ & $64(20.45 \%)$ & $14(30.43 \%)$ & $50(18.73 \%)$ \\
\hline Zoloft $^{(R)}$ & $73(23.32 \%)$ & $9(19.57 \%)$ & $64(23.97 \%)$ \\
\hline Celexa $^{(B)}$ & $31(9.90 \%)$ & $7(15.22 \%)$ & $24(8.99 \%)$ \\
\hline Lexapro $^{(R)}$ & $28(8.95 \%)$ & $4(8.70 \%)$ & $24(8.99 \%)$ \\
\hline Wellbutrin ${ }^{(R)}$ & $41(13.10 \%)$ & $5(10.87 \%)$ & $36(13.48 \%)$ \\
\hline Cymbalta $^{(B)}$ & $13(4.15 \%)$ & $0(0.00 \%)$ & $13(4.87 \%)$ \\
\hline Effexor $^{(R)}$ & $13(4.15 \%)$ & $1(2.17 \%)$ & $12(4.50 \%)$ \\
\hline Remeron $^{(B)}$ & $1(0.32 \%)$ & $0(0.00 \%)$ & $1(0.37 \%)$ \\
\hline Pamelor $^{(R)}$ & $2(0.64 \%)$ & $0(0.00 \%)$ & $2(0.75 \%)$ \\
\hline Paxil $^{(\mathbb{R}}$ & $3(0.96 \%)$ & $2(4.34 \%)$ & $1(0.37 \%)$ \\
\hline $\begin{array}{l}\text { Listed multiple } \\
\text { antidepressants }\end{array}$ & $44(14.06 \%)$ & $4(8.70 \%)$ & $40(14.98 \%)$ \\
\hline
\end{tabular}

In the event the second-line of treatment for major depressive disorder in adolescents is not successful, pediatricians $(52.00 \%)$ indicated using some “other' type of treatment for adolescents. In contrast, the majority $(66.43 \%)$ of child psychiatrists indicated they would switch another type of antidepressant and $20.00 \%$ of the child psychiatrists reported they would try some "other" type of treatment. Table 4.50 shows the results for physicians' third-line of treatment for adolescents with major depressive disorder.

Table 4.50: Third-Line of Treatment for Adolescents with Major Depressive Disorder

\begin{tabular}{|l|c|c|c|}
\hline \multicolumn{1}{|c|}{ Type of Treatment } & $\begin{array}{c}\text { All } \\
\text { Physicians } \\
\mathbf{N}(\mathbf{\%})\end{array}$ & $\begin{array}{c}\text { Pediatricians } \\
\mathbf{N}(\mathbf{\%})\end{array}$ & $\begin{array}{c}\text { Child } \\
\text { Psychiatrists } \\
\mathbf{N}(\boldsymbol{\%})\end{array}$ \\
\hline Augment with Antidepressants & $28(8.26 \%)$ & $1(2.00 \%)$ & $27(9.34 \%)$ \\
\hline Switch to a Different Antidepressant & $\begin{array}{c}172 \\
(50.74 \%)\end{array}$ & $8(16.00 \%)$ & $\begin{array}{c}164 \\
(56.75 \%)\end{array}$ \\
\hline Augment with Counseling Psychotherapy & $32(9.44 \%)$ & $11(22.00 \%)$ & $21(7.27 \%)$ \\
\hline Switch or Augment with Antidepressant & $5(1.47 \%)$ & $2(4.00 \%)$ & $3(1.04 \%)$ \\
\hline Switch or Refer Patient & $2(0.59 \%)$ & $2(4.00 \%)$ & $0(0.00 \%)$ \\
\hline Switch or Other Treatment & $4(1.18 \%)$ & $0(0.00 \%)$ & $4(1.38 \%)$ \\
\hline Other Treatment & $96(28.32 \%)$ & $26(52.00 \%)$ & $70(24.22 \%)$ \\
\hline
\end{tabular}

The majority of the pediatricians $(96.15 \%)$, who indicated they would use some "other" treatment as the third-line for adolescents, specified they would refer these patients to psychiatry. In comparison, the majority of the child psychiatrists $(84.29 \%)$ who indicated they would utilize some 
"other" treatment reported the use of some other type of medication. These child psychiatrists

indicated they would use antipsychotics, mood stabilizers, anticonvulsants, thyroid medications, or a combination of these medications. The results for the "other" treatment may be found in Tables 4.51 and 4.52 .

Table 4.51: Pediatricians" "Other $3^{\text {rd }}$ Line of Treatment" for Adolescents

\begin{tabular}{|l|c|}
\hline \multicolumn{1}{|c|}{ Type of Treatment } & Pediatricians N (\%) \\
\hline Refer to Psychiatry & $25(96.15 \%)$ \\
\hline Antipsychotic & $1(3.85 \%)$ \\
\hline
\end{tabular}

Table 4.52: Child Psychiatrists" "Other $3^{\text {rd }}$ Line Treatment" for Adolescents

\begin{tabular}{|l|c|}
\hline \multicolumn{1}{|c|}{ Type of Treatment } & Child Psychiatrists N (\%) \\
\hline Antipsychotic & $14(20.00 \%)$ \\
\hline Mood Stabilizer & $13(18.57 \%)$ \\
\hline Anticonvulsant & $10(14.29 \%)$ \\
\hline Lithium & $11(15.71 \%)$ \\
\hline Combination of Antidepressants & $5(7.14 \%)$ \\
\hline Lithium or Thyroid & $2(2.86 \%)$ \\
\hline Antipsychotic or Anticonvulsant & $1(1.43 \%)$ \\
\hline Mood Stabilizer or Antipsychotic & $1(1.43 \%)$ \\
\hline Thyroid or Anticonvulsant & $1(1.43 \%)$ \\
\hline Benzodiazepine & $1(1.43 \%)$ \\
\hline $\begin{array}{l}\text { Other: Re-evaluate environment, } \\
\text { hospitalization, other counseling, etc }\end{array}$ & $11(15.71 \%)$ \\
\hline
\end{tabular}

Of those reporting, the third-line of treatment for adolescents included the use of either an SSRI or NDRI for the majority of pediatricians and child psychiatrists. Pediatricians utilized either SSRIs $(46.15 \%)$ or NDRIs $(38.46 \%)$. In contrast, child psychiatrists reported using NDRIs (41.81\%) more often than SSRIs (33.33\%). Results for physicians' third-line of treatment for adolescents with major depressive disorder by drug category can found in Table 4.54 . 
Table 4.53: Therapeutic Category of Antidepressant Used as Third-Line of Treatment for Adolescents

\begin{tabular}{|l|c|c|c|}
\hline \multicolumn{1}{|c|}{ Drug Class } & $\begin{array}{c}\text { All } \\
\text { Physicians N } \\
(\mathbf{\%})\end{array}$ & $\begin{array}{c}\text { Pediatricians } \\
\mathbf{N}(\mathbf{\%})\end{array}$ & $\begin{array}{c}\text { Child } \\
\text { Psychiatrists } \\
\mathbf{N}(\boldsymbol{\%})\end{array}$ \\
\hline $\begin{array}{l}\text { Tricyclic Antidepressants } \\
\text { (TCAs) }\end{array}$ & $1(0.53 \%)$ & $0(0.00 \%)$ & $1(0.56 \%)$ \\
\hline Tetracyclic Antidepressants & $1(0.53 \%)$ & $0(0.00 \%)$ & $1(0.56 \%)$ \\
\hline $\begin{array}{l}\text { Selective Serotonin Reuptake } \\
\text { Inhibitors (SSRIs) }\end{array}$ & $65(34.21 \%)$ & $6(46.15 \%)$ & $59(33.33 \%)$ \\
\hline $\begin{array}{l}\text { Selective-norepinephrine } \\
\text { Reuptake Inhibitors (SNRIs) }\end{array}$ & $43(22.63 \%)$ & $2(15.39 \%)$ & $41(23.16 \%)$ \\
\hline $\begin{array}{l}\text { Norepinephrine and } \\
\text { Dopamine Reuptake } \\
\text { Inhibitors (NDRIs) }\end{array}$ & $79(41.57 \%)$ & $5(38.46 \%)$ & $74(41.81 \%)$ \\
\hline Other Antidepressants & $1(0.53 \%)$ & $0(0.00 \%)$ & $1(0.56 \%)$ \\
\hline
\end{tabular}

Of those reporting, approximately one-third of pediatricians $(31.25 \%)$ and child psychiatrists $(37.76 \%)$ indicated they would utilize Wellbutrin ${ }^{\circledR}$, as part of their third-line treatment for adolescents. Although many physicians indicated the use of SSRIs the choice of the specific SSRI was varied. The most preferred antidepressant for third-line treatment by both pediatricians $(18.75 \%)$ and child psychiatrists $(37.76 \%)$ is Lexapro ${ }^{\circledR}$. The next most preferred antidepressant by child psychiatrists $(10.20 \%)$ was Zoloft ${ }^{\circledR}$. All other antidepressants were preferred by less than ten percent of both pediatricians and child psychiatrists. The results of the physicians' choice of antidepressant for the third-line of treatment for adolescents with major depressive disorder are listed in Table 4.54 . 
Table 4.54: Specific Antidepressant Used as Third-Line Treatment for Adolescents

\begin{tabular}{|c|c|c|c|}
\hline Antidepressant & $\begin{array}{c}\text { All } \\
\text { Physicians } \\
\text { N }(\%)\end{array}$ & $\begin{array}{l}\text { Pediatricians } \\
\text { N }(\%)\end{array}$ & $\begin{array}{c}\text { Child } \\
\text { Psychiatrists } \\
\text { N }(\%)\end{array}$ \\
\hline Prozac $^{(R)}$ & $8(3.77 \%)$ & $1(6.25 \%)$ & $7(3.57 \%)$ \\
\hline Zoloft $^{(R)}$ & $21(9.91 \%)$ & $1(6.25 \%)$ & $20(10.20 \%)$ \\
\hline Celexa $^{\left({ }^{(}\right)}$ & $11(5.19 \%)$ & $0(0.00 \%)$ & $11(5.61 \%)$ \\
\hline Lexapro $^{(\mathbb{R}}$ & $11(5.19 \%)$ & $3(18.75 \%)$ & $8(4.08 \%)$ \\
\hline Wellbutrin $^{(R)}$ & $79(37.26 \%)$ & $5(31.25 \%)$ & $74(37.76 \%)$ \\
\hline Cymbalta $^{(B)}$ & $10(4.72 \%)$ & $0(0.00 \%)$ & $10(5.10 \%)$ \\
\hline Effexor $^{(R)}$ & $29(13.68 \%)$ & $2(12.50 \%)$ & $27(13.78 \%)$ \\
\hline Tofranil $^{(\mathbb{R}}$ & $1(0.47 \%)$ & $0(0.00 \%)$ & $1(0.51 \%)$ \\
\hline Remeron $^{(R)}$ & $1(0.47 \%)$ & $0(0.00 \%)$ & $1(0.51 \%)$ \\
\hline Desyrel $^{(\circledR)}$ & $1(0.47 \%)$ & $0(0.00 \%)$ & $1(0.51 \%)$ \\
\hline Paxil $^{(B)}$ & $5(2.36 \%)$ & $1(6.25 \%)$ & $4(2.04 \%)$ \\
\hline Luvox $^{(R)}$ & $1(0.47 \%)$ & $0(0.00 \%)$ & $1(0.51 \%)$ \\
\hline $\begin{array}{l}\text { Listed multiple } \\
\text { antidepressants }\end{array}$ & $34(16.04 \%)$ & $3(18.75 \%)$ & $31(15.82 \%)$ \\
\hline
\end{tabular}

Objective 17: To determine the difference in first, second, and third lines of antidepressant treatment prescribed by physicians to newly diagnosed adolescents with major depressive disorder by a) the pharmacotherapy category and $b$ ) specific antidepressant prescribed.

Null Hypothesis 17.a: There is no difference in the pharmacotherapy category prescribed by physicians for first, second, and third lines of antidepressant treatment for newly diagnosed adolescents with major depressive disorder.

Null Hypothesis 17.b: There is no difference in the specific antidepressant prescribed by physicians for first, second, and third lines of treatment for newly diagnosed adolescents with major depressive disorder.

In order to determine whether there is an association between the first, second, and third lines of antidepressant treatment and physician type several steps were required for the statistical analysis.

First, a series of $\chi^{2}$ tests, examined the association between two sets of variables: physician type (pediatrician versus child psychiatrist) and pharmacotherapy category (TCAs, Tetracyclics, SSRIs, SNRIs, NDRIs, and Other Antidepressants). Separate $\chi^{2}$ tests examined the association between the first-line of pharmacotherapy class and physician type, second-line of pharmacotherapy class and physician type, and third-line of pharmacotherapy class and physician type. Each of these three $\chi^{2}$ tests indicated no significance between the variables. Furthermore, over $20 \%$ of the cell counts for 
each of the tests were less than five. When this is the case the $\chi^{2}$ test is probably not a valid statistical test. Researchers can manage small expected values by collapsing or combining cells. In this study, groups of antidepressant categories were collapsed or combined. Since the majority of the scientific research has focused on utilizing SSRIs in treating adoelscents, it was decided to combine antidepressant categories into SSRIs and Non-SSRIs. After recoding the data into these two groups, $\chi^{2}$ tests were run to determine whether there was a relationship between physician type (pediatrician versus child psychiatrist) and the new antidepressant categories (SSRIs versus NonSSRIs) for first, second, and third-lines of treatment. Even after collapsing the antidepressant drugs by drug category the $\chi^{2}$ tests still resulted in small expected values. If this occurs, however, another statistic may be used to examine the associations between physician type and antidepressant categories. This statistic is the Fisher's exact test. The Fisher's exact test may be utilized when a researcher wants to make a comparison between two binomial variables. This test is especially useful when small sample sizes because the assumption of normal approximation to the binomial distribution is relaxed.

Table 4.55 shows no statistically significant $(p=0.871$ to $p=0.3733$ ) association between physician type and the antidepressant category prescribed for first, second, or third-lines of treatment for adolescents with major depressive disorder. On the basis of these tests, the Null Hypothesis 17.a: There is no difference in the pharmacotherapy category prescribed by physicians (pediatricians versus child psychiatrists) for first, second, and third lines of antidepressant treatment for newly diagnosed adolescents with major depressive disorder is not rejected. 
Table 4.55: Association of Physician Type and Antidepressant Category

\begin{tabular}{|l|c|}
\hline Association & Two-sided Probability \\
\hline $\begin{array}{c}\text { Adolescent's First-line of Antidepressant: } \\
\text { Physician Type * Antidepressant Type }\end{array}$ & 0.1349 \\
\hline $\begin{array}{l}\text { Adolescent's Second-line of } \\
\text { Antidepressant: } \\
\text { Physician Type * Antidepressant Type }\end{array}$ & 0.0871 \\
\hline $\begin{array}{c}\text { Adolescent's Third-line of Antidepressant: } \\
\text { Physician Type * Antidepressant Type }\end{array}$ & 0.3733 \\
\hline
\end{tabular}

As was the case with the first part of Objective 17 several steps were necessary to determined whether there is an association between the first, second, and third lines of specific antidepressant treatment and physician type. Three $\chi^{2}$ tests, one for each line of treatment (first, second, and thirdline) were conducted and examined the association between two variables: physician type (pediatrician versus child psychiatrist) and specific antidepressant prescribed. However, the specific type of antidepressant medication varied so that for the first-line of treatment there were 12 different groups of antidepressants, for the second-line of treatment there were 30 different groups of antidepressants, and for the third-line there were 34 different antidepressant groups. Since the number of groups were so large, it was necessary to collapse the antidepressant categories. Prozac ${ }^{\circledR}$ is the only antidepressant, U.S. FDA approved to treat major depressive disorder in adolescents, therefore, it was decided to collapse the antidepressants into two categories, either Prozac ${ }^{\circledR}$ or nonProzac $^{\circledR}$ type antidepressants. Therefore, for each line of treatment (first, second, and third) the $\chi^{2}$ statistic tested whether or not there is an association between physician type (pediatrician versus child psychiatrist) and specific antidepressant $\left(\operatorname{Prozac}^{\circledR}\right.$ versus non- Prozac $\left.{ }^{\circledR}\right)$. The results of these analyses are in Table 4.56 below. 
Table 4.56: Association of Physician Type and Specific Antidepressant

\begin{tabular}{|c|c|c|c|c|}
\hline & $\begin{array}{l}\text { Pediatrician } \\
\text { (N) }\end{array}$ & $\begin{array}{l}\text { Child } \\
\text { Psychiatrist } \\
\text { (N) }\end{array}$ & Test Statistic & p-value \\
\hline $\begin{array}{l}1^{\text {st }} \text {-Line of Antidepressant } \\
\text { Treatment: } \\
\text { Non-Prozac }^{\circledR} \\
\text { Prozac }{ }^{\circledR}\end{array}$ & $\begin{array}{l}34 \\
23\end{array}$ & $\begin{array}{l}170 \\
124\end{array}$ & $\chi^{2}=0.5338$ & 0.4650 \\
\hline $\begin{array}{l}\text { 2nd-Line of Antidepressant } \\
\text { Treatment: } \\
\text { Non-Prozac }^{\circledR} \\
\text { Prozac }{ }^{\circledR}\end{array}$ & $\begin{array}{l}42 \\
14\end{array}$ & $\begin{array}{c}232 \\
50\end{array}$ & $\chi^{2}=3.2576$ & 0.0711 \\
\hline $\begin{array}{l}3^{\text {rd }} \text {-Line of Antidepressant } \\
\text { Treatment: } \\
\text { Non-Prozac }^{\circledR} \\
\text { Prozac }^{\circledR}\end{array}$ & $\begin{array}{c}53 \\
1\end{array}$ & $\begin{array}{c}279 \\
7\end{array}$ & $\begin{array}{c}\text { Fisher's } \\
\text { Exact Test }\end{array}$ & 0.4721 \\
\hline
\end{tabular}

Based on the $\chi^{2}$ tests and the fisher's exact test there is not statistically significant association between physician type and the specific antidepressant prescribed to adolescents. Hence, we must fail to reject the Null Hypothesis 17.b: There is no difference in the specific antidepressant prescribed by physicians (pediatricians versus child psychiatrists) for first, second, and third lines of treatment for newly diagnosed adolescents with major depressive disorder.

Objective 18: To predict which physician characteristics affect the treatment prescribed for adolescents with major depressive disorder.

Logistic regression was utilized to estimate the probability that a physician would prescribe antidepressant medication versus counseling to adolescents with major depressive disorder. The explanatory or independent variables utilized in this model were physician characteristics (specialty of physician, gender of physician, age of physician, physicians' primary practice site, geographic location of physician, population of community of physicians' primary practice site, physicians' board certification, patient volume per week, and length of time physician has treated the child and adolescent population). The pre-specified criterion of $\mathrm{p}=0.15$ was utilized and a stepwise logistic regression model was estimated using $\mathrm{SAS}^{\circledR}$, just as was conducted for the child population. 
However, in this model convergence was not achieved. Estimation of the logistic model is an iterative process involving many approximations. This process ceases when the change in the coefficients become very small, at this point the model is said to have converged (Allison, 1999). Two reasons convergence may not be achieved. These two reasons are complete separation and quasi-complete separation of the data. Complete separation occurs when the dependent variable is perfectly predicted by some linear combination of the independent variables (Allison, 1999). The other reason, quasi-complete separation, is what occurred in the data for this model. Quasi-complete separation is similar to complete separation except for there being a value for the predictor (or independent variable) for which both values of the dependent variable occur (Allison, 1999). Quasicomplete separation can occur when all of the cases at one level of the independent variable fall into one of the two levels of the dependent variable. This can be seen if cross-tabs of the independent and dependents variables are examined. Examination of the cross-tabs for the data in this model reveals the independent variable, number of adolescents treated per week, has this property. This is shown below in Table 4.57. One way to manage quasi-complete separation is to recode and collapse categories of the independent variable (Allison, 1999). In the current data set, the independent variable has only two levels already. Therefore, collapsing these variables is not possible. Another method and most common method to manage quasi-separation is to delete the cases(s) causing the problem (Allison, 1999). In this case, the cases were deleted and the stepwise logistic procedure recalculated.

Table 4.57: Crosstabs of Treatment by Number of Adolescents Seen Per Week

\begin{tabular}{|l|c|c|}
\hline & 40 Patients or Less & 41 Patients or Greater \\
\hline Treatment: & 248 & 21 \\
\hline Countidepressants & 51 & 0 \\
\hline
\end{tabular}

Based on our pre-specified criterion, two variables, type of physician and age of physician were retained in the stepwise model. The final logistic regression model resulted in no independent 
variables being retained, based on a $\mathrm{p} \leq 0.05$ criterion. However, it should be noted that age of the physician approached statistical significance $\left(\chi^{2}=3.2178, p=0.0728\right)$. These results are listed in Table 4.58. Therefore, it can be concluded from this model that none of our independent variables are significantly associated with the probability of a physician prescribing antidepressant treatment for an adolescent patient.

Table 4.58: Logistic Regression Analysis of Physicians' Antidepressant Prescribing to Adolescents with Major Depressive Disorder

\begin{tabular}{|l|c|c|c|c|c|c|c|}
\hline \multicolumn{1}{|c|}{ Variable } & $\begin{array}{c}\text { Estimate } \\
\boldsymbol{\beta}\end{array}$ & SE $\boldsymbol{\beta}$ & $\begin{array}{c}\text { Wald's } \\
\boldsymbol{\chi}^{\mathbf{2}}\end{array}$ & $\boldsymbol{d f}$ & p-value & $\begin{array}{c}\text { Point } \\
\text { Estimate }\end{array}$ & $\begin{array}{c}\text { 95\% CI } \\
\text { Intercept }\end{array}$ \\
\hline Child Psychiatrist & -0.2345 & 0.4708 & 22.5219 & 1 & $<0.0001$ & NA & NA \\
\hline $\begin{array}{l}\text { Age of Physician } \\
\text { Greater than 60 years }\end{array}$ & 0.8238 & 0.4972 & 2.6632 & 1 & 0.1027 & 0.444 & $0.168-$ \\
1.177 & $0.927-$ \\
\hline
\end{tabular}

$\mathrm{SE}=$ Standard Error, $\mathrm{df}=$ degrees of freedom, $\mathrm{CI}=$ Confidence Interval

Objective 19: To determine the average length of antidepressant treatment for newly diagnosed adolescents with major depressive disorder.

Physicians were asked to indicate how long on average an antidepressant be prescribed to an adolescent, if the treatment was successful in terms of decreasing depressive symptoms. The majority of the physicians, both pediatricians $(25.00+38.46=63.46 \%)$ and child psychiatrists $(46.59+24.90=71.49 \%)$ indicated they would prescribe the antidepressant medication to an adolescent for at least ten months. These frequencies are listed in Table 4.59.

Table 4.59: Frequencies of Average Length of Antidepressant Treatment for Adolescents

\begin{tabular}{|l|c|c|c|}
\hline $\begin{array}{l}\text { Length of } \\
\text { Antidepressant } \\
\text { Treatment }\end{array}$ & $\begin{array}{c}\text { All Physicians } \\
\text { N }(\%)\end{array}$ & $\begin{array}{c}\text { Pediatricians } \\
\mathbf{N}(\boldsymbol{\%})\end{array}$ & $\begin{array}{c}\text { Child Psychiatrists } \\
\text { N (\%) }\end{array}$ \\
\hline $\mathbf{1 - 3}$ months & $1(0.33)$ & $0(0.00)$ & $1(0.40)$ \\
\hline 4-6 months & $36(11.96)$ & $10(19.23)$ & $26(10.44)$ \\
\hline 7-9 months & $53(17.61)$ & $9(17.31)$ & $44(17.67)$ \\
\hline $\mathbf{1 0 - 1 2}$ months & $129(42.86)$ & $13(25.00)$ & $116(46.59)$ \\
\hline $\begin{array}{l}\text { Greater than 12 } \\
\text { months }\end{array}$ & $82(27.24)$ & $20(38.46)$ & $62(24.90)$ \\
\hline
\end{tabular}


The American Academy of Child and Adolescent Psychiatry has recently recommended adolescents be treated for a minimum of six months (American Academy of Child and Adolescent Psychiatry, 2007). The categorical variable, length of treatment, was then transformed into a continuous variable so comparisons could be made to the six month minimum. The categorical variable was re-coded by computing the average number of months the physician treats the adolescent with an antidepressant. The variable was re-coded as follows: 1-3 months was transformed into 2 months, 4-6 months was transformed into 5 months, 7-9 months was transformed into 8 months, 10-12 months was transformed into 11 months, and greater than 12 months was transformed into 12 months. The average length of time pediatricians and child psychiatrists prescribed antidepressant treatment for adolescents was then compared to the minimum length of time. It was found that both pediatricians and child psychiatrists treat adolescents significantly longer than the six month minimum. These results are listed in Table 4.60.

Table 4.60: Length of Antidepressant Treatment Compared to the AACAP Recommendations

\begin{tabular}{|l|c|c|c|c|}
\hline $\begin{array}{l}\text { Physician } \\
\text { Type }\end{array}$ & $\begin{array}{l}\text { Length of } \\
\text { Antidepressant } \\
\text { Treatment } \\
\text { (Mean + SD) }\end{array}$ & $\begin{array}{l}\text { Minimum Length } \\
\text { of AACAP } \\
\text { Recommendations } \\
\text { (months) }\end{array}$ & Test Statistic & Significance p \\
\hline Pediatrician & $9.712 \pm 2.710$ & 6 & $\mathrm{t}=9.874$ & $0.000^{*}$ \\
\hline $\begin{array}{l}\text { Child } \\
\text { Psychiatrist }\end{array}$ & $10.056 \pm 2.248$ & 6 & $\mathrm{t}=28.473$ & $0.000^{*}$ \\
\hline
\end{tabular}

*Significant at $\mathrm{p} \leq 0.05, \mathrm{SD}=$ Standard Deviation

Objective 20: To determine the types of pharmacotherapy monitoring in newly diagnosed adolescents with major depressive disorder.

Physicians were asked several questions related to the monitoring they conduct, in the event they utilize antidepressant treatment for adolescents with major depressive disorder. More specifically physicians were asked the mode of monitoring (e.g., how is the monitoring done), who conducts the monitoring, the type of monitoring they conduct, and the frequency with which they monitor. The physicians' responses to the mode of monitoring, who conducts the monitoring, and the type of 
monitoring conducted are listed in Table 4.61, Table 4.62, and Table 4.63, respectively. The majority of pediatricians $(89.10 \%)$ and child psychiatrists $(96.48 \%)$ indicated they would conduct monitoring through an individual office visit with the adolescent. Both pediatricians $(96.36 \%)$ and child psychiatrists $(95.41 \%)$ indicated, almost exclusively, they would conduct the monitoring themselves. Greater than ninety-five percent of pediatricians and child psychiatrists reported they monitor for adverse events, suicidality, and monitor clinical symptoms. Some pediatricians $(27.78 \%)$ and three-fourths of the child psychiatrists $(74.65 \%)$ indicated they would conduct some type of labwork to monitor medication therapy.

Some pediatricians (\%) and child psychiatrists (\%) indicated they conduct some other type of monitoring for adolescents. Other types of monitoring physicians listed included monitoring ongoing psychotherapy progress, monitoring school, social, family, or interpersonal functioning, and monitoring depressive symptoms through the use of scales (ex. Beck's Depression Inventory).

Table 4.61: Mode of Antidepressant Monitoring for Adolescents

\begin{tabular}{|l|c|c|c|}
\hline $\begin{array}{l}\text { Mode of } \\
\text { Monitoring }\end{array}$ & $\begin{array}{c}\text { All Physicians } \\
\mathbf{N}(\%)\end{array}$ & $\begin{array}{c}\text { Pediatricians } \\
\mathbf{N}(\%)\end{array}$ & $\begin{array}{c}\text { Child Psychiatrists } \\
\mathbf{N}(\%)\end{array}$ \\
\hline $\begin{array}{l}\text { Individual Office } \\
\text { Visit }\end{array}$ & $323(95.28)$ & $49(89.10)$ & $274(96.48)$ \\
\hline Telephone & $6(1.77)$ & $3(5.45)$ & $3(1.06)$ \\
\hline Other & $10(2.95)$ & $3(5.45)$ & $7(2.46)$ \\
\hline
\end{tabular}

Table 4.62: Healthcare Provider Conducting Antidepressant Monitoring for Adolescents

\begin{tabular}{|l|c|c|c|}
\hline Healthcare Provider & $\begin{array}{c}\text { All Physicians } \\
\text { N(\%) }\end{array}$ & Pediatricians N(\%) & $\begin{array}{c}\text { Child Psychiatrists } \\
\text { N(\%) }\end{array}$ \\
\hline Physician & $323(95.56)$ & $53(96.36)$ & $270(95.41)$ \\
\hline Nurse/Nurse Practitioner & $5(1.48)$ & $1(1.82)$ & $5(1.77)$ \\
\hline Counselor/Psychotherapist & $4(1.18)$ & $1(1.82)$ & $3(1.06)$ \\
\hline Other & $6(1.78)$ & $0(0.00)$ & $5(1.77)$ \\
\hline
\end{tabular}


Table 4.63: Type of Antidepressant Monitoring for Adolescents

\begin{tabular}{|l|c|c|c|}
\hline $\begin{array}{l}\text { Type of } \\
\text { Monitoring }\end{array}$ & $\begin{array}{c}\text { All Physicians } \\
(\mathbf{N = 3 4 0 )}\end{array}$ & $\begin{array}{c}\text { Pediatricians } \\
(\mathbf{N}=\mathbf{5 4})\end{array}$ & $\begin{array}{c}\text { Child Psychiatrists } \\
(\mathbf{N = 2 8 4 )}\end{array}$ \\
\hline Adverse Events & $337(99.12)$ & $54(100.00)$ & $283(99.65)$ \\
\hline Suicidality & $335(98.53)$ & $52(96.30)$ & $283(99.65)$ \\
\hline Conduct Labwork & $227(66.76)$ & $15(27.78)$ & $212(74.65)$ \\
\hline Clinical Symptoms & $334(98.24)$ & $53(98.15)$ & $281(98.94)$ \\
\hline Other & $78(22.94)$ & $4(7.41)$ & $74(26.06)$ \\
\hline
\end{tabular}

Physicians were also asked to indicate how frequently they monitor adolescents treated with antidepressants during the first three months of treatment. During the first month of treatment over half of the pediatricians $(53.70 \%)$ indicated they monitor children every two weeks, with another $38.89 \%$ pediatricians reported monitoring once a week. In comparison, approximately the same percentage of child psychiatrists reported, monitoring adolescents either once a week (38.95\%) or every two weeks $(32.98 \%)$ during the first month of antidepressant treatment. The findings for monitoring frequency during the first month of treatment are listed in Table 4.64.

Table 4.64: Frequency of Antidepressant Monitoring: Month One

\begin{tabular}{|l|c|c|c|}
\hline & $\begin{array}{c}\text { All Physicians } \\
(\mathbf{N})\end{array}$ & $\begin{array}{c}\text { Pediatricians } \\
(\mathbf{N})\end{array}$ & $\begin{array}{c}\text { Child Psychiatrists } \\
(\mathbf{N})\end{array}$ \\
\hline Frequency of Monitoring: & & & $2(0.70 \%)$ \\
\hline Two Times per Week & $2(0.59 \%)$ & $0(0.00 \%)$ & $111(38.95 \%)$ \\
\hline Once a Week & $132(38.94 \%)$ & $21(38.89 \%)$ & $94(32.98 \%)$ \\
\hline Every Two Weeks & $123(36.28 \%)$ & $29(53.70 \%)$ & $14(4.91 \%)$ \\
\hline Every Three Weeks & $14(4.13 \%)$ & $0(0.00 \%)$ & $37(12.98 \%)$ \\
\hline Once a Month & $40(11.80 \%)$ & $3(5.56 \%)$ & $0(0.00 \%)$ \\
\hline Greater than Once a Month & $0(0.00 \%)$ & $0(0.00 \%)$ & $27(9.47 \%)$ \\
\hline Other & $28(8.26 \%)$ & $1(1.85 \%)$ & \\
\hline
\end{tabular}

For the second month of antidepressant treatment about two-thirds of pediatricians $(62.97 \%)$ monitor adolescents once a month, while another one-fourth (24.07\%) monitor adolescents every two weeks. The majority of child psychiatrists indicated they monitor adolescents either once a month $(45.77 \%)$ or every two weeks $(30.28 \%)$. Results for the frequency of monitoring, by these physicians, during the second month of treatment are listed in Table 4.65. 
Table 4.65: Frequency of Antidepressant Monitoring: Month Two

\begin{tabular}{|l|c|c|c|}
\hline & $\begin{array}{c}\text { All Physicians } \\
(\mathbf{N})\end{array}$ & $\begin{array}{c}\text { Pediatricians } \\
(\mathbf{N})\end{array}$ & $\begin{array}{c}\text { Child Psychiatrists } \\
(\mathbf{N})\end{array}$ \\
\hline Frequency of Monitoring: & & & $2(0.70 \%)$ \\
\hline Two Times per Week & $2(0.59 \%)$ & $0(0.00 \%)$ & $14(4.93 \%)$ \\
\hline Once a Week & $15(4.44 \%)$ & $1(1.85 \%)$ & $86(30.28 \%)$ \\
\hline Every Two Weeks & $99(29.29 \%)$ & $13(24.07 \%)$ & $28(9.86 \%)$ \\
\hline Every Three Weeks & $29(8.58 \%)$ & $1(1.85 \%)$ & $130(45.77 \%)$ \\
\hline Once a Month & $164(48.52 \%)$ & $34(62.97 \%)$ & $12(4.23 \%)$ \\
\hline Greater than Once a Month & $16(4.73 \%)$ & $4(7.41 \%)$ & $12(4.23 \%)$ \\
\hline Other & $13(3.85 \%)$ & $1(1.85 \%)$ & \\
\hline
\end{tabular}

During month three, over ninety percent of the pediatricians reported they monitor adolescents either once a month $(42.60 \%)$ or at some time interval greater than one month $(50.00 \%)$. The majority of child psychiatrists $(62.68 \%)$ indicated they monitor adolescents once a month. Another $21.48 \%$ of the child psychiatrists reported they monitor adolescents at some interval greater than once a month. Table 4.66 shows the results of the frequency of monitoring by physicians during the third month of treatment.

Table 4.66: Frequency of Antidepressant Monitoring: Month Three

\begin{tabular}{|l|c|c|c|}
\hline & $\begin{array}{c}\text { All Physicians } \\
(\mathbf{N})\end{array}$ & $\begin{array}{c}\text { Pediatricians } \\
(\mathbf{N})\end{array}$ & $\begin{array}{c}\text { Child Psychiatrists } \\
(\mathbf{N})\end{array}$ \\
\hline Frequency of Monitoring: & & & $2(0.70 \%)$ \\
\hline Two Times per Week & $2(0.59 \%)$ & $0(0.00 \%)$ & $9(3.17 \%)$ \\
\hline Once a Week & $9(2.66 \%)$ & $0(0.00 \%)$ & $9(3.17 \%)$ \\
\hline Every Two Weeks & $10(2.96 \%)$ & $1(1.85 \%)$ & $10(3.52 \%)$ \\
\hline Every Three Weeks & $12(3.55 \%)$ & $2(3.70 \%)$ & $178(62.68 \%)$ \\
\hline Once a Month & $201(59.47 \%)$ & $23(42.60 \%)$ & $61(21.48 \%)$ \\
\hline Greater than Once a Month & $88(26.04 \%)$ & $27(50.00 \%)$ & $15(5.28 \%)$ \\
\hline Other & $16(4.73 \%)$ & $1(1.85 \%)$ & \\
\hline
\end{tabular}

Objective 21: To determine differences in antidepressant monitoring for newly diagnosed adolescents with major depressive disorder and the U.S. FDA recommendations for monitoring adolescents treated with antidepressants.

Null Hypothesis 21.0: There is no difference in pharmacotherapy monitoring for newly diagnosed adolescents with major depressive disorder and the U.S. FDA recommendations for monitoring adolescents treated with antidepressants.

The frequencies associated with physician monitoring of adolescents treated with antidepressant medication was provided in the above objective, and listed in Tables 4.64 4.65, and 4.66. Physicians 
answered the monitoring frequency question by selecting one of the following categories: "two times per week”, “once a week”, “every two weeks', “every three weeks”, “once a month”, greater than once a month", or "other". These variables are categorical in nature. Therefore, to compute an average number of times per month a physician monitors adolescents on antidepressants these categories were re-coded. This was accomplished as follows: "two times per week" was transformed into eight times per month, "once a week" was transformed into four times a month, "every two weeks" was transformed into two times per month, "every three weeks" was transformed into 1.4 times per month, "once a month" was transformed into 1 time per month, and "greater than once a month" was transformed into .5 times per month. For this analysis the "other" category was eliminated. The frequencies of the recoded variables are provided below in Tables 4.67, 4.68, and 4.69.

Table 4.67: Recoded Frequency of Antidepressant Monitoring: Month One

\begin{tabular}{|c|c|c|c|}
\hline $\begin{array}{l}\text { Frequency of Monitoring } \\
\text { (Number of Times per } \\
\text { Month) : }\end{array}$ & $\begin{array}{c}\text { All Physicians } \\
(\mathbf{N})\end{array}$ & $\begin{array}{c}\text { Pediatricians } \\
(\mathbf{N})\end{array}$ & $\begin{array}{c}\text { Child Psychiatrists } \\
(\mathbf{N})\end{array}$ \\
\hline $\mathbf{0 . 5}$ & 0 & 0 & 0 \\
\hline $\mathbf{1}$ & 40 & 3 & 37 \\
\hline $\mathbf{1 . 4}$ & 14 & 0 & 14 \\
\hline $\mathbf{2}$ & 123 & 29 & 94 \\
\hline $\mathbf{4}$ & 132 & 21 & 111 \\
\hline $\mathbf{8}$ & 2 & 0 & 2 \\
\hline
\end{tabular}

Table 4.68: Recoded Frequency of Antidepressant Monitoring: Month Two

\begin{tabular}{|c|c|c|c|}
\hline $\begin{array}{l}\text { Frequency of Monitoring } \\
\text { (Number of Times per } \\
\text { Month): }\end{array}$ & $\begin{array}{c}\text { All Physicians } \\
(\mathbf{N})\end{array}$ & $\begin{array}{c}\text { Pediatricians } \\
(\mathbf{N})\end{array}$ & $\begin{array}{c}\text { Child Psychiatrists } \\
(\mathbf{N})\end{array}$ \\
\hline $\mathbf{0 . 5}$ & 16 & 4 & 12 \\
\hline $\mathbf{1}$ & 164 & 34 & 130 \\
\hline $\mathbf{1 . 4}$ & 29 & 1 & 28 \\
\hline $\mathbf{2}$ & 99 & 13 & 86 \\
\hline $\mathbf{4}$ & 15 & 1 & 14 \\
\hline $\mathbf{8}$ & 2 & 0 & 2 \\
\hline
\end{tabular}


Table 4.69: Recoded Frequency of Antidepressant Monitoring: Month Three

\begin{tabular}{|c|c|c|c|}
\hline $\begin{array}{l}\text { Frequency of Monitoring } \\
\text { (Number of Times per } \\
\text { Month): }\end{array}$ & $\begin{array}{c}\text { All Physicians } \\
(\mathbf{N})\end{array}$ & $\begin{array}{c}\text { Pediatricians } \\
(\mathbf{N})\end{array}$ & $\begin{array}{c}\text { Child Psychiatrists } \\
(\mathbf{N})\end{array}$ \\
\hline $\mathbf{0 . 5}$ & 88 & 27 & 61 \\
\hline $\mathbf{1}$ & 201 & 23 & 178 \\
\hline $\mathbf{1 . 4}$ & 12 & 2 & 10 \\
\hline $\mathbf{2}$ & 10 & 1 & 9 \\
\hline $\mathbf{4}$ & 9 & 0 & 9 \\
\hline $\mathbf{8}$ & 2 & 0 & 2 \\
\hline
\end{tabular}

The U.S. FDA recommendation, for physician monitoring of antidepressant treatment is one time per week for the first four weeks of treatment (U.S.FDA, 2005). During the second month of treatment the patient should be seen biweekly, and at week 12, during the third month (U.S.FDA, 2005). These recommendations were compared to the number of times per month the physicians reported they monitor adolescents, during the first three months of antidepressant treatment. For the first month of treatment pediatricians $(\mathrm{t}=-7.967, \mathrm{p}=0.000)$ and child psychiatrists $(\mathrm{t}=-15.941$, $\mathrm{p}=0.000$ ) monitor adolescents significantly less than the U.S. FDA recommended four times. During the second month of treatment, both pediatricians $(\mathrm{t}=-8.715, \mathrm{p}=0.000)$ and child psychiatrists $(\mathrm{t}=-$ $8.078, p=0.000)$ monitor significantly less than the U.S. FDA recommended two times per month. During the third month of treatment pediatricians $(\mathrm{t}=-4.947, \mathrm{p}=0.000)$ still monitor significantly less than the U.S. FDA recommendations. However, child psychiatrists' $(t=1.847, \mathrm{p}=0.101)$ monitoring does not differ significantly from the U.S. FDA recommendations of one time during month three. These comparisons are listed in Table 4.70. 
Table 4.70: Comparisons of Physician Monitoring to U.S. FDA Recommendations

\begin{tabular}{|l|c|c|c|}
\hline & Mean \pm SD & Test Statistic & Significance \\
\hline Month One: & & & \\
All Physicians & $2.732 \pm 1.242$ & $\mathrm{t}=-18.001$ & $0.000^{*}$ \\
Pediatricians & $2.736 \pm 1.059$ & $\mathrm{t}=-7.967$ & $0.000^{*}$ \\
Child Psychiatrists & $2.731 \pm 1.277$ & $\mathrm{t}=-15.941$ & $0.000^{*}$ \\
\hline Month Two: & & & \\
All Physicians & $1.497 \pm 0.896$ & $\mathrm{t}=-8.130$ & $0.000^{*}$ \\
Pediatricians & $1.272 \pm 0.608$ & $\mathrm{t}=-8.715$ & $0.000^{*}$ \\
Child Psychiatrists & $1.541 \pm 0.937$ & $\mathrm{t}=-8.078$ & $0.000^{*}$ \\
\hline Month Three: & & & \\
All Physicians & $1.037 \pm 0.814$ & $\mathrm{t}=0.893$ & 0.372 \\
Pediatricians & $0.779 \pm 0.325$ & $\mathrm{t}=-4.947$ & $0.000^{*}$ \\
Child Psychiatrists & $1.087 \pm 0.870$ & $\mathrm{t}=1.847$ & 0.101 \\
\hline
\end{tabular}

*Significant at $\mathrm{p} \leq 0.05, \mathrm{SD}=$ Standard Deviation, U.S. FDA=United States Food and Drug Administration

Objective 22: To determine whether there are differences, by physician type, in the average number of times per month physicians monitor adolescents with major depressive disorder.

Null Hypothesis 22.0: There is no difference, by physician type, in the average number of times per month physicians monitor adolescents with major depressive disorder.

The hypothesis that there is no difference by physician type (pediatricians versus child psychiatrists) in the average number of times per month physicians monitor adolescents was tested. The recoded data from Objective \#21 was utilized to analyze this objective. This data was used to compare the average number of times per month pediatricians monitor adolescents to the average number of times child psychiatrists monitor adolescents on antidepressant therapy. The Levene's test for equality of variances was first conducted on each of the comparisons. If the Levene's test for equality was significant then equal variances could not be assumed. If the Levene's test for equality was not significant then equal variances were assumed. Next, the appropriate two sample t-test, either for the assumption of equal variances or unequal variances was conducted. The results are listed below in Table 4.71. 
Table 4.71: Comparison of Pediatricians and Child Psychiatrists Monitoring of Adolescents

\begin{tabular}{|l|c|c|c|}
\hline & Mean \pm SD & Test Statistic & p-value \\
\hline Month One: & $2.74 \pm 1.06$ & $t=0.029$ & 0.977 \\
Pediatricians & $2.73 \pm 1.28$ & & \\
Child Psychiatrists & & & \\
\hline Month Two: & $1.27 \pm 0.61$ & $t=-2.667$ & $0.009 *$ \\
Pediatricians & $1.54 \pm 0.94$ & & \\
Child Psychiatrists & & & \\
\hline Month Three: & $0.78 \pm 0.32$ & $t=-2.541$ & $0.012^{*}$ \\
Pediatricians & $1.09 \pm 0.87$ & & \\
Child Psychiatrists & 1.09 & \\
\hline
\end{tabular}

* Significant at $\mathrm{p} \leq 0.05$

The average number of times physicians (pediatricians versus child psychiatrists) monitored adolescents did not significantly differ during the first $(p=0.977)$ month of antidepressant treatment. Child psychiatrists monitored significantly more than pediatricians during the second $(\mathrm{p}=0.009)$ and third $(\mathrm{p}=0.012)$ months of treatment. Therefore, Null Hypothesis 13.0: There is no difference, by physician type, in the average number of times per month physicians monitor adolescents with major depressive disorder, will fail to be rejected for month one and will be rejected for months two and three of treatment.

\section{Phase II Results for Exploratory Factor Analysis}

Objective 23: To determine the relative importance which physicians place on each factor prior to prescribing antidepressants to newly diagnosed children and adolescents with major depressive disorder.

Objective 24: To determine the factors associated with physicians' antidepressant prescribing behavior for children and adolescents newly diagnosed with major depressive disorder.

Section seven of the phase II survey asked physicians to rate the extent to which 28 variables influenced their decisions to prescribe or not to prescribe an antidepressant to a newly diagnosed child or adolescent with major depressive disorder. The physicians rated the influence of these 28 
variables on a scale of $1-4$, where $1=$ not influential, $2=$ somewhat influential, $3=$ influential, and $4=$ extremely influential.

The physicians' ratings of these 28 variables are listed in Table 4.68. Both pediatricians and child psychiatrists on average rated clinical experience with prescribing antidepressants, co-existing conditions of patient (e.g. obsessive compulsive disorder), comfort in managing MDD in youth, drug safety, drug efficacy, familiarity with an antidepressant being prescribed, severity of MDD symptoms, and suicidal thinking as being "influential" or "extremely influential".

Pediatricians and child psychiatrists rated advertisements to physicians via journals and/or mail, availability of patient education materials, direct-to-consumer advertising, face-to-face detailing by medical sciences liaison and/or pharmaceutical representatives, FDA approved, formulary inclusion, frequency of dosing, generic form of drug available, manufacturer provides free drugs to indigent patients, medication cost, monitoring requirements, parents' education level, parental use of antidepressants, patient's ability to perform daily activities, patient's age, patient's family income, patient's gender, patient's insurance, and sample drugs available as being either "not influential" or only "somewhat influential".

Pediatricians rated potential adverse effects as being "not influential" or only "somewhat influential", while child psychiatrists rated potential adverse effects as being either "influential" or "extremely influential". 
Table 4.72: Means and Standard Deviations of Variables/Factors Which Influence Antidepressant Prescribing Decisions for Child Psychiatrists and Pediatricians

\begin{tabular}{|c|c|c|c|c|}
\hline Factor & $\begin{array}{c}\text { Child Psychiatrists } \\
\text { (Mean } \pm \text { S.D.) }\end{array}$ & $\begin{array}{l}\text { Pediatricians } \\
(\text { Mean } \pm \text { S.D. })\end{array}$ & t-test & $\begin{array}{c}\text { Significance } \\
(p)\end{array}$ \\
\hline $\begin{array}{l}\text { Advertisements to physicians via } \\
\text { journals and/or mail }\end{array}$ & $1.2 \pm 0.5$ & $1.1 \pm 0.4$ & -2.009 & 0.048 \\
\hline $\begin{array}{l}\text { Availability of patient education } \\
\text { materials }\end{array}$ & $1.4 \pm 0.7$ & $1.3 \pm 0.5$ & -1.881 & 0.063 \\
\hline $\begin{array}{l}\text { Clinical experience with prescribing } \\
\text { antidepressants }\end{array}$ & $3.8 \pm 0.4$ & $3.5 \pm 0.6$ & -3.535 & $0.001 *$ \\
\hline $\begin{array}{l}\text { Co-existing conditions of patient (e.g. } \\
\text { obsessive compulsive disorder) }\end{array}$ & $3.7 \pm 0.6$ & $3.5 \pm 0.6$ & -2.583 & $0.012 *$ \\
\hline Comfort in managing MDD in youth & $3.5 \pm 0.8$ & $3.3 \pm 0.6$ & -1.226 & 0.221 \\
\hline Direct-to-consumer advertising & $1.3 \pm 0.5$ & $1.0 \pm 0.2$ & -5.309 & $0.000 *$ \\
\hline Drug efficacy & $3.8 \pm 0.4$ & $3.5 \pm 0.6$ & -4.017 & $0.000^{*}$ \\
\hline Drug safety & $3.8 \pm 0.4$ & $3.7 \pm 0.5$ & -1.520 & 0.133 \\
\hline $\begin{array}{l}\text { Face-to-face detailing by medical } \\
\text { sciences liaison and/or pharmaceutical } \\
\text { representatives }\end{array}$ & $1.5 \pm 0.6$ & $1.3 \pm 0.5$ & -2.188 & $0.032 *$ \\
\hline $\begin{array}{l}\text { Familiarity with an antidepressant being } \\
\text { prescribed }\end{array}$ & $3.7 \pm 0.5$ & $3.6 \pm 0.5$ & -1.864 & 0.063 \\
\hline FDA approved & $2.5 \pm 1.0$ & $2.9 \pm 1.0$ & 2.783 & $0.006^{*}$ \\
\hline Formulary inclusion & $2.4 \pm 0.9$ & $2.6 \pm 0.9$ & 1.883 & 0.061 \\
\hline Frequency of dosing & $2.8 \pm 0.8$ & $2.6 \pm 0.8$ & -1.029 & 0.304 \\
\hline Generic form of drug available & $2.4 \pm 0.9$ & $2.5 \pm 0.8$ & 0.850 & 0.396 \\
\hline $\begin{array}{l}\text { Manufacturer provides free drugs to } \\
\text { indigent patients }\end{array}$ & $2.0 \pm 0.9$ & $1.5 \pm 0.7$ & -4.366 & $0.000 *$ \\
\hline Medication cost & $2.5 \pm 0.8$ & $2.5 \pm 0.6$ & 0.018 & 0.985 \\
\hline Monitoring requirements & $2.4 \pm 0.9$ & $2.3 \pm 0.8$ & -0.582 & 0.561 \\
\hline Parents' education level & $1.9 \pm 0.9$ & $1.9 \pm 0.8$ & 0.071 & 0.943 \\
\hline Parental use of antidepressants & $2.6 \pm 0.9$ & $2.1 \pm 0.9$ & -3.683 & $0.000 *$ \\
\hline $\begin{array}{l}\text { Patient's ability to perform daily } \\
\text { activities }\end{array}$ & $2.9 \pm 0.9$ & $2.8 \pm 0.9$ & -0.638 & 0.524 \\
\hline Patient's age & $2.9 \pm 0.8$ & $2.8 \pm 0.7$ & -0.384 & 0.701 \\
\hline Patient's family income & $1.5 \pm 0.8$ & $1.4 \pm 0.6$ & -1.748 & 0.084 \\
\hline Patient's gender & $1.3 \pm 0.6$ & $1.2 \pm 0.4$ & -1.487 & 0.140 \\
\hline Patient's insurance & $1.7 \pm 0.9$ & $1.7 \pm 0.8$ & 0.109 & 0.913 \\
\hline Potential adverse effects & $3.3 \pm 0.7$ & $3.0 \pm 0.7$ & -3.139 & $0.002 *$ \\
\hline Sample drugs available & $1.8 \pm 0.8$ & $1.4 \pm 0.7$ & -2.854 & $0.005^{*}$ \\
\hline Severity of MDD symptoms & $3.7 \pm 0.6$ & $3.3 \pm 0.9$ & -3.301 & $0.002 *$ \\
\hline Suicidal thinking & $3.6 \pm 0.7$ & $3.5 \pm 0.8$ & -1.451 & 0.148 \\
\hline
\end{tabular}

* Significant at $\mathrm{p}<0.05$, S.D. $=$ Standard Deviation 
Comparisons of the pediatricians' ratings of the factors and child psychiatrists' ratings of the factors were made. The Levene's test for equality of variances was first conducted on each of the 28 comparisons. If this test was significant then equal variances were not assumed, if the Levene's test was not significant then equal variances could be assumed. Next, the appropriate two-sample t-test, either for equal variances or unequal variances was conducted. The results are listed in the Table 4.72. Mean ratings were significantly different for pediatricians and child psychiatrists for the following factors: clinical experience with prescribing antidepressants, co-existing conditions of patient (e.g. obsessive compulsive disorder), direct-to-consumer advertising, drug efficacy, face-toface detailing by medical sciences liaison and/or pharmaceutical representatives, FDA approved, manufacturer provides free drugs to indigent patients, parental use of antidepressants, potential adverse effects, sample drugs available, and severity of MDD symptoms.

Next, an exploratory factor analysis was conducted on the physicians' responses to the 28 variables. Exploratory factor analysis is appropriate when the researcher has obtained measures on a number of variables (in this study the variables are the 28 factors or variables association with the decision to prescribe or not prescribe an antidepressant) and wants to identify the factor structure or underlying factors or constructs in the set of data (Hatcher, 1994). A factor "is an unobserved variable (or latent variable)" or a "hypothetical construct" that you believe exists and influences certain "manifest or observed variables" (Hatcher, 1994). Some variables will correlate strongly/are intercorrelated with each other because these variables are all "caused by the same latent factor" or construct (Hatcher, 1994).

There are guidelines to choose the sample size that is adequate for a factor analysis (Hatcher, 1994). The minimal number of subjects should be at least 100 or five times the number of variables being analyzed (Hatcher, 1994). In the current study physicians were asked to rate how influential 28 variables are when deciding whether or not to prescribe an antidepressant medication to children 
or adolescent patients. Therefore, $28 * 5$ or a minimum of 140 subjects are required to conduct a factor analysis in the current study. A factor analysis was not conducted for the pediatrician group because only 57 useable surveys were obtained from pediatricians. For the child psychiatrist group there were 299 returned and usable surveys. If a subject fails to answer even one item they will not provide usable data for a factor analysis and SAS will drop these subjects from the final sample (Hatcher, 1994). The final sample consisted of 259 subjects. This number is more than the 140 subjects minimally required for a factor analysis.

There are three decisions points or steps in conducting an exploratory factor analysis. The researcher must decide which extraction method to utilize, the number of factors to be retained in the analysis for rotation, and choose a rotation method.

There are several extraction methods that can be utilized when conducting a factor analysis. However, information regarding the strengths and weaknesses of these methods is limited (Osborne \& Costello, 2005). The most common methods utilized are principal components analysis and principal axis factoring (Hatcher, 1994; Osborne \& Costello, 2005; Thompson, 2004). There is much debate regarding whether or not principal components analysis should be utilized in as an extraction method in exploratory factor analysis (Osborne \& Costello, 2005; Thompson, 2004). Additionally, principal axis factoring is more robust and does not even assume that data is normally distributed. For these reasons the researcher took a conservative approach and utilized the principal axis method for this study.

The researcher also needs to determine the number of factors to retain (Hatcher, 1994; Osborne \& Costello, 2005). In other words the researcher must decide how many factors are meaningful factors and should be retained for rotation and interpretation. Usually it can be expected that the first few factors in the model account for the large majority of the common variance and are therefore more meaningful (Hatcher, 1994). There are several guidelines to follow in order to determine the number 
of factors to retain for interpretation (Hatcher, 1994). Since these are guidelines and are rather subjective, it has been recommended that these guidelines be used in combination, in order for the researcher maximize his/her chances of identifying the correct factor structure for the data (Hatcher, 1994). The four guidelines utilized to determine the number of factors to be retained are as follows: 1) Kaiser Criterion, 2) Scree Test, 3) Proportion of Variance, and 4) Interpretability Criterion (Hatcher, 1994).

The Kaiser Criterion calls for factors to be retained if they have an eigenvalue equal to 1.0 or greater (Hatcher, 1994). In this study, the first four factors (4.66, 2.04, 1.30, and 1.00 respectively) produced rounded eigenvalues equal to or greater than 1.0. Therefore, based on this criterion four factors should be retained.

The scree test plots the eigenvalues for each factor against the number of each factor. The researcher looks for "breaks" in the scree plot to determine how many factors should be retained (Cattell, 1966; Hatcher, 1994). In this study, the scree plot showed four breaks after factor 1, factor 2, factor 3, and factor 4 . Therefore, based on this criterion four factors should be retained.

The proportion of variance criteria can also be utilized to determine the number of factors to retain for rotation. According to this criterion, a factor is retained if it accounts for a certain percentage of the variance in a set of data (Hatcher, 1994). This method has been criticized for being subjective (Hatcher, 1994). If applied to this study the proportion of variance criteria yields the slightly different results as the other methods. For example, if any factor that accounts for at least $10 \%$ of the common variance is retained, as suggested by Hatcher (1994) only three factors would be retained. The fourth factor having a proportion of variance equal to 0.0922 , would not be retained. Although subjective this criterion can serve as a check for the other criterion, especially if the results are in agreement. 
The last guideline is the interpretability criterion. This guideline is not empirical in nature, but involves the researcher examining the variables that load on any given factor and determining whether or not they seem to share some common conceptual meaning (Hatcher, 1994). Table 4.73 lists the variables which loaded on each of the three factors.

Table 4.73: Initial Factor Pattern

\begin{tabular}{|l|l|}
\hline \multicolumn{1}{|c|}{ Variable } & Factor \\
\hline Face-to-face detailing by medical sciences liaison and/or & Factor 1 \\
pharmaceutical representatives & \\
Formulary inclusion & \\
Frequency of dosing & \\
Generic form of drug available & \\
Manufacturer provides free drugs to indigent patients & \\
Medication cost & \\
Monitoring requirements & \\
Parents' education level & \\
Parental use of antidepressants & \\
Patient's ability to perform daily activities & \\
Patient's age & \\
Patient's family income & \\
Patient's insurance & \\
Potential adverse effects & \\
Sample drugs available & \\
\hline Patient's ability to perform daily activities & Factor 2 \\
Severity of MDD symptoms & \\
Suicidal thinking & Factor 3 \\
\hline Drug efficacy & Factor 4 \\
\hline Drug safety & \\
\hline Formulary inclusion & \\
\hline
\end{tabular}

According to the interpretable criterion the variables which load on each of the three factors should have something in common or seem to group together. On the first factor the variables faceto-face detailing by medical sciences liaison and/or pharmaceutical representatives, formulary inclusion, frequency of dosing, generic form of drug available, manufacturer provides free drugs to indigent patients, medication cost, monitoring requirements, parents' education level, parental use of antidepressants, patient's ability to perform daily activities, patient's age, patient's family income, patient's insurance, potential adverse effects, and sample drugs available load. These variables seem 
to relate to the concepts of "drug cost and socio-economic status of the patient". Patient's ability to perform daily activities, severity of major depressive disorder symptoms, and suicidal thinking all seem to correspond to the idea of "disease presentation or severity of disease". The drug efficacy and drug safety variables which load on factor 3 could both be related to the concept of "drug profile”. In this initial factor pattern matrix, the variable formulary inclusion loads by itself on factor 4. If this factor continued to load only one variable, it should probably be dropped from the analysis, as it would be considered a weak or unstable factor. However, this is not the case as seen in the remaining analysis.

The next step in factor analysis is rotation of the data. There are two main types of rotation that may be utilized. These rotation methods are orthogonal rotation or oblique rotation (Hatcher, 1994; Osborne \& Costello, 2005). Orthogonal rotation seems to be easier to interpret. However oblique rotation seems to provide better results for many types of variables, as it allows factors to correlate with one another. If the factors are correlated and orthogonal rotation is used this information is lost. Oblique rotation is more appropriate in social sciences because behavior is rarely placed in neat packages and variables tend to correlate (Hatcher, 1994; Osborne \& Costello, 2005). Therefore, this study utilized oblique rotation.

The goal of rotation is to simplify the structure of the data. Simple structure of the data is said to be achieved when the variables have "relatively high factor loadings" on one factor and low factor loadings (near zero) on the other factors (Hatcher, 1994). In other words, maximize high factor loadings while minimizing low factor loadings.

Factor loadings are the coefficients that result in the factor pattern matrix or factor structure matrix in the results of the factor analysis or the coefficients of the variable on each of the factors (Hatcher, 1994). 
For analysis utilizing oblique rotation the researcher must interpret at least two matrices in order to understand the results. These are the "Rotated Factor Pattern" and the Factor Structure Matrix" (Hatcher, 1994). In order to understand the results the researcher reviewed the "Rotated Factor Pattern" first. The variables which have meaningful loadings on the factors are identified. For the social sciences factor loadings/ communalities are considered meaningful if they are greater than 0.40 (Osborne \& Costello, 2005; Stevens, 1986). Second if variables have meaningful loadings on two or more factors they are said to crossload and researchers tend to drop these variables, as they do not represent a "pure" measure of any one factor or construct (Hatcher, 1994). The other matrix that should be examined is the "Factor Structure Matrix". This matrix is less likely to demonstrate simple structure, and for this reason it is recommended that researchers rely more on the interpretation gained from the rotated factor pattern (Hatcher, 1994). The results for these matrices are listed below in Table 4.74 . 
Table 4.74: Results of Rotated Factor Pattern and Factor Structure Matrix

\begin{tabular}{|c|c|c|}
\hline & \multicolumn{2}{|c|}{ Factor Loadings } \\
\hline Factor 1: & Rotated Factor Pattern & Factor Structure Matrix \\
\hline $\begin{array}{l}\text { 1. Direct-to-consumer } \\
\text { advertising }\end{array}$ & 0.47 & 0.46 \\
\hline $\begin{array}{l}\text { 2. Face-to-fact detailing by } \\
\text { medical sciences liaison } \\
\text { and/or pharmaceutical } \\
\text { representative }\end{array}$ & 0.46 & 0.48 \\
\hline 3. Monitoring requirements & 0.42 & $\mathrm{CL}$ \\
\hline 4. Parents' education level & 0.55 & 0.58 \\
\hline $\begin{array}{l}\text { 5. Parental use of } \\
\text { antidepressants }\end{array}$ & 0.48 & 0.50 \\
\hline 6. Patient's family income & 0.67 & 0.67 \\
\hline 7. Patient's gender & 0.59 & 0.51 \\
\hline $\begin{array}{l}\text { 8. Availability of patient } \\
\text { education materials }\end{array}$ & DNL & 0.43 \\
\hline 9. Patient's age & DNL & $\mathrm{CL}$ \\
\hline \multicolumn{3}{|l|}{ Factor 2: } \\
\hline $\begin{array}{l}\text { 1. Patient's ability to perform } \\
\text { daily activities }\end{array}$ & 0.59 & 0.63 \\
\hline $\begin{array}{l}\text { 2. Severity of MDD } \\
\text { symptoms }\end{array}$ & 0.77 & 0.73 \\
\hline 3. Suicidal thinking & 0.80 & 0.76 \\
\hline 4. Patient's age & DNL & $\mathrm{CL}$ \\
\hline \multicolumn{3}{|l|}{ Factor 3: } \\
\hline 1. Formulary inclusion & 0.66 & 0.60 \\
\hline 2. Frequency of dosing & 0.43 & 0.50 \\
\hline $\begin{array}{l}\text { 3. Generic form of drug } \\
\text { available }\end{array}$ & 0.69 & 0.66 \\
\hline $\begin{array}{l}\text { 4. Manufacturer provides free } \\
\text { drugs to indigent patients }\end{array}$ & 0.51 & 0.56 \\
\hline 5. Medication cost & 0.62 & $\mathrm{CL}$ \\
\hline 6. Monitoring requirements & DNL & $\mathrm{CL}$ \\
\hline 7. Patient's insurance & DNL & 0.42 \\
\hline 8. Sample drugs to patients & DNL & $\mathrm{CL}$ \\
\hline \multicolumn{3}{|l|}{ Factor 4: } \\
\hline 1. Drug efficacy & 0.68 & 0.67 \\
\hline 2. Drug safety & 0.64 & 0.65 \\
\hline $\begin{array}{l}\text { 3. Co-existing conditions of } \\
\text { patient }\end{array}$ & DNL & 0.41 \\
\hline 4. Potential adverse effects & DNL & 0.44 \\
\hline
\end{tabular}

$\mathrm{DNL}=$ variable did not achieve a factor loading greater than 0.40 on the matrix

$\mathrm{CL}=$ variable had a meaningful factor loading on two factors under the matrix structure

The next step is to determine whether or not the variables which load on each factor in the rotated factor matrix have anything in common or seem to measure a similar construct. In reviewing the 
variables which loaded on Factor 1 (Direct-to-consumer advertising, Face-to-face detailing by medical sciences liaison and/or pharmaceutical representatives, Monitoring requirements, Parents' education level, Parental use of antidepressants, Patient's family income, and Patient's gender) these variables have a theme of drug marketing or patient socio-economics. The variables which loaded on Factor 2 (Patient's ability to perform daily activities, Severity of major depressive disorder symptoms, and Suicidal thinking) all seem to measure the construct of disease severity. The variables (Formulary inclusion, Frequency of dosing, Generic form of dug available, Manufacturer provides free drugs to indigent patients, and Medication cost) that loaded on Factor 3 all measure treatment or antidepressant cost to the patient. The variables (Drug efficacy and Drug safety) loaded on Factor 4 and both measure antidepressant drug profile.

The "Reference Structure Matrix" can be reviewed in the case where variables do not demonstrate simple structure in the "Rotated Factor Pattern". This can result if the factors are correlated with one another. The analysis indicated that Factor 1 and Factor 3 have an inter-factor correlation coefficient of 0.50 . This is not a strong correlation, but does show that these two factors are correlated. Conceptually, this does make sense as the variables which load on Factor 1 are related to the patient's socio-economic status and the variable which load on Factor 3 are related to the cost of the medication. Socio-economic status and the ability to pay for the medication are related concepts or constructs. Since some of the variables have meaningful loadings on one of the four factors identified above, but do not have zero or near-zero loadings on the other factors, the "Reference Structure Matrix", will be reviewed. Factor loadings on the "Reference Structure Matrix" are listed below in Table 4.75. 
Table 4.75: Factor Loadings on the Reference Structure Matrix

\begin{tabular}{|l|c|}
\hline & Factor Loading \\
\hline $\begin{array}{l}\text { Factor 1: Socio-economic Status of } \\
\text { Patient }\end{array}$ & 0.47 \\
\hline 1. Parents' education level & 0.41 \\
\hline 2. Parental use of antidepressants & 0.57 \\
\hline 3. Patient's family income & 0.50 \\
\hline 4. Patient's gender & 0.57 \\
\hline Factor 2: Disease Severity & \\
\hline $\begin{array}{l}\text { 1. Patient's ability to perform daily } \\
\text { activities }\end{array}$ & 0.75 \\
\hline 2. Severity of MDD symptoms & 0.77 \\
\hline 3. Suicidal thinking & 0.57 \\
\hline Factor 3: Medication Cost & 0.59 \\
\hline 1. Formulary inclusion & 0.44 \\
\hline 2. Generic form of drug available & \\
\hline $\begin{array}{l}\text { 3. Manufacturer provides free drugs to } \\
\text { indigent patients }\end{array}$ & 0.53 \\
\hline 4. Medication cost & \\
\hline Factor 4: Drug Profile & 0.66 \\
\hline 1. Drug efficacy & 0.62 \\
\hline 2. Drug safety & \\
\hline
\end{tabular}

Conceptually, the evaluation of this matrix provides a cleaner split of the variables. The variables that load on Factor 1 all measure patients' socio-economic status, the variables on Factor 2 measure disease severity, the variables on Factor 3 measure drug cost to the patient, and the variables on Factor 4 measure drug profile. No variables crossloaded on two factors on this matrix and simple structure was achieved for most variables. The drawback to the interpretation of this matrix is that only two variable loaded on factor 4 . The number of variables, however, was not increased in the rotated factor pattern in this study. This analysis shows this matrix is most useful for our in interpretation of the four factors underlying our variables. Therefore, it can be concluded that four factors labeled socio-economic status of the patient, disease severity, medication cost, and drug profile influence child psychiatrists' decision to prescribe or not to prescribe antidepressant medication to a child or adolescent who has been newly diagnosed with major depressive disorder. 


\section{CHAPTER FIVE: DISSCUSION \& CONCLUSIONS}

This chapter contains the discussion and the conclusions of this study. The results are discussed in the context of their significance and relation to the current published literature. This discussion is followed by study limitations, conclusions, and directions for future research. 


\section{Discussion and Conclusions for Phase I}

The purpose of Phase I of this study was to determine whether pediatricians treat children and/or adolescents with major depressive disorder. It has been documented in the literature that children and adolescents receive antidepressant treatment from primary care physicians (Olfson, 2008; Rushton et al., 2000). Due to resource limitations, the present study surveyed only one group of primary care providers, pediatricians. The current study found $60 \%$ of the pediatricians surveyed did not treat children or adolescents for major depressive disorder. None of the pediatricians surveyed treated children only, while $11.80 \%$ treated only adolescents. Additionally, $28.20 \%$ of the pediatricians reported treating both children and adolescents for major depressive disorder. A study conducted after the 2004 United States (U.S.) FDA black box warning on antidepressants, reported a shift away from primary health care providers to specialists treating children and adolescents with depression (Nemeroff et al., 2007). Nemeroff et al. (2007) found before the warning, psychiatrists accounted for $44 \%$ of the patient care for these depressed children and adolescents, however after the warning psychiatrists cared for $63 \%$ of the depressed children and adolescents (Nemeroff et al., 2007). If the current study had been conducted before the 2004 "black box" warning the results may have indicated more pediatricians willing to treat children and adolescents with major depressive disorder, however, this is not known to be a fact.

Even before the 2004 U.S. FDA warning, many pediatricians referred children and adolescents to other mental health care professionals for treatment. One such study conducted by Olfson (2008) found that pediatricians referred $78-79 \%$ of cases to other professionals. This was consistent with the findings of the current study which showed that over $80 \%$ of the pediatricians reported they refer children and adolescents to some other type of health care provider. Results also showed that pediatricians' decision to refer or treat was not necessarily a mutually exclusive decision. Psychiatrists were the primary health care provider to whom pediatricians most often refer children 
$(67.60 \%)$ and adolescents $(67.30 \%)$. The second most commonly cited health care professional was a psychologist for both children (13.70\%) and adolescents (14.00\%). Although the previously conducted studies did not focus specifically on major depressive disorder in children and adolescents, as did the current study, the results represent a consistent trend and hesitation of pediatricians to treat any form of depression in children and adolescents, including major depressive disorder.

The reason for pediatricians' hesitation to treat these patients may be due to their lack of confidence in their ability and training regarding the diagnosis and management of this disorder. A 2001 study found that $90 \%$ of pediatricians feel a responsibility to recognize depression in children and adolescents, but only 26-27\% feels responsible for treating these patients (Olfson, 2008). Few pediatricians (10-14\%) felt confident in treating children and adolescents with depression, however, $35 \%$ of these physicians indicated they felt motivated to enhance skills to recognize and manage these patients (Olfson, 2008). This implies a readiness for education and training in the assessment and treatment of children and adolescents with major depressive disorder. This also implies a need for the creation of educational resources for pediatricians related to the management and treatment of childhood and adolescent major depressive disorder.

From Phase I, it can be concluded that the proportion of pediatricians who treat children $\left(\chi^{2}=\right.$ $6.532, \mathrm{p}=0.088)$ and adolescents $\left(\chi^{2}=4.019, \mathrm{p}=0.259\right)$ across the U.S. does not significantly vary according to geographic region. However, pediatricians in the Midwest are somewhat more likely to treat children, while pediatricians in the Northeast are somewhat less likely to treat children for major depressive disorder. Geographic variation in physician prescribing has been documented in other studies, so the trend toward statistical significance is not surprising (Cox, Motheral, Henderson, \& Mager, 2003; Hull, Aquino, \& Cotter, 2005). The current study like the previous 
ones, however, did not reveal the reasons behind the geographic variation (Cox et al., 2003; Hull et al., 2005).

The other purpose of Phase I was to identify pediatricians who treat children and/or adolescents for major depressive disorder and who were willing to participate in the larger Phase II survey, regarding specific treatment practices. Only $39.95 \%$ of the pediatricians who returned surveys indicated they treat children and/or adolescents. Of those 163 pediatricians who treat children and/or adolescents, only $67.48 \%(n=110)$ were willing to participate in the Phase II survey. This information is useful by providing a basis for calculating future sample sizes when surveying pediatricians who treat children and/or adolescents with major depressive disorder.

\section{Discussion and Conclusions for Phase II}

\section{Choice of Treatment for Children and Adolescents}

The American Academy of Child and Adolescent Psychiatry (AACAP) recently published Practice Parameters for the treatment of depression in children and adolescents (AACAP, 2007). According to the Practice Parameters, children and adolescents with mild depression may benefit from education, supportive counseling, and case management (AACAP, 2007). More severe cases of depression, such as the population investigated in the current study, generally require treatment with antidepressants (AACAP, 2007). According to the AACAP the child or adolescent may be treated with antidepressants, either alone or in combination with counseling/psychotherapy (AACAP, 2007). It should be noted the Practice Parameters outline treatments shown to be effective in the treatment of depression but do not specify how physicians should treat children and adolescents with any type of depression, including major depressive disorder. The treatment of depression remains an individualized physician's decision.

One purpose of the Phase II study was to determine physicians' first, second, and third-lines of treatment for children and adolescents with major depressive disorder. The preponderance of child 
psychiatrists indicated they would first attempt to use a combination of antidepressants and counseling to treat children $(52.19 \%)$ and adolescents $(76.95 \%)$ with major depressive disorder. The same finding was reported by the majority of the pediatricians that they utilize a combination of antidepressants and counseling to treat children $(63.46 \%)$ and adolescents $(87.72 \%)$ with major depressive disorder. However, many other physicians indicated they would first attempt to treat the child or adolescent with counseling only. Child psychiatrists and pediatricians reported they use this approach more for children $(40.07 \% ; 28.85 \%)$ than adolescents $(15.93 \% ; 8.77 \%)$.

In the event the first-line of treatment is not successful the majority of child psychiatrists $(93.71 \%)$ and pediatricians $(74.00 \%)$ would switch the child to a different antidepressant medication or augment the counseling therapy, as the second-line of treatment. For adolescents, the majority of child psychiatrists $(72.73 \%)$ and pediatricians $(68.43 \%)$ reported switching the patient to a different antidepressant medication.

In the event the second-line of treatment was not successful, two-thirds of the child psychiatrists $(66.43 \%)$ reported switching the child to another antidepressant medication. While another $20 \%$ of the child psychiatrists indicated they would use some "other" type of treatment. For the child psychiatrists this "other" treatment consisted of treating the child with some other type of medication. These medications included antipsychotics (17.86\%), mood stabilizers (17.86\%), anticonvulsants $(8.93 \%)$, or lithium $(8.93 \%)$. The majority of pediatricians $(51.28 \%)$ reported attempting some "other treatment" for children. This "other treatment" consisted of pediatricians referring these children for psychiatric care. In the event the second-line of treatment was not successful for adolescents most of the child psychiatrists $(56.75 \%)$ reported switching these patients to another type of antidepressant medication. Over one-half of the pediatricians $(52.00 \%)$ reported they would attempt some "other" treatment. That treatment consists of referring the adolescent to a psychiatrist. Twenty four $(24.22 \%)$ percent of the child psychiatrists also indicated attempting some 
"other" treatment for these adolescents. For the child psychiatrists this "other" treatment consisted of treating the adolescent with some other type of medication. These medications included antipsychotics (20.00\%), mood stabilizers (18.57\%), anticonvulsants (14.29\%), or lithium (15.71\%).

The findings of this study indicate the preponderance of child psychiatrists and pediatricians utilize a combination of antidepressant treatment and counseling/psychotherapy for children and adolescents with major depressive disorder. This treatment is consistent with the American Academy of Child and Adolescent Psychiatry's recommendations for the treatment of children and adolescents with major depressive disorder (AACAP, 2007). The current study also found that many child psychiatrists and pediatricians try counseling/psychotherapy only as a first-line treatment for children. This seemingly more conservative approach should not be interpreted as an inadequate treatment, as this therapy is also supported by the AACAP for the treatment of depression. This approach may be related back to the pediatricians' lack of confidence in diagnosing and managing this disorder (Olfson, 2008). The child psychiatrists' desire to treat children with counseling only could be a function of their training, education, and expertise in counseling and psychotherapeutic techniques (AACAP, 2004). More investigation is necessary to draw valid conclusions on the reason for these treatment choices. Additionally, more examination is necessary to explore the timelines associated with switching treatments. Presently there are no guidelines on switching treatment in children and adolescents. Based on the adult literature, however, it is understood that treatment response to antidepressants is not immediate and requires several weeks (AACAP, 2004). The purpose of this study did not include investigating how long physicians wait for a treatment response until they switch to a new treatment for a child or adolescent with major depressive disorder. This could be investigated in future research.

In the event physicians utilize an antidepressant medication for the first-line of treatment for children or adolescents, they indicated they most commonly prescribe either Prozac ${ }^{\circledR}$ or Zoloft ${ }^{\circledR}$. 
This result was found for both child psychiatrists and pediatricians. For the first-line of treatment, the majority of child psychiatrists (51.98\%) and pediatricians (56.76\%) indicated they utilize Prozac $^{\circledR}$ to treat children. Other child psychiatrists $(27.12 \%)$ and pediatricians $(24.33 \%)$ indicated the use of Zoloft ${ }^{\circledR}$ to treat children. The findings were similar for physicians treating adolescents. For the first-line of treatment the majority of the child psychiatrists indicated they would utilize either Prozac ${ }^{\circledR}(50.21 \%)$ or Zoloft ${ }^{\circledR}(19.84 \%)$ to treat adolescents. This was also true for most of the pediatricians who indicated they would utilize either Prozac ${ }^{\circledR}(44.23 \%)$ or Zoloft ${ }^{\circledR}(38.46 \%)$.

For the second-line of treatment the majority of the physicians still reported utilizing Prozac ${ }^{\circledR}$ or Zoloft $^{\circledR}$ to treat children. The choice of antidepressant for the treatment of adolescents, however, varied somewhat for both child psychiatrists and pediatricians. The second-line of treatment choice was varied for the child psychiatrists. They utilized Zoloft ${ }^{\circledR}(23.97 \%)$, Prozac ${ }^{\circledR},(18.73 \%)$, Wellbutrin $(13.48 \%)$, and Celexa ${ }^{\circledR}(8.99 \%)$ and Lexapro ${ }^{\circledR}(8.99 \%)$. In comparison to pediatricians who reported utilizing Prozac ${ }^{\circledR}(36.85 \%)$, Zoloft ${ }^{\circledR}(28.95 \%)$, or Celexa ${ }^{\circledR}(15.22 \%)$.

For the third-line of treatment physicians' choice of antidepressant treatment for children and adolescents was more varied than for the first and second-lines of treatment. Child psychiatrists primarily reported utilizing one of the SSRI type antidepressants, but thirty percent (30.24\%) noted a preference for Wellbutrin $^{\circledR}$ as a third-line of treatment for children. In comparison, the majority $(55.56 \%)$ of the pediatricians indicated they would try the child on Wellbutrin ${ }^{\circledR}$. Another one-third, of the pediatricians (33.33\%) indicated the use of Zoloft ${ }^{\circledR}$ as a third-line of treatment.

When treating adolescents, the choice of antidepressants was even more varied. Approximately $40 \%$ of child psychiatrists reported using Wellbutrin ${ }^{\circledR}$. However, many indicated they would utilize some type of SSRI (most frequently Zoloft ${ }^{\circledR}$ ) or Effexor ${ }^{\circledR}$ (SNRI). In contrast, pediatricians (31.25\%) utilized Wellbutrin ${ }^{\circledR}$ or some type of SSRI. Of those reporting, Lexapro ${ }^{\circledR}$ was the most frequent SSRI chosen. The specific antidepressant most commonly used as first-line treatment for 
both children and adolescents by child psychiatrists and pediatricians was Prozac ${ }^{\circledR}$. The second most commonly used antidepressant by both specialties is Zoloft ${ }^{\circledR}$. As a second line of antidepressant treatment child psychiatrists and pediatricians and still utilized Prozac ${ }^{\circledR}$ and Zoloft ${ }^{\circledR}$ more commonly than other antidepressants for both children and adolescents.

The reasons for the popularity of these antidepressants may be related to the fact Prozac ${ }^{\circledR}$ is the only U.S. FDA approved antidepressant treatment for children and adolescents with major depressive disorder (U.S. FDA, 2004). The 2004 U. S. FDA warning highlighted a possible increase in suicidality in child and adolescents who are treated with antidepressants. Because of this risk, physicians may view $\operatorname{Prozac}^{\circledR}$ as a safer or more conservative treatment option and be hesitant to prescribe off-label antidepressants to children and adolescents. Although Zoloft ${ }^{\circledR}$ is not approved for the treatment of depression in children and adolescents; it is indicated for the treatment of obsessivecompulsive disorder in the pediatric population (U.S.FDA, 2007). Since this medication is indicated for the treatment of another disorder in this population, physicians may feel more comfortable prescribing it to this age group. The current study, however, did not investigate the specific rationale for prescribing one antidepressant over another.

\section{Association of Physician Type and Antidepressant Category}

The relationship between physician type and antidepressant category was assessed for the first, second, and third-lines of treatment for children and then for adolescents treated for major depressive disorder. It was concluded there was no significant difference in the antidepressant category prescribed by physicians (child psychiatrists versus pediatricians) for children or adolescents for either the first, second, or third-line of treatment. This result may have been due to the fact there was a small sample size of pediatricians and there was not enough power to detect a statistical difference between the two physician groups. These comparisons have not been reported in the literature to date. 


\section{Association of Physician Type and Specific Antidepressant}

The relationship between physician type and the specific antidepressant prescribed was also assessed for the first, second, and third-lines of treatment for children and then for adolescents treated for major depressive disorder. It was concluded there was no significant difference in the specific antidepressant prescribed by physicians (child psychiatrists versus pediatricians) for children or adolescents for the first, second, and third-lines of treatment. This result may have been due to the fact there was a small sample size of pediatricians and there was not enough power to detect a statistical difference between the two physician groups. Again, these comparisons have not been reported in the literature.

\section{Association of Physician Characteristics and Type of Treatment Prescribed for Children and Adolescents with Major Depressive Disorder}

The association between physician characteristics and type of treatment (antidepressant treatment versus counseling) prescribed for children, was assessed by the use of logistic regression. It was found that the type of physician, age of the physician, and geographic region in which the physician practiced was associated with prescribing antidepressant medication for a child with major depressive disorder.

The odds in favor of a physician prescribing an antidepressant is 0.402 times greater for a child psychiatrist as compared to a pediatrician. At first this finding may seem counterintuitive; however, this study found that many child psychiatrists use counseling only as a first-line approach to treat children and adolescents. This association of physician type and probability of prescribing an antidepressant medication for treatment may be related, at least in part, to the fact that child psychiatrists receive more training in conducting counseling/psychotherapy and are more confident in their abilities to treat the child or adolescent with counseling/psychotherapy (AACAP, 2004).

The odds in favor of a physician prescribing an antidepressant medication is greater for physicians older than 60 years of age. This finding may be related to the idea that many physicians 
rely on their own clinical experience to guide treatment choices. The current study found that a majority of the physicians surveyed utilize their own clinical experience or that of their colleagues to help guide their treatment choices. Perhaps even with the U.S. FDA "black box" warning many of these physicians have successfully utilized antidepressants in children and adolescents for many years in their own practices.

The odds in favor of physicians prescribing antidepressant medication whose practices are located in the South, Midwest, or Pacific/West are respectively, 2.625, 2.694, and 2.421, times greater as compared to physicians who practice in the Northeast. Geographic variation in prescribing psychotropic medications has been documented (Cox et al., 2003; Hull et al., 2005; Webster, Cifuentes, Verma, \& Pransky, 2008). This variation has been related to the demographics of the physicians. For example, Hull et al. (2005) reported, Asian-trained physicians were less likely to prescribe antidepressants to adults patients. Another study attributed geographic variation to differential training of physicians (Cox et al., 2003). The current study found that specialty of physician $(p=0.0249)$, physician age $(p=0.0551)$, and geographic location $(p=0.0040$ to $p=0.0168)$ were significantly associated with physicians prescribing antidepressants as treatment. The findings of the current study suggest an association between these variables and not causation. Therefore, to better understand the relationships between geographic variation, physician characteristics, and the treatment prescribed for children and adolescents with major depressive disorder, further study of these associations is warranted.

\section{Average Length of Treatment for Children and Adolescents}

The current study found approximately two-thirds $(65.15 \%)$ of child psychiatrists and one-half $(51.35 \%)$ of pediatricians continue to prescribe antidepressant medication to both children and adolescents for a period of at least ten months. Additionally, it was found the majority of child psychiatrists $(71.49 \%)$ and pediatrician $(63.46 \%)$ prescribe antidepressant medication for 
adolescents for at least ten months. The average length of time the physicians treat children and adolescents with antidepressant therapy was compared to the recent recommendations published by the AACAP. These recommendations are to continue treatment for depression for at least six months. This time frame has been associated with a lower rate of relapse of depressive symptoms. A randomized controlled trial compared children and adolescents with major depressive disorder on Prozac $^{\circledR}$ to patients on placebo. The objective of this trial was to determine whether treatment for six months could prevent relapse. It was concluded that the mean time to relapse was significantly longer $(\mathrm{p}=0.046)$ in the patients taking Prozac ${ }^{\circledR}$ than those given placebo treatment (Emslie et al., 2004). Therefore, based on the findings of the current study, both child psychiatrists and pediatricians are prescribing antidepressant medications to children and adolescents in accordance with the recently published recommendations of the AACAP (AACAP, 2207). The significance of this finding is that both children and adolescents, who are treated by pediatricians and child psychiatrists are receiving antidepressant medication for a sufficient length of time in order to prevent disease relapse.

\section{Pharmacotherapy Monitoring for Children and Adolescents}

Both child psychiatrists and pediatricians reported they conduct monitoring as part of an office visit with the child or adolescent. Furthermore, child psychiatrists and pediatricians indicated they would conduct the monitoring themselves. Over $90 \%$ of the pediatricians and child psychiatrists reported monitoring for adverse events, suicidality, and clinical symptoms. Some child psychiatrists and pediatricians also indicated they conduct some type of labwork for children and adolescents treated with an antidepressant.

Physicians were asked to indicate how frequently they monitored child and adolescent patients during the first three months of antidepressant treatment. For the first month of treatment, the majority of child psychiatrists monitor either once a week $(41.43 \%)$ or every two weeks 
(30.71\%) while pediatricians (54.35\%) reported monitoring children every two weeks. During the second month, the majority of child psychiatrists indicated they monitor either once a month (42.65\%) or every two weeks (34.05\%) compared to most pediatricians $(65.23 \%)$, who indicated they monitor once a month. Throughout the third month, the preponderance of child psychiatrists $(62.72 \%)$ monitor children once a month, whereas most of pediatricians $(52.18 \%)$ monitor children at some interval greater than once a month. For adolescents, during the first month, child psychiatrists monitor either once a week (38.95\%) or every two weeks (32.98\%) in comparison to most of the pediatricians $(53.70 \%)$ who monitor adolescents every two weeks. During the second month of treatment, child psychiatrists continue to monitor once (45.77\%) or twice a month $(30.28 \%)$, whereas pediatricians $(62.97 \%)$ reported that they did more frequent monitoring during the second month of treatment (once a month) than in the first month. During the third month of treatment, child psychiatrists $(62.68 \%)$ continue to monitor adolescents on antidepressant therapy once a month. In contrast, pediatricians monitor adolescents either once a month (42.60\%) or interval greater than once a month $(50.00 \%)$. The fact that physicians monitor more frequently early in treatment may be related to the idea that antidepressants can trigger agitation in some patients, and this agitation has been linked to an increase in suicidality (NIMH, 2009).

The frequency with, which physicians monitor children and adolescents, while they are on antidepressant treatment, was compared to the U.S. FDA recommendations. It was concluded that child psychiatrists and pediatricians monitor, both children and adolescents significantly less than the U.S. FDA recommendations during the first and second month of antidepressant therapy. During month three pediatricians still monitor children and adolescents significantly less than the U.S. FDA recommendations. However, the frequency with which child psychiatrists monitor children and adolescents, who are on antidepressant treatment, during the third month of treatment, does not differ significantly from the U.S. FDA recommendations. 
A recent study compared the frequency of physician monitoring before and after the U.S. FDA black box warning and found that less than $5 \%$ of all patients met the U.S. FDA monitoring recommendations before or after the 2004 warning (Morrato et al., 2008). Another recent study found that only $7.5 \%$ of "prescribing physicians" met the U.S. FDA recommendations for monitoring frequency (Bhatia et al., 2008). The results of the current study seem to be in agreement with other, similar studies in that physicians are not monitoring as frequently as the U.S. FDA recommended in 2004. The rationale for the monitoring frequency, however, was not explored in the current study.

The U.S. FDA recommends children and adolescents on antidepressant medication be monitored as follows: one time per week for the first month of treatment, biweekly during the second month of treatment, and at week twelve (U.S. FDA, 2004). Therefore, if child psychiatrists and pediatricians wish to monitor according to the U.S. FDA recommendations, they need to increase the frequency of monitoring during the first and second months of treatment. Pediatricians also need to increase monitoring frequency for children and adolescents during the third month of antidepressant treatment.

\section{Variables Influencing Physicians’ Decision to Prescribe Antidepressants}

Physicians were asked to rate the extent to which 28 variables influenced their decisions of whether or not to prescribe an antidepressant to a child or adolescent with major depressive disorder. Both child psychiatrists and pediatricians on average rated clinical experience with prescribing antidepressants, co-existing conditions of patient (e.g. obsessive compulsive disorder), comfort in managing major depressive disorder in youth, drug safety, drug efficacy, familiarity with an antidepressant being prescribed, severity of major depressive disorder symptoms, and suicidal thinking as being "influential" or "extremely influential”. Child psychiatrists also, rated potential 
adverse effects as being either "influential" or "extremely influential", while pediatricians rated potential adverse effects as being "not influential" or only "somewhat influential".

Exploratory factor analysis revealed four underlying factors socio-economic status of patient, disease severity, medication cost, and drug profile. Based on this analysis it was concluded that these four factors influence child psychiatrists' decision of whether or not to prescribe antidepressant medication to a child or adolescent who had been newly diagnosed with major depressive disorder.

This was the first study to examine these relationships for children and adolescents with major depressive disorder. However, other studies have examined the relationships between variables and physician prescribing behavior. Patient characteristics have been found to be related to physicians prescribing of antidepressants and medication for the treatment of panic disorder (Freeman et al., 1993; Sleath \& Shih, 2003). Disease severity and physical impairment have been shown to be related to physicians prescribing of antidepressants and antipsychotics to adults (Benson, 1983; Sleath \& Shih, 2003). Medication cost has been found to be related to physicians prescribing antidepressants to adults (Cates, 2001). Drug safety and efficacy have been found to influence physicians prescribing of antidepressants and medications to treat panic disorder in adults (Cates, 2001; Freeman et al., 1993). The results of this study also show associations similar to those in the aforementioned studies conducted for various disorders in the adult population.

\section{Study Limitations}

The limitations to the current study are related to the survey methodology employed. Surveys can be prone to sampling error, non-response bias, measurement error, and self-report. Steps were taken in this study to help mitigate the impact of these factors. The sample utilized in this survey was a national random sample of pediatricians and child psychiatrists. This was done in order to increase the generalizability of the results of the survey. The degree to which the returned surveys were geographically representative to the original sample was not assessed in this study. 
The reason for this was that the researcher did not have access to an electronic database of the original sample of pediatricians and child psychiatrists and data analysis was not feasible. Also, two mailings of each survey were completed in order to increase the response rate. The length of the survey, at eight pages was long and may have impacted the response rates to some extent.

Physicians are busy people especially, child psychiatrists, in light of the current shortage of child psychiatrists in the United States (AACAP, 2004). Incentives have been shown to increase response rates, however due to limited resources, offering an incentive was not feasible for this study (Kellerman, 2001).

Non-response bias can be a problem with survey research if the respondents differ from the nonresponders. A non-response analysis was conducted, which compared early responders of the Phase II survey to late responders (who served as a proxy for non-responders). The non-response analysis found no statistical significant difference between early responders and non-responders. Based on this analysis, it appears that non-response bias was not a factor in this survey.

Measurement error occurs when respondents do not understand the survey questions or surveys instructions, and will impact the accuracy of the inferences drawn from the survey responses. A pilot study was done in order to assess the survey instrument for Phase II. Based on the findings from the pilot study it was concluded some of the questions and instructions regarding treatment choices (first, second, and third-line of treatment) for children and adolescents were unclear and were misunderstood. These questions were revised and the instructions were re-written. The changes to the survey seemed to help clarify these issues somewhat when the final survey was sent to the larger sample of child psychiatrists and pediatricians. Some of the child psychiatrists $(20.25 \%)$ still indicated their first-line of treatment was "counseling only", but also listed the use of an antidepressant for the first-line of treatment. Since the majority of these physicians also listed the same antidepressant in the second-line of treatment, the researchers made the assumption that 
"counseling only" was truly their first-line of treatment and the antidepressant chosen was their second-line of treatment. This is a reasonable assumption; however, if a similar survey is conducted in the future the wording of these questions should be re-examined and pilot tested to further ensure clarity.

This study surveyed a national sample of both pediatricians and child psychiatrists. Thus, the results from the study should be generalizable. A response rate of $22.9 \%$ was obtained for Phase I of the study and a response rate of $15.1 \%$ was obtained for the surveyed child psychiatrists (Phase II). However, only 57 pediatricians' surveys were usable out of the 110 mailed in Phase II. This was a function of the finding that $60 \%$ of the pediatricians in Phase I do not treat children or adolescents for major depressive disorder. Unfortunately, this impacted some of the planned analyses for this population. For instance, factor analysis requires at a very minimum five subjects for every variable (Hatcher, 1994). In this study, there were 28 variables and a minimum of 140 subjects needed to conduct factor analysis. The 57 pediatricians did not meet these minimum standards. The small sample size of pediatricians in Phase II is also a cause for concern in comparisons between pediatricians and child psychiatrists. Post hoc power analyses failed to demonstrate adequate power to conduct many of these comparisons. The associations between physician type and class of antidepressant (SSRIs versus Non-SSRIs) and then specific type of antidepressant (Prozac ${ }^{\circledR}$ versus $^{-}$ Non-Prozac ${ }^{\circledR}$ ) were tested. None of these comparisons resulted in statistically significant associations. For these comparisons, the actual sample sizes for the pediatricians ranged from 9 to 57, and for the child psychiatrists ranged from 175 to 294 . The significance level was $\alpha=0.05$ and the post hoc power for these comparisons resulted in 0.51 or less power for all comparisons (Cohen, 1988). For other objectives the t-test statistic was utilized to test for differences between the average number of times pediatricians and child psychiatrists monitor patients during months one, two, and three of antidepressant treatment. The sample sizes for the pediatricians ranged from 45-53, and 
ranged from 251-272 for child psychiatrists. The observed power for these comparisons ranged from $0.05-0.88$ power. The sample size of 53 pediatricians and 269 child psychiatrists, achieved 0.88 power to detect an effect size of $d=0.47(d=0.50$ represents a "medium" effect size $)$ using a ttest with a significance level of $\alpha=0.05$ (Cohen, 1988). Power analyses were conducted using the computer programs PASS ${ }^{\circledR}$ or G*Power 3 (Erdfelder, 1996). In summary, the number of pediatricians was not adequate to conduct all of the comparisons, with adequate power, between pediatricians and child psychiatrists for this study. Additionally, because of the limited number of pediatricians in Phase II, caution should be exercised when extrapolating the findings from this survey to the entire population of pediatricians in the U.S.

\section{Overall Conclusions}

In the absence of empirical research to guide the selection of antidepressant treatment, research was necessary to examine: what physicians consider to be the most appropriate antidepressant treatment, physicians' recommended course of treatment (i.e., length of treatment, monitoring), and the factors which impact physicians' decisions to treat major depressive disorder in children and adolescents with antidepressants.

In achieving these goals some preliminary information needed to be collected on pediatricians, in Phase I. The findings from this phase provide a basis for calculating a sample size for future surveys of pediatricians who treat children and/or adolescents with major depressive disorder and allowed for the identification of pediatricians eligible for Phase II of this study.

The treatment of depression is an individualized choice and therefore strict guidelines for treatment choices do not exist. The AACAP has published Practice Parameters to outline the treatments that have been shown, through randomized clinical trials, to be effective in the treatment of major depressive disorder in children and adolescents. These parameters are meant to help direct physicians in treating children and adolescents with major depressive disorder, but in no way dictate 
proper treatment of these patients. The current study gathered information on pediatricians' and child psychiatrists' preferred treatment choices for children and adolescents with major depressive disorder and these preferences are in line with the current AACAP Practice Parameters.

The current study gathered information on the frequency with which physicians monitor children and adolescents who are prescribed antidepressant medication. These findings indicate pediatricians and child psychiatrists are not monitoring as frequently as the U.S. FDA recommends. The reasons for this are not known.

Exploratory factor analysis did reveal four underlying factors (socio-economic status of patient, disease severity, medication cost, and drug profile) related to the physicians' decision of whether or not to prescribe antidepressant treatment. The associations between physician characteristics (specialty of physician, geographic location of practice, and physician age) and the treatment prescribed were also found in this study and concur with similar studies in other patient populations.

\section{Future Research}

Four areas of future research were identified. First, the study gathered preliminary information regarding pediatricians' treatment of children and adolescents with major depressive disorder. Since this information is now available, it will be possible to conduct a larger, more representative study regarding pediatricians' treatment choices for treating children and adolescents with major depressive disorder. Additionally, a larger study of pediatricians can investigate in more detail areas why pediatricians lack training and skills to diagnose and treat major depressive disorder.

Second, the study collected information on pediatricians' and child psychiatrists' treatment choices for children and adolescents with major depressive disorder. However, it did not investigate the rationale behind these choices. For example, although the majority of physicians treat patients with a combination of antidepressants and counseling, some physicians opt to treat with counseling only as a fist-line of therapy. Additionally, as a third-line of treatment, many physicians treat with 
other type of medications such as, antipsychotics or mood stabilizers. Also, the most popular choices for antidepressant treatment were Prozac ${ }^{\circledR}$ and Zoloft ${ }^{\circledR}$. Future studies should also explore why these were the choices of the physicians surveyed.

Third, according to the findings of this study and other recent studies (Bhatia et al., 2008; Morrato et al., 2008), pediatricians and child psychiatrists do not monitor as frequently as the U.S. FDA recommendations. The reasons for this could not be determined from this study and should be an area for further research.

Fourth, the researcher found that the socio-economic status of the patient, disease severity, medication cost, and drug profile are related to the physicians' decision of whether or not to prescribe antidepressant treatment. Also, associations between physician characteristics (specialty, age, and geographic location) and the treatment prescribed were found in this study. In order to better understand these relationships, these associations warrant further investigation. 


\section{References}

Achenbach, T., \& Rescorla, L. (2001). Manual for the ASEBA School-Age Forms and Profiles. Burlington,VT: University of Vermont Research Center for Children Youth and Families.

Agency for Health Care Policy and Research (AHCPR). (1993). Depression Guideline Panel. Depression in Primary Care: Volume 2. Treatment of Major Depression. Clinical Practice Guideline, Number 5. Retrieved February 2, 2006, from http://www.mentalhealth.com/bookah/p44-d2a.html\#Head37.

Allison, P. (1999). Logistic Regression Using SAS ${ }^{\Theta}$. SAS Institute and Wiley: Cary, NC. Ambrosini, P. (2000). A Review of Pharmacotherapy of Major Depresssion in Children and Adolescents. Psychiatric Services, 51(5), 627-633.

American Academy of Child and Adolescent Psychiatry. (1998). Summary of the Practice Parameters for the Assessment and Treatment of Children and Adolescents with Depressive Disorders. Journal of the American Academy of Child and Adolescent Psychiatry, 37.

American Academy of Child and Adolescent Psychiatry. (2007). Practice Parameters for the Assessment and Treatment of Children and Adolescents with Depressive Disorders. Journal of the American Academy of Child and Adolescent Psychiatry, 46,1503-1526.

American Psychiatric Association. (2000). The Diagnostic and Statistical Manual of Mental Disorders (Fourth Edition ed.). Arlington, VA: American Psychiatric Press, Inc.

American Psychiatric Association. (2006). About APA. Retrieved May 20, 2006, from http://www.psych.org/about_apa/.

American Psychiatric Association. (2006). Background Information and Review of Available Evidence. Retrieved February 2, 2006, from http://www.psych.org/psych_pract/treatg/pg/Depression2e.book-12.cfm\#c.

American Psychiatric Association. (2006). Frequently Asked Questions: Diagnostic and Statistical Manual of Mental Disorders. Retrieved May 20, 2006, from http://www.psych.org/research/dor/dsm/dsmintro81301.cfm.

American Psychiatric Association, \& American Academy of Child and Adolescent Psychiatry. (2004). The Use of Medication in Treating Childhood and Adolescents Depression: Information for Physicians. Retrieved January 26 2006, from http://www.parentsmedguide.org/physiciansmedguide.pdf.

Ananth, C., \& Kleinbaum, D. (1997). Regression Models for Ordinal Responses: A Review of Methods and Applications. International Journal of Epidemiology 26, 1323-1333.

Angst, J., Gamma, A., Sellaro, R., Lavori, P., \& Zhang, H. (2003). Recurrence of Bipolar Disorders and Major Depression. A Life-Long Perspective. European Archives of Psychiatry and Clinical Neuroscience, 253(5), 236-240.

Armstrong, J., \& Overton, T. (1977). Estimating Nonresponse Bias in Mail Surveys. Journal of Marketing Reseach, 14, 396-402.

Beck, A., \& Steer, R. (1987). Manual for the Beck Depression Inventory. San Antonio,TX: Psychological Corporation.

Benson, P. (1983). Factors Associated with Antipsychotic Drug Prescribing by Southern Psychiatrists. Medical Care, 21(6), 639-654.

Berton, O., \& Nestler, E. (2006). New Approaches to Antidepressant Drug Discovery: Beyond Monoamines Nature Reviews, 7, 137-151.

Bewick, V., Cheek, L., \& Ball, J. (2005). Statistics review 14: Logistic Regression. Critical 
Care, 9, 112-118.

Bhatia, S., Rezac, A., Vitiello, B., Sitorious, M., Buehler, B., \& Kratochvil, C. (2008).

Antidepressant Prescribing Practices for the Treatment of Children and Adolescents. Journal of Child and Adolescent Psychopharmacology, 18(1), 70-80.

Birmaher, B., Ryan, N., \& Williamson, D. (1996). Childhood and Adolescent Depression: A

Review of the Past 10 Years, Part I. Journal of Child and Adolescent

Psychopharmacology, 35(11), 1427-1439.

Birmaher, B., Waterman, S., Ryan, N., Perel, J., McNabb, J., Balach, L., et al. (1998).

Randomized, Controlled Trial of Amitriptyline Versus Placebo for Adolescents with

"Treatment-Resistant" Major Depression Journal of the American Academy of Child and Adolescent Psychiatry, 37(5), 527-535.

Bramble, D. (1995). Antidepressant Prescription by British Child Psychiatrists: Practice and Safety Issues. Journal of the American Academy of Child and Adolescent Psychiatry, 34(3), 327-331.

Brent, D., Holder, D., Kolko, D., Birmaher, B., Baugher, M., Roth, C., et al. (1997). A Clinical Psychotherapy Trial for Adolescent Depression Compaing Cognitive, Family, and Supportive Therapy. Archives of General Psychiatry, 54(9), 877-885.

Brent, D. (2005). Is the Medication Bottle for Pediatric and Adolescent Depression Half-Full or Half-Empty? Journal of Adolescent Health, 37, 431-433.

Bridge, J., Salary, C., Birmaher, B., Asare, A., \& Brent, D. (2005). The Risks and Benefits of Antidepressant Treatment for Youth Depression. Annals of Medicine, 37, 404-412.

Campbell, D., \& Stanley, J. (1963). Experimental and Quasi-Experimental Designs for Research. Boston, MA: Houghton Mifflin Company.

Caplow, T., \& Raymond, J. (1954). Factors Influencing the Selection of Pharmaceutical Products. The Journal of Marketing, 18-23.

Carson, R., Butcher, J., \& Mineka, S. (2002). Fundamentals of Abnormal Psychology and Modern Life. Boston, MA: Allyn and Bacan.

Cates, M. (2001). Selecting Antidepressant Therapy for Patients with Major Depression. American Journal of Pharmaceutical Education, 65, 190-194.

Cattell, R. (1966). The Scree Test for the Number of Factors. Multivariate Behavioral Research, 1, 245-276.

Chen, A., \& Chang, R. (2002). Factors Associated With Prescription Drug Expenditures Among Children: An Analysis of the Medical Expenditure Panel Survey. Pediatrics, 109(5), 728-732.

Chew, L., O'Young, T., Hazlet, T., Bradley, K., Maynard, C., \& Lessler, D. (2000). A Physician Survey of the Effect of Drug Sample Availability on Physicians' Behavior Journal of General Internal Medicine, 15, 478-483.

Churchill, G. (1999). Marketing Research: Methodological Foundations (Seventh ed.). Fort Worth, TX: The Dryden Press Harcourt Brace College Publishers.

Clark, J., Potter, D., \& McKinlay, J. (1991). Bringing Social Structure Back into Clinical Decision Making. Social Science \& Medicine, 32(8), 853-866.

Cody, R., \& Smith, J. (1997) Applied Statistics and the SAS ${ }^{\circledR}$ Programming Language. Upper Saddle River, NJ: Prentice-Hall, Inc.

Cohen, J. (1988). Statistical Power Analysis for the Behavioral Sciences. Hillsdale, NJ: Erlbaum Associates.

Compton, S., March, J., Brent, D., Albano, A., Weersing, V., \& Curry, J. (2004). CognitiveBehavioral Psychotherapy for Anxiety and Depressive Disorders in Children and Adolescents: An Evidence-Based Medicine Review. Journal of the American 
Academy of Child and Adolescent Psychiatry, 43(8), 930-959.

Costello, E., Pine, D., Hammen, C., March, J., Plotsky, P., Weissman, M., et al. (2002). Development and Natural History of Mood Disorder. Society of Biological Psychiatry, 52, 529-542.

Costello, E., Mustillo, S., Erkanli, A., Keeler, G., \& Angold, A. (2003). Prevalence and Development of Psychiatric Disorders in Childhood and Adolescence. Archives of General Psychiatry, 60, 837-844.

Courtney, D. (2004). Selective Serotonin Reuptake Inhibitor and Venlafaxine use in Children and Adolescents with Major Depressive Disorder: A Systematic Review of Published Randomized Controlled Trials Canadian Journal of Psychiatry, 49, 557563.

Cox, E., Motheral, B., Henderson, R., \& Mager, D. (2203) Geographic Variation in the Prevalence of Stimulant Medication Use Among Children 5 to 14 Years Old: Results from a Commercially Insured US Sample. Pediatrics, 111; 237-243.

Denig, P., Haaijer-Ruskamp, M., \& Zijsling, D. (1988). How Physicians Choose Drugs. Social Science \& Medicine, 27(12), 1381-1386.

Depont, F., Rambelomanana, S., Le Puil, S., Begaud, B., Verdoux, H., \& Moore, N. (2003). Antidepressants: Psychiatrists' Opinions and Clinical Practice. Acta Psychiatrica Scandinavica, 108, 24-31.

Dopheide, J. A. (2006). Recognizing and Treating Depression in Children and Adolescents. American Journal of Health System Pharmacy, 63, 233-243.

Drummond, M., O'Brien, B., Stoddart, G., \& Torrance, G. (1997). Methods for the Economic Evaluation of Health Care Programmes. Oxford, UK: Oxford University Press.

Dubitsky, G. M. (204). Review and Evaluation of Clinical Data: Placebo-Controlled Antidepressant Studies in Pediatric Patients. Retrieved January 29 2006, from http://www.fda.gov/ohrms/dockets/ac/04/briefing/2004-4065b1-08-TAB06-DubitskyReview.pdf.

Erdfelder, E., Faul, F., \& Buchner, A. (1996). GPOWER: A General Power Analysis Program. Behavior Research Methods, Instruments, and Computers, 28, 1-11.

Efron, D., Hiscock, H., Sewell, J., Cranswick, N., Vance, A., Tyl, Y., et al. (2003).

Prescribing of Psychotropic Medications for Children by Australian Pediatricians and Child Psychiatrists. Pediatrics, 111(2), 372-375.

Eisenberg, J. M. (1979). Sociological Influences on Decision-Making by Clinicians. Annals of Internal Medicine, 90, 957-964.

Emslie, G., Rush, J., Weinberg, W., Gullion, C., Rintelmann, J., \& Hughes, C. (1997). Recurrence of Major Depressive Disorder in Hospitalized Children and Adolescents. Journal of the American Academy of Child and Adolescent Psychiatry, 36(6), 785792.

Emslie, G., Walkup, J., Pliszka, S., \& Ernst, M. (1999). Nontricyclic Antidepressants: Current Trends in Children and Adolescents. Journal of the American Academy of Child and Adolescent Psychiatry, 38(5), 517-528.

Emslie, G., Heiligenstein, J., Wagner, K., Hoog, S., Ernest, D., Brown, E., et al. (2002). Fluoxetine for Acute Treatment of Depression in Children and Adolescents: A Placebo-Controlled, Randomized Clinical Trial. Journal of the American Academy of Child and Adolescent Psychiatry, 41, 1205-1215.

Emslie, G., Heiligenstein, J., Hoog, S., Wagner, K., Findling, R., McCraken, J., et al. (2004). Fluoxetine Treatment for Prevention of Relapse of Depression in Children and Adolescents: A Double-Blind, Placebo-Controlled Study. Journal of the American 
Academy of Child and Adolescent Psychiatry, 43, 1397-1405

Emslie, G., Ryan, N., \& Wagner, K. (2005). Major Depressive Disorder in Children and

Adolescents: Clinical Trial Design and Antidepressant Efficacy. Journal of Clinical

Psychiatry, 66, 14-20.

Emslie, G., Findling, R., Yeung, P., Kunz, N., \& Li, Y. (2007). Venlafaxine ER for the

Treatment of Pediatric Subjects with Depression: Results of Two Placebo-

Controlled Trials. Journal of the American Academy of Child and Adolescent Psychiartry, 46, 479-488.

Epstein, S., Gonzales, J., Weinfurt, K., Boekeloo, B., Yuan, N., \& Chase, G., (2001). Are

Psychiatrists' Characteristics Related to How They Car for Depression in the Medically III?. Psychosomatics, 46, 482-489.

Fergert, J., Kolch, M., Zito, J., Glaeske, G., \& Janhsen, K. (2006). Antidepressant use in Children and Adolescents in Germany Journal of Child and Adolescent Psychopharmacology, 16, 197-206.

Fiedorowicz, J., \& Swartz, K. (2004). The Role of Monoamine Oxidase Inhibitors in Current Psychiatric Practice. Journal of Psychiatric Practice, 10(4), 239-248.

Frank, E., Kupfer, D., Wagner, E., McEachram, A., \& Cornes, C. (1991). Efficacy of Interpersonal Psychotherapy as a Maintenance Treatment of Recurrent Depression. Contributing Factors. Archives of General Psychiatry, 48(12), 1053-1059.

Frank, E., Prien, R., Jarrett, R., Keller, M., Kupfer, D., Lavori, P., et al. (1991). Conceptualization and Rationale for Consensus Definitions of Terms in Major Depressive Disorder. Remission, recovery, relapse, and recurrence. Archives of General Psychiatry, 48(9), 851-855.

Freeman, J., Barnes, J., Summers, K., \& Szeinbach, S. (1993). Modeling Physicians' Prescribing Decisions for Patients with Panic Disorder. Journal of Health Care Marketing, 34-39.

Garrison, G., \& Levin, G. (2000). Factors Affecting Prescribing of the Newer Antidepressants. The Annals of Pharmacotherapy, 34(1), 10-14.

Geller, B., Reising, D., Leonard, H., Riddle, M., \& Walsh, T. (1999). Critical Review of Tricyclic Antidepressant Use in Children and Adolescents. Journal of the American Academy of Child and Adolescent Psychiatry, 3, 513-516.

GlaxoSmithKline. (1997). Antidepressant Medication Guide. Retrieved February 6, 2006, from http://www.wellbutrin-xl.com/prescribed/side_effects.html.

GlaxoSmithKline. (2006). Medication Guide for Wellbutrin XL. Retrieved January 29, 2006, from http://www.wellbutrin-xl.com/prescribed/side_effects.html.

Goodwin, R., Gould, M. S., Blanco, C., \& Olfson, M. (2001). Prescription of Psychotropic Medications to Youths in Office-Based Practice. Psychiatric Services, 52(8), 10811087.

Gorsuch, R. (1983). Factor Analysis. Hillsdale, NJ: Erlbaum.

Greenberg, P., Kessler, R., Birnbaum, H., Leong, S., Lowe, S., Berglund, P., et al. (2003). The Economic Burden of Depression in the United States: How Did it Change Between 1990 and 2000? Journal of Clinical Psychiatry, 64(12), 1465-1475.

Green-Hennessy, S., Hennessy, K. D., \& (1999). Demographic Differences in Medication use Among Individuals with Self-Reported Major Depression. Psychiatric Services, 50(2), 257-259.

Guy, W. (1976). Early Clinical Drug Evaluation Assessment Manual for Psychopharmacology. Rockville: United States Department of Health Education and Welfare Public Health Service Alcohol Drug Abuse and Mental Health Administration 
United States National Institute of Mental Health Psychopharmacology Research Branch.

Haapaslo-Pesu, K., Erkolahti, R., Saarijarvi, S., \& Aalberg, V. (2004). Prescription of Psychotropic Drugs in Adolescent Psychiatry Wards in Finland. Nordic Journal of Psychiatry, 58(3), 213-218.

Haby, M., Tonge, B., Littlefield, L., Carter, R., \& Vos, T. (2004). Cost-effectiveness of Cognitive Behavorial Therapy and Selective Serotonin Reuptake Inhibitors for Major Depression in Children and Adolescents. Australian and New Zealand Journal of Psychiatry, 38(8), 579-591.

Hatcher, L. (1994). A Step-by-Step Approach to Using SAS for Factor Analysis and Structural Equation Modeling. Cary, NC: SAS Publishing.

Haller, D. (2006). Treatment of Depression in Children and Adolescents. The Lancet, 366, 1694-1695.

Hamilton, M. (1960). A Rating Scale for Depression. Journal of Neurology and Neurosurgery Psychiatry, 23, 56-62.

Harpaz-Rotem, I., \& Rosenheck, R. (2006). Prescribing Practices of Psychiatrist and Primary Care Physicians Caring for Children with Mental Illness. Child: Care, Health and Development, 32(2), 225-237.

Hazell, P., O'Connell, D., \& Heathcote, D. (1995). Efficacy of Tricyclic Drugs in Treating Child and Adolescent Depression. British Medical Journal, 310, 897-901.

HealthyPlace. (2006). Retrieved February 2, 2006, from http://healthyplace.com/Communities/Depression/treatment/antidepressant/tricyclic.a sp.

Hickie, I., Scott, E., \& Davenport, T. (1999). Are Antidepressants all the same? Surveying the Opinions of Australian Psychiatrists. Australian and New Zealand Journal of Psychiatry, 33, 642-649.

Hong, S., \& Shepherd, M. (1996). Psychosocial and Demographic Predictors of Pediatric Psychotropic Medication Use. American Journal of Health System Pharmacy, 53(16), 1934-1939.

Hosmer, D., Lemeshow, S. (2000). Applied Logistic Regression. New York: John Wiley and Sons, Inc.

Hugtenburg, J., Heerdink, E., \& Tso, Y. (2005). Psychoactive Drug Prescribing by Dutch Child and Adolescent Psychiatrists. Acta Paediatrica, 94, 1484-1487.

Hull, S., Aquino, P., Cotter, S. (2005) Explaining Variation in Antidepressant Prescribing Rates in East London: A Cross-Sectional Study. Family Practice, 22(1), 37-42.

Huszonek, J., Dewan, M., \& Donnelly, M. (1995). Factors Associated with Antidepressant Choice. Psychosomatics, 42-47.

Jensen, P., Bhatara, V., Vitiello, B., Hoagwood, K., Feil, M., \& Burke, L. (1999). Psychoactive Medication Prescribing Practices for U.S. Children: Gaps Between Research and Clinical Practice. Journal of the American Academy of Child and Adolescent Psychiatry, 38(5), 557-565.

Kaplan, S., \& Busner, J. (1997). Prescribing Practices of Inpatient Child Psychiatrists Under Three Auspices of Care. Journal of Child and Adolescent Psychopharmacology, 7(4), 275-286.

Karasu, T. B., Gelenberg, A., Merriam, A., \& Wang, P. (2000). Practice Guideline for the Treatment of Patients with Major Depressive Disorder. Retrieved January 29 20067, from http://www.psych.org/psych_pract/treatg/pg/MDD2e_05-15-06.pdf.

Keller, M., Ryan, N., Strober, M., Klein, R., Kutcher, S., Birmaher, B., et al. (2001). Efficacy 
of Paroxetine in the Treatment of Adolescent Major Depression: A Randomized, Controlled Trial Journal of the American Academy of Child and Adolescent Psychiatry, 40(7), 762-772.

Kellerman, S., \& Herold, J. (2001). Physician Reponse to Surveys: A Review of the Literature. American Journal of Preventive Medicine, 20(1), 61-67.

Kovacs, M., Feinberg, T., Crouse-Novak, M., Pualauskas, S., \& Finkelstein, R. (1984). Depressive Disorders in Childhood I: A Longitudinal Prospective Study of Characteristics and Recovery. Archives of General Psychiatry, 41(3), 229-237.

Kovacs, M., Feinberg, T., Crouse-Novak, M., Paulauskas, S., Pollack, M., \& Finkelstein, R. (1984). Depressive Disorders in Children II: A Longitudinal Study of the Risk for a Subsequent Major Depression. Archives of General Psychiatry, 41(7), 643-649.

Kovacs, M. (1992). Children's Depression Inventory Manual. North Tonawanda, NY: MultiHealth Systems, Inc.

Kovacs, M., Obrosky, D. S., Gatsonis, C., \& Richards, C. (1997). First-Episode Major Depressive and Dysthymic Disorder in Childhood: Clinical and Sociodemographic Factors in Recovery. Journal of the American Academy of Child and Adolescent Psychiatry, 36(6), 777-784.

Kravitz, R., Epstein, R., Feldman, M., Franz, C., Azari, R., Wilkes, M., et al. (2005). Influence of Patients' Requests for Direct-to-Consumer Advertised Antidepressants. Journal of the American Medical Association, 293(16), 1995-2002.

Kurian, B., Ray, W., Arbogast, P., Fuchs, D., Dudley, J., \& Cooper, W. (2007). Effect of Regulatory Warnings on Antidepressant Prescribing for Children and Adolescents, Archives of Pediatric and Adolescent Medicine, 161(7) 690-696.

Lekhwani, M., Nair, C., Nikhinson, I., \& Ambrosini, P. (2004). Psychotropic Prescription Practices in Child Psychiatric Inpatients 9 Years Old and Younger. Journal of Child and Adolescent Psychopharmacology, 14(1), 95-103.

Lewinsohn, P., Rohde, P., \& Seeley, J. R. (1998). Major Depressive Disorder in Older Adolescents: Prevalence, Risk Factors, and Clinical Implications. Clinical Psychology Review, 18, 765-794.

Lewinsohn, P., Rohde, P., Klein, D., \& Seeley, J. (1999). Natural Course of Adolescent Major Depressive Disorder: I. Continuity into Young Adulthood Journal of the American Academy of Child and Adolescent Psychiatry, 38(1), 56-63.

Lieberman, J. (2003). History of the Use of Antidepressants in Primary Care. Journal of Clinical Psychiatry, 5(suppl 7), 6-10.

Mandoki, M., Tapia, M., Tapia, M., Sumner, G., \& Parker, J. (1997). Venlafaxine in the Treatment of Children and Adolescents with Major Depression.

Psychopharmacology Bulletin, 33(1), 149-154.

March, J., \& The Treatment for Adolescents with Depression Study (TADS) Team. (2003). Treatment for Adolescents with Depression Study (TADS): Rationale, Design, and Methods. Journal of the American Academy of Child and Adolescent Psychiatry, 42(5), 531-542.

March, J., \& Treatment for Adolescents with Depression Study (TADS) Team. (2004). Fluoxetine, Cognitive-Behavioral Therapy, and their Combination for Adolescents with Depression Journal of the American Medical Association, 292, 807-820.

Martin, B. (1974). Don't Survey Physicians'. Chicago: Center for Health Services Research and Development, American Medical Association.

Mayo Clinic. (2004). Retrieved February 2, 2006, from http://www.mayoclinic.com/health/maois/HQ01575. 
McCabe, B. (1986). Dietary Tyramine and other Pressor Amines in MAOI Regimes: A Review. Journal of the American Dietetic Association 86, 1059-1064.

Mclntyre, J., Charles, S., Anzia, D., Cook, I., Finnerty, M., Johnson, B., et al. (2000). American Psychiatric Association Steering Committee on Practice Guidelines. Retrieved May 20, 2006, from http:www.psych.org/psych_pract/treatg/pg/MDD2e_05-15-06.pdf.

MedicineNet.com. (1996). Desyrel. Retrieved January 29, 2006, from http://www.medicinenet.com/script/main/art.asp?articlekey=6081\&pf=3\&page=1.

MedicineNet.com. (1997). Serzone. Retrieved January 29, 2006, from http://www.medicinenet.com/script/main/art.asp?articlekey=833\&pf=3\&page=1.

MedicineNet.com. (1999). Remeron. Retrieved January 29, 2006, from $\mathrm{http}: / / \mathrm{www}$.medicinenet.com/script/main/art.asp?articlekey=6081\&pf=3\&page1.

MedicineNet.com. (2003). Wellbutrin, Wellbutrin SR, Wellbutrin XL, Zyban Retrieved January 29, 2006, from http://www.medicinenet.com/script/main/art.asp?articlekey=707\&pf=3\&page=1.

Medicines and Healthcare Products Regulatory Agency. (2004). Selective Serotonin Reuptake Inhibitors (SSRIs)-overview of regulatory status and CSM advice relating to major depressive disorder (MDD) in children and adolescents: Summary of clinical trials. Retrieved October 9, 2004, from http://medicines.mhra.gov.uk/ourwork/monitorsafequalmed/safetymessages/ssriover view.

Melfi, C., Croghan, T., Hanna, M., \& Robinson, R. (2000). Racial Variation in Antidepressant Treatment in a Medicaid Population. Journal of Clinical Psychiatry, 61(1), 16-21.

Morrato, E., Libby, A., Orton, H., Degruy, F., Brent, D., Allen, R., et al. (2008). Frequency of Provider Contact After FDA Advisory on Risk of Pediatric Suicidality with SSRIs. American Journal of Psychiatry, 165(1) 42-50.

Mufson, L., \& Fairbanks, J. (1996). Interpersonal Psychotherapy for Depressed Adolescents: A One-Year Naturalistic Follow-Up Study. Journal of the American Academy of Child and Adolescent Psychiatry, 35(9), 1145-1155.

Mufson, L., Weissman, M., Moreau, D., \& Garfinkel, R. (1999). Efficacy of Interpersonal Psychotherapy for Depressed Adolescents. Archives of General Psychiatry, 56(6), 573-579.

Mufson, L., Dorta, K., Wickramaratne, P., Nomura, Y., Olfson, M., \& Weissman, M. (2004). A Randomized Effectiveness Trial of Interpersonal Psychotherapy for Depression Adolescents. Archives of General Psychiatry, 61(6), 577-584.

Murray, M., deVries, C., \& Wong, I. (2004). A Drug Utilisation Study of Antidepressants in Children and Adolescents Using the General Practice Research Database. Archives of Disease in Childhood, 89, 1098-1102.

Murray, M., Thompson, M., Santosh, P., \& Wong, I. (2005). Effects of the Committee on Safety of Medicines Advice on Antidepressant Prescribing to Children and Adolescents in the UK. Drug Safety, 28(12), 1151-1157.

Naijar, F., Welch, C., Grapentine, W., Sachs, H., Siniscalchi, J., \& Price, L. (2004). Trends in Psychotropic Drug Use in a Child Psychiatric Hospital from 1991-1998. Journal of Child and Adolescent Psychopharmacology, 14(1), 87-93.

National Alliance for the Mentally III. (2004). Depressive in Children and Adolescents. Retrieved September 15, 2004, from http://www.nami.org/Template.cfm?section= Search\&Template=Search/SearchDisplay.cfm. 
National Institute of Mental Health. (2004). Retrieved January 26, 2006, from http://www.nimh.nih.gov/healthyinformation/antidepressant_child.cfm.

National Institute of Mental Health. (2004). Suicide Facts and Statistics. Retrieved September 15, 2004, from http://www.nimh.nih.gov/suicideprevention/suifact.cfm National Institute of Mental Health (2009). Antidepressant Medications for Children and Adolescents: Information for Parents and Caregivers. Retrieved March 15, 2009, from http://www.nimh.nih.gov/health/topics/child-and-adolescent-mental-health.

National Institutes of Health. (2005). Drug Information: Antidepressants, Monoamine Oxidase (MAO) Inhibitor. Retrieved February 2, 2006, from http://www.nlm.nih/medlineplus/druginfo/uspi/202054.html.

National Institutes of Health, (2006). Suicide in the U.S.: Statistics and Prevention. Retrieved January 17, 2007, from http://www.nimh.nih.gov/publicat/harmsway. cfm.

Nemeroff, C., Kalali, A., Keller, M., Charney, D., Lenderts, S., Cascade, E., et al. (2007). Impact of Publicity Concerning Pediatric Suicidality Data on Physician Practice Patterns in the United States. Archives of General Psychiatry, 64(4), 466-472.

Nutescu, E., Park, H., Walton, S., Blackburn, J., Finley, J., Lewis, R., et al. (2005). Factors that Influence Prescribing within a Therapeutic Class. Journal of Evaluation in Clinical Practice, 11(4), 357-365.

O'Connor, K. (2000). The Play Therapy Primer. New York: John Wiley \& Sons, Inc.

Olfson, M., Gameroff, M., Marcus, S., \& Waslick, B. (2003). Outpatient Treatment of Child and Adolescent Depresssion in the United States. Archives of General Psychiatry, 60, 1236-1242.

Olfson, M.,Marcus, S., \& Druss, B. (2008). Effects of Food and Drug Administration Warnings on Antidepressant Use in a National Sample. Archives of General Psychiatry, 65, 94-101.

Organization, W. H. (2007). Depression. Retrieved January 20, 2007, from http://www.who.int/mental health/management/depression/definition/en/

Osborne, J., \& Costello, A. (2005). Best Practices in Exploratory Factor Analysis: Four Recommendations for Getting the Most From Your Analysis. Practical Assessment, Research and Evaluation, 10(7), 1-9.

Petersen, T., Dording, C., Neault, N., Kornbluh, R., Alpert, J., Nierenberg, A., et al. (2002). A Survey of Prescribing Practices in the Treatment of Depression. Progress in Neuro-Psychopharmacology and Biological Psychiatry, 26, 177-187.

Pincus, H., Tanielian, T., Marcus, S., Olfson, M., Zarin, D., Thompson, J., et al. (1998). Prescribing Trends in Psychotropic Medications: Primary Care, Psychiatry, and Other Medical Specialites. Journal of the American Medical Association, 279(7), 526-531.

Pletscher, A. (1991). The Discovery of Antidepressants: A Winding Path. Experientia, 47(1), 4-8.

Poznanski, E., \& Mokros, H. (1996). Children's Depression Rating Scale Revised (CDRSR). Los Angeles: Western Psychological Services.

Psychiatry, A. A. o. C. a. A. (2001). Definition of a Child and Adolescent Psychiatrist. Retrieved January 29, 2007, from http://www.aacap.org/page.ww?section=About+Us\&name=Definition+of+a+Child + an $\mathrm{d}+$ Adolescent+Psychiatrist.

Ringold, S. (2005). Antidepressant Warning Focuses Attention on Unmet Need for Child Psychiatrists. Journal of the American Medical Association, 293, 537-538.

Rosner, B. (2000). Fundamentals of Biostatistics. Pacific Grove, CA 
Duxbury Thomson Learning.

Rushton, J., Clark, S., \& Freed, G. (2000). Pediatrician and Family Physician Prescription of Selective Serotonin Reuptake Inhibitors. Pediatrics, 105(6), E82-E87.

Rushton, J., \& Whitmire, J. (2001). Pediatric Stimulant and Selective Serotonin Reuptake Inhibitor Prescription Trends. Archives of Pediatric and Adolescent Medicine, 155, 560-565.

Ryan, N., Puig-Antich, J., Rabinovich, H., Fried, J., Ambrosini, P., Meyer, V., et al. (1988). MAOIs in Adolescent Major Depression Unresponsive to Tricyclic Antidepressants. Journal of the American Academy of Child and Adolescent Psychiatry, 27(6), 755758.

Ryan, N. (2005). Treatment of Depression in Children and Adolescents The Lancet, 366, 933-940.

Rynn, M., Riddle, M., Yeung, P., \& Kunz, N. (2007). Efficacy and Safety of ExtendedRelease Venlafaxine in the Treatment of Generalized Anxiety Disorder in Children and Adolescents: Two Placebo-Controlled Trials. American Journal of Psychiatry, 164, 290-300.

Sackett, D., Rosenberg, W., Gray, J., Haynes, R., \& Richardson, W. (1996). EvidenceBased Medicine: What It Is and What It Isn't British Medical Journal, 312, 71-72.

Safer, D. (1997). Changing Patterns of Psychotropic Medications Prescribed by Child Psychiatrists in the 1990s. Journal of Child and Adolescent Psychopharmacology, 7(4), 267-274.

Salant, P., \& Dillman, D.. (1994). How to Conduct Your Own Survey. New York: John Wiley \& Sons, Inc.

Simeon, J., Denicola, V., Ferguson, B., \& Copping, W. (1990). Adolescent Depression: A Placebo-Controlled Fluoxetine Treatment Study and Follow-Up. Progress in NeuroPsychopharmacology and Biological Psychiatry, 14, 791-795.

Sleath, B., \& Shih, Y. (2003). Sociological Influences on Antidepressant Prescribing. Social Science \& Medicine, 56(6), 1335-1344.

Staller, J., Wade, M., \& Baker, M. (2005). Current Prescribing Patterns in Outpatient Child and Adolescent Psychiatric Practice in Central New York. Journal of Child and Adolescent Psychopharmacology, 15(1), 57-61.

Stevens, J. (1986). Applied Multivariate Statistics for the Social Sciences. Newbury Park, CA: Sage.

Substance Abuse and Mental Health Services Administration. (2005). The Depression Report Retrieved May 20, 2006, from http://www.oas.samhs.gov/2K5/youthDepression/youthDepression.htm.

Thomas, C., Conrad, P., Casler, R., \& Goodman, E. (2006). Trends in the Use of Psychotropic Medications Among Adolescents, 1994 to 2001. Psychiatric Services, 57, 63-69.

Thompson, B. (2004). Exploratory and Confirmatory Factor Analysis. Washington, DC: American Psychological Association.

Trujillo, K., \& Chinn, A. (1996). Antidepressants. Retrieved January 26, 2006, from http://www.csusm.edu/DandAd.html

United States Department of Health and Human Services, S. A. M. H. S. A. (2004). Major Depression in Chidren and Adolescents. Retrieved September 15, 2004, from http://www.mentalhealth.org/publications/allpubs/CA-0011/default.asp\#5.

United States Food and Drug Administration. (2004). Antidepressant Use in Children, Adolescents, and Adults. Retrieved February 2, 2006, from 
http://www.fda.gov/cder/drug/antidepressants/default.htm.

United States Food and Drug Administration. (2004). FDA Public Health Advisory:

Suicidality in Children and Adolescents Being Treated with Antidepressant

Medications October 15, 2004. Retrieved January, 15 2006, from

http://www.fda.gov/cder.drug/antidepressants/SSRIPHA200410.htm.

United States Food and Drug Administration. (2004). Information Sheets. Retrieved

February 6, 2006, from

http://www.fda.gov/cder/drug/InfoSheets/patient/nefazodonePT.htm.

United States Food and Drug Administration. (2004). Medication Guide. Retrieved January 26, 2006, from

http://www.fda.gov/cder/drug/antidepressants/MDD_aldruglist.pdf.

United States Food and Drug Administration. (2005). Class Suicidality Labeling Language for Antidepressants. Retrieved January 29

2006, from http://www.fda.gov/cder/drug/antidepressants/PI_template.pdf

United States Food and Drug Administration. (2005). Medication Guide. Retrieved

February 2, 2006, from

http://www.fda.gov/cder/drug/antidepressants/MG_template.pdf.

United States Food and Drug Administration. (2005). Patient Information Sheet:

Nefazodone hydrochloride. Retrieved January 29, 2006, from

http://www.fda.gov/cder/drug/lnfosheets/patient/nefazodonePT.htm.

United States Food and Drug Administration. (2006). United States Food and Drug

Administration. Retrieved January 29 2006, from

http://www.fda.gov/cder/Offices/DDI/pathfinder.htm.

United States Food and Drug Administration. (2007). Drugs @ FDA: FDA Approved Drug Products Retrieved January 29, 2007, from

http://www.accessdata.fda.gov/scripts/cder/drugsatfda/index.cfm?fuseaction=Search .Label_ApprovalHistory\#apphist.

United States Food and Drug Administration (2007a). FDA Statement Regarding the Antidepressant Paxil for Pediatric Population. Retrieved December 20, 2008 from http://www.fda.gov/bbs/topics/ANSWERS/2003/ANS01230.html.

United States Food and Drug Administration (2007b). Questions and Answers on Antidepressant Use in Children, Adolescents, and Adults. Retrieved December, 20, 2008 from http://www.fda.gov/cder/drug/antidepressants/Q\&A antidepressants.htm.

United States Food and Drug Administration (2008). Drugs @ FDA: FDA Approved Drug Products. Retrieved January 2, 2009 from http://www.accessdata.fda.gov/ scripts/cder/drugsatfda/index.cfm?fuseaction=Search.DrugDetails

Vitiello, B., Bhatara, V., \& Jensen, P. (1999). Introduction-Current Knowledge and Unmet Needs in Pediatric Psychopharmacology. Journal of the American Academy of Child and Adolescent Psychiatry, 38(5), 501-502.

Vitiello, B., Zuvekas, S. H., \& Norquist, G. (2006). National Estimates of Antidepressant Medication Use Among U.S. Children 1997-2002. Journal of the American Academy of Child and Adolescent Psychiatry, 45(3), 271-279.

Vittinghoff, E., Glidden, D., Shiboski, S., \& McCulloch, C. (2005). Regression Methods in Biostatistics. New York: Springer Science+Business Media, Inc.

Wagner, K., Ambrosini, P., Rynn, M., Wohlberg, C., Ruoyong, Y., Greenbaum, M., et al. (2003). Efficacy of Sertraline in the Treatment of Children and Adolescents with Major Depressive Disorder: Two Randomized Controlled Trials. Journal of the American Medical Association, 290(8), 1033-1041. 
Wagner, K., Robb, A., Findling, R., Jin, J., Gutierrez, M., \& Heydorn, W. (2004). A Randomized, Placebo-Controlled Trial of Citalopram for the Treatment of Major Depression in Children and Adolescents. American Journal of Psychiatry 161, 10791083.

WebMD. (2004). Serzone Sales to Stop; Generic Version Still Available Retrieved February 6, 2006, from http://www.webmd.com/content/Article/87/99492.htm?printing=true.

Webster, B., Cifuentes, M., Verma, S., \& Pransky, G. (2008). Geographic Variation in Opioid Prescribing for Acute, Work-Related, Low Back Pain and Associated Factors: A Multilevel Analysis. American Journal of Industrial Medicine,Nov(17).

Weissman, M., \& Bothwell, S. (1976). Assessment of Social Adjustment by Patient SelfReport. Archives of General Psychiatry, 33(9), 1111-1115.

Weissman, M., Wolk, S., Wickramaratne, P., Goldstein, R., Adams, P., Greenwald, S., et al. (1999). Children with Prepubertal-Onset Major Depressive Disorder and Anxiety Grown Up Archives of General Psychiatry, 56(9), 794-801.

Wells, K., Katon, W., \& Camp, P. (1994). Use of Minor Tranquilizers and Antidepressant Medications by Depressed Outpatients: Results from the Medical Outcomes Study. The American Journal of Psychiatry, 151, 694-700.

Whittington, C. , Kendall, T., Fonagy, P., Cottrell, D., Cotgrove, A., \& Boddington, E. (2004). Selective Serotonin Reuptake Inhibitors in Childhood Depression: Systematic Review of Published Versus Data. The Lancet, 363, 1341-1345.

Williams, J., Klinepeter, K., Palmes, G., Pulley, A., \& Foy, J. (2004). Diagnosis and Treatment of Behavioral Health Disorders in Pediaric Practice. Pediatrics, 114(3), 601-606.

Wyeth Pharmaceuticals. (2002). New \& Announcements: About Venlafaxine HCL. Retrieved January 26, 2006, from http:..www.wyeth.com/news/Pressed_and_Released/pr05_21_2002a.asp?archive=2 002.

Zimmerman, M., Posternak, M., Friedman, M., Attiullah, N., Baymiller, S., Boland, R., et al. (2004). Which Factors Influence Psychiatrists' Selection of Antidepressants? American Journal of Psychiatry, 161(7), 1285-1289.

Zito, J., Safer, D., dosReis, S., Gardner, J., Boles, M., \& Lynch, F. (2000). Trends in the Prescribing of Psychotropic Medications to Preschoolers. Journal of the American Medical Association, 283(8), 1025-1030.

Zito, J., Safer, D., dosReis, S., Gardner, J., Soeken, K., Boles, M., et al. (2002). Rising Prevalence of Antidpressants Among US Youth. Pediatrics, 109(5), 721-727.

Zito, J., Safer, D.., dosReis, S., Gardner, J., Magder, L., Socken, K., et al. (2003). Psychotropic Practice Patterns for Youth: A 10-Year Perspective. Archives of Pediatric and Adolescent Medicine, 157, 17-25. 


\section{APPENDIX A}

Identification of Physicians Treating Children and Adolescents with Major Depressive Disorder (MDD)

Instructions: This survey is designed to identify physicians who treat children and adolescents with MDD and who are willing to participate in a larger study related to MDD in children and adolescents.

1. Please check all age group(s) whom you treat in an outpatient setting for MDD.

Children ( $5-12$ years old $)$

$\square$ Adolescents $(13-18$ years old)

$\square$ Do not treat

2. Please check all age group(s) whom you refer for the treatment of MDD and indicate the type of health care provider to whom you refer these patients.

Refer children (5 - 12 years) to

$\square$ Refer adolescents (13 - 18 years) to

$\square$ Do not refer

3. If you treat children and/or adolescents with MDD, are you willing to participate in a more in-depth questionnaire designed to gain information about physicians' prescribing habits in treating those patients?
Yes

No

Comments: Please use this space to provide additional comments. 


\title{
APPENDIX B \\ Physician Prescribing Behavior and Factors Related to Antidepressant Prescribing to Children and Adolescents with Major Depressive Disorder (MDD)
}

\begin{abstract}
Instructions: This survey is designed to determine 1) your first, second, and third-lines of outpatient treatment for children and/or adolescents who have been diagnosed with MDD, 2) the type and length of pharmacotherapy monitoring you conduct, and 3) the factors that influence your decision to prescribe an antidepressant. The survey is divided into eight sections.

For this survey, the definition of major depressive disorder is a condition that is "manifested by a combination of symptoms that interfere with the ability to work, study, sleep, eat, and enjoy once pleasurable activities"(NIMH, 2007). MDD can be diagnosed using the criteria set forth by the Diagnostic and Statistical Manual of Mental Disorders (DSM-IV-TR). In the scientific literature, children are typically defined as being 5 through 12 years of age while adolescents are 13 through 18 years old. This survey will utilize these definitions of age for both children and adolescents.
\end{abstract}

Reference: National Institute of Mental Health. (2007). Retrieved October 15, 2007, from http://www.nimh.nih.gov/health/publications/depression/what-is-a-depressive-disorder.shtml.

\section{Section 1: Outpatient Treatment versus Referral of Children and Adolescents with Major Depressive Disorder (MDD)}

1. Please check all age group(s) whom you treat for MDD.

$\square$ Children $(5-12$ years old $)$

$\square$ Adolescents $(13-18$ years old)

$\square$ Do not treat (please skip to Section 8, Question \#23)

2. Please check the age group(s) of patients you refer for the treatment of MDD and indicate the type of health care provider to whom you refer these patients.

$\square$ Refer children (5 - 12 years) to

$\square$ Refer adolescents (13 - 18 years) to

$\square$ Do not refer

3. Please indicate the youngest patient (under 13 years of age) with MDD to whom you would consider prescribing an antidepressant medication.
$\square 1-4$ years
5 - 7 years
$8-10$ years
$\square 11-12$ years
$\square$ Do not prescribe for children less than 13 years

\section{Section 2: Preferred First-Line Outpatient Treatment}

4. Check your first-line of outpatient treatment, for children and/or adolescents who have been newly diagnosed with MDD.

\begin{tabular}{|l|l|}
\hline \multicolumn{1}{|c|}{ Children (5-12 years) } & \multicolumn{1}{c|}{ Adolescents (13-18 years) } \\
\hline$\square$ Antidepressants only & $\square$ Antidepressants only \\
\hline$\square$ Counseling/psychotherapy only & $\square$ Counseling/psychotherapy only \\
\hline $\begin{array}{l}\square \text { Both antidepressant and } \\
\text { counseling/psychotherapy }\end{array}$ & $\begin{array}{l}\text { Both antidepressant and } \\
\text { counseling/psychotherapy }\end{array}$ \\
\hline$\square$ Other, please specify & $\square$ Other, please specify \\
\hline
\end{tabular}




\section{If your first-line of treatment (in Question \#4) included antidepressants (either alone or in combination with counseling/psychotherapy), for EITHER children or adolescents please answer Questions \#5 - \#8, otherwise skip to Section 3, Question \#9.}

5. As indicated in Question \#4, check the ONE antidepressant (either alone or in combination with counseling/psychotherapy) you would most commonly select as a typical first-line treatment for that child (5-12 years old) and/or adolescent (13-18 years old) newly diagnosed with MDD.

\begin{tabular}{|c|c|}
\hline Child (5-12 years) & Adolescent (13-18 years) \\
\hline$\square$ Celexa $^{\circledR} \quad$ (citalopram HBr) & $\square$ Celexa $^{\circledR} \quad$ (citalopram HBr) \\
\hline$\square$ Cymbalta $^{\circledR}$ (duloxetine $\mathrm{HCl}$ ) & $\square$ Cymbalta $^{\circledR}$ (duloxetine $\mathrm{HCl}$ ) \\
\hline E Effexor $^{\circledR}$ (venlafaxine $\mathrm{HCl}$ ) & $\square$ Effexor $^{\circledR}$ (venlafaxine $\mathrm{HCl}$ ) \\
\hline$\square \quad$ Elavil $^{\circledR}$ (amitriptyline $\mathrm{HCl}$ ) & $\square$ Elavil $^{\circledR}$ (amitriptyline $\mathrm{HCl}$ ) \\
\hline$\square$ Desyrel $^{\circledR}$ (trazodone $\mathrm{HCl}$ ) & $\square$ Desyrel $^{\circledR}$ (trazodone $\mathrm{HCl}$ ) \\
\hline$\square$ Lexapro $^{\circledR}$ (escitalopram oxalate) & $\square$ Lexapro $^{\circledR}$ (escitalopram oxalate) \\
\hline$\square \quad$ Luvox $^{\circledR}$ (fluvoxamine maleate) & $\square$ Luvox ${ }^{\circledR}$ (fluvoxamine maleate) \\
\hline$\square$ Nardii $^{\circledR}$ (phenelzine sulfate) & $\square$ Nardil $^{\circledR}$ (phenelzine sulfate) \\
\hline$\square$ Norpramin $^{\circledR}$ (desipramine $\mathrm{HCl}$ ) & 口 Norpramin $^{\circledR}$ (desipramine $\left.\mathrm{HCl}\right)$ \\
\hline$\square$ Pamelor $^{\circledR}$ (nortriptyline $\mathrm{HCl}$ ) & $\square$ Pamelor $^{\circledR}$ (nortriptyline $\mathrm{HCl}$ ) \\
\hline$\square$ Paxil $^{\circledR}$ (paroxetine $\mathrm{HCl}$ ) & $\square$ Paxil $^{\circledR}$ (paroxetine $\mathrm{HCl}$ ) \\
\hline$\square$ Parnate $^{\circledR}$ (tranlcypromine sulfate) & $\square$ Parnate $^{\circledR}$ (tranlcypromine sulfate) \\
\hline$\square \operatorname{Prozac}^{\circledR}$ (fluoxetine $\mathrm{HCl}$ ) & $\square \operatorname{Prozac}^{\circledR}$ (fluoxetine $\mathrm{HCl}$ ) \\
\hline$\square$ Remeron $^{\circledR}$ (mirtazpine) & $\square$ Remeron $^{\circledR}$ (mirtazpine) \\
\hline$\square$ Serzone $^{\circledR}$ (nefazodone $\mathrm{HCl}$ ) & $\square$ Serzone $^{\circledR}$ (nefazodone $\mathrm{HCl}$ ) \\
\hline$\square$ Tofranil $^{\Theta}$ (imipramine $\mathrm{HCl}$ ) & $\square$ Tofranil $^{\circledR}$ (imipramine $\mathrm{HCl}$ ) \\
\hline$\square$ Wellbutrin ${ }^{\circledR}$ (buproprion $\mathrm{HCl}$ ) & $\square$ Wellbutrin $^{\circledR}$ (buproprion $\mathrm{HCl}$ ) \\
\hline$\square$ Zoloft $^{\circledR}$ (sertraline $\mathrm{HCl}$ ) & $\square$ Zoloft $^{\circledR}$ (sertraline $\left.\mathrm{HCl}\right)$ \\
\hline$\checkmark$ Other, please specify & $\square$ Other, please specify \\
\hline
\end{tabular}

6. For the first-line antidepressant(s) selected above, please indicate the standard total daily starting dosage and the standard maximum total daily dosage you use for an outpatient child and/or adolescent with MDD.

\begin{tabular}{|l|r|r|}
\hline Drug Dosage & Child (5-12 years) & Adolescent (13-18 years) \\
\hline $\begin{array}{l}\text { Starting dosage } \\
\text { (mg/day) }\end{array}$ & $\mathrm{mg}$ & $\mathrm{mg}$ \\
\hline $\begin{array}{l}\text { Maximum dosage } \\
\text { (mg/day) }\end{array}$ & $\mathrm{mg}$ & $\mathrm{mg}$ \\
\hline
\end{tabular}

7. If antidepressant therapy is successful, how long do you continue prescribing the antidepressant(s) to the newly diagnosed outpatient child and/or adolescent? (Check one)

\begin{tabular}{|c|c|}
\hline \multicolumn{1}{|c|}{ Child (5-12 years) } & Adolescent (13-18 years) \\
\hline$\square \quad 1-3$ months & $\square$ 1-3 months \\
\hline$\square \quad 4-6$ months & $\square$ 4-6 months \\
\hline$\square \quad 7-9$ months & $\square$ 7-9 months \\
\hline$\square$ 10-12 months & $\square$ 10-12 months \\
\hline$\square>12$ months & $\square>12$ months \\
\hline
\end{tabular}


8. If there is no improvement in the depressive symptoms of the child and/or adolescent, after reaching the antidepressant's tolerated maximum prescribed dosage (assuming no adverse events), how long do you continue to prescribe the drug before considering another treatment approach? (Check one)

\begin{tabular}{|l|l|}
\hline \multicolumn{1}{|c|}{ Child (5-12 years) } & \multicolumn{1}{c|}{ Adolescent (13-18 years) } \\
\hline$\square<2$ weeks & $<2$ weeks \\
\hline$\square 2-4$ weeks & $\square 2-4$ weeks \\
\hline$\square 5-6$ weeks & $\square 5-6$ weeks \\
\hline$\square 7-8$ weeks & $\square 7-8$ weeks \\
\hline$\square 9-10$ weeks & $\square 9-10$ weeks \\
\hline$\square>10$ weeks & $\square>10$ weeks \\
\hline
\end{tabular}

\section{Section 3: Preferred Second-Line Outpatient Treatment}

9. Assuming you have re-evaluated and confirmed the diagnosis of MDD, if there are no improvements in depressive symptoms with the first-line treatment, what would you typically recommend as your next step in outpatient treatment for this child and/or adolescent? (Check one)

\begin{tabular}{|l|l|}
\hline \multicolumn{1}{|c|}{ Child (5-12 years) } & \multicolumn{1}{c|}{ Adolescent (13-18 years) } \\
\hline$\square$ Augment with antidepressant therapy & $\square$ Augment with antidepressant therapy \\
\hline$\square$ Switch to a different antidepressant & $\square$ Switch to a different antidepressant \\
\hline$\square$ Augment with counseling/psychotherapy & $\square$ Augment with counseling/psychotherapy \\
\hline$\square$ Other treatment, please specify & $\square$ Other treatment, please specify \\
\hline
\end{tabular}

10. If you indicated above (Question \# 9) you would augment with antidepressant therapy or switch to a different antidepressant, what would you typically prescribe as your second-line of treatment for this child and/or adolescent (otherwise please skip to Question \#11)?

\begin{tabular}{|l|c|c|}
\hline & Child (5-12 years) & Adolescent (13-18 years) \\
\hline Antidepressant & & \\
\hline
\end{tabular}

\section{Section 4: Preferred Third-Line Outpatient Treatment}

11. If there are no improvements in depressive symptoms with the second-line treatment, what would you typically recommend as your next step in outpatient treatment for this child and/or adolescent? (Check one)

\begin{tabular}{|l|l|}
\hline \multicolumn{1}{|c|}{ Child (5-12 years) } & \multicolumn{1}{c|}{ Adolescent (13-18 years) } \\
\hline$\square$ Augment with antidepressant therapy & $\square$ Augment with antidepressant therapy \\
\hline$\square$ Switch to a different antidepressant & $\square$ Switch to a different antidepressant \\
\hline$\square$ Augment with counseling/psychotherapy & $\square$ Augment with counseling/psychotherapy \\
\hline$\square$ Other treatment, please specify & $\square$ Other treatment, please specify \\
\hline
\end{tabular}

12. If you indicated above (Question \# 11) you would augment with antidepressant therapy or switch to a different antidepressant, what would you typically prescribe as your third-line of treatment for this child and/or adolescent (otherwise please skip to Question \#13)?

\begin{tabular}{|l|l|l|}
\hline & Child (5-12 years) & Adolescent (13-18 years) \\
\hline Antidepressant & & \\
\hline
\end{tabular}




\section{Section 5: Counseling/Psychotherapy}

13. If you believe the child and/or adolescent should have counseling/psychotherapy, would you refer to a counselor or psychotherapist or conduct the counseling/psychotherapy yourself? (Check one)

$\square$ Refer the child and/or adolescent to

$\square$ Conduct my own therapy (please skip to Question \# 15)

$\square$ Do not utilize counseling/psychotherapy (please skip to Section \#6, Question \#16)

14. If you refer a child and/or adolescent with MDD for counseling/psychotherapy treatment, please indicate how far, in approximate miles, the patient would have to travel, from their residence, to visit a counselor/psychotherapist. Miles (please skip to Section 6, Question \#16)

15. If you conduct your own counseling/psychotherapy, please rank the following types of counseling/psychotherapy based on how likely you would be to utilize them when treating a child and/or adolescent, newly diagnosed with MDD. Rank the following types from $1-7$, where $1=$ the type you would most likely recommend or utilize and $7=$ the type you would least likely recommend or utilize.

\begin{tabular}{|c|c|c|c|}
\hline Rank & Children (5-12 years) & Rank & Adolescents (13-18 years) \\
\hline & Cognitive behavioral therapy & & Cognitive behavioral therapy \\
\hline & Family therapy & & Family therapy \\
\hline & Interpersonal therapy & & Interpersonal therapy \\
\hline & Patient education & & Patient education \\
\hline & Play therapy & & Play therapy \\
\hline & Psychodynamic therapy & & Psychodynamic therapy \\
\hline & Supportive counseling & & Supportive counseling \\
\hline
\end{tabular}

\section{Section 6: Pharmacotherapy Monitoring of Outpatient Children and Adolescents}

\section{If you do not utilize pharmacotherapy, please skip to Section 7, Question \#22}

16. Check the primary mode of monitoring outpatient children and/or adolescents who are receiving an antidepressant for MDD? (Check one)

\begin{tabular}{|l|l|}
\hline \multicolumn{1}{|c|}{ Children (5-12 years) } & \multicolumn{1}{c|}{ Adolescents (13-18 years) } \\
\hline$\square$ Individual patient office visit & $\square$ Individual patient office visit \\
\hline$\square$ Telephone contact & $\square$ Telephone contact \\
\hline$\square$ Patient medication group & $\square$ Patient medication group \\
\hline$\square$ Other, please specify & $\square$ Other, please specify \\
\hline
\end{tabular}

17. Check the primary type of health care provider who conducts the monitoring? (Check one)

\begin{tabular}{|l|l|}
\hline \multicolumn{1}{|c|}{ Children (5-12 years) } & \multicolumn{1}{c|}{ Adolescents (13-18 years) } \\
\hline$\square$ Physician & $\square$ Physician \\
\hline$\square$ Nurse/Nurse Practitioner & $\square$ Nurse/Nurse Practitioner \\
\hline$\square$ Counselor/Psychotherapist & $\square$ Counselor/Psychotherapist \\
\hline$\square$ Pharmacist & $\square$ Pharmacist \\
\hline$\square$ Physician Assistant & $\square$ Physician Assistant \\
\hline$\square$ Other, please specify & $\square$ Other, please specify \\
\hline
\end{tabular}


18. Check all types of monitoring conducted for outpatient children and/or adolescents taking an antidepressant for MDD?

\begin{tabular}{|l|l|}
\hline \multicolumn{1}{|c|}{ Children (5-12 years) } & \multicolumn{1}{c|}{ Adolescents (13-18 years) } \\
\hline$\square$ Monitor for adverse events & $\square$ Monitor for adverse events \\
\hline$\square$ Monitor for suicidality & $\square$ Monitor for suicidality \\
\hline $\begin{array}{l}\square \text { Conduct labwork related to treatment } \\
\text { Monitor clinical symptoms (e.g. sleep, } \\
\text { appetite, energy, activities) }\end{array}$ & $\begin{array}{l}\square \text { Conduct labwork related to treatment } \\
\text { Moppetite, energy, activities) }\end{array}$ \\
\hline$\square$ Other, please specify & $\square$ Other, please specify \\
\hline
\end{tabular}

19. During the first month of treatment, check the most appropriate timeline you use, on average, to monitor outpatient children and/or adolescents taking an antidepressant for MDD?

\begin{tabular}{|l|l|}
\hline \multicolumn{1}{|c|}{ Children (5-12 years) } & \multicolumn{1}{c|}{ Adolescents (13-18 years) } \\
\hline$\square$ Two times per week & $\square$ Two times per week \\
\hline$\square$ Once a week & $\square$ Once a week \\
\hline$\square$ Every 2 weeks & $\square$ Every 2 weeks \\
\hline$\square$ Every 3 weeks & $\square$ Every 3 weeks \\
\hline$\square$ Once a month & $\square$ Once a month \\
\hline$\square$ Greater than 1 month & $\square$ Greater than 1 month \\
\hline$\square$ Other, please specify & $\square$ Other, please specify \\
\hline
\end{tabular}

20. During the second month of treatment, check the most appropriate timeline you use, on average, to monitor outpatient children and/or adolescents taking an antidepressant for MDD?

\begin{tabular}{|l|l|}
\hline \multicolumn{1}{|c|}{ Children (5-12 years) } & \multicolumn{1}{c|}{ Adolescents (13-18 years) } \\
\hline$\square$ Two times per week & $\square$ Two times per week \\
\hline$\square$ Once a week & $\square$ Once a week \\
\hline$\square$ Every 2 weeks & $\square$ Every 2 weeks \\
\hline$\square$ Every 3 weeks & $\square$ Every 3 weeks \\
\hline$\square$ Once a month & $\square$ Once a month \\
\hline$\square$ Greater than 1 month & $\square$ Greater than 1 month \\
\hline$\square$ Other, please specify & $\square$ Other, please specify \\
\hline
\end{tabular}

21. During the third month of treatment, check the most appropriate timeline you use, on average, to monitor outpatient children and/or adolescents taking an antidepressant for MDD?

\begin{tabular}{|l|l|}
\hline \multicolumn{1}{|c|}{ Children (5-12 years) } & \multicolumn{1}{c|}{ Adolescents (13-18 years) } \\
\hline$\square$ Two times per week & $\square$ Two times per week \\
\hline$\square$ Once a week & $\square$ Once a week \\
\hline$\square$ Every 2 weeks & $\square$ Every 2 weeks \\
\hline$\square$ Every 3 weeks & $\square$ Every 3 weeks \\
\hline$\square$ Once a month & $\square$ Once a month \\
\hline$\square$ Greater than 1 month & $\square$ Greater than 1 month \\
\hline$\square$ Other, please specify & $\square$ Other, please specify \\
\hline
\end{tabular}




\section{Section 7: Factors Influencing Whether or Not to Prescribe an Antidepressant}

22. Please circle the number that best represents the extent to which the following factors influence your decision of whether or not to prescribe an antidepressant to a newly diagnosed child or adolescent with MDD, in an outpatient setting (e.g. selecting an antidepressant versus some other type of treatment).

\begin{tabular}{|c|c|c|c|c|}
\hline Factor & $\begin{array}{c}\text { Not } \\
\text { Influential }\end{array}$ & $\begin{array}{l}\text { Somewhat } \\
\text { Influential }\end{array}$ & Influential & $\begin{array}{l}\text { Extremely } \\
\text { Influential }\end{array}$ \\
\hline $\begin{array}{l}\text { Advertisements to physicians via journals } \\
\text { and/or mail }\end{array}$ & 1 & 2 & 3 & 4 \\
\hline Availability of patient education materials & 1 & 2 & 3 & 4 \\
\hline $\begin{array}{l}\text { Clinical experience with prescribing } \\
\text { antidepressants }\end{array}$ & 1 & 2 & 3 & 4 \\
\hline $\begin{array}{l}\text { Co-existing conditions of patient (e.g. } \\
\text { obsessive compulsive disorder) }\end{array}$ & 1 & 2 & 3 & 4 \\
\hline Comfort in managing MDD in youth & 1 & 2 & 3 & 4 \\
\hline Direct-to-consumer advertising & 1 & 2 & 3 & 4 \\
\hline Drug efficacy & 1 & 2 & 3 & 4 \\
\hline Drug safety & 1 & 2 & 3 & 4 \\
\hline $\begin{array}{l}\text { Face-to-face detailing by medical } \\
\text { sciences liaison and/or pharmaceutical } \\
\text { representatives }\end{array}$ & 1 & 2 & 3 & 4 \\
\hline $\begin{array}{l}\text { Familiarity with an antidepressant being } \\
\text { prescribed }\end{array}$ & 1 & 2 & 3 & 4 \\
\hline FDA approved & 1 & 2 & 3 & 4 \\
\hline Formulary inclusion & 1 & 2 & 3 & 4 \\
\hline Frequency of dosing & 1 & 2 & 3 & 4 \\
\hline Generic form of drug available & 1 & 2 & 3 & 4 \\
\hline $\begin{array}{l}\text { Manufacturer provides free drugs to } \\
\text { indigent patients }\end{array}$ & 1 & 2 & 3 & 4 \\
\hline Medication cost & 1 & 2 & 3 & 4 \\
\hline Monitoring requirements & 1 & 2 & 3 & 4 \\
\hline Parents' education level & 1 & 2 & 3 & 4 \\
\hline Parental use of antidepressants & 1 & 2 & 3 & 4 \\
\hline Patient's ability to perform daily activities & 1 & 2 & 3 & 4 \\
\hline Patient's age & 1 & 2 & 3 & 4 \\
\hline Patient's family income & 1 & 2 & 3 & 4 \\
\hline Patient's gender & 1 & 2 & 3 & 4 \\
\hline Patient's insurance & 1 & 2 & 3 & 4 \\
\hline Potential adverse effects & 1 & 2 & 3 & 4 \\
\hline Sample drugs available & 1 & 2 & 3 & 4 \\
\hline Severity of MDD symptoms & 1 & 2 & 3 & 4 \\
\hline Suicidal thinking & 1 & 2 & 3 & 4 \\
\hline
\end{tabular}




\section{Section 8: Demographic Information}

23. Please indicate your gender:
$\square$ Male

$\square$ Female

24. Please indicate your age-group:

$\square 30$ years or younger

$\square 31$ to 40 years

$\square 41$ to 50 years

$\square 51$ to 60 years

$\square 61$ years and older

25. Year of graduation from medical school:

26. Your primary practice site:

$\square$ Hospital based: non-university-affiliated

$\square$ Hospital based: university-affiliated

$\square$ Private practice: solo, office-based

$\square$ Private practice: group, office-based

$\square$ Other, please specify

27. In which state is your primary practice site located?

28. Check the population of the community where your primary practice site is located?
口 Less than 10,000
$\square \quad 10,000-24,999$
$25,000-49,999$
$\square \quad 50,000-.99,999$
$\square 100,000-249,999$
$\square 250,000-499,999$
$\square 500,000-999,999$
$\square \quad 1$ million or more

29. Please check all of your practice specialties:

$\square$ Adult psychiatry

$\square$ Child \& adolescent psychiatry

$\square$ Family practice

$\square$ General practice

$\square$ Pediatrics

$\square$ Other, please specify

30. Please check all of your board certifications:

$\square$ Adult psychiatry

$\square$ Child \& adolescent psychiatry

$\checkmark$ Family practice

$\square$ General practice

$\square$ Pediatrics

$\square$ Not board certified

$\square$ Other, please specify

31. Average number of children (5-12 years) with MDD seen in your office. per week

32. Average number of adolescents (13 - $\mathbf{1 8}$ years) with MDD seen in your office. per week 
33. How long have you treated children and/or adolescents?

$\square$ One year or less

$\square$ Greater than one year to five years

$\square$ Greater than five years to 10 years

$\square$ Greater than 10 years

34. Check all reasons that influence your choice of treatment for children and/or adolescents with MDD.

$\square$ Results of randomized clinical trials

$\square$ Results of pilot studies, chart reviews, case studies, letters to the editor

$\square$ Own clinical experience

$\square$ Clinical experience of colleagues

$\square$ Other, please specify

35. Are you aware of the U.S. FDA black box warning for antidepressant medication for children and/or adolescents?

$\square$ Yes

$\square$ No

36. Has the U.S. FDA black box warning had any impact on your decision-making about treatment of children and/or adolescents with MDD?

$\square$ Yes (Go to Question 37)

$\square$ No

37. Please describe any major changes you have made in the treatment of MDD in children and/or adolescents as a result of the FDA black box warning.

Comments : Please use this space to provide additional comments. 


\title{
APPENDIX C \\ Physician Prescribing Behavior and Factors Related to Antidepressant Prescribing to Children and Adolescents with Major Depressive Disorder (MDD)
}

\begin{abstract}
Instructions: This survey is designed to determine 1) your first, second, and third-lines of treatment for outpatient children and/or adolescents who have been diagnosed with MDD, 2) the type and length of pharmacotherapy monitoring you conduct, and 3) the factors that influence your decision to prescribe an antidepressant. The survey is divided into six sections.

For this survey, the definition of major depressive disorder is a condition that is "manifested by a combination of symptoms that interfere with the ability to work, study, sleep, eat, and enjoy once pleasurable activities"(NIMH, 2007). MDD can be diagnosed using the criteria set forth by the Diagnostic and Statistical Manual of Mental Disorders (DSM-IV-TR). In the scientific literature, children are typically defined as being 5 through 12 years of age while adolescents are 13 through 18 years old. This survey will utilize these definitions of age for both children and adolescents.
\end{abstract}

Reference: National Institute of Mental Health. (2007). Retrieved October 15, 2007, from http://www.nimh.nih.gov/health/publications/depression/what-is-a-depressive-disorder.shtml.

\section{Section 1: Treatment versus Referral of Outpatient Children and Adolescents with Major Depressive Disorder (MDD)}

1. Please check all age group(s) whom you treat for MDD.

$\square$ Children $(5-12$ years old $)$

$\square$ Adolescents (13 - 18 years old)

$\square$ Do not treat

2. Please check the age group(s) of patients you refer for the treatment of MDD and indicate the type of health care provider to whom you refer these patients.

$\square$ Refer children (5 - 12 years) to

$\square$ Refer adolescents (13 - 18 years) to

$\square$ Do not refer

3. Please indicate the youngest patient (under 13 years of age) with MDD to whom you would consider prescribing an antidepressant medication.

․ 1 - 4 years

ㄷ $5-7$ years

$8-10$ years

$\square 11-12$ years

$\square$ Do not prescribe for children less than 13 years

\section{Section 2: Preferred Outpatient Treatment}

4. Check your first-line of outpatient treatment, for children and/or adolescents who have been newly diagnosed with MDD.

\begin{tabular}{|c|c|}
\hline Children (5-12 years) & Adolescents (13-18 years) \\
\hline$\square$ Do not treat & Do not treat \\
\hline$\square$ Antidepressants & $\square$ Antidepressants \\
\hline$\square$ Counseling/psychotherapy & $\square$ Counseling/psychotherapy \\
\hline $\begin{array}{l}\text { Both antidepressant and } \\
\text { Counseling/psychotherapy }\end{array}$ & $\begin{array}{l}\text { Both antidepressant and } \\
\text { counseling/psychotherapy }\end{array}$ \\
\hline$\square$ Other, please specify & $\square$ Other, please specify \\
\hline
\end{tabular}


5. Check ALL reasons, why this would be your first choice for treatment

$\square$ Results of randomized clinical trials

$\square$ Results of pilot studies, chart reviews, case studies, letters to the editor

$\square$ Own clinical experience

$\square$ Clinical experience of colleagues

$\square$ Other, please specify

6. Check the ONE antidepressant (either alone or in combination with counseling/psychotherapy) you would most commonly select as a typical first-line outpatient antidepressant treatment for a child (5-12 years old) and/or adolescent (13-18 years old) newly diagnosed with MDD?

\begin{tabular}{|c|c|}
\hline Child (5-12 years) & Adolescent (13-18 years) \\
\hline$\square$ Celexa $^{\circledR} \quad$ (citalopram HBr) & $\square$ Celexa $^{\circledR} \quad$ (citalopram HBr) \\
\hline$\square$ Cymbalta $^{\circledR}$ (duloxetine $\mathrm{HCl}$ ) & $\square$ Cymbalta $^{\circledR}$ (duloxetine $\mathrm{HCl}$ ) \\
\hline$\square$ Effexor $^{\circledR}$ (venlafaxine $\mathrm{HCl}$ ) & $\square$ Effexor $^{\circledR}$ (venlafaxine $\mathrm{HCl}$ ) \\
\hline$\square$ Elavil $^{\circledR}$ (amitriptyline $\mathrm{HCl}$ ) & $\square \quad$ Elavil $^{\circledR}$ (amitriptyline $\mathrm{HCl}$ ) \\
\hline$\square$ Desyrel $^{\circledR}$ (trazodone $\mathrm{HCl}$ ) & $\square$ Desyrel $^{\circledR}$ (trazodone $\mathrm{HCl}$ ) \\
\hline$\square$ Lexapro $^{\circledR}$ (escitalopram oxalate) & $\square$ Lexapro $^{\circledR}$ (escitalopram oxalate) \\
\hline$\square$ Luvox ${ }^{\circledR}$ (fluvoxamine maleate) & $\square$ Luvox $^{\circledR}$ (fluvoxamine maleate) \\
\hline$\square \mathrm{Nardil}^{\circledR}$ (phenelzine sulfate) & $\square$ Nardil $^{\circledR}$ (phenelzine sulfate) \\
\hline$\square$ Norpramin $^{\circledR}$ (desipramine $\mathrm{HCl}$ ) & №rpramin ${ }^{\circledR}$ (desipramine $\left.\mathrm{HCl}\right)$ \\
\hline$\square$ Pamelor $^{\circledR}$ (nortriptyline $\mathrm{HCl}$ ) & $\square$ Pamelor $^{\circledR}$ (nortriptyline $\mathrm{HCl}$ ) \\
\hline$\square$ Paxil $^{\circledR}$ (paroxetine $\mathrm{HCl}$ ) & $\square$ Paxil $^{\circledR}$ (paroxetine $\mathrm{HCl}$ ) \\
\hline$\square$ Parnate $^{\circledR}$ (tranlcypromine sulfate) & $\square$ Parnate $^{\circledR}$ (tranlcypromine sulfate) \\
\hline$\square \operatorname{Prozac}^{\circledR}$ (fluoxetine $\mathrm{HCl}$ ) & $\square \operatorname{Prozac}^{\circledR}$ (fluoxetine $\mathrm{HCl}$ ) \\
\hline$\square$ Remeron $^{\circledR}$ (mirtazpine) & $\square$ Remeron $^{\circledR}$ (mirtazpine) \\
\hline$\square$ Serzone ${ }^{\circledR}$ (nefazodone $\mathrm{HCl}$ ) & $\square$ Serzone $^{\circledR}$ (nefazodone $\mathrm{HCl}$ ) \\
\hline$\square$ Tofranil $^{\circledR}$ (imipramine $\mathrm{HCl}$ ) & $\square$ Tofranil $^{\circledR}$ (imipramine $\mathrm{HCl}$ ) \\
\hline$\square$ Wellbutrin $^{\circledR}$ (buproprion $\mathrm{HCl}$ ) & $\square$ Wellbutrin $^{\circledR}$ (buproprion $\mathrm{HCl}$ ) \\
\hline$\square$ Zoloft $^{\circledR}$ (sertraline $\left.\mathrm{HCl}\right)$ & $\square$ Zoloft $^{\circledR}$ (sertraline $\mathrm{HCl}$ ) \\
\hline$\square$ Other, please specify & $\square$ Other, please specify \\
\hline
\end{tabular}

7. For the first-line antidepressant(s) selected above, please indicate the standard total daily starting dosage and the standard maximum total daily dosage you use for an outpatient child and/or adolescent with MDD.

\begin{tabular}{|l|r|r|}
\hline Drug Dosage & Child (5-12 years) & Adolescent (13-18 years) \\
\hline $\begin{array}{l}\text { Starting dosage } \\
\text { (mg/day) }\end{array}$ & $\mathrm{mg}$ & $\mathrm{mg}$ \\
\hline $\begin{array}{l}\text { Maximum dosage } \\
\text { (mg/day) }\end{array}$ & $\mathrm{mg}$ & $\mathrm{mg}$ \\
\hline
\end{tabular}

8. If antidepressant therapy is successful, how long do you continue prescribing the antidepressant(s) to the newly diagnosed outpatient child and/or adolescent? (Check one)

\begin{tabular}{|l|l|}
\hline \multicolumn{1}{|c|}{ Child (5-12 years) } & Adolescent (13-18 years) \\
\hline$\square \quad 1-3$ months & $\square$ 1-3 months \\
\hline$\square \quad 4-6$ months & $\square$ 4-6 months \\
\hline$\square \quad 7-9$ months & $\square$ 7-9 months \\
\hline$\square$ 10-12 months & $\square$ 10-12 months \\
\hline$\square \quad>12$ months & $\square \quad>12$ months \\
\hline
\end{tabular}


9. If there is no improvement in the depressive symptoms of the child and/or adolescent, after reaching the antidepressant's tolerated maximum prescribed dosage (assuming no adverse events), how long do you continue to prescribe the drug before considering another treatment approach? (Check one)

\begin{tabular}{|l|l|}
\hline \multicolumn{1}{|c|}{ Child (5-12 years) } & \multicolumn{1}{c|}{ Adolescent (13-18 years) } \\
\hline$\square<2$ weeks & $<2$ weeks \\
\hline$\square 2-4$ weeks & $\square 2-4$ weeks \\
\hline$\square 5-6$ weeks & $\square 5-6$ weeks \\
\hline$\square 7-8$ weeks & $\square 7-8$ weeks \\
\hline$\square 9-10$ weeks & $\square 9-10$ weeks \\
\hline$\square>10$ weeks & $\square>10$ weeks \\
\hline
\end{tabular}

10. If there is no improvement in depressive symptoms with the first-line antidepressant, what would you typically prescribe as your next step in outpatient treatment for this child and/or adolescent? (Check one)

\begin{tabular}{|l|l|}
\hline \multicolumn{1}{|c|}{ Child (5-12 years) } & \multicolumn{1}{c|}{ Adolescent (13-18 years) } \\
\hline$\square$ Augment antidepressant therapy & $\square$ Augment antidepressant therapy \\
\hline$\square$ Switch to a different antidepressant & $\square$ Switch to a different antidepressant \\
\hline$\square$ Augment with counseling/psychotherapy & $\square$ Augment with counseling/psychotherapy \\
\hline$\square$ Other treatment, please specify & $\square$ Other treatment, please specify \\
\hline
\end{tabular}

11. If you indicated above that you would augment antidepressant therapy or switch to a different antidepressant, what would you typically prescribe as your second-line of antidepressant treatment for this child and/or adolescent?

\begin{tabular}{|c|c|c|}
\hline & Child (5-12 years) & Adolescent (13-18 years) \\
\hline $2^{\text {nd }}$-Line & & \\
Antidepressant & \\
\hline
\end{tabular}

12. If there is no improvement in depressive symptoms with the second-line antidepressant, what would you typically prescribe as your third-line of antidepressant treatment for this child and/or adolescent?

\begin{tabular}{|c|c|c|}
\hline & Child (5-12 years) & Adolescent (13-18 years) \\
\hline $3^{\text {rd }}$-Line & & \\
Antidepressant & & \\
\hline
\end{tabular}

\section{Section 3: Counseling/Psychotherapy}

13. If you believe the child and/or adolescent should have counseling/psychotherapy, would you refer to a counselor or psychotherapist or conduct the counseling/psychotherapy yourself? (Check one)

$\square$ Refer the child and/or adolescent to

$\square$ Conduct my own therapy

$\square$ Do not utilize counseling/psychotherapy

14. If you refer a child and/or adolescent with MDD for counseling/psychotherapy treatment, please indicate how far, in approximate miles, the patient would have to travel to visit a counselor/psychotherapist. Miles 
15. What type of counseling/psychotherapy, would you most likely recommend/utilize? (Check all that apply)

\begin{tabular}{|l|l|}
\hline \multicolumn{1}{|c|}{ Children (5-12 years) } & \multicolumn{1}{c|}{ Adolescents (13-18 years) } \\
\hline$\square$ Cognitive behavioral therapy & $\square$ Cognitive behavioral therapy \\
\hline$\square$ Family therapy & $\square$ Family therapy \\
\hline$\square$ Interpersonal therapy & $\square$ Interpersonal therapy \\
\hline$\square$ Patient education & $\square$ Patient education \\
\hline$\square$ Play therapy & $\square$ Play therapy \\
\hline$\square$ Supportive counseling & $\square$ Supportive counseling \\
\hline$\square$ Do not utilize counseling/psychotherapy & $\square$ Do not utilize counseling/psychotherapy \\
\hline$\square$ Other, Please Specify & $\square$ Other, Please Specify \\
\hline
\end{tabular}

\section{Section 4: Pharmacotherapy Monitoring of Outpatient Children and Adolescents}

16. Check the primary mode of monitoring outpatient children and/or adolescents who are receiving an antidepressant for MDD?

\begin{tabular}{|l|l}
\hline Children (5-12 years) \\
\hline$\square$ Individual patient office visit \\
\hline$\square$ Telephone contact \\
\hline$\square$ Patient medication group \\
\hline$\square$ Other, please specify \\
\hline
\end{tabular}

Adolescents (13-18 years)

$\square$ Individual patient office visit

$\square$ Telephone contact

Patient medication group

$\checkmark$ Other, please specify

17. Check the primary type of health care provider who conducts the monitoring?

\begin{tabular}{|l|l|}
\hline Children (5-12 years) & Adolescents (13-18 years) \\
\hline$\square$ Physician & $\square$ Physician \\
\hline$\square$ Nurse & $\square$ Nurse \\
\hline$\square$ Counselor/Psychotherapist & $\square$ Counselor/Psychotherapist \\
\hline$\square$ Pharmacist & $\square$ Pharmacist \\
\hline$\square$ Other, please specify & $\square$ Other, please specify \\
\hline
\end{tabular}

18. Check ALL types of monitoring conducted for outpatient children and/or adolescents taking an antidepressant for MDD?

\begin{tabular}{|l|l|}
\hline Children (5-12 years) & Adolescents (13-18 years) \\
\hline$\square$ Monitor for adverse events & $\square$ Monitor for adverse events \\
\hline$\square$ Monitor for suicidality & $\square$ Monitor for suicidality \\
\hline$\square$ Conduct labwork & $\square$ Conduct labwork \\
\hline $\begin{array}{c}\square \text { Monitor clinical symptoms (e.g. sleep, } \\
\text { appetite, energy, activities) }\end{array}$ & $\begin{array}{c}\square \text { Monitor clinical symptoms (e.g. sleep, } \\
\text { appetite, energy, activities) }\end{array}$ \\
\hline$\square$ Other, please specify & $\square$ Other, please specify \\
\hline
\end{tabular}


19. During the first month of treatment, check the most appropriate timeline you use, on average, to monitor outpatient children and/or adolescents taking an antidepressant for MDD?

\begin{tabular}{|l|l|}
\hline Children (5-12 years) & Adolescents (13-18 years) \\
\hline$\square$ Two times per week & $\square$ Two times per week \\
\hline$\square$ Once a week & $\square$ Once a week \\
\hline$\square$ Every 2 weeks & $\square$ Every 2 weeks \\
\hline$\square$ Every 3 weeks & $\square$ Every 3 weeks \\
\hline$\square$ Once a month & $\square$ Once a month \\
\hline$\square$ Greater than 1 month & $\square$ Greater than 1 month \\
\hline$\square$ Other, please specify & $\square$ Other, please specify \\
\hline
\end{tabular}

20. During the second month of treatment, check the most appropriate timeline you use, on average, to monitor outpatient children and/or adolescents taking an antidepressant for MDD?

\begin{tabular}{|l|l|}
\hline Children (5-12 years) & Adolescents (13-18 years) \\
\hline$\square$ Two times per week & $\square$ Two times per week \\
\hline$\square$ Once a week & $\square$ Once a week \\
\hline$\square$ Every 2 weeks & $\square$ Every 2 weeks \\
\hline$\square$ Every 3 weeks & $\square$ Every 3 weeks \\
\hline$\square$ Once a month & $\square$ Once a month \\
\hline$\square$ Greater than 1 month & $\square$ Greater than 1 month \\
\hline$\square$ Other, please specify & $\square$ Other, please specify \\
\hline
\end{tabular}

21. During the third month of treatment, check the most appropriate timeline you use, on average, to monitor outpatient children and/or adolescents taking an antidepressant for MDD?

\begin{tabular}{|l|l|}
\hline Children (5-12 years) & Adolescents (13-18 years) \\
\hline$\square$ Two times per week & $\square$ Two times per week \\
\hline$\square$ Once a week & $\square$ Once a week \\
\hline$\square$ Every 2 weeks & $\square$ Every 2 weeks \\
\hline$\square$ Every 3 weeks & $\square$ Every 3 weeks \\
\hline$\square$ Once a month & $\square$ Once a month \\
\hline$\square$ Greater than 1 month & $\square$ Greater than 1 month \\
\hline$\square$ Other, please specify & $\square$ Other, please specify \\
\hline
\end{tabular}

\section{Please continue to the next page}




\section{Section 5: Factors Influencing Your Decisions to Prescribe}

22. Please circle the number that best represents the extent to which the following factors influence your decision of whether or not to prescribe an antidepressant to a newly diagnosed child or adolescent with MDD, in an outpatient setting (e.g. selecting an antidepressant versus some other type of treatment).

\begin{tabular}{|c|c|c|c|c|}
\hline Factor & $\begin{array}{c}\text { Not } \\
\text { Influential }\end{array}$ & $\begin{array}{l}\text { Somewhat } \\
\text { Influential }\end{array}$ & Influential & $\begin{array}{l}\text { Extremely } \\
\text { Influential }\end{array}$ \\
\hline $\begin{array}{l}\text { Advertisements to physicians via journals } \\
\text { and/or mail }\end{array}$ & 1 & 2 & 3 & 4 \\
\hline Availability of patient education materials & 1 & 2 & 3 & 4 \\
\hline $\begin{array}{l}\text { Clinical experience with prescribing } \\
\text { antidepressants }\end{array}$ & 1 & 2 & 3 & 4 \\
\hline $\begin{array}{l}\text { Co-existing conditions of patient (e.g. } \\
\text { obsessive compulsive disorder) }\end{array}$ & 1 & 2 & 3 & 4 \\
\hline Comfort in managing MDD in youth & 1 & 2 & 3 & 4 \\
\hline Direct-to-consumer advertising & 1 & 2 & 3 & 4 \\
\hline Drug efficacy & 1 & 2 & 3 & 4 \\
\hline Drug safety & 1 & 2 & 3 & 4 \\
\hline $\begin{array}{l}\text { Face-to-face detailing by medical } \\
\text { sciences liaison and/or pharmaceutical } \\
\text { representatives }\end{array}$ & 1 & 2 & 3 & 4 \\
\hline $\begin{array}{l}\text { Familiarity with an antidepressant being } \\
\text { prescribed }\end{array}$ & 1 & 2 & 3 & 4 \\
\hline FDA approved & 1 & 2 & 3 & 4 \\
\hline Formulary inclusion & 1 & 2 & 3 & 4 \\
\hline Frequency of dosing & 1 & 2 & 3 & 4 \\
\hline Generic form of drug available & 1 & 2 & 3 & 4 \\
\hline $\begin{array}{l}\text { Manufacturer provides free drugs to } \\
\text { indigent patients }\end{array}$ & 1 & 2 & 3 & 4 \\
\hline Medication cost & 1 & 2 & 3 & 4 \\
\hline Monitoring requirements & 1 & 2 & 3 & 4 \\
\hline Parents' education level & 1 & 2 & 3 & 4 \\
\hline Parental use of antidepressants & 1 & 2 & 3 & 4 \\
\hline Patient's ability to perform daily activities & 1 & 2 & 3 & 4 \\
\hline Patient's age & 1 & 2 & 3 & 4 \\
\hline Patient's family income & 1 & 2 & 3 & 4 \\
\hline Patient's gender & 1 & 2 & 3 & 4 \\
\hline Patient's insurance & 1 & 2 & 3 & 4 \\
\hline Potential adverse effects & 1 & 2 & 3 & 4 \\
\hline Sample drugs available & 1 & 2 & 3 & 4 \\
\hline Severity of MDD symptoms & 1 & 2 & 3 & 4 \\
\hline Suicidal thinking & 1 & 2 & 3 & 4 \\
\hline
\end{tabular}




\section{Section 6: Demographic Information}

23. Please indicate your gender:
$\square$ Male

$\square$ Female

24. Please indicate your age-group:

$\square 30$ years or younger

$\square 31$ to 40 years

$\square 41$ to 50 years

$\square 51$ to 60 years

$\square 61$ years and older

25. Year of graduation from medical school:

26. Your primary practice site:

$\square$ Hospital based: non-university-affiliated

$\square$ Hospital based: university-affiliated

$\square$ Private practice: solo, office-based

$\square$ Private practice: group, office-based

$\square$ Other, please specify

27. In which state is your primary practice site located?

28. Check the population of the community where your primary practice site is located?
口 Less than 10,000
$\square \quad 10,000-24,999$
$25,000-49,999$
$\square \quad 50,000-.99,999$
$\square 100,000-249,999$
$\square 250,000-500,000$
$\square 500,000-999,999$
$\square \quad 1$ million or more

29. Please check all of your practice specialties:

$\square$ Adult psychiatry

$\square$ Child \& adolescent psychiatry

$\square$ Family practice

$\square$ General practice

$\square$ Pediatrics

$\square$ Other, please specify

30. Please check all of your board certifications:

$\square$ Adult psychiatry

$\square$ Child \& adolescent psychiatry

$\checkmark$ Family practice

$\square$ General practice

$\square$ Pediatrics

$\square$ Not board certified

$\square$ Other, please specify

31. Average number of children (5 - 12 years) with MDD seen in your office. per week

32. Average number of adolescents (13 - $\mathbf{1 8}$ years) with MDD seen in your office. per week 
33. How long have you treated children and/or adolescents?

$\square$ One year or less

$\square$ Greater than one year to five years

$\square$ Greater than five years to 10 years

$\square$ Greater than 10 years

34. Are you aware of the U.S. FDA black box warning for antidepressant medication for children and/or adolescents?

$\square$ Yes

№

35. Has the U.S. FDA black box warning had any impact on your decision-making about treatment of children and/or adolescents with MDD?

$\square$ Yes (Go to Question 36)

$\square$ No

36. Please describe any major changes you have made in the treatment of MDD in children and/or adolescents as a result of the FDA black box warning.

Comments : Please use this space to provide additional comments. 


\section{APPENDIX D}

November 26, 2007

\section{Dear Physician:}

My name is Andrea Pfalzgraf, a Doctoral Candidate in the Department of Pharmaceutical Systems and Policy at West Virginia University (WVU) School of Pharmacy. My dissertation consists of conducting a national survey of pediatricians and child psychiatrists who may be involved in treating children and/or adolescents with major depressive disorder in an outpatient setting. This research study is designed to examine the prescribing behavior and the factors that influence the prescribing behavior of antidepressant medication to children and adolescents with major depressive disorder. The enclosed survey is designed to identify physicians who treat children and adolescents with major depressive disorder and who would be willing to participate in the study.

The enclosed questionnaire will take only a few minutes to complete. Your participation is voluntary and you are not required to answer every question in the survey. Your responses will be kept as confidential as legally possible and will be analyzed and reported in aggregate form. .

If you choose to participate, please complete the survey and mail in the enclosed business reply envelope. Any questions related to the questionnaire may be directed to Andrea Pfalzgraf, 412-2256845 or Dr. Ginger Scott at 304-293-1553. Thank you in advance for your valuable time and information.

Sincerely,

Andrea Pfalzgraf, MPH

Doctoral Candidate
Virginia (Ginger) Scott, PhD, MS, RPh Professor and Advisor

WVU IRB reviewed and acknowledged 


\section{APPENDIX E}

January 10, 2008

Dear Physician:

My name is Andrea Pfalzgraf, a Doctoral Candidate in the Department of Pharmaceutical Systems and Policy at West Virginia University (WVU) School of Pharmacy. My dissertation consists of conducting a national survey of pediatricians and child psychiatrists who may be involved in treating children and/or adolescents with major depressive disorder in an outpatient setting. This research study is designed to examine the prescribing behavior and the factors that influence the prescribing behavior of antidepressant medication to children and adolescents with major depressive disorder.

The enclosed questionnaire will take less than ten minutes to complete. Your participation is voluntary and you are not required to answer every question in the survey. However, your input is essential to determine antidepressant prescribing behavior of physicians and the factors that influence the prescribing behavior of physicians in children and adolescents with major depressive disorder in an outpatient setting. Your responses will be kept as confidential as legally possible and will be analyzed and reported in aggregate form.

If you choose to participate, please complete the survey and mail in the enclosed business reply envelope. Any questions related to the questionnaire may be directed to Andrea Pfalzgraf, 412-2256845 or Dr. Ginger Scott at 304-293-1553. Thank you in advance for your valuable time and information.

Sincerely,

Andrea Pfalzgraf, MPH

Doctoral Candidate
Virginia (Ginger) Scott, $\mathrm{PhD}, \mathrm{MS}, \mathrm{RPh}$

Professor and Advisor

WVU IRB reviewed and acknowledged 


\section{APPENDIX F}

January 10, 2008

Dear Physician:

Recently you indicated you would be willing to participate in a survey that is an integral part of my dissertation, as a Doctoral Candidate in the Department of Pharmaceutical Systems and Policy at West Virginia University (WVU) School of Pharmacy. My dissertation consists of conducting a national survey of pediatricians and child psychiatrists who may be involved in treating children and/or adolescents with major depressive disorder in an outpatient setting. This research study is designed to examine the prescribing behavior and the factors that influence the prescribing behavior of antidepressant medication to children and adolescents with major depressive disorder.

The enclosed questionnaire will take less than ten minutes to complete. Your participation is voluntary and you are not required to answer every question in the survey. However, your input is essential to determine antidepressant prescribing behavior of physicians and the factors that influence the prescribing behavior of physicians in children and adolescents with major depressive disorder in an outpatient setting. Your responses will be kept as confidential as legally possible and will be analyzed and reported in aggregate form.

Thank you for volunteering to participate in this study. Please complete the survey and mail in the enclosed business reply envelope. Any questions related to the questionnaire may be directed to Andrea Pfalzgraf, 412-225-6845 or Dr. Ginger Scott at 304-293-1553. Thank you in advance for your valuable time and information.

Sincerely,

Andrea Pfalzgraf, MPH

Doctoral Candidate
Virginia (Ginger) Scott, $\mathrm{PhD}, \mathrm{MS}, \mathrm{RPh}$

Professor and Advisor

WVU IRB reviewed and acknowledged 